Beyond the diagnosis:

A PROactive approach to fatigue, daily life participation, and health-related quality of life in paediatric chronic disease

Merel Nap - van der Vlist 
Beyond the diagnosis: A PROactive approach to fatigue, daily life participation, and health-related quality of life in paediatric chronic disease

ISBN/EAN

Copyright

Cover design:

Lay-out:

Printed by:
978-94-6419-227

(C) M.M. Nap-van der Vlist, 2021

No part of this thesis may be reproduced, stored or transmitted in any way or by any means without prior permission of the author

Annelies Wisse

Annelotte Snetselaar

Gildeprint

The research described in this manuscript was financially supported by the 'WKZFonds' (R3939 Towards a healthy future and improved societal participation).

Additionally, financial support was received from the Vertex Circle of Care grant and NFU eHealth Citrien grant for the PROfeel study. The Dynamics of Youth Invigoration grant financially supported the project on dyadic coping in paediatric chronic disease. All mentioned grants were unrestricted.

Printing of this thesis was kindly financially supported by: IJsfontein; Dynamics of Youth; Nederlandse vereniging voor Slaap- en Waak Onderzoek; Chipsoft

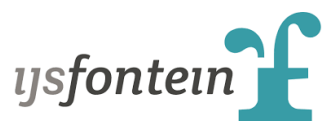

Playful solutions with serious impact

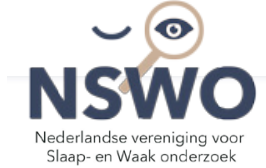

Slaap- en Waak onderzoek
ChipSoft 


\title{
Beyond the diagnosis: \\ A PROactive approach to fatigue, daily life participation, and health-related quality of life in paediatric chronic disease
}

\author{
Voorbij de diagnose: op een PROactieve manier meer grip op \\ vermoeidheid, meedoen in het dagelijks leven en kwaliteit van \\ leven bij kinderen met een chronische ziekte \\ (met een samenvatting in het Nederlands)
}

\section{Proefschrift}

ter verkrijging van de graad van doctor aan de Universiteit Utrecht

op gezag van de rector magnificus, prof. Dr. H.R.B.M. Kummeling, ingevolge het besluit van het college voor promoties in het openbaar te verdedigen op dinsdag 14 september 2021 des middags te 2.15 uur

door

Merel Marlena Nap-van der Vlist

geboren op 18 augustus 1992

te Woerden 


\section{PROMOTOREN:}

Prof. Dr. E.M. van de Putte

Prof. Dr. M.A. Grootenhuis

COPROMOTOREN:

Dr. S.L. Nijhof

Dr. G.W. Dalmeijer 
Aan Diegene die de mens zo wonderbaarlijk mooi en complex gemaakt heeft 


\section{THESIS OUTLINE}

\section{General Introduction}

Chapter 1 General introduction and aims of this thesis

\section{Part I Fatigue and health-related quality of life in growing up with a chronic disease}

Chapter 2 In this chapter, the prevalence of fatigue among (young) adults with cystic fibrosis is described Journal of Cystic Fibrosis 2018

Chapter 3 Describes the prevalence of severe fatigue in children and adolescents with various chronic diseases Archives of Disease in Childhood 2019

Chapter 4 This chapter presents transdiagnostic biological or lifestyle, psychological and social factors associated with fatigue in children with a chronic disease BMJ Paediatrics Open 2021

Chapter 5 This chapter describes parental factors that are associated with paediatric fatigue in the child with a chronic disease BMJ Paediatrics Open 2021

Chapter 6 In this chapter, the process of dyadic coping in children with a 99 chronic disease and their parents is described Submitted to Frontiers in Psychology

Part II The consequence of a chronic disease on daily life participation

Chapter $\mathbf{7} \quad$ This chapter presents the child's perspective on its daily life participation in the light of a chronic disease Archives of Disease in Childhood 2020

Chapter 8 In this chapter, the parental perspective on the child's daily participation is described, and how parents and children relate to each other regarding daily life participation of the child with a chronic disease BMJ Paediatrics Open 2021 
Part IIII PROfeel: personalized assessment and advice

Chapter 9 This chapter presents a feasibility study of PROfeel:

a smartphone application that uses ecological momentary assessments and personalized treatment advice for children and adolescents with a chronic disease

Internet Interventions 2021

\section{General Discussion}

Chapter 10 An overview and discussion of the work in this thesis is provided.

Addenda Summary of findings 200

Nederlandse samenvatting Summary in Dutch 204

Dankwoord Acknowledgements 210

$\begin{array}{ll}\text { Curriculum vitae } & 214\end{array}$

List of publications $\quad 215$

$\begin{array}{ll}\text { List of abbreviations } & 217\end{array}$ 


\section{1}
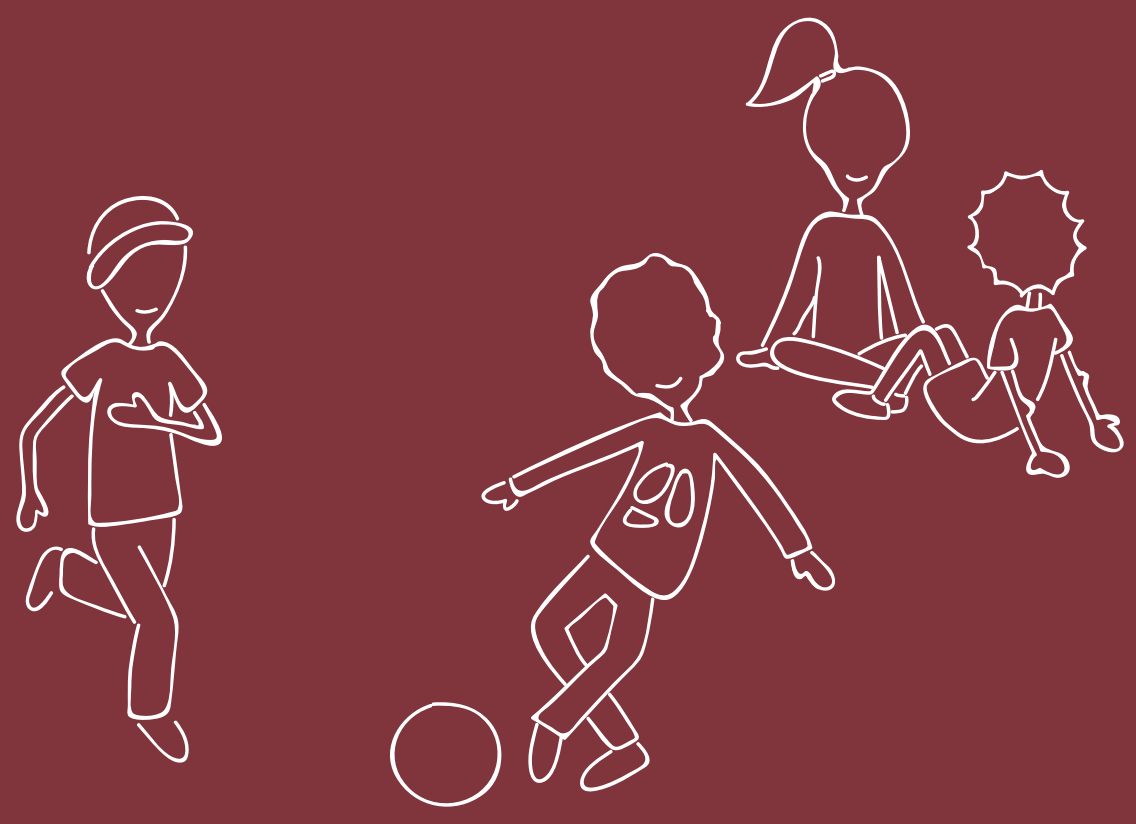
General Introduction 


\section{GENERAL INTRODUCTION}

\section{Growing up with a chronic disease}

Revolutionary progress has been made in paediatric medicine over the last decades. Due to improved medical care and lower mortality rates, the number of children who survive and grow up with a chronic disease increases! The downside is that growing up with a chronic disease is a challenge. And this challenge of growing up with a chronic disease presents itself to more and more children. ${ }^{1-3}$ Children with a chronic disease, such as cystic fibrosis (CF) or juvenile idiopathic arthritis, often face more obstacles than their healthy peers, which may impact their physical, social-emotional and cognitive development.4-6 In the short run, examples of these obstacles are symptoms such as fatigue or pain, decreased daily life participation, the stress of doctor's visits, or the challenges of a therapeutic regimen. Also, the adjustment to the disease may lead to alterations in the parent-child interaction.? In the long run, children with a chronic disease reach developmental milestones later than their healthy peers and many children will remain dependent on medication and/ or will be limited in their daily life activities. ${ }^{8}$ These developing children are vulnerable to the consequences of a chronic disease, which may impact their health-related quality of life (HRQOL). ${ }^{9}$ It may not only impact them now, but it may impact their physical, mental and social development with consequences for later in life.10,11 This underlines the importance of assessing important outcomes, and what influences these outcomes, for children with a chronic disease. This may lead to tailored assistance. This thesis focusses on fatigue, daily life participation, and HRQOL as important outcomes for the child with a chronic disease. Various generic biological or lifestyle, psychological, and social factors of influence are taken into account.

\section{Definition of health}

When growing up with a chronic disease, biological, psychological and social factors all influence children's outcomes, such as fatigue, daily life participation, and HRQOL.'2 In 1948, the World Health Organization (WHO) already defined health as "a state of complete physical, mental and social well-being and not merely the absence of disease or infirmity." In 2016, a new definition of health was proposed, health as "the ability to adapt and to self-manage, in the face of social, physical and emotional challenges".13 This thesis builds on this view that health is a dynamic concept and changes over time, with biological, psychological and social factors all influencing one's health. In children with a chronic disease, it is therefore highly relevant to assess these different factors related to health - i.e. beyond just somatic factors - over the course of their lifespan, since their increased vulnerability during the important years of their development is a fact. This view on health is translated into not only assessing somatic factors, but also generic or lifestyle factors, psychological factors, social factors and generic outcomes, such as fatigue, daily life participation or HRQOL in children with a chronic disease. This assessment does therefore not necessarily have to be disease-specific. There is a broad range of paediatric chronic diseases, and each disease has its specific somatic characteristics. Notwithstanding, the encountered challenges, such as fatigue or decreased daily life participation, show considerable similarities across various diseases. ${ }^{14}$ 


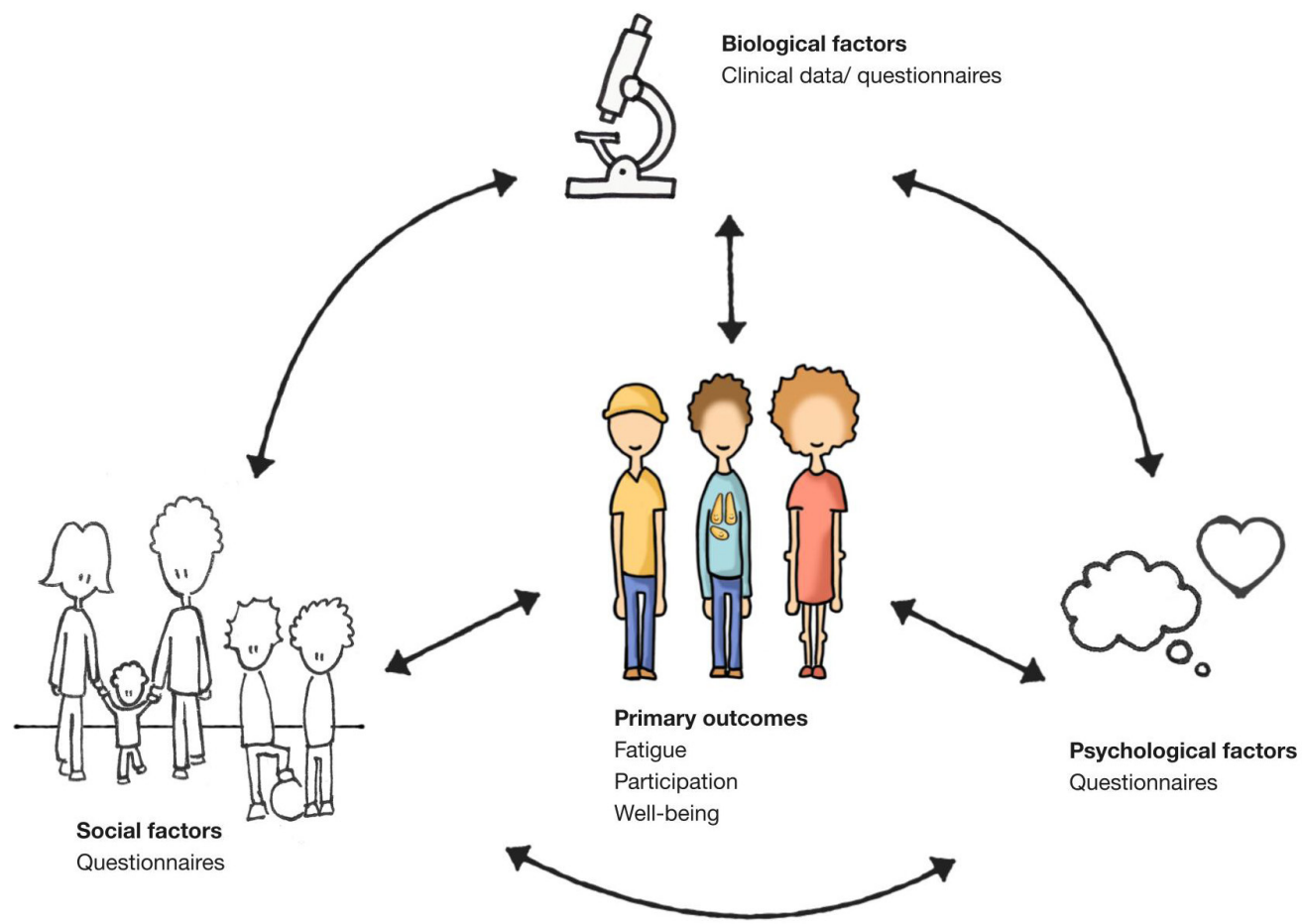

Figure 1. Outcome measures of the PROactive study within the biopsychosocial model.

\section{Theoretical models}

This way of assessing children with a chronic disease is in line with the biopsychosocial model and will help us move toward a full comprehension of health and disease..$^{15-17}$ Engel argues in his description of the biopsychosocial model that for a disease, biological factors alone at best "define a necessary, but not a sufficient condition for the occurrence of the human experience of disease."15 How a disease and its accompanying symptoms are experienced by a child and how they affect his/her outcomes, all require consideration of psychological, social and environmental factors. For example, it will not help a child to find a biological substrate for his/her fatigue, if psychological and social factors are not taken into account. Therefore, this thesis aims to identify the core biopsychosocial processes that are associated with fatigue and health-related quality of life in children with a chronic disease (Figure 1).

Although the biopsychosocial model tells us which kind of factors should be included when assessing children with a chronic disease, it does not outline how these factors relate to the child's outcome over time. The cognitive behavioural model to explain phenomena, such as fatigue, distinguishes predisposing, precipitating, and perpetuating factors. ${ }^{18}$ Predisposing factors are factors that precede fatigue and do not easily change, such as the chronic disease or the environment the child grows up in, or factors that make the child vulnerable for fatigue, such as hypermobility. Precipitating factors are stressors which may trigger, for example, the fatigue, but are not on the forefront anymore, such as infections or life events. In case of a chronic 
disease, one may hypothesize that there are more possible stressors than for a healthy peer, such as exacerbations, hospital admissions or infections. Lastly, the model speaks of perpetuating factors. Perpetuating factors describe biopsychosocial factors that co-occur with and perpetuate symptoms such as fatigue, but do not necessarily precede the fatigue. This interplay of cognitive, behavioural, affective and physiological responses is thought to be self-maintaining; symptoms and perpetuating factors sustain one another in a vicious circle.

Lastly, the model by Wallander \& Varni complements these two models. Their disability-stress-coping model describes that the stressors children with a chronic disease face are multifaceted and that several personal and family risk- and protective factors are of influence. 19 Their focus is on adjustment, which is defined as changeable age-appropriate behaviour. Therefore, it is important that we put the outcomes we assess in children with a chronic disease in perspective to what is normal behaviour for healthy peers of their age. Second, they add that a distinction should be made between intrapersonal factors and interpersonal or social-ecological factors. In this thesis we therefore choose to include both self- and proxy-reported questionnaires and in the qualitative study, examine both the child's as well as the parent's perspective.

\section{Fatigue}

One of the most frequent and disabling challenges that children with a chronic disease encounter is fatigue..$^{20-23}$ They report fatigue as a distressing and debilitating symptom. ${ }^{20-24}$ This fatigue may affect children's HRQOL and ability to participate in daily life. At time of diagnosis and initial treatment, fatigue may be explained by disease activity or getting used to a new therapeutic regimen. ${ }^{20,25}$ Nevertheless, fatigue can also persist even with low or absent disease activity and fatigue is often not strongly correlated with disease-specific factors. ${ }^{26,27}$ Recently, in adults, the incidence and severity of fatigue was found to exist rather independently from the somatic diagnosis and was labelled as a transdiagnostic symptom across somatic diagnoses. ${ }^{27}$ Fatigue has also been studied in several paediatric chronic diseases, but not yet across different somatic diagnoses..$^{3-5}$ This thesis aims to investigate whether fatigue in paediatric chronic disease should be viewed as a transdiagnostic symptom. Is fatigue part of the challenge of growing up with a chronic disease or should it be viewed as an unavoidable side effect of the disease?

If fatigue can be viewed as a transdiagnostic symptom, it is also of interest to know if there are generic factors associated with this fatigue that are potentially modifiable. According to the biopsychosocial model, a number of potentially modifiable generic biological/lifestyle, psychological, and/or social factors may be associated with - and may perpetuate - fatigue in children with a chronic disease. For example, pain, sleep, and physical activity are potentially modifiable biological or lifestyle factors that have been investigated in specific disease groups, but they may be transdiagnostic or generic. 20,22,28-30 Moreover, several psychological and social factors such as depressive symptoms, anxiety, and social support have been associated with fatigue in specific disease groups, but they may also be transdiagnostic. ${ }^{20,31,32}$ Whether these fatigueperpetuating factors in children with chronic disease are indeed transdiagnostic is yet an open question. 
In order to answer the above-mentioned questions, this thesis first aims to quantify how fatigued children with a chronic disease are in comparison with healthy peers. Second, in this thesis we investigate whether this fatigue appears in a similar way across diseases. Third, we investigate which modifiable factors (e.g. biological/lifestyle, psychological, and/or social) are associated with fatigue across various paediatric chronic diseases, and how much each of these factors contributes to explaining the variance in fatigue. If a better understanding of fatigue and its associated factors can be achieved in paediatric chronic disease, there may be a window of opportunity to intervene during childhood/adolescence to prevent symptoms from becoming persistent and debilitating in adulthood.

\section{Families of children with a chronic disease}

In line with the theoretical model by Wallander \& Varni, it is crucial to consider the child's social environment. Specifically, parents need to be taken into account, as they form the child's primary social environment and have a major impact on their fatigue, daily life participation and HRQOL. 19,33 Parental factors may influence the child's outcomes, such as fatigue. The influence of parental factors on paediatric fatigue in children with a chronic disease has not been described yet. Nevertheless, several parental physical factors, such as parental pain, fatigue and a focus on bodily symptoms, have been shown to negatively influence paediatric outcomes in children with chronic pain or chronic fatigue syndrome (CFS).14-18 Several parental psychological factors, such as parental distress or catastrophizing thoughts, have been shown to negatively influence paediatric health outcomes, such as fatigue or pain, in several paediatric chronic diseases.14,15,19-21 In this thesis we to therefore aim to explore the association between parental physical and psychosocial factors and fatigue in children with a chronic disease.

Not only may parents influence the child's outcome, a paediatric chronic disease may also influence family functioning and the parent-child relationship. $4,7,34-37 \mathrm{~A}$ paediatric chronic disease exerts stress on the child, the parent(s), the rest of the family, and therefore influences their mutual interactions. In partner relationships, this process of jointly coping with a common stressor is called dyadic coping (DC). 38 Understanding the concept of jointly or dyadic coping with stressors may be of interest in the parentchild relationship as well. How the child feels may influence the parent(s) and family functioning and vice versa, how the parent feels may influence the child's functioning and HRQOL. In this thesis, we therefore explore the concept of dyadic coping in the parent-child relationship and its association with HRQOL for children with a chronic disease.

\section{Health-related Quality of life}

Children with a chronic disease often report lower on HRQOL than their healthy peers.? HRQOL includes measures of physical symptoms, functional status and disease impact on psychological and social functioning. ${ }^{39}$ In this thesis, we have used the Paediatric Quality of Life Generic Core Scales 4.0 (PedsQL GCS) to capture HRQoL.40 This questionnaire provides a total HRQoL score as well as sub scores on physical functioning, social functioning, and emotional functioning and school functioning HRQOL in this regard can serve both as an outcome, but the different subscales of functioning may also influence other outcomes, such as fatigue. More precisely, 
physical, emotional, and social functioning adequately capture a generic biological, a psychological, and a social factor of the biopsychosocial model. This thesis investigates how these three factors are associated with fatigue.

\section{The PROactive study}

In order to achieve the aims described above, in the winter of 2016 we created the PROactive cohort study: Patient Reported Outcomes in children and Adolescents with a Chronic disease and Tailored InterVentions in a digital Environment. In this cohort, fatigue, daily life participation and HRQOL are assessed in children with different chronic diseases. The assessment of these patient-reported outcome measures (PROMs) are integrated with the child's usual care, as this gives us the opportunity to link the PROM data to data from the child's medical record. Also, it gives clinicians the opportunity to screen for important paediatric health outcomes and immediately act upon them.

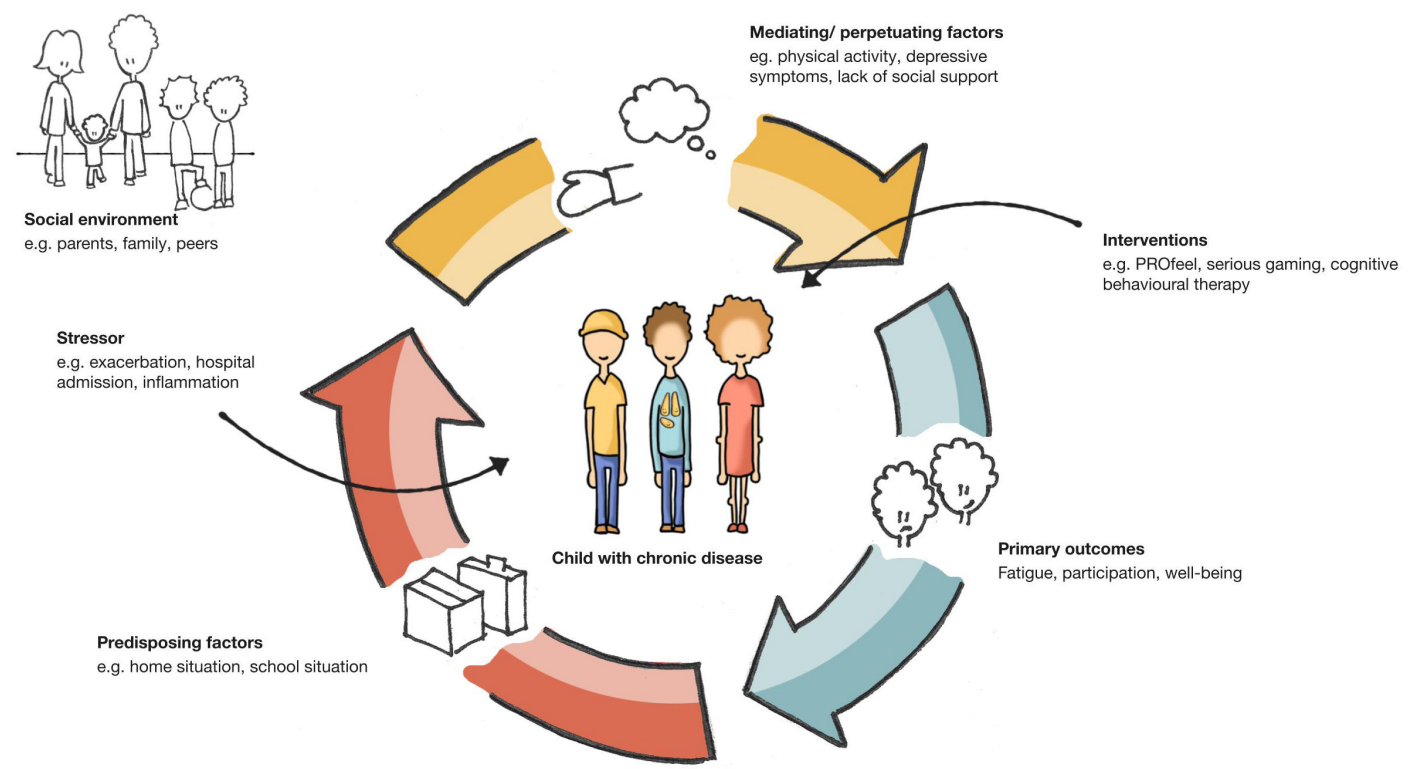

Figure 2. Theoretical model of the PROactive cohort study

Children 2-18 years of age with CF, an autoimmune disease, or post-cancer treatment, and their parents are included. These patient groups are chosen as they are large, welldescribed patient populations within our hospitals and they cover a broad spectrum of serious paediatric chronic diseases, both congenital and acquired, and both life threatening and non-life threatening. The children and their parents in this cohort are annually measured before an outpatient visit to the Wilhelmina Children's Hospital or the Princess Máxima Center for paediatric oncology, the Netherlands. The PROactive cohort lays a foundation for life cycle paediatrics: following children, adolescents and adults with a chronic disease over time in order to monitor them and offer tailored assistance when needed. Within this line of thought, this thesis also looks into one adult patient population and assesses fatigue and its associated disease-specific and generic biopsychosocial associated factors for (young) adults with CF. 
Figure 2 summarizes the theoretical model behind the PROactive cohort. The circle around the child with a chronic disease represents various factors: predisposing factors, stressors, mediating or perpetuating factors and the outcome measures fatigue, daily life participation, and health-related quality of life. The outer (darker) circle represents those factors in the direct environment of the child.

\section{Data collection of the PROactive study}

PROactive has a continuous longitudinal design, including a broad age range. Inclusion can take place anywhere between 2 and 18 years of age, depending on when the child has been diagnosed. Our aim was to assess the child in a stable phase of the disease. Therefore, children were included who were at least one year post-diagnosis (the CF and autoimmune disease groups) or who were within one year after completing their cancer treatment. The reason for this moment of inclusion was that disease activity is generally highest in the first year after diagnosis and may interfere with fatigue, and secondly, receiving the diagnosis and starting treatment, can cause significant disruptions with fatigue as a result. We aimed to include children who passed through this first phase.

All children and their parents are assessed using a baseline assessment at time of inclusion. Thereafter, they are measured annually with a core set of questionnaires. At certain developmentally important ages, children and their parents fill out an extended set of questionnaires (figure 3). In this thesis, the first cross-sectional analyses of the PROactive study are described. Data from the baseline assessment was used for chapter 3 and 4 of this theses and data from the extended assessment for chapter 5 and 6 .

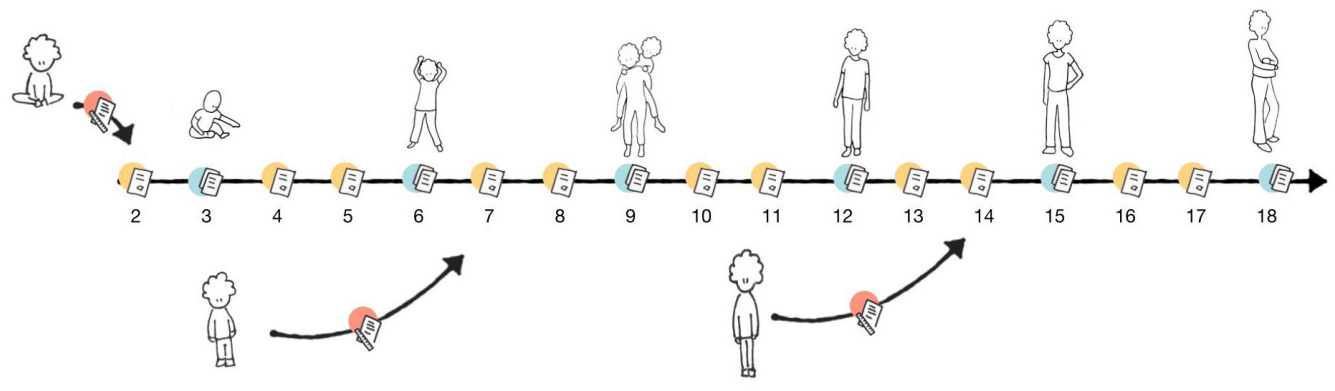

B Baseline meting op moment van inclusie

园 Jaarlijkse vragenlijst

侮 Uitgebreide vragenlijst

Figure 3. Longitudinal data collection in the PROactive cohort study

\section{Daily life participation}

Daily life participation is essential for children's development and enables them to form their identity and grow into autonomous adults that take part in our society. ${ }^{4 l}$ Decreased daily life participation is a serious risk when you grow up with a disease and its limitations, such as fatigue.,11 This participation is defined by the World Health Organisation (WHO) as "involvement in a life situation", such as engaging in 
social interactions or take on a role in sports or academia. ${ }^{42}$ Some parts of daily life participation can be measured, such as school presence or absence or amount of social interactions..$^{43}$ Involvement, or whether children feel they can fully participate, may be harder to capture than just measuring school participation." Patients with disabilities or asthma have reported that participation is more than attending activities. ${ }^{44,45}$ Young adults who grew up with a chronic disease often achieved participation milestones at a later age compared to peers and needed extra social support. ${ }^{46-49}$ What we do not know yet is the perception of children with different chronic diseases on daily life participation. Understanding this concept may help healthcare professionals to empower and support them in what they perceive as participation. ${ }^{46,50}$

More so, not only the child's perspective is important, but also the perspective of their parents. The child's and his/her parent's perspective together are crucial in patientcentred care, shared decision making and self-management.51-53 Paired qualitative analyses in this field are scarce, but provide important insights into the child-parent relationship and the role of their collaboration in shaping the child's daily life.47,49,54 Therefore, a qualitative semi-structured interview study was embedded in the PROactive cohort. The qualitative semi-structured interview study aims to reveal the child's own perspective on daily life participation. Moreover, the parent's view on the child's daily life participation was also assessed as well as how parents and children interrelate when their participation goals are not aligned.

\section{PROfeel: personalized assessment and advice}

Besides assessing quantitative and qualitative outcomes in a large cohort of children with various chronic diseases, this thesis aims to assess children's outcomes in an individual longitudinal manner. Hippocrates already stated: "It is more important to know what sort of person has a disease, than to know what sort of disease a person has." Therefore, an ecological momentary assessment (EMA) study was also embedded in the PROactive cohort. The EMA study PROfeel makes it is possible to translate what we know about modifiable factors of fatigue on a group level into patient-tailored insights on underlying mechanisms of symptoms such as fatigue..$^{55-59}$ We aimed to investigate how we can help children and adolescents to regain control over their fatigue and daily life participation in a personalized way. Knowing which modifiable factors play a role for the individual patient makes it possible to intervene in a tailored way, as shown with the intervention arrow in figure 2 . Although figure 2 is applicable to understand mechanisms for children with a chronic disease on a group level, eventually this model needs to be personalized in order to be relevant for the individual child.

\section{Aims of this thesis}

This thesis focuses on fatigue, daily life participation, and health-related quality of life in children and adolescents growing up with a chronic disease. The aim was to 1) gain insight into the frequency, extent and aetiology of fatigue in paediatric chronic disease and its association with health-related quality of life, 2) assess the consequence of growing up with a chronic disease on daily life participation and 3) investigate how we can help children and adolescents to regain control over their fatigue and daily life 
participation in a personalized way.

Part I of this thesis describes the prevalence of severe fatigue among children and adolescents with various chronic diseases and how biological, psychological and social factors relate to this fatigue. In addition, the association between fatigue and quality of life is described. In line with a life cycle perspective, one chapter describes fatigue among (young) adults and its associations with biopsychosocial factors.

Part II describes how children and their parents look at the child's participation in daily life and what they describe as important themes.

Part III details an approach that is promising for future interventions for fatigue across various paediatric chronic diseases. 


\section{REFERENCES}

1. Perrin JM, Bloom SR, Gortmaker SL. The Increase of Childhood Chronic Conditions in the United States. JAMA. 2007;297(24):2755. doi:10.1001/jama.297.24.2755

2. Verwey-Jonker Instituut. Een Actueel Perspectief Op Kinderen En Jongeren Met Een Chronische Aandoening in Nederland.; 2019.

3. Mokkink LB, van der Lee JH, Grootenhuis MA, Offringa M, Heymans HSA. Defining chronic diseases and health conditions in childhood ( $0-18$ years of age): national consensus in the Netherlands. Eur J Pediatr. 2008;167(12):1441-1447. doi:10.1007/ s00431-008-0697-y

4. Zan H, Scharff RL. The Heterogeneity in Financial and Time Burden of Caregiving to Children with Chronic Conditions. Matern Child Health J. 2015;19(3):615-625. doi:10.1007/s10995-014-1547-3

5. Pinquart $M$, Teubert D. Academic, physical, and social functioning of children and adolescents with chronic physical illness: a meta-analysis. J Pediatr Psychol. 2012:37(4):376-389. doi:10.1093/jpepsy/jsr106

6. Leeman J, Crandell JL, Lee A, Bai J, Sandelowski M, Knafl K. Family Functioning and the Well-Being of Children With Chronic Conditions: A Meta-Analysis. Res Nurs Health. 2016;39(4):229-243. doi:10.1002/nur.21725

7. Pinquart M. Do the Parent-Child Relationship and Parenting Behaviors Differ Between Families With a Child With and Without Chronic Illness? A Meta-Analysis. J Pediatr Psychol. 2013;38(7):708-721. doi:10.1093/jpepsy/jst020

8. Maurice-Stam H, Nijhof SL, Monninkhof AS, Heymans HSA, Grootenhuis MA. Review about the impact of growing up with a chronic disease showed delays achieving psychosocial milestones. Acta Paediatr. Published online August 27, 2019:apa.14918. doi:10.1111/apa.14918

9. Silva N, Pereira M, Otto C, Ravens-Sieberer U, Canavarro MC, Bullinger M. Do 8- to 18-year-old children/adolescents with chronic physical health conditions have worse health-related quality of life than their healthy peers? a meta-analysis of studies using the KIDSCREEN questionnaires. Qual Life Res. 2019;28(7):1725-1750. doi:10.1007/s11136-019-02189-7

10. Wallander J, Thompson R, Routh D. Psychosocial adjustment of children with chronic physical conditions. In: Handbook of Pediatric Psychology (2nd Ed.). ; 1995:124-141.

11. Imms C, Granlund M, Wilson PH, Steenbergen B, Rosenbaum PL, Gordon AM. Participation, both a means and an end: a conceptual analysis of processes and outcomes in childhood disability. Dev Med Child Neurol. 2017;59(1):16-25. doi:10.1111/ dmen. 13237

12. McCabe M. Fatigue in children with long-term conditions: An evolutionary concept analysis. J Adv Nurs. 2009;65(8):1735-1745. doi:10.1111/j.1365-2648.2009.05046.x

13. Huber M, van Vliet M, Giezenberg M, et al. Towards a "patient-centred" operationalisation of the new dynamic concept of health: a mixed methods study. BMJ Open. Published online 2016:5e010091. 
14. Stein REK, Jessop DJ. What diagnosis does not tell: The case for a noncategorical approach to chronic illness in childhood. Soc Sci Med. 1989;29(6):769-778. doi:10.1016/0277-9536(89)90157-3

15. Engel GL. The need for a new medical model: a challenge for biomedicine. Science. 1977;196(4286):129-136. doi:10.1126/science.847460

16. Geneva W. World Health Organization: The First Ten Years of the World Health Organization:; 1958.

17. Yeo M, Sawyer S. Chronic illness and disability. BMJ. 2005;330(7493):721-723. doi:10.1136/bmj.330.7493.721

18. Deary V, Chalder T, Sharpe M. The cognitive behavioural model of medically unexplained symptoms: A theoretical and empirical review. Clin Psychol Rev. 2007;27(7):781-797. doi:10.1016/j.cpr.2007.07.002

19. Wallander JL, Varni JW. Effects of pediatric chronic physical disorders on child and family adjustment. J Child Psychol Psychiatry. 1998;39(1):29-46. Accessed February 14, 2019. http://www.ncbi.nlm.nih.gov/pubmed/9534085

20. Armbrust W, Siers NE, Lelieveld OTHM, Mouton LJ, Tuinstra J, Sauer P. Fatigue in patients with juvenile idiopathic arthritis: A systematic review of the literature. Semin Arthritis Rheum. 2016;45(5):587-595. doi:10.1016/j.semarthrit.2015.10.008

21. Jóhannsdóttir IMR, Hjermstad MJ, Moum T, et al. Increased prevalence of chronic fatigue among survivors of childhood cancers: A population-based study. Pediatr Blood Cancer. 2012;58(3):415-420. doi:10.1002/pbc.23111

22. Jarad NA, Sequeiros IM, Patel P, Bristow K, Sund Z. Fatigue in cystic fibrosis: a novel prospective study investigating subjective and objective factors associated with fatigue. Chron Respir Dis. 2012;9(4):241-249. doi:10.1177/1479972312464236

23. Sawicki CS, Sellers DE, Robinson WM. Associations between illness perceptions and health-related quality of life in adults with cystic fibrosis. J Psychosom Res. 2011;70(2):161-167. doi:10.1016/j.jpsychores.2010.06.005

24. ter Wolbeek M, van Doornen LJP, Kavelaars A, Heijnen CJ. Severe Fatigue in Adolescents: A Common Phenomenon? Pediatrics. 2006;117(6):el078-el086. doi:10.1542/peds.2005-2575

25. Langeveld NE, Grootenhuis MA, Voûte PA, de Haan RJ, van den Bos C. No excess fatigue in young adult survivors of childhood cancer. Eur J Cancer. 2003;39(2):204214. Accessed July 24, 2018. http://www.ncbi.nlm.nih.gov/pubmed/12509953

26. Nijhof LN, van de Putte EM, Wulffraat NM, Nijhof SL. Prevalence of severe fatigue among adolescents with pediatric rheumatic diseases. Arthritis Care Res (Hoboken). Published online August 28, 2015:n/a-n/a. doi:10.1002/acr.22710

27. Menting J, Tack CJ, Bleijenberg C, et al. Is fatigue a disease-specific or generic symptom in chronic medical conditions? Heal Psychol. 2018;37(6):530-543. doi:10.1037/hea0000598

28. Nap-van der Vlist MM, Burghard M, Hulzebos HJ, et al. Prevalence of severe fatigue among adults with cystic fibrosis: A single center study. J Cyst Fibros. 2018;17(3):368374. doi:10.1016/j.jcf.2018.03.003 
29. Walter LM, Nixon GM, Davey MJ, Downie PA, Horne RSC. Sleep and fatigue in pediatric oncology: A review of the literature. Sleep Med Rev. 2015;24:71-82. doi:10.1016/j.smrv.2015.01.001

30. Van Dijk-Lokkart EM, Steur LMH, Braam KI, et al. Longitudinal development of cancer-related fatigue and physical activity in childhood cancer patients. Pediatr Blood Cancer. 2019;66(12):e27949. doi:10.1002/pbc.27949

31. Vijver E Van de, Gils A Van, Beckers L, Driessche Y Van, Moes ND, Rheenen PF van. Fatigue in children and adolescents with inflammatory bowel disease. World J Gastroenterol. 2019;25(5):632-643. doi:10.3748/wjg.v25.i5.632

32. Daniel LC, Brumley LD, Schwartz LA. Fatigue in adolescents with cancer compared to healthy adolescents. Pediatr Blood Cancer. 2013;60(11):1902-1907. doi:10.1002/ pbc. 24706

33. Minuchin P. Families and Individual Development: Provocations from the Field of Family Therapy Author ( $\mathrm{s}$ ): Patricia Minuchin Published by: Wiley on behalf of the Society for Research in Child Development Stable URL : http://www.jstor.org/ stable/1129720 REFERENCES. Child Dev. 1985;56(2):289-302. doi:10.1002/pen.21025

34. Cousino MK, Hazen RA. Parenting stress among caregivers of children with chronic illness: A systematic review. J Pediatr Psychol. 2013;38(8):809-828. doi:10.1093/ jpepsy/jst0 49

35. Knafl K, Leeman J, Havill NL, Crandell JL, Sandelowski M. The Contribution of Parent and Family Variables to the Well-Being of Youth With Arthritis. J Fam Nurs. 2015;21(4):579-616. doi:10.1177/1074840715601475

36. Logan DE, Scharff L. Relationships between family and parent characteristics and functional abilities in children with recurrent pain syndromes: an investigation of moderating effects on the pathway from pain to disability. J Pediatr Psychol. 2005;30(8):698-707. doi:10.1093/jpepsy/jsj060

37. Palermo TM, Valrie CR, Karlson CW. Family and parent influences on pediatric chronic pain: a developmental perspective. Am Psychol. 2014;69(2):142-152. doi:10.1037/a0035216

38. Bodenmann G, Falconier MK, Randall AK. Editorial: Dyadic Coping. Front Psychol. 2019;10. doi:10.3389/FPSYG.2019.01498

39. Haverman L, Limperg PF, Young NL, Grootenhuis MA, Klaassen RJ. Paediatric health-related quality of life: what is it and why should we measure it? Arch Dis Child. 2017;102(5):393-400. doi:10.1136/archdischild-2015-310068

40. Engelen V, Haentjens MM, Detmar SB, Koopman HM, Grootenhuis MA. Health related quality of life of Dutch children: psychometric properties of the PedsQL in the Netherlands. BMC Pediatr. 2009;9(1):68. doi:10.1186/1471-2431-9-68

41. King G, McDougall J, Dewit D, Petrenchik T, Hurley P, Law M. Predictors of Change Over Time in the Activity Participation of Children and Youth with Physical Disabilities. Child Health Care. 2009;38(4):321-351. doi:10.1080/02739610903237352

42. World Health Organization. Towards a Common Language for Functioning, Disability and Health - ICF.; 2002. 
43. Di Marino E, Tremblay S, Khetani M, Anaby D. The effect of child, family and environmental factors on the participation of young children with disabilities. Disabil Health J. 2018;11(1):36-42. doi:10.1016/j.dhjo.2017.05.005

44. Martin Ginis KA, Evans MB, Mortenson W Ben, Noreau L. Broadening the Conceptualization of Participation of Persons With Physical Disabilities: A Configurative Review and Recommendations. Arch Phys Med Rehabil. 2017;98(2):395-402. doi:10.1016/j.apmr.2016.04.017

45. Westergren T, Berntsen S, Ludvigsen MS, et al. Relationship between physical activity level and psychosocial and socioeconomic factors and issues in children and adolescents with asthma. JBI Database Syst Rev Implement Reports. 2017;15(8):2182-2222. doi:10.11124/JBISRIR-2016-003308

46. Stam H, Hartman EE, Deurloo JA, Groothoff J, Grootenhuis MA. Young adult patients with a history of pediatric disease: impact on course of life and transition into adulthood. J Adolesc Health. 2006;39(1):4-13. doi:10.1016/j. jadohealth.2005.03.011

47. Fereday J, MacDougall C, Spizzo M, Darbyshire P, Schiller W. "'There's nothing I can't do - I just put my mind to anything and I can do it"..: a qualitative analysis of how children with chronic disease and their parents account for and manage physical activity. BMC Pediatr. 2009;9(1):1. doi:10.1186/1471-2431-9-1

48. Bailey PK, Hamilton AJ, Clissold RL, et al. Young adults' perspectives on living with kidney failure: a systematic review and thematic synthesis of qualitative studies. BMJ Open. 2018;8(1):e019926. doi:10.1136/bmjopen-2017-019926

49. Peeters MAC, Hilberink SR, van Staa A. The road to independence: lived experiences of youth with chronic conditions and their parents compared. J Pediatr Rehabil Med. 2014;7(1):33-42. doi:10.3233/PRM-140272

50. Britto PR, Lye SJ, Proulx K, et al. Nurturing care: promoting early childhood development. Lancet. 2017;389(10064):91-102. doi:10.1016/S0140-6736(16)31390-3

51. Gutman T, Hanson C, Bernays S, et al. Child and Parental Perspectives on Communication and Decision Making in Pediatric CKD: A Focus Group Study. Am J Kidney Dis. 2018;72(4). doi:10.1053/J.AJKD.2018.05.005

52. Coyne I, Amory A, Kiernan G, Gibson F. Children's participation in shared decisionmaking: children, adolescents, parents and healthcare professionals' perspectives and experiences. Eur J Oncol Nurs. 2014;18(3):273-280. doi:10.1016/j.ejon.2014.01.006

53. Schmidt S, Petersen C, Bullinger M. Coping with chronic disease from the perspective of children and adolescents--a conceptual framework and its implications for participation. Child Care Health Dev. 2003;29(1):63-75. Accessed July 10, 2019. http://www.ncbi.nlm.nih.gov/pubmed/12534568

54. Hilberink SR, van Ool M, van der Stege HA, et al. Skills for Growing Up-Epilepsy: An exploratory mixed methods study into a communication tool to promote autonomy and empowerment of youth with epilepsy. Epilepsy Behav. 2018;86:116123. doi:10.1016/J.YEBEH.2018.05.040

55. Van Roekel E, Vrijen C, Heininga VE, Masselink M, Bos EH, Oldehinkel AJ. An 
Exploratory Randomized Controlled Trial of Personalized Lifestyle Advice and Tandem Skydives as a Means to Reduce Anhedonia. Behav Ther. 2017;48(1):76-96. doi:10.1016/j.beth.2016.09.009

56. Houtveen JH, Sorbi MJ. Prodromal functioning of migraine patients relative to their interictal state--an ecological momentary assessment study. Sommer C, ed. PLoS One. 2013;8(8):e72827. doi:10.1371/journal.pone.0072827

57. Houtveen JH, Lipovsky MM, Kool M, Sorbi M, Bühring MEF, van BroeckhuysenKloth S. The day-to-day concurrence of bodily complaints and affect in patients with severe somatoform disorder. Scand J Psychol. 2015;56(5):553-559. doi:10.1111/ sjop. 12228

58. Myin-Cermeys I, Oorschot M, Collip D, Lataster J, Delespaul P, van Os J. Experience sampling research in psychopathology: opening the black box of daily life. Psychol Med. 2009;39(9):1533-1547. doi:10.1017/S0033291708004947

59. Kroeze R, van der Veen DC, Servaas MN, et al. Personalized feedback on symptom dynamics of psychopathology: A proof-of-principle study. J Pers Res. 2017;3(1):1-11. doi:10.17505/jpor.2017.01 


\section{Part 1 \\ Fatigue and health-related \\ quality of life in growing up with \\ a chronic disease}

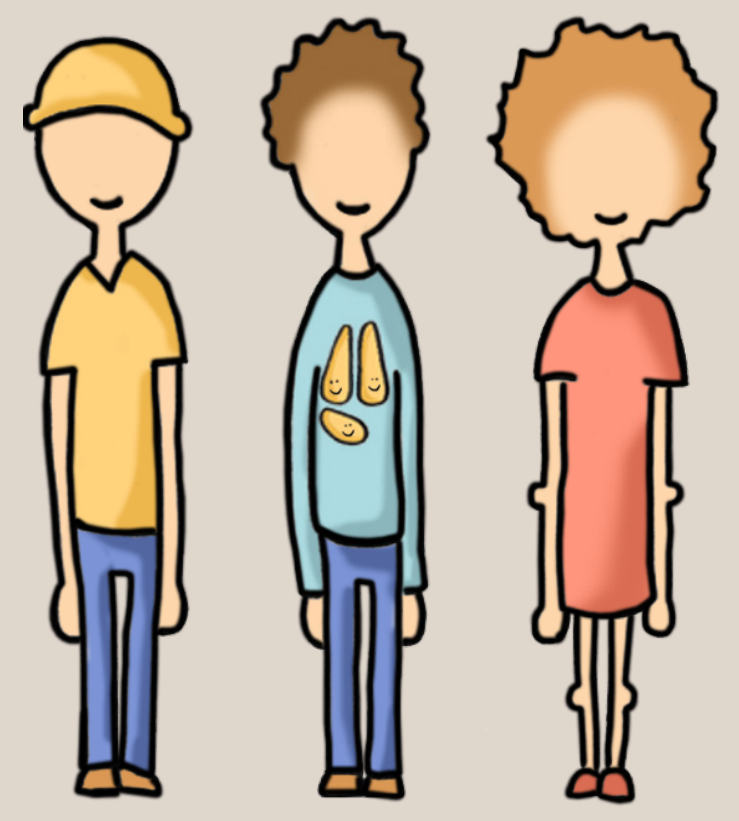



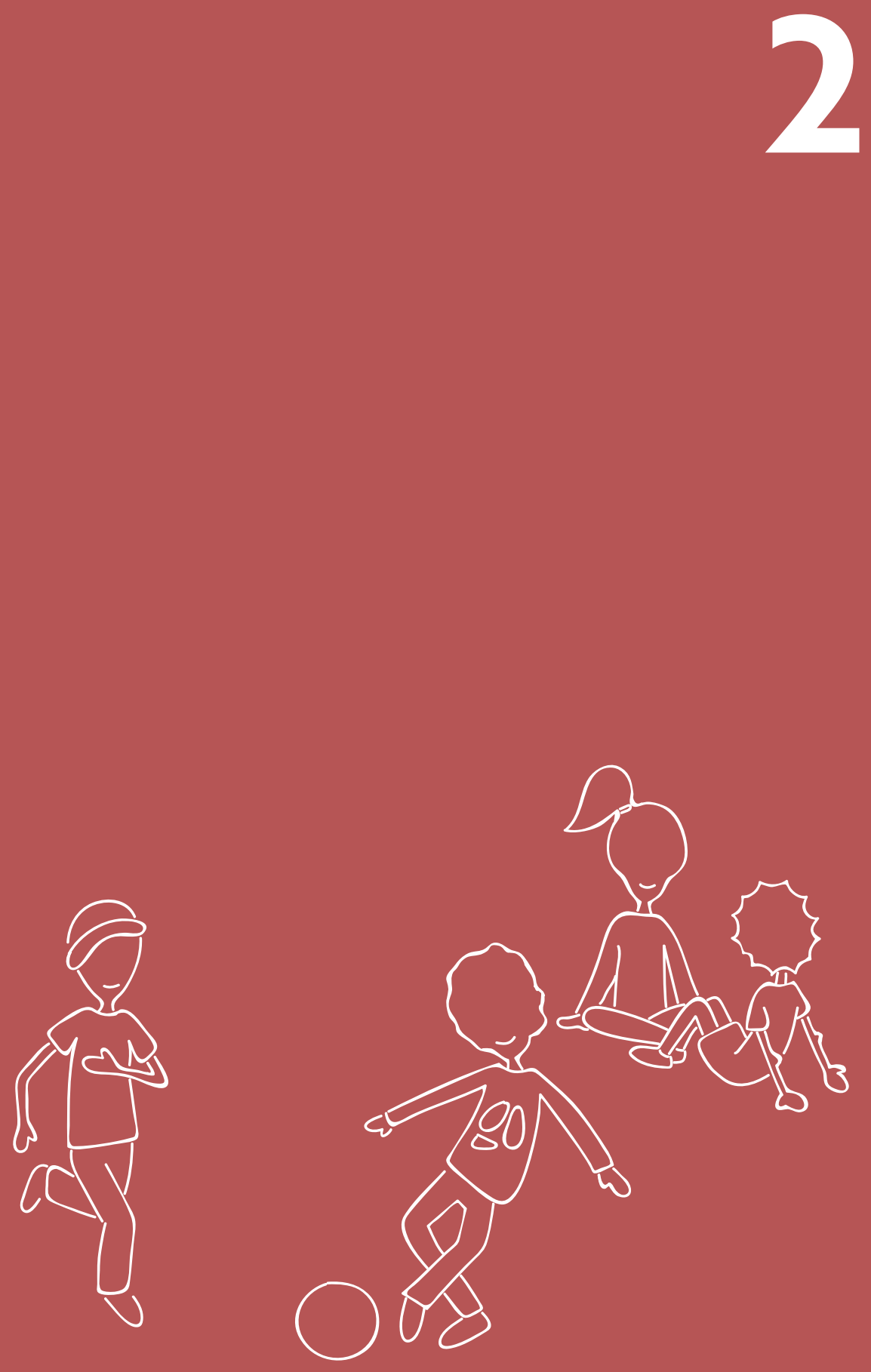


\title{
Prevalence of severe fatigue among adults with cystic fibrosis: a single center study
}

\author{
Merel M. Nap-van der Vlista, \\ Marcella Burghard \\ Erik J. Hulzebosb, \\ Wytze R. Doelemanc, \\ Harry G. Heijermanc \\ C. Kors van der Ent \\ Sanne L. Nijhofa
}

a Department of Paediatrics, Wilhelmina Children's Hospital, University Medical Center Utrecht, PO Box 85090, 3508AB, Utrecht University, Utrecht, The Netherlands

${ }^{b}$ Child Development \& Exercise Center, Wilhelmina Children's Hospital, University Medical Center Utrecht, PO Box 85090, 3508AB, Utrecht University, Utrecht, The Netherlands c Cystic Fibrosis Center Utrecht, University Medical Center Utrecht, PO Box 85500, 3508 GA Utrecht University, Utrecht, The Netherlands

¿ Department of Paediatric Pulmonology, Wilhelmina Children's Hospital, University Medical Center Utrecht, Utrecht University, Utrecht, The Netherlands 


\section{ABSTRACT}

\section{Background:}

With life expectancy increasing among patients with cystic fibrosis (CF), the prevalence of complications such as fatigue is also expected to increase. Our aim was to investigate the prevalence of severe fatigue among adults with CF and to identify factors associated with fatigue.

\section{Methods:}

Adult patients with CF receiving treatment at a single center were invited to complete three questionnaires. We then studied the associations between fatigue and clinically measured parameters and between fatigue and patient-reported outcomes.

\section{Results:}

A total of 77 patients (age 19-54years; 56\% males; mean FEVI: 63\%) completed the questionnaires ( $43 \%$ response rate). The prevalence of severe fatigue among these patients was $26 \%$. The variance in fatigue was explained partially by clinically measured parameters. However, patient-reported outcomes were stronger independently associated with fatigue and included the patients' reported respiratory symptoms, emotional functioning, and social functioning.

\section{Conclusions:}

Fatigue is a clinically important and highly prevalent issue among adults with CF and is associated with a significant reduction in health-related quality of life and participation in society. In addition, fatigue is associated more strongly with the patient's perception of symptoms and well-being than with clinically measured parameters. 


\section{INTRODUCTION}

\section{Expanding our focus on cystic fibrosis}

Thanks to extensive research and improvements in patient care, the life expectancy of patients with cystic fibrosis (CF) now exceeds 50 years.' However, as a result of living longer with this chronic, life-threatening condition, many patients develop chronic or intermittent fatigue as they age.,3 Persistent fatigue can be highly debilitating, leading to reduced societal participation and increased psychological distress. ${ }^{4}$ Therefore, researchers are increasingly interested in developing methods to manage these symptoms and increase the patient's health-related quality of life (HRQOL). ${ }^{5}$

\section{Fatigue in cystic fibrosis}

Despite the impact that fatigue can have on daily life, relatively few studies have examined the prevalence or extent of fatigue among patients with CF. We therefore performed a search regarding fatigue and CF in PubMed, Embase, and the Cochrane Library. This search revealed that Sawicki and colleagues reported that $77 \%$ of adult patients (age 19-64 years) with CF reported a "lack of energy". ${ }^{2}$ Moreover, Jarad and colleagues found that fatigue is more common among patients with CF compared to healthy subjects. ${ }^{3}$ Nevertheless, fatigue as a symptom is a distinct entity from severe, debilitating fatigue; normal fatigue can be experienced by anyone, whereas debilitating fatigue can lead to decreased functioning in daily life. Importantly, the prevalence of severe, debilitating fatigue has not been investigated among patients with CF.

\section{Potential causes of fatigue}

Precisely what causes fatigue in patients with CF is largely unknown. Given that fatigue is a complex phenomenon, it is likely that a multifactorial model will be needed in order to understand the cause of fatigue in these patients. Fatigue can be influenced by both biological and psychosocial factors, giving rise to the so-called biopsychosocial model.6 In other chronic diseases such as rheumatoid arthritis, multiple sclerosis, and diabetes, fatigue was explained only partially by biological factors, requiring the addition of psychosocial factors such as social support and/ or feelings of depression. ${ }^{7-9}$ Whether decreased pulmonary function can serve as a biological predictor of fatigue in CF is currently a matter of debate. 3 Deconditioning and suboptimal nutritional status are other possible biological factors that may be related to more severe levels of fatigue. ${ }^{10}$ Moreover, patients with CF often report poor sleep patterns and increased daytime drowsiness, which have been shown to be associated with reduced physical activity and increased fatigue." Finally, fatigue can be associated with psychological factors, including depressive symptoms and anxiety, both of which are more prevalent among CF patients compared to the general population and have been correlated with fatigue in other chronic diseases. ${ }^{7-9,12}$

\section{Aim of the study}

The aim of this study was to bridge the current knowledge gap with respect to: i) the prevalence of severe fatigue among adults with CF, and ii) the putative association between fatigue and clinically measured outcomes and patient-reported outcomes (PROs). Obtaining a better understanding of these factors may provide the foundation 
for developing future therapies directed at treating and/or preventing debilitating fatigue, thereby improving HRQOL.

\section{METHODS}

\section{Study design}

In this cross-sectional, single-center study we recruited adult patients ( $\geq 18$ years of age) with CF who were receiving treatment at our outpatient clinic at Utrecht University Medical Center. The following exclusion criteria were applied: patients with a pulmonary infection (defined as requiring supplemental antibiotics upon maintenance treatment and/or hospitalization at the time of inclusion); an active comorbidity that was not related to CF (e.g., active arthritis); and patients who were unable to complete the forms and questionnaires in Dutch.

This study was conducted in accordance with the Declaration of Helsinki and was approved by our institution's Ethics Review Board. All included patients provided written informed consent.

\section{Questionnaires}

Participating patients were asked to complete validated questionnaires regarding fatigue, HRQoL, and physical activity. These three questionnaires were sent to the patient's home in August 2016 and were self-administered. If no response was received within four weeks, the non-responding participants received a telephone reminder. Data were collected from August 2016 through December 2016.

The Cystic Fibrosis Questionnaire version 1.2 (CFQ) was used to assess HRQoL. This validated questionnaire provides a CF-specific measure of HRQOL. ${ }^{13}$ The CFQ consists of twelve subscales with a score ranging from 0-100 points; higher scores represent reduced frequency of symptoms and higher HRQOL. Internal consistency was acceptable for most domains of the CFQ (Cronbach's alpha: 0.43-0.92), and test-retest reliability was high for all domain scores (0.72-0.98).

The well-validated Checklist Individual Strength-20 (CIS-20) was used to assess fatigue. $7,14,15$ In this questionnaire, the patient is asked about fatigue experienced in the previous two weeks and consists of the following four subscales: severity of fatigue, concentration, motivation, and activity. This questionnaire has good reliability (Cronbach's alpha: 0.83-0.92) and discriminative validity. A score of 35 or higher on the severity of fatigue subscale is used to define severe fatigue in adults. ${ }^{14}$

For physical activity, we used the Habitual Activity Estimation Scale (HAES), a wellvalidated questionnaire for assessing physical activity in patients with CF.16 Patients were instructed to complete the questionnaire for a typical weekday and a typical Saturday within the previous two weeks. The percentage of time spent awake was categorized as: inactive, somewhat inactive, somewhat active, or very active. The total number of hours being active and the total number of hours being inactive were calculated for weekdays, weekend days, and overall. The intra-class correlation 
coefficient of reliability for the HAES was estimated at $0.72(P<0.0001)$.

\section{Clinical assessments}

To link the data gathered via the questionnaires with the most up-to-date disease status, we searched the patient's medical records for the clinically measured parameters measured closest to time at which the questionnaires were completed. The patient's demographics and disease-specific clinically measured parameters were searched for up to 18 months prior to the time at which the questionnaires were completed. The following data were collected: age, gender, body mass index (BMI), presence of diabetes (CF-related or otherwise), presence of liver disease, gene mutations, number of hospitalizations, whether the patient's respiratory tract was colonized with Pseudomonas aeruginosa (i.e., whether P. aeruginosa was present in two or more cultures performed in the preceding year), and whether the patient had received antibiotics (not including maintenance treatment) during the past 18 months.

CF-specific parameters included FEV (the percentage of predicted forced expiratory volume in one second) and the following three symptom scales from the CFQ questionnaire: weight, respiratory symptoms, and digestive symptoms. FEV, was calculated using the global lung function reference equations published in 2012.7 The Modified Shuttle Test (MST) and the peripheral muscle strength test were used to objectively measure exercise capacity.18,19 In addition, peripheral muscle strength was measured using a Cybex dynamometer (Lumex, Ronkonkoma, NY) in order to assess the maximum isometric quadriceps strength for the patient's dominant leg.19

\section{Statistical analysis}

Descriptive statistics were used to summarize the demographics and clinical characteristics of the patients and to describe the prevalence of fatigue and the disease status. In the event that a test for normality yielded a value less than 0.05 (indicating an abnormal distribution), the median value is provided together with the $25^{\text {th }}-75^{\text {th }}$ percentile range. In the event that the test for normality revealed a normal distribution, the mean and standard deviation are provided.

A linear regression analysis was performed for all variables in order to assess the effect size and the significance of the relationship with fatigue. Effect sizes of $<0.5,0.5-0.8$, and $>0.8$ were considered small, moderate, and large, respectively. In these analyses, fatigue was used as a continuous variable. In the published literature, both age and gender are described as important factors associated with fatigue, including chronic fatigue, ${ }_{r}^{20}$ therefore, both age and gender were used as covariates in all analyses. All analyses were performed using SPSS version 21, and differences with a P-value $<0.05$ was considered statistically significant.

\section{RESULTS}

\section{Characteristics of the study population}

A total of 180 patients were invited to participate in this study, and 77 patients completed and returned the three questionnaires (corresponding to a response/ 
participation rate of 43\%). The reasons given for not participating were the time investment required and having to complete too many questionnaires. There was no significant difference between the responders and non-responders with respect to their baseline patient characteristics, with the exception that a significantly smaller percentage of non-responders received antibiotics compared to the responders (40.9\% vs. 63.2\%, respectively; $P=0.008$ ). Patients who previously underwent a lung transplantation were excluded from the initial recruitment phase; however, two of the 77 responding patients underwent a lung transplantation during the inclusion period and were therefore included in the analysis.

Table 1 summarizes the demographics and clinical characteristics of the study population. The median age among the 77 adult patients was 28 years (range: 19-54 years), and the mean FEV ( \pm SD) value was 63 $22.4 \%$ (range: $21-106 \%$ ).

\section{Table 1. Descriptive characteristics of the patients with CF in this study}

Patients $(n=77)$

Severely fatigued Not severely patients ${ }^{\mathrm{a}}(\mathrm{n}=20) \quad$ fatigued patients $(n=57)$

\section{Patient characteristics}

Age in years, median (25th - 75th percentile)

Male, n (\%)

$28.4(23.7-35.7)$

$32.0(26.7-41.5)$

$27.5(23.3-35.4)$

BMl in kg/m2, median (25th - 75th percentile)

$43(56 \%)$

$10(50 \%)$

33 (58\%)

Mutation in the CFTR gene

\begin{tabular}{|c|c|c|c|c|}
\hline \multicolumn{2}{|c|}{ Homozygous F508del mutation } & $43(56 \%)$ & $9(53 \%)$ & $34(60 \%)$ \\
\hline \multicolumn{2}{|c|}{ Heterozygous F508del mutation } & $24(31 \%)$ & $5(29 \%)$ & $19(33 \%)$ \\
\hline \multicolumn{2}{|l|}{ Other } & $7(9 \%)$ & $3(18 \%)$ & $4(7 \%)$ \\
\hline \multicolumn{2}{|l|}{ Unknown } & $3(4 \%)$ & $3(15 \%)$ & $0(0 \%)$ \\
\hline \multicolumn{5}{|l|}{ Comorbidities } \\
\hline \multicolumn{2}{|l|}{ Diabetes, n (\%) } & $29(38 \%)$ & $5(25 \%)$ & $24(42 \%)$ \\
\hline \multirow[t]{3}{*}{ Liver disease, $n(\%)^{b}$} & -No liver disease & $36 / 40(90 \%)$ & $8 / 8(100 \%)$ & $28 / 32(88 \%)$ \\
\hline & $\begin{array}{l}\text { - Liver disease without } \\
\text { cirrhosis }\end{array}$ & $1(3 \%)$ & $0(0 \%)$ & $3(9 \%)$ \\
\hline & $\begin{array}{l}\text { - Cirrhosis without } \\
\text { hypertension }\end{array}$ & $3(8 \%)$ & $0(0 \%)$ & $1(3 \%)$ \\
\hline \multicolumn{2}{|c|}{ Colonization with P. aeruginosa, n (\%) } & $36(47 \%)$ & $10(50 \%)$ & $26(46 \%)$ \\
\hline \multicolumn{5}{|l|}{ Disease outcome } \\
\hline \multicolumn{2}{|c|}{ Received antibiotics, n (\%) } & $48(62 \%)$ & $8(40 \%)$ & $40(70 \%)$ \\
\hline \multicolumn{2}{|c|}{ Hospitalization in the past year, n (\%) } & $35(45 \%)$ & $11(55 \%)$ & $24(42 \%)$ \\
\hline \multicolumn{2}{|c|}{ FEVI in \%pred, mean (SD) } & $63 \%(22.4)$ & $57.2(23.6)$ & $65.2(21.8)$ \\
\hline \multicolumn{2}{|c|}{$\begin{array}{l}\text { Meters run on Modified Shuttle Test, median } \\
\text { (25th - 75th percentile) }\end{array}$} & 1125 (815-1500) & 1005 (527-1203) & $1180(910-1500)$ \\
\hline \multicolumn{2}{|c|}{$\begin{array}{l}\text { Peripheral muscle strength in Newton, mean } \\
\text { (SD) }\end{array}$} & $207(60.6)$ & $210(58.3)$ & $206(61.9)$ \\
\hline
\end{tabular}




\section{Prevalence of severe fatigue}

The mean score for all 77 patients on the CIS fatigue severity subscale was 29.1 12.2 ; in contrast, the mean score in a healthy population is 23.0 .4 Of the 77 patients in our study, 20 (26\%) were categorized as severely fatigued, which was defined as a score of 35 or higher on the CIS fatigue severity subscale.14

\section{Fatigue and clinically measured parameters}

On average, severe fatigue was more prevalent among older patients ( $B=0.38 ; P=0.001$; $\left.\mathrm{R}^{2}=0.135\right)$. In addition, the use of antibiotics was less common among patients with higher fatigue scores $\left(P=0.013 ; R^{2}=0.067\right)$. We also found that having a higher fatigue score was associated with lower $F E V_{1}\left(B=-0.37 ; P=0.001 ; R^{2}=0.123\right)$.

With respect to exercise capacity assessed using the MST, patients with higher fatigue scores performed significantly worse (i.e., ran a shorter average distance) than patients with lower fatigue scores $\left(B=-0.44 ; P<0.001 ; R^{2}=0.183\right)$. In contrast, we found no correlation between peripheral muscle strength and fatigue score $(B=-0.03 ; P=0.810)$. The results of our association analysis are summarized in Table 2.

\section{Table 2. Association between higher fatigue scores and clinically measured parameters}

\begin{tabular}{|c|c|c|c|c|c|}
\hline \multirow[t]{2}{*}{ Clinical parameters } & \multicolumn{3}{|c|}{ Univariate analyses } & \multicolumn{2}{|c|}{ Multivariate analyses ${ }^{a}$} \\
\hline & Effect size (ß) & $P$-value & Adjusted R2 & Effect size (ß) & $P$-value \\
\hline \multicolumn{6}{|l|}{ Patient characteristics } \\
\hline Age & 0.38 & 0.001 & 0.135 & & \\
\hline Gender & -0.11 & 0.349 & -0.001 & & \\
\hline BMI & 0.18 & 0.117 & 0.020 & 0.08 & 0.486 \\
\hline
\end{tabular}

\begin{tabular}{|c|c|c|c|c|c|}
\hline \multicolumn{6}{|l|}{ Comorbidity } \\
\hline Diabetes & -0.14 & 0.223 & 0.007 & -0.32 & 0.003 \\
\hline Presence of liver disease ${ }^{b}$ & -0.27 & 0.088 & 0.050 & -0.13 & 0.465 \\
\hline $\begin{array}{l}\text { Colonization with } \\
\text { P. Aeruginosa }\end{array}$ & 0.13 & 0.273 & 0.003 & 0.10 & 0.362 \\
\hline
\end{tabular}

\begin{tabular}{|c|c|c|c|c|c|}
\hline \multicolumn{6}{|l|}{ Disease outcome } \\
\hline Received antibiotics & -0.28 & 0.013 & 0.067 & -0.25 & 0.017 \\
\hline Prevalence of hospitalization & 0.08 & 0.491 & -0.007 & 0.10 & 0.350 \\
\hline $\mathrm{FEV}_{1}$ & -0.37 & 0.001 & 0.123 & -0.31 & 0.004 \\
\hline $\begin{array}{l}\text { Meters run on Shuttle Run } \\
\text { Test }\end{array}$ & -0.44 & $<0.001$ & 0.183 & -0.42 & 0.002 \\
\hline Peripheral muscle strength & -0.03 & 0.810 & -0.017 & -0.03 & 0.818 \\
\hline
\end{tabular}

a Multivariate analyses were adjusted for age and gender.

${ }^{b}$ Analyses were based on 40 patients only.

$B M I$, body mass index; FEVI, predicted percentage of forced expiratory volume in 1 second

\section{Fatigue and patient-related outcomes}

The mean CFQ scores (on a range of 1-100) were 81.0 $\pm 28.3,62.9 \pm 18.8$, and $80.3 \pm 20.4$ for respiratory symptoms, digestive symptoms, and weight, respectively. Our analyses revealed that a higher fatigue score was associated with an increased prevalence of respiratory symptoms ( $\left.B=-0.61 ; P<0.001 ; R^{2}=0.359\right)$, digestive symptoms $(B=-0.43$; $\left.P<0.001 ; R^{2}=0.174\right)$, and difficulty retaining weight ( $\left.B=-0.52 ; P<0.001 ; R^{2}=0.263\right)$. In 
addition, respiratory symptoms were significantly correlated with $F E V_{1}(B=0.48 ; P<0.001$; $\left.\mathrm{R}^{2}=0.148\right)$. The results of these analyses are summarized in Table 3 and Supplementary Table S1.

\begin{tabular}{|c|c|c|c|c|c|}
\hline \multirow[t]{2}{*}{ Patient-reported outcomes } & \multicolumn{3}{|c|}{ Univariate analyses } & \multicolumn{2}{|c|}{ Multivariate analyses ${ }^{a}$} \\
\hline & $\begin{array}{l}\text { Effect size } \\
\text { (B) }\end{array}$ & P-value & Adjusted $\mathrm{R}^{2}$ & $\begin{array}{l}\text { Effect size } \\
\text { (B) }\end{array}$ & P-value \\
\hline \multicolumn{6}{|l|}{ Disease activity } \\
\hline CFQ Weight & -0.52 & $<0.001$ & 0.263 & -0.54 & $<0.001$ \\
\hline CFQ Respiratory symptoms & -0.61 & $<0.001$ & 0.359 & -0.55 & $<0.001$ \\
\hline CFQ Digestion & -0.43 & $<0.001$ & 0.174 & -0.41 & $<0.001$ \\
\hline \multicolumn{6}{|l|}{ Physical activity } \\
\hline $\begin{array}{l}\text { HAES Week+Weekend Total } \\
\text { Inactive }\end{array}$ & 0.19 & 0.096 & 0.024 & 0.16 & 0.134 \\
\hline $\begin{array}{l}\text { HAES Week+Weekend Total } \\
\text { Active }\end{array}$ & -0.34 & 0.003 & 0.100 & -0.26 & 0.015 \\
\hline \multicolumn{6}{|l|}{ Health-related quality of life } \\
\hline CFQPhysical & -0.71 & $<0.001$ & 0.501 & -0.66 & $<0.001$ \\
\hline CFQ Emotional & -0.61 & $<0.001$ & 0.364 & -0.60 & $<0.001$ \\
\hline CFQSocial & -0.65 & $<0.001$ & 0.416 & -0.60 & $<0.001$ \\
\hline CFQ Burden of therapy & -0.46 & $<0.001$ & 0.204 & -0.42 & $<0.001$ \\
\hline CFQ Perception of Health & -0.64 & $<0.001$ & 0.402 & -0.63 & $<0.001$ \\
\hline
\end{tabular}

a Multivariate analyses were adjusted for age and gender.

CFQ Cystic Fibrosis Questionnaire; HAES, Habitual Activity Estimation Scale

Having a higher fatigue score was also associated with lower physical activity scores reported on the HAES questionnaire ( $\left.B=-0.34 ; P=0.003 ; R^{2}=0.100\right)$. In addition, lower physical activity scores were significantly correlated with lower MST scores ( $P=0.005)$. Finally, a higher fatigue score was significantly associated with reduced $H R Q O L$ as reported for all domains in CFQ including physical functioning ( $B=-0.71 ; P<0.001$; $\left.R^{2}=0.501\right)$, vitality $\left(B=-0.79 ; P<0.001 ; R^{2}=0.611\right)$, emotional functioning $(B=-0.61 ; P<0.001$; $\left.R^{2}=0.364\right)$, social functioning $\left(B=-0.65 ; P<0.001 ; R^{2}=0.416\right)$, burden of therapy $(B=-0.46$; $\left.P<0.001 ; R^{2}=0.204\right)$, and perception of health $\left(B=-0.64 ; P<0.001 ; R^{2}=0.402\right)$.

\section{DISCUSSION}

\section{Main results}

Our analysis revealed that $26 \%$ of adults with CF in our sample report experiencing severe fatigue, suggesting that this is a common health issue among this patient population. Importantly, this prevalence is higher than has been reported in the general population, which ranges from $15 \%$ to $22 \%$, depending on the population and the way in which fatigue was measured. 4,14,21,22

Another important result is that in our patient population, the patients' perception of symptoms and well-being (measured using the CFQ and HAES) are more strongly 
correlated with severe fatigue than clinically measured parameters (e.g., FEV and exercise capacity). Specifically, we found that a higher fatigue score is associated with a significant decrease in the patient's perception of physical, emotional, and social functioning, and with a significant increase in the patient's perceived symptoms.

\section{Results in the context of published findings}

Our results shed new light on the perception of fatigue among adult patients with CF. With respect to characterizing fatigue as a clinically significant symptom in patients with CF, our results are consistent with results obtained by Sawicki et al. ${ }^{2}$ and Friedman et al. ${ }^{23}$, who reported that a lack of energy is highly prevalent $73 \%$ and $77 \%$, respectively) and distressing. Interestingly, these studies attributed the patients' lack of energy primarily to chronic respiratory effects associated with CF and to sleep problems. However, these authors measured lack of energy as a symptom, without using a clear cut-off value for defining an impact on daily life. Jarad and colleagues examined the association between fatigue and several clinically measured parameters. ${ }^{3}$ They found no clear correlation between fatigue (measured using the Chalder Fatigue Questionnaire) and parameters of disease activity, including spirometry, BMI, haemoglobin level, C-reactive protein level, or the burden of pulmonary exacerbation. In contrast, we found a correlation between fatigue and spirometry, although the correlation between fatigue and patient-reported outcome was stronger. Consistent with our findings, Jarad et al. reported that the subjective aspects of somatic and psychological symptoms may be the primary cause of the higher perception of increased fatigue. ${ }^{3}$

Habib et al. conducted a systematic review of HRQOL in CF and found that FEV, and pulmonary exacerbation have the broadest impact on HRQOL and therefore should remain the focus of attention when treating patients with CF. ${ }^{5}$ On the other hand, our data suggest that HRQOL should not be the sole patient-reported outcome that is taken into account; indeed, fatigue is also an important determinant of well-being and participation in society.

\section{Toward a multidimensional explanation for fatigue}

Fatigue has been studied more extensively in chronic diseases other than CF. It is therefore plausible that physical factors such as FEV, may partially explain the severity and extent of fatigue. With a complex phenomenon such as fatigue, physical factors, social factors, and psychological factors-as well as interactions between these factors-all play a role; thus, the key to understanding the role of fatigue in CF may lie in identifying the multidimensional cause and in understanding the dynamic interplay between mind and body. ${ }^{6}$ In rheumatic diseases, disease-related factors have been associated with fatigue; however, patient-reported factors such as physical inactivity, sleep disturbances, and feeling depressed explained the majority of the variation in fatigue within this patient population. ${ }^{24}$ In addition, patients who undergo a kidney transplantation also have a stronger correlation between fatigue and several patientreported outcomes than between fatigue and transplant-related factors; these PROs include pain, discrepancies with respect to social support, depressive symptoms, and sleep problems. ${ }^{25}$ Research in multiple sclerosis has also shown that psychosocial factors can influence fatigue. ${ }^{9}$ With respect to respiratory conditions, it is interesting 
to note that Spruit et al..$^{15}$ recently described a model in which factors can precipitate and perpetuate fatigue in patients with COPD; such a model may also be applicable to patients with CF. This suggests that new therapies should focus on both somatic aspects (e.g. controlling disease and providing exercise therapy) and psychosocial aspects, thereby changing the patient's self-perception, for example using cognitive behavioural therapy (CBT). Importantly, this combined approach was effective in fatigued patients with COPD, ${ }^{15}$ and a similar approach has been effective in other patient groups, including survivors of breast cancer, patients with type 1 diabetes, and patients with fascioscapulohumeral muscular dystrophy. Thus, we suggest that interventions such as CBT and/or graded exercise are worth investigating in fatigued patients with CF.

\section{Fatigue and physical exercise capacity}

In exploring the possible underlying causes of fatigue, another consideration is the significant association between the severity of fatigue and physical exercise capacity measured using the MST. Our analysis revealed an association between physical exercise capacity and the perception of physical activity measured using the CFQ. Moreover, the association between perceived physical activity and fatigue was stronger than the association between measured physical exercise capacity and fatigue. Whether fatigue decreases physical activity, or whether low levels of physical activity lead to deconditioning and therefore the subjective feeling of fatigue, is currently a topic of debate. Daily activity is positively correlated with aerobic capacity and may influence the patient's experience of fatigue. ${ }^{10}$ However, because perception also seems to play an important role, simply improving physical capacity without addressing the patient's perception of physical abilities and functioning might not be sufficient.

\section{Strengths of this study}

This study has several important strengths. First, this is the first study designed to determine the prevalence of severe fatigue among adult patients with CF, and it is the first study to investigate the association between fatigue and measures of HRQOL in addition to clinically measured parameters in this patient population. Moreover, we measured fatigue using a validated questionnaire that is commonly used in patients who are chronically ill, including patients with rheumatic disease and COPD; importantly, this questionnaire has a clear cut-off value for defining severe fatigue.,14,15

\section{Limitations of this study}

This study also has several limitations that warrant discussion. First, the study included a relatively modest number of participants and had a risk of non-response bias, particularly given the $43 \%$ response rate. Nevertheless, our patient characteristics are similar to larger cohorts of patients in the US and the UK with respect to mean FEV (63\%) and mean age (28.4)..$^{29}$ Although our analysis revealed that non-responders were generally similar to responders, significantly fewer non-responders received antibiotics compared to responders; similarly, the use of antibiotics was lower among fatigued patients compared to non-fatigued patients. If response bias played a role in this finding, we might expect that more patients with severe fatigue would not have participated in the study; in this case, the actual percentage of adults with CF who 
are severely fatigued might be even higher than in our study cohort. Nevertheless, given that our results show that fatigue is more prevalent among adults with CF than in the general population, these results should be validated in a larger-preferably longitudinal-cohort study.

Second, the cross-sectional design of the study precluded the ability to link the study to a hospital visit. Therefore, the relationship between fatigue and the latest clinically measured parameters might be more direct in some cases than in others.

Third, assessing different PROs at the same point in time can potentially subject the data to shared method variance, which may have affected the measured associations between fatigue and other PROs. Nevertheless, all three questionnaires are wellvalidated tools that measure distinct concepts; therefore, we believe that this approach provided the most effective measures of severe fatigue, quality of life, and activity.

Finally, the use of the CFQ version 1.2 is a limitation. In current literature, there is a preference for the CFQ revised version. ${ }^{5}$ The CFQ version 1.2 is a validated questionnaire in Dutch and the majority of questions in version 1.2 are similar to the CFQ revised version. Nevertheless, we recommend using the CFQ-R version in future studies.

\section{Clinical implications}

Our findings underscore the need for improved structural measurements of PROs with respect to physical and psychosocial domains-in addition to clinically measured parameters-among patients with CF. With a symptom as prevalent as fatigue, a relatively simple, validated screening questionnaire may be clinically useful. For example, the CIS, which provides a clear cut-off value for determining severe fatigue, could help initiate a conversation regarding the patient's well-being in the context of functional limitations. This approach would improve patient-centred care and may create new opportunities for the timely prevention of severe, debilitating fatigue in these patients.

\section{Recommendations for future research}

Both severe fatigue and chronic fatigue are generally well treatable in patients with chronic disease..$^{26-28}$ Ideally, future studies should measure fatigue and associated biological and/or psychosocial factors using a longitudinal design, thereby helping identify factors that can serve as predictors of fatigue. We found that fatigue is associated with reduced emotional functioning; therefore, future studies should investigate further which psychosocial factors are associated with fatigue. For example, depressive symptoms should clearly be taken into account, given that these symptoms are frequently correlated with fatigue in other patient populations, and given their increased prevalence among patients with CF.'2 However, several studies regarding various chronic diseases found that severe fatigue may not necessarily be merely an expression of depression, as only a portion of severely fatigued patients have depressive symptoms.,25,30 Furthermore, future studies should be designed in order to develop tailored interventions-or combinations of interventions-to reduce fatigue, 
for example CBT and/or graded exercise therapy.

\section{CONCLUSION}

Our results indicate that fatigue is an important and prevalent condition among adults with CF and can lead to a significant reduction in health-related quality of life. In addition, fatigue is associated more strongly with the patient's perception of symptoms and well-being than with clinically measured parameters. We therefore recommend that clinicians screen patients with CF for severe fatigue during hospital visits and-if necessary-initiate a conversation with the patient with respect to their fatigue and well-being. This proactive approach will likely improve patient-centred care. 


\section{REFERENCES}

1. Stephenson AL, Tom M, Berthiaume Y, et al. A contemporary survival analysis of individuals with cystic fibrosis: a cohort study. Eur Respir J. 2015;45(3):670-679. doi:10.1183/09031936.00119714

2. Sawicki CS, Sellers DE, Robinson WM. Self-Reported Physical and Psychological Symptom Burden in Adults with Cystic Fibrosis. J Pain Symptom Manage. 2008;35(4):372-380. doi:10.1016/j.jpainsymman.2007.06.005

3. Jarad NA, Sequeiros IM, Patel P, Bristow K, Sund Z. Fatigue in cystic fibrosis: a novel prospective study investigating subjective and objective factors associated with fatigue. Chron Respir Dis. 2012;9(4):241-249. doi:10.1177/1479972312464236

4. Bültmann U, Kant I, Kasl S V, Beurskens AJHM, van den Brandt PA. Fatigue and psychological distress in the working population: psychometrics, prevalence, and correlates. J Psychosom Res. 2002;52(6):445-452. Accessed December 11, 2017. http://www.ncbi.nlm.nih.gov/pubmed/12069868

5. Habib A-RR, Manji J, Wilcox PG, Javer AR, Buxton JA, Quon BS. A Systematic Review of Factors Associated with Health-Related Quality of Life in Adolescents and Adults with Cystic Fibrosis. Ann Am Thorac Soc. 2015;12(3):420-428. doi:10.1513/ AnnalsATS.201408-3930C

6. Knoop H, Prins JB, Moss-Morris R, Bleijenberg C. The central role of cognitive processes in the perpetuation of chronic fatigue syndrome. J Psychosom Res. 2010;68(5):489-494. doi:10.1016/j.jpsychores.2010.01.022

7. van Hoogmoed D, Fransen J, Bleijenberg G, van Riel P. Physical and psychosocial correlates of severe fatigue in rheumatoid arthritis. Rheumatology. 2010;49(7):12941302. doi:10.1093/rheumatology/keq043

8. Goedendorp MM, Tack CJ, Steggink E, Bloot L, Bazelmans E, Knoop H. Chronic Fatigue in Type 1 Diabetes: Highly Prevalent but Not Explained by Hyperglycemia or Clucose Variability. Diabetes Care. 2014;37(1):73-80. doi:10.2337/dcl3-0515

9. Kos D, Kerckhofs E, Nagels G, D'hooghe MB, Ilsbroukx S. Origin of fatigue in multiple sclerosis: review of the literature. Neurorehabil Neural Repair. 2008;22(1):91-100. doi:10.1177/1545968306298934

10. Troosters T, Langer D, Vrijsen B, et al. Skeletal muscle weakness, exercise tolerance and physical activity in adults with cystic fibrosis. Eur Respir J. 2009;33(1):99-106. doi:10.1183/09031936.00091607

11. Katz ES. Cystic fibrosis and sleep. Clin Chest Med. 2014;35(3):495-504. doi:10.1016/j. ccm.2014.06.005

12. Quittner AL, Goldbeck L, Abbott J, et al. Prevalence of depression and anxiety in patients with cystic fibrosis and parent caregivers: results of The International Depression Epidemiological Study across nine countries. Thorax. 2014;69(12):10901097. doi:10.1136/thoraxjnl-2014-205983

13. Klijn PH, van Stel HF, Quittner AL, et al. Validation of the Dutch cystic fibrosis questionnaire (CFQ) in adolescents and adults. J Cyst Fibros. 2004;3(1):29-36. doi:10.1016/j.jcf.2003.12.006 
14. Worm-Smeitink M, Gielissen M, Bloot L, et al. The assessment of fatigue: Psychometric qualities and norms for the Checklist individual strength. J Psychosom Res. 2017;98:40-46. doi:10.1016/j.jpsychores.2017.05.007

15. Spruit MA, Vercoulen JH, Sprangers MAG, Wouters EFM. Fatigue in COPD: an important yet ignored symptom. Lancet Respir Med. Published online April 2017. doi:10.1016/\$2213-2600(17)30158-3

16. Wells CD, Wilkes DL, Schneiderman-Walker J, et al. Reliability and validity of the habitual activity estimation scale (HAES) in patients with cystic fibrosis. Pediatr Pulmonol. 2008;43(4):345-353. doi:10.1002/ppul.20737

17. Quanjer PH, Stanojevic S, Cole TJ, et al. Multi-ethnic reference values for spirometry for the 3-95-yr age range: the global lung function 2012 equations. Eur Respir J. 2012;40(6):1324-1343. doi:10.1183/09031936.00080312

18. Bradley J, Howard J, Wallace E, Elborn S. Validity of a modified shuttle test in adult cystic fibrosis. Thorax. 1999;54(5):437-439. Accessed December 22, 2016. http://www. ncbi.nlm.nih.gov/pubmed/10212110

19. Decramer M, Gosselink R, Troosters T, Verschueren M, Evers C. Muscle weakness is related to utilization of health care resources in COPD patients. Eur Respir J. 1997;10(2):417-423. Accessed December 22, 2016. http://www.ncbi.nlm.nih.gov/ pubmed/9042643

20. Nijhof S, Maijer K, Bleijenberg G, Uiterwaal C, Kimpen J, van de Putte E. Adolescent Chronic Fatigue Syndrome: Prevalence, Incidence, and Morbidity. Paediatrics. 2011;127(5):el169-el175. doi:10.1542/peds.2010-1147

21. Poort H, van der Graaf WTA, Tielen R, et al. Prevalence, Impact, and Correlates of Severe Fatigue in Patients With Gastrointestinal Stromal Tumors. J Pain Symptom Manage. 2016;52(2):265-271. doi:10.1016/j.jpainsymman.2016.02.019

22. Poort H, Kaal SEJ, Knoop H, et al. Prevalence and impact of severe fatigue in adolescent and young adult cancer patients in comparison with population-based controls. Support Care Cancer. 2017;25(9):2911-2918. doi:10.1007/s00520-017-3746-0

23. Friedman D, Linnemann RW, Altstein LL, et al. The CF-CARES primary palliative care model: A CF-specific structured assessment of symptoms, distress, and coping. J Cyst Fibros. Published online March 14, 2017. doi:10.1016/j.jcf.2017.02.011

24. Katz P. Fatigue in Rheumatoid Arthritis. Curr Rheumatol Rep. 2017;19(5):25. doi:10.1007/s11926-017-0649-5

25. Goedendorp MM, Hoitsma AJ, Bloot L, Bleijenberg G, Knoop H. Severe fatigue after kidney transplantation: a highly prevalent, disabling and multifactorial symptom.

Transpl Int. 2013;26(10):1007-1015. doi:10.1111/tri.12166

26. Voet N, Bleijenberg G, Hendriks J, et al. Both aerobic exercise and cognitivebehavioural therapy reduce chronic fatigue in FSHD: An RCT. Neurology. 2014;83(21):1914-1922. doi:10.1212/WNL.0000000000001008

27. Menting J, Tack CJ, van Bon AC, et al. Web-based cognitive behavioural therapy blended with face-to-face sessions for chronic fatigue in type 1 diabetes: a multicentre randomised controlled trial. Lancet Diabetes Endocrinol. 
2017:5(6):448-456. doi:10.1016/S2213-8587(17)30098-0

28. Abrahams HJG, Gielissen MFM, Donders RRT, et al. The efficacy of Internetbased cognitive behavioural therapy for severely fatigued survivors of breast cancer compared with care as usual: A randomized controlled trial. Cancer. 2017;123(19):3825-3834. doi:10.1002/cncr.30815

29. Goss CH, MacNeill SJ, Quinton HB, et al. Children and young adults with CF in the USA have better lung function compared with the UK. Thorax. 2015;70(3):229-236. doi:10.1136/thoraxjnl-2014-205718

30. Goedendorp MM, Gielissen MFM, Verhagen CAH, Peters MEJW, Bleijenberg C. Severe fatigue and related factors in cancer patients before the initiation of treatment. Br J Cancer. 2008;99(9):1408-1414. doi:10.1038/sj.bjc.6604739 


\section{3}
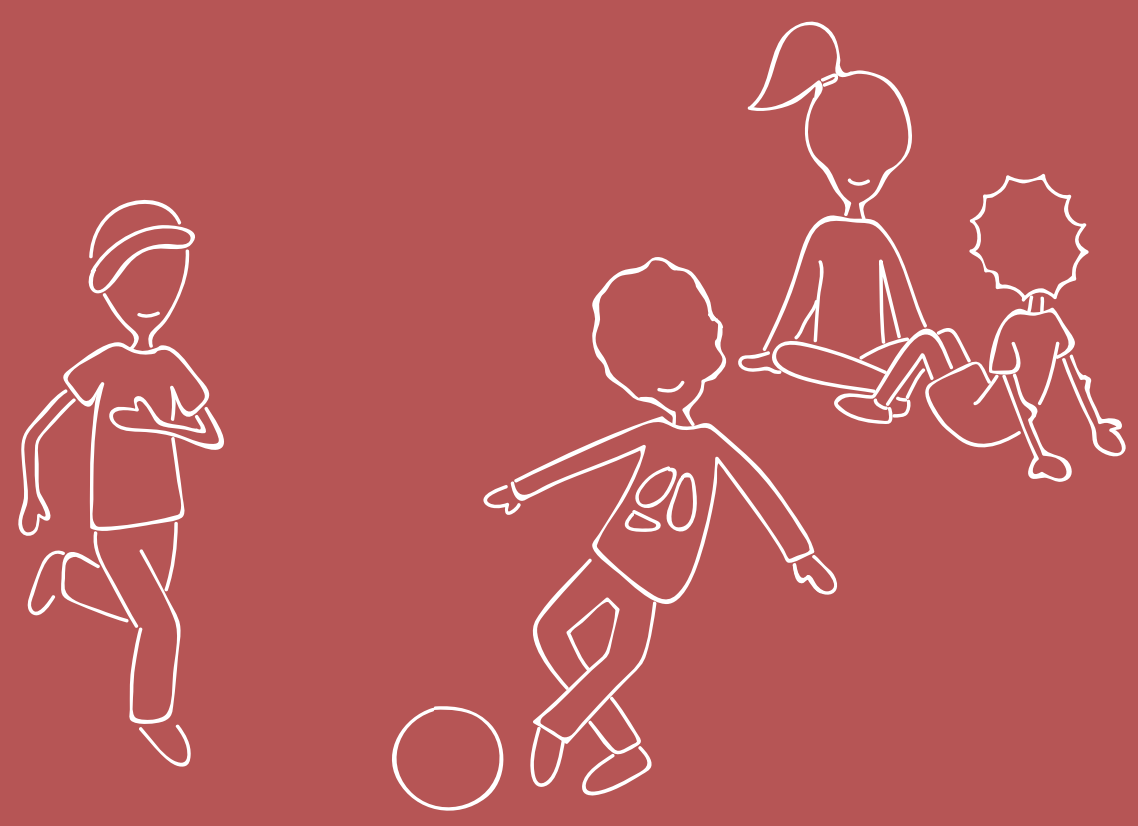


\title{
Fatigue in childhood chronic disease
}

\author{
Merel M. Nap-van der Vlist, \\ MSca; Geertje W. Dalmeijer, PhD; \\ Martha A. Grootenhuis, PhD; \\ Cornelis K. van der Ent, PhD d; \\ Marry M. van den Heuvel-Eibrink, PhD'; \\ Nico M. Wulffraat, PhDe; \\ Joost F. Swart, PhDe \\ Raphaële R.L. van Litsenburg, PhDc,f \\ Elise M. van de Putte, PhD a; \\ Sanne L. Nijhof, PhDa
}

a Department of Paediatrics, Wilhelmina Children's Hospital, University Medical Center Utrecht, Utrecht University, Utrecht, The Netherlands

b Julius Center for Health Sciences and Primary Care, University Medical Center Utrecht, Utrecht University, Utrecht, The Netherlands

c Princess Máxima Center for Paediatric Oncology, Utrecht, The Netherlands

d Department of Paediatric Pulmonology, Wilhelmina Children's Hospital, University Medical Center Utrecht, Utrecht University, Utrecht, The Netherlands

e Department of Paediatric Rheumatology/Immunology, Wilhelmina Children's Hospital, University Medical Center Utrecht, Utrecht University, Utrecht, The Netherlands f Department of Paediatric Oncology-Haematology, Emma Children's Hospital, Vrije Universiteit, Amsterdam, Amsterdam UMC, The Netherlands 


\section{ABSTRACT}

\section{Background and objectives:}

Recently, in adults, the incidence and severity of fatigue was found to exist rather independently from the somatic diagnosis. Since fatigue is distressing when growing up with a chronic disease, we aim to investigate 1) the prevalence and extent of fatigue among various paediatric chronic diseases, and 2) the effect of fatigue on healthrelated quality of life (HRQOL).

\section{Design and setting:}

Cross-sectional study in two children's hospitals.

\section{Patients:}

Children and adolescents 2-18 years old with cystic fibrosis, an autoimmune disease, or post-cancer treatment visiting the outpatient clinic.

\section{Outcome measures:}

Fatigue and HRQoL were assessed using the PedsQL multidimensional fatigue scale (with lower scores indicating more fatigue) and PedsQL generic core scales, respectively. Linear regression and ANCOVA analyses were used to compare fatigue scores across disease groups, and against two control groups. The effect of fatigue on HRQOL was calculated. Data were adjusted for age, sex, and reporting method.

\section{Results:}

481 children and adolescents were assessed (60\% participation rate, mean age 10.7 44.9 , $42 \%$ male). Children and adolescents with chronic disease reported more fatigue than the general population (mean difference -6.6, 95\% Cl -8.9,-4.3 (range 0-100)), with a prevalence of severe fatigue of $21.2 \%$. Fatigue scores did not differ significantly between disease groups on any fatigue domain. Fatigue was associated with lower HRQOL on all domains.

\section{Conclusions:}

Fatigue in childhood chronic disease is a common symptom that presents across disease, age, and sex groups. Fatigue affects HRQoL. Our findings underscore the need to systematically assess fatigue. Future studies should determine possible biological and psychosocial treatment targets. 


\section{INTRODUCTION}

Thanks to major advances in paediatric medicine, many paediatric diseases can now be stabilized or cured.' As a result, children and adolescents with a chronic medical condition such as cystic fibrosis (CF) or an autoimmune disease, as well as children and adolescents who were successfully treated for a life-threatening disease with long-term consequences (e.g., childhood cancer), often face several challenges while growing up; here, we define these conditions collectively as "childhood chronic diseases". These challenges can include both somatic and psychosocial aspects., ${ }^{2,3}$ Fatigue is often one such challenge and can have a significant impact on the wellbeing and participation in daily life of the child or adolescent and his or her family.4-6

Recently, in adults, the incidence and severity of fatigue was found to exist rather independently from the somatic diagnosis? This emerging concept has not yet been studied in children and adolescents, although it has been reported that fatigue can persist despite low disease activity. ${ }^{7-9}$ In adolescence, fatigue is known to be more prevalent than in younger children and can partially be explained by physical and psychosocial changes in puberty, such as changing sleep patterns. ${ }^{10}$ Even though fatigue is generally recognized as a frequent and distressing symptom, the prevalence and extent of fatigue among various paediatric chronic diseases are currently unknown. $8,9,11$ Determining whether fatigue is a general rather than a disease-specific phenomenon is an important first step toward developing more general fatigue interventions. In children and adolescents, the ability to adequately assess and treat fatigue can improve their current well-being, as well as their future well-being and participation in daily life and can prevent fatigue from becoming persistent.12,13 Therefore, understanding the extent and nature of fatigue among various childhood chronic diseases is needed. To address this need, the primary aim of our study was to investigate the prevalence and extent of fatigue among children and adolescents with chronic disease and two control groups. In addition, we investigated the effect of fatigue on health-related quality of life (HRQOL).

\section{METHODS}

\section{Study design}

A cross-sectional study was conducted in the outpatient clinics of the Wilhelmina Children's Hospital and the Princess Máxima Center for Paediatric Oncology in the Netherlands, from December 2016 through September 2018. Fatigue in children and adolescents with a chronic disease was compared with fatigue in the general population as well as fatigue among children and adolescents with chronic fatigue syndrome (CFS). ${ }^{10}$ This study was classified by the institutional review board as exempt of the Medical Research Involving Human Subjects Act (16-707/C). Informed consent was obtained for the use of questionnaires for scientific purposes and for the extraction of data from the participating children's medical records.

\section{Participants}

The group of children and adolescents (2-18 years old) with chronic disease included 
children with CF, children with an autoimmune disease, and children who completed treatment for cancer. The last group was included within one year after completing treatment; we refer to these children and adolescents as "children post-cancer treatment". The group of participants with an autoimmune disease consisted of children and adolescents with an autoimmune disease, an immunodeficiency, or an auto-inflammatory condition. We intended to create a cohort with a wide range of somatic diagnoses, both life threatening and non-life threatening, and both congenital and acquired, to cover a wide range of serious paediatric chronic diseases. Participants with an autoimmune disease or with CF were included at least one year after initial diagnosis. In the first year after diagnosis, disease activity is generally highest and the new diagnosis, start of treatment and the disease itself can all cause significant fatigue. By choosing children at least one year after diagnosis, we aim to describe the fatigue that persists in a stable phase of the disease. The following exclusion criteria were applied: i) insufficient understanding of the Dutch language to complete the questionnaires, and ii) in case of childhood cancer, relapse of the primary diagnosis.

\section{Study procedures}

Patients and their parents were approached via email three weeks before their appointment. They were invited to register at home using a web-based tool (www. hetklikt.nu) through which they could complete the questionnaires electronically. If no response was received, they were reminded once via email and once via telephone. A research team was available to answer questions and assist with registration.

\section{Questionnaires}

Two validated questionnaires were used to assess fatigue and HRQOL. For children 2-7 years old, their parents completed the questionnaires, whereas children and adolescents 8-18 years old completed the questionnaires themselves. Children 8-11 years old were offered assistance by their parents. In addition, all parents of children 8-18 years old were asked to fill out the parent-reported version of the two questionnaires as well. If children 8-18 years old did not want to participate or did not respond, the parent-reported version on the questionnaires was used.

The Dutch version of the PedsQL multidimensional fatigue scale (PedsQL MFS) was used to assess fatigue. This questionnaire consists of three subscales (general fatigue, sleep/rest fatigue, and cognitive fatigue) with 23 items, yielding a score ranging from 0-100 points; lower scores indicates more fatigue. The general fatigue scale contains questions about the subjective feeling of fatigue and about the energy to execute activities, the sleep/rest fatigue scale contains questions about the quantity and quality of sleep and rest, and the cognitive fatigue scale contains questions regarding attention and memory. The Dutch version of the PedsQL MFS has good internal consistency. ${ }^{10}$ To compare our results to both ends of the fatigue spectrum, the data were compared to: i) a group of children and adolescents from the general population, which served as a relatively non-fatigued group, and ii) a group of children and adolescents with CFS, which served as a fatigued control group. ${ }^{10}$ The CFS control group was recruited from a cohort of children and adolescents with a diagnosis of CFS at the Wilhelmina Children's Hospital. We used the data from the general population from an existing reference population collected by Gordijn et. al (2011), that were 
collected at day care facilities and schools in the Netherlands, between October 2009 and May 2010.10

To quantify the number of severely fatigued children and adolescents, we used a cut-off value of 2 standard deviations (SD) below the norm, taking into account sex and age category (2-4, 5-7, 8-11, and 12-18 years old). Children and adolescents who scored >ISD below the norm were defined as "fatigued". The PedsQL generic core scales 4.0 (PedsQL GCS) was used to assess HRQoL." Higher scores indicate higher HRQoL and better functioning. The PedsQL CCS consists of four subscales, with a total score ranging from 0-100: physical, emotional, social, and school functioning. This instrument has good validity and reliability.14

\section{Clinical assessments}

Sex, age, diagnosis, time elapsed between diagnosis and assessment, and disease status at assessment were extracted from the medical record of the child or adolescent. For participants with CF, forced expiratory volume in one second (FEV $)$ was used as a proxy for disease status and is expressed as the percentage of predicted $F E V_{1}$. This predicted percentage is based on the reference values for spirometry of the global lung function 2012 equations by Quanjer et al. (2012), providing age- and sexmatched reference values, with 100\% indicating normal lung function. ${ }^{15}$ For participants with juvenile idiopathic arthritis (JIA), the clinical Juvenile Arthritis Disease Activity Score (cJADAS) and erythrocyte sedimentation rate (ESR) were used as a proxy for disease status; for participants with other autoimmune diseases, only ESR was used.

\section{Data analyses}

Descriptive statistics were used to summarize the clinical characteristics of the various groups and the prevalence of severe fatigue ( $>2 S D$ below the norm). Differences between participants and non-participants were analysed using the Student's t-test or the chi-square test. Normally distributed data are presented as mean \pm SD; otherwise median and interquartile range were provided. Using linear regression, fatigue scores of children and adolescents with chronic disease were compared to the general population. These differences are described using the mean difference, or unstandardized beta, and 95\% confidence interval (CI). Age, sex, and reporting method (self-reporting versus parent-reporting) have been reported as important determinants of fatigue, including chronic fatigue. ${ }^{16,17}$ Therefore, these three variables were used as covariates in all analyses.

Different multivariable ANCOVA (analysis of covariance) were used to study the differences in fatigue scores on different fatigue domains between the disease groups, with age, sex and reporter as covariates. Using linear regression, severely fatigued participants with chronic disease were compared to both the general population and to the group with CFS in order to gain further insight into their fatigue profile. Linear regression was used to describe the effect of fatigue on HRQOL. In sensitivity analyses, we excluded the cases in which the parent-report was used for children 8 years or older. Differences in which the $95 \% \mathrm{Cl}$ did not include zero were considered statistically significant. 


\section{RESULTS}

Of the 800 children and adolescents who were eligible for inclusion, 481 (60\%) participated and could be assessed for fatigue. Of these 481participants, 440 (91\%) also provided informed consent for the use of data from the medical record of the child or adolescent. There was no difference between the participants and non-participants with respect to the distribution of sex, age, disease duration or disease activity, with the exception that non-participants with CF had significantly lower FEV, values (81.1 \pm 16.6$)$ than participants with CF (87.2 \pm 18.2$)$. In the group 2-7 years old, 146 parents of completed the questionnaires, in the group 8-12 years old 125 children completed the questionnaires themselves, and in the group 13-18 years old 201 adolescents completed the questionnaires themselves. For 9 adolescents in the group 13-18 year old, parents completed the questionnaires instead. All participants completed the questionnaires entirely. Common reasons given for not participating were personal circumstances and participating in other research.

Clinical characteristics of the participants are summarized in Table 1. The group of children and adolescents with chronic diseases consisted of patients who regularly visited the outpatient clinic. In total, 111 participants (23\%) had CF, 277 (58\%) had an autoimmune disease, and 93 (19\%) were post-cancer treatment. The group of patients with an autoimmune disease and the CFS control group contained more females than males (with 65\% and 75\% females, respectively); the other two disease groups and the general population contained approximately equal numbers of males and females. Participants in the CF and autoimmune disease groups were significantly older than participants in the post-cancer treatment group and the general population.

\begin{tabular}{|c|c|c|c|c|c|}
\hline & \multicolumn{3}{|c|}{ Chronic disease groups } & \multicolumn{2}{|c|}{ Control groups } \\
\hline & Children with CF & $\begin{array}{l}\text { Children with } \\
\text { autoimmune } \\
\text { disease }\end{array}$ & $\begin{array}{l}\text { Children } \\
\text { post-cancer } \\
\text { treatment }\end{array}$ & $\begin{array}{l}\text { Children } \\
\text { with chronic } \\
\text { fatigue } \\
\text { syndrome }\end{array}$ & $\begin{array}{l}\text { General } \\
\text { population }\end{array}$ \\
\hline $\begin{array}{l}\text { Filled out } \\
\text { questionnaires }\end{array}$ & $N=111$ & $N=277$ & $N=93$ & $N=56$ & $N=502$ \\
\hline Age (mean $\pm S D)$ & $11.3 \pm 5.0$ & $11.4 \pm 4.4$ & $7.7 \pm 5.0$ & $15.2 \pm 1.8$ & $9.4 \pm 4.8$ \\
\hline Sex, male (N, \%) & $54(49 \%)$ & $98(35 \%)$ & $50(54 \%)$ & $14(25 \%)$ & $234(48 \%)$ \\
\hline $\begin{array}{l}\text { Consented to use of } \\
\text { information child's } \\
\text { medical record }\end{array}$ & $N=103$ & $N=253$ & $N=84$ & & \\
\hline
\end{tabular}

a Disease duration: years since diagnosis until inclusion for children with JIA; years from end of treatment until inclusion for children post-cancer treatment.

b If the data were normally distributed, the mean $\pm S D$ is given; if not, the median and interquartile range is given.

$C F=$ cystic fibrosis; SD = standard deviation; $J I A=$ juvenile idiopathic arthritis; $C J A D A S=$ clinical Juvenile Arthritis Disease Activity Score; ESR = erythrocyte sedimentation rate; FEV $\%$ = predicted percentage of forced expiratory volume in one second; NA = not applicable. 
Table 1. Baseline characteristics of the children with a chronic disease and two control groups.

\begin{tabular}{|c|c|c|c|c|c|}
\hline & \multicolumn{3}{|c|}{ Chronic disease groups } & \multicolumn{2}{|c|}{ Control groups } \\
\hline & Children with CF & $\begin{array}{l}\text { Children with } \\
\text { autoimmune } \\
\text { disease }\end{array}$ & $\begin{array}{l}\text { Children } \\
\text { post-cancer } \\
\text { treatment }\end{array}$ & $\begin{array}{l}\text { Children } \\
\text { with chronic } \\
\text { fatigue } \\
\text { syndrome }\end{array}$ & $\begin{array}{l}\text { General } \\
\text { population }\end{array}$ \\
\hline Diagnosis & $\begin{array}{l}57(57 \%) \text { homo- } \\
\text { zygote dF508 } \\
37(36 \%) \text { hetero- } \\
\text { zygote dF508 } \\
6(6 \%) \text { other } \\
3 \text { missing }(7 \%)\end{array}$ & $\begin{array}{l}39(15 \%) \text { poly-ar- } \\
\text { ticular JIA } \\
101(40 \%) \text { oli- } \\
\text { go-articular JIA } \\
19(8 \%) \text { systemic } \\
\text { JIA } \\
21(8 \%) \text { other } \\
\text { form of JIA } \\
73(29 \%) \text { other } \\
\text { autoimmune } \\
\text { disease }\end{array}$ & $\begin{array}{l}53(63 \%) \text { solid } \\
\text { tumours } \\
29(35 \%) \\
\text { leukaemia/ } \\
\text { lymphoma } \\
2 \text { (2\%) brain } \\
\text { tumour }\end{array}$ & NA & NA \\
\hline $\begin{array}{l}\text { Duration of disease } \\
\text { status, years }^{a} \\
\text { (mean } \pm S D)\end{array}$ & $11.3 \pm 5.0$ & $5.6 \pm 3.8$ & $0.6 \pm 0.5$ & NA & NA \\
\hline Disease activity ${ }^{b}$ & $\begin{array}{l}\text { FEVI \%: } 87.2 \pm \\
18.2\end{array}$ & $\begin{array}{l}\text { CJADAS: } 0(0-3) \\
\text { ESR: } 5 \mathrm{~mm} / \mathrm{lst} \mathrm{hr} \\
(2-8)\end{array}$ & $\begin{array}{l}\text { All post- } \\
\text { treatment }\end{array}$ & NA & NA \\
\hline
\end{tabular}

a Disease duration: years since diagnosis until inclusion for children with JIA; years from end of treatment until inclusion for children post-cancer treatment.

b If the data were normally distributed, the mean $\pm S D$ is given; if not, the median and interquartile range is given.

$C F=$ cystic fibrosis; SD = standard deviation; JIA = juvenile idiopathic arthritis; CJADAS = clinical Juvenile Arthritis Disease Activity Score; ESR = erythrocyte sedimentation rate; FEV \% = predicted percentage of forced expiratory volume in one second; NA = not applicable.

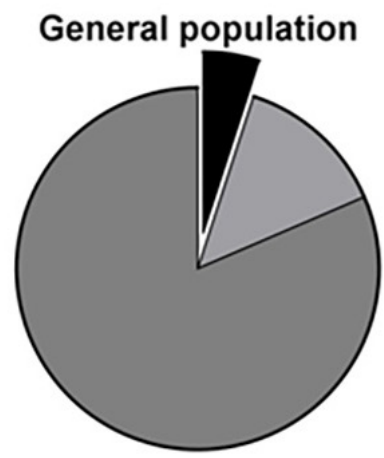

Total $=502$

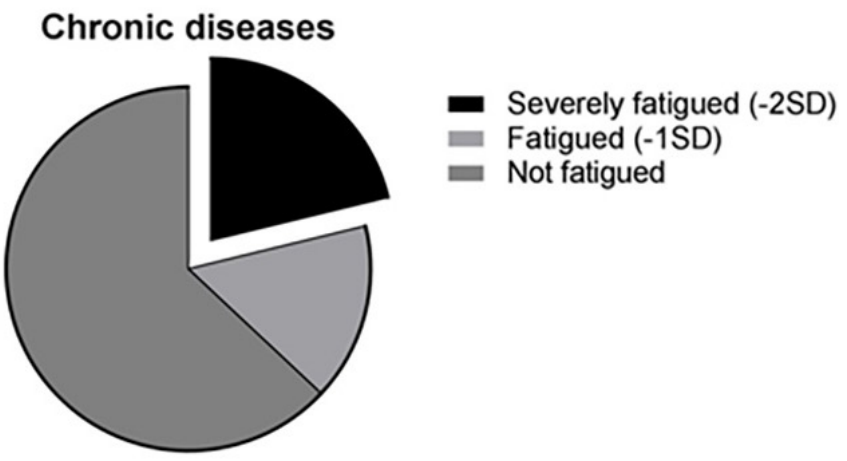

Total $=\mathbf{4 8 1}$

Figure 1. Distribution of severe fatigue in the general population ( $\mathrm{n}=502$ children) and in children 2-18 years old with a chronic disease $(n=481)$.

Among all children and adolescents with chronic disease, 21.2\% scored severely fatigued (defined as $>2$ SD below the norm), and 37\% scored $\geq 1$ SD below the norm (Figure 1). Fatigue scores per age group are provided in table 2 for children and adolescents with chronic diseases and the general population. The group of children and adolescents with chronic disease scored more fatigued compared to the general 
population with respect to total fatigue (mean difference: -3.9 points; $95 \% \mathrm{Cl}:-5.8$, -2.0), general fatigue (mean difference: -6.6 points; $95 \% \mathrm{Cl}:-8.9,-4.3$ ), and sleep/ rest fatigue (mean difference: -5.8 points; $95 \% \mathrm{Cl}$ : $-8.0,-3.6$ ), but scored similarly for cognitive fatigue (mean difference: $0.9 ; 95 \% \mathrm{Cl}$ : $-1.5,3.3$ ) (Table 3). Within the total group of children and adolescents with chronic disease, both higher age and female sex-but not reporting method-were associated with lower general fatigue scores, with a mean difference of -0.8 points $(95 \% \mathrm{Cl}:-1.2,-0.4)$ and -7.0 points $(95 \% \mathrm{Cl}$ : $-11.1,-3.0)$ for age and female sex, respectively, and -2.4 points $(95 \% \mathrm{Cl}$ : $-6.8,1.9)$ for reporting method.

Table 2. Fatigue scores per age category for children and adolescents with chronic disease $(n=481)$ and the general population $(n=502)$.

\begin{tabular}{|c|c|c|}
\hline & $\begin{array}{l}\text { Children with a chronic } \\
\text { disease }\end{array}$ & General population \\
\hline Children 2-7 year old, parent report & $N=146$ & $N=187$ \\
\hline Total fatigue & $78.0 \pm 19.0$ & $82.9 \pm 11.0$ \\
\hline General fatigue & $74.6 \pm 23.4$ & $83.5 \pm 12.1$ \\
\hline Sleep/rest fatigue & $77.2 \pm 22.0$ & $85.1 \pm 12.9$ \\
\hline Cognitive fatigue & $82.2 \pm 19.5$ & $80.1 \pm 16.3$ \\
\hline Percentage severely fatigued & $23.3 \%$ & $4.3 \%$ \\
\hline Children 8-12 year old, child report & $N=125$ & $N=143$ \\
\hline Total fatigue & $77.1 \pm 15.2$ & $78.7 \pm 12.5$ \\
\hline General fatigue & $78.9 \pm 18.5$ & $82.7 \pm 12.9$ \\
\hline Sleep/rest fatigue & $74.0 \pm 17.2$ & $77.5 \pm 15.0$ \\
\hline Cognitive fatigue & $77.4 \pm 19.6$ & $75.8 \pm 19.1$ \\
\hline Percentage severely fatigued & $16.2 \%$ & $3.9 \%$ \\
\hline Children 13-18 year old, child report* & $N=210$ & $N=155$ \\
\hline Total fatigue & $69.5 \pm 18.8$ & $75.2 \pm 11.9$ \\
\hline General fatigue & $68.2 \pm 23.8$ & $76.7 \pm 14.3$ \\
\hline Sleep/rest fatigue & $65.6 \pm 20.0$ & $71.9 \pm 14.2$ \\
\hline Cognitive fatigue & $75.4 \pm 22.1$ & $77.2 \pm 15.3$ \\
\hline Percentage severely fatigued & $22.2 \%$ & $6.7 \%$ \\
\hline
\end{tabular}

All fatigue scores are reported as mean \pm SD. *In the group of children with chronic diseases,

9 questionnaires were parent reported instead of child reported.

Table 3. Unadjusted and adjusted mean differences in fatigue scores between children with a chronic disease $(n=481)$ and children in the general population $(n=502)$

\begin{tabular}{|l|l|l|l|l|}
\hline & \multicolumn{2}{l}{} & \multicolumn{2}{l|}{ Adjusted model a } \\
\hline & Unadjusted model & Mean difference & $95 \% \mathrm{Cl}$ \\
\hline Total fatigue & -5.3 & $-7.2 ;-3.3$ & -3.9 & $-5.8 ;-2.0$ \\
\hline General fatigue & -8.2 & $-10.6 ;-5.9$ & -6.6 & $-8.9 ;-4.3$ \\
\hline
\end{tabular}

a The adjusted model was corrected for age, sex, and reporting method. The PedsQL MFS is scored on a scale from 0-100, with a lower score indicating more severe fatigue. Thus, a negative mean difference indicates a lower score for the children with a chronic disease, indicating more fatigue.

$\mathrm{Cl}=$ confidence interval. Significant differences in bold. 
Table 3. Unadjusted and adjusted mean differences in fatigue scores between children with a chronic disease $(n=481)$ and children in the general population $(n=502)$.

Sleep/rest fatigue

Cognitive fatigue
$-7.4$
$-9.6 ;-5.1$

$-2.2 ; 2.6$

$-5.8$

0.9
$-8.0 ;-3.6$

$-1.5 ; 3.3$

a The adjusted model was corrected for age, sex, and reporting method. The PedsQL MFS is scored on a scale from 0-100, with a lower score indicating more severe fatigue. Thus, a negative mean difference indicates a lower score for the children with a chronic disease, indicating more fatigue.

$\mathrm{Cl}=$ confidence interval. Significant differences in bold.

Multivariable ANCOVAs revealed that fatigue scores did not differ significantly between children and adolescents with CF, an autoimmune disease, and post-cancer treatment with respect to total fatigue $(P=0.19)$, general fatigue $(P=0.14)$, sleep/rest fatigue $(P=0.14)$, or cognitive fatigue $(P=0.42)$ (Figure 2 and Table 4).

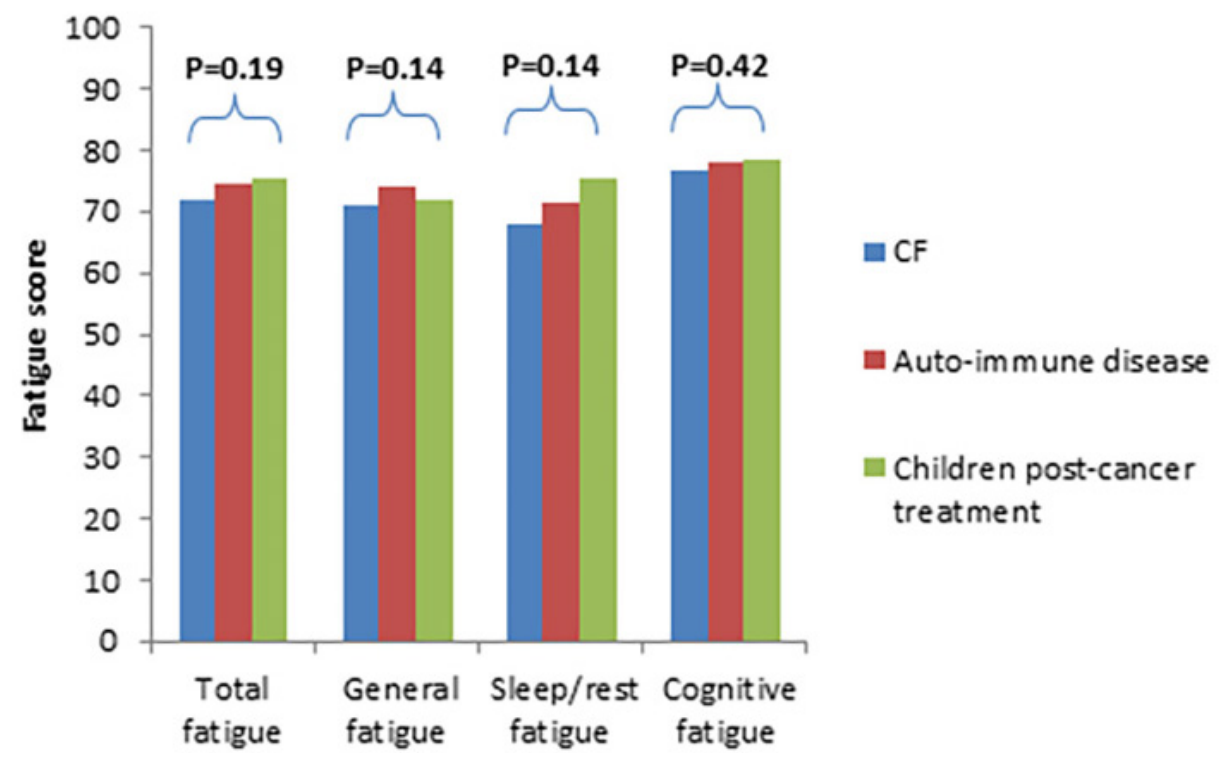

Figure 2. Summary of mean fatigue scores for various childhood disease groups, adjusted for age, gender, and reporting method (child or proxy).

Table 4. Mean ( \pm SD) PedsQL MFS scores for indicated disease groups and the general population group.

\begin{tabular}{|l|l|l|l|l|}
\hline & Cystic fibrosis & $\begin{array}{l}\text { Autoimmune } \\
\text { disease }\end{array}$ & $\begin{array}{l}\text { Post-cancer } \\
\text { treatment }\end{array}$ & General population \\
\hline & $\mathrm{N}=111$ & $\mathrm{~N}=277$ & $\mathrm{~N}=93$ & $\mathrm{~N}=502$ \\
\hline Total fatigue & $72.0 \pm 18.6$ & $74.5 \pm 18.3$ & $75.3 \pm 18.6$ & $79.3 \pm 12.3$ \\
\hline Ceneral fatigue & $71.3 \pm 24.2$ & $73.9 \pm 22.0$ & $72.0 \pm 23.4$ & $81.1 \pm 13.5$ \\
\hline Sleep/rest fatigue & $67.8 \pm 22.8$ & $71.4 \pm 19.4$ & $75.3 \pm 20.7$ & $78.7 \pm 15.1$ \\
\hline Cognitive fatigue & $76.9 \pm 19.8$ & $78.2 \pm 21.4$ & $78.6 \pm 20.7$ & $77.8 \pm 17.3$ \\
\hline
\end{tabular}

Children and adolescents with chronic disease who were severely fatigued (>2SD below the norm) scored an average of 29.0 points lower $(95 \% \mathrm{Cl}:-31.6,-26.4)$ on the total fatigue score compared to the general population. Specifically, these children and adolescents scored lower for general fatigue (mean difference: -41.2 points; $95 \% \mathrm{Cl}$ : 
-44.0, -38.4), sleep/rest fatigue (mean difference: -27.4 points; $95 \% \mathrm{Cl}$ : -30.6, -24.2), and cognitive fatigue (mean difference: -18.9 points; $95 \% \mathrm{Cl}$ : $-22.8,-15.0$ ) compared to the general population (Table 5). Moreover, the fatigue profile for these participants was similar to the participants in the CFS group (Table 6).

Table 5. Unadjusted and adjusted mean differences in fatigue scores between children with a chronic disease who are severely fatigued (defined as $>2$ SD below the norm; $n=102$ ) and the general population $(n=502)$

\begin{tabular}{l|l|l|l|l|}
\hline & \multicolumn{3}{l}{ Unadjusted model } & Adjusted model a \\
& Mean difference & $95 \% \mathrm{Cl}$ & Mean difference & $95 \% \mathrm{Cl}$ \\
\hline Total fatigue & -30.1 & $-32.7 ;-27.5$ & -29.0 & $-31.6 ;-26.4$ \\
\hline General fatigue & -42.6 & $-45.4 ;-39.8$ & -41.2 & $-44.0 ;-38.4$ \\
\hline Sleep/rest fatigue & -28.7 & $-32.0 ;-25.4$ & -27.4 & $-30.6 ;-24.2$ \\
\hline Cognitive fatigue & -19.3 & $-23.2 ;-15.4$ & -18.9 & $-22.8 ;-15.0$
\end{tabular}

a The adjusted model was corrected for age, gender, and reporting method.

PedsQL MFS is scored on a scale from 0-100, with a lower score indicating more severe fatigue. A negative mean difference indicates a lower score for the children with a chronic disease, indicating more fatigue.

$\mathrm{Cl}=$ confidence interval. Significant differences in bold

Table 6. Unadjusted and adjusted mean differences in fatigue scores between children with CFS ( $n=56)$ and the general population $(n=502)$

\begin{tabular}{|l|l|l|l|l|}
\hline & \multicolumn{3}{l}{ Unadjusted model } & Adjusted model a \\
& Mean difference & $95 \% \mathrm{Cl}$ & Mean difference & $95 \% \mathrm{Cl}$ \\
\hline Total fatigue & -36.7 & $-40.1 ;-33.3$ & -32.6 & $-36.3 ;-29.0$ \\
\hline Ceneral fatigue & -49.8 & $-53.5 ;-46.1$ & -45.9 & $-49.8 ;-41.9$ \\
\hline Sleep/rest fatigue & -35.7 & $-39.9 ;-31.5$ & -30.3 & $-34.7 ;-25.9$ \\
\hline Cognitive fatigue & -24.1 & $-29.1 ;-19.2$ & -21.8 & $-27.2 ;-16.4$
\end{tabular}

a The adjusted model was corrected for age, gender, and reporting method.

PedsQL MFS is scored on a scale from 0-100, with a lower score indicating more severe fatigue. A negative mean difference indicates a lower score for the children with a chronic disease, indicating more fatigue.

$\mathrm{Cl}=$ confidence interval. Significant differences in bold.

Among children and adolescents with chronic disease, having a lower score on the total fatigue score was associated with a lower total HRQOL score. For each 1-point reduction in the PedsQL MFS score, the same child's score for HRQOL was on average 0.70 points lower $(95 \% \mathrm{Cl}$ : $-0.65,0.75)$. A similar association was found with respect to physical functioning (mean difference: -0.80; 95\% Cl:-0.68,-0.92), emotional functioning (mean difference: $-0.70 ; 95 \% \mathrm{Cl}$ :-0.62,-0.78), social functioning (mean difference: -0.56 ; $95 \% \mathrm{Cl}:-0.49,-0.63$ ), and school functioning (mean difference: -0.75 ; 95\% Cl: -0.68, -0.82) (Table 7). In sensitivity analyses, all results were unaffected by the exclusion of the parent-reported cases in children 8 years or older. 
Table 7. Relationship between total fatigue and HRQoL for children with chronic diseases $(n=481)$

\begin{tabular}{|l|l|l|l|l|}
\hline & Unadjusted model & Adjusted model a \\
\hline & Mean difference & $95 \% \mathrm{Cl}$ & Mean difference & $95 \% \mathrm{Cl}$ \\
\hline Total HRQoL & 0.69 & $0.64 ; 0.73$ & 0.70 & $0.65 ; 0.75$ \\
\hline Physical functioning & 0.79 & $0.66 ; 0.91$ & 0.80 & $0.68 ; 0.92$ \\
\hline Emotional functioning & 0.65 & $0.57 ; 0.73$ & 0.70 & $0.62 ; 0.78$ \\
\hline Social functioning & 0.53 & $0.46 ; 0.60$ & 0.56 & $0.49 ; 0.63$ \\
\hline School functioning & 0.76 & $0.69 ; 0.83$ & 0.75 & $0.68 ; 0.82$
\end{tabular}

a The adjusted model was corrected for age, sex, and reporting method (child or proxy). PedsQL CCS is scored on a scale from 0-100, with lower scores indicating reduced HRQoL. Positive mean differences indicate a higher HRQOL score on the PedsQL GCS, indicating higher HRQOL. Specifically, for each l-point reduction in the PedsQL MFS score (indicating more fatigue), the same child's score for HRQOL was on average 0.70 points lower. Cl = confidence interval; HRQOL = health-related quality of life. Significant differences in bold.

\section{DISCUSSION}

Our results indicate that fatigue is highly prevalent-and therefore highly relevantamong children and adolescents with chronic disease. Fatigue in childhood chronic disease is a common symptom that presents across disease, age, and sex groups and severely affects quality of life. This is the first study to identify and quantify fatigue in a large and representative paediatric sample with various chronic diseases and to compare fatigue in this population with both the general population and patients with CFS. Our results therefore emphasize the need for increased awareness of fatigueand the need to accurately assess fatigue-in children and adolescents with chronic disease.

Our finding that fatigue is more prevalent among children and adolescents with chronic disease compared to the general population is consistent with previous reports regarding children with JIA and survivors of childhood cancer. 9.18 Other studies do not report more fatigue in long-term survivors of childhood cancer..$^{18-20}$ It may be that the fatigue we found in our study represents the residual consequences of treatment and decreases over time. Also, Armbrust et al. ${ }^{4}$ did not report more fatigue in children with JIA, which may be due to the younger mean age of the children in their study. ${ }^{4}$ With respect to CF, fatigue has not been studied previously in children and adolescents. Studies involving adults have shown that fatigue is a prevalent and distressing symptom. ${ }^{8,21}$ Furthermore, our finding that fatigue has a major impact on HRQOL in children and adolescents with chronic disease is consistent with previous reports. ${ }^{4,22}$

Fatigue might not necessarily be a disease-specific process. ${ }^{7.23}$ Several studies reported that fatigue persists despite low disease activity. $4.8,9$ In addition, we found no significant differences in fatigue scores between disease groups on any fatigue domain. Subsequently, in our study, the pattern of fatigue was similar between severely fatigued children and adolescents with chronic disease and children and adolescents with CFS with no biological explanation for their fatigue, especially concerning cognitive fatigue. 
Fatigue is likely not simply a biological side-effect of the disease and its treatment, but also the result of the physical and psychosocial challenges of growing up with a chronic disease. ${ }^{723-25}$ We therefore suggest that interventions should focus on both the somatic and psychosocial aspects of fatigue, as, for example, in cognitive behavioural therapy (CBT). ${ }^{26}$ CBT has been proven to reduce fatigue in adolescents with CFS, and in fatigued adults with various chronic diseases. ${ }^{26-28}$ Other promising interventions include education, exercise or relaxation or are designed to improve one's self-efficacy or sleeppattern., 49,30 Whether children and adolescents with fatigue and a chronic disease respond to CBT and other interventions in the same way as adolescents with CFS, is of interest for future studies. Future studies should be designed to determine which biological and psychosocial targets would be suitable for more general fatigue interventions and which interventions are effective for fatigue in younger children, when CBT is not yet a suitable option.

A clear strength of our study is that we examined fatigue across a broad spectrum of chronic diseases, thus increasing the generalizability of fatigue among children and adolescents with chronic disease. Moreover, fatigue was measured in participants 2-18 years old, revealing that fatigue is also prevalent in young children; in contrast, most previous studies focused on fatigue in adolescents. If we wish to shift our focus from treating fatigue to also preventing debilitating fatigue, we must expand our focus to include younger children.

Our study had several limitations. First, we combined child-reported data and parent-reported data in our analysis, even though a parent's reporting of their child can differ from the child's own reporting. ${ }^{7}$ We attempted to compensate for this difference by adjusting our analyses for reporting method. We did not find any evidence that reporting method influenced the results. Second, non-participants with CF had lower FEV, values than participants. Given that lower FEV, values are associated with fatigue, it is reasonable to speculate that the actual prevalence of severe fatigue among children and adolescents with CF may be even higher than in our study. Third, the age and sex distribution in the reference group were not exactly the same as in the chronically diseased group. We compensated for this by adjusting all analyses for sex and age. In this study, we were unable to look at the influence of developmental stage besides chronological age. For future studies, looking at the relationship with developmental stage besides chronological age would be of interest. Female participants were overrepresented in the CFS group and in patients with an autoimmune disease; however, this difference reflects clinical practice. ${ }^{4,16}$ Finally, within the post-cancer treatment group, the percentage of participants with a solid tumour was higher than previously reported; this difference might be due to the start of a paediatric oncology centre in the Netherlands which centralization of care started with children and adolescents with solid tumors. ${ }^{31}$

With a symptom as prevalent as fatigue, the ability to implement a relatively simple, validated screening questionnaire such as the PedsQL MFS may be clinically valuable in an outpatient setting. ${ }^{32}$ Monitoring fatigue can improve patient-centred care and will help shift the clinician's focus to the individual child's needs. 


\section{CONCLUSION}

Fatigue is highly prevalent-and therefore highly relevant-among children and adolescents with chronic disease. Fatigue in childhood chronic disease is a common symptom that presents across disease, age, and sex groups and severely affects quality of life. Our findings underscore the need for systematically assessing fatigue in children and adolescents with chronic disease. Future studies should determine possible biological and psychosocial treatment targets. 


\section{REFERENCES}

1. Perrin JM, Bloom SR, Gortmaker SL. The Increase of Childhood Chronic Conditions in the United States. JAMA. 2007;297(24):2755. doi:10.1001/jama.297.24.2755

2. Berglund MMU. Learning turning points-in life with long-term illness-visualized with the help of the life-world philosophy. Int I Qual Stud Health Well-being. 2014;9(0). doi:10.3402/qhw.v9.22842

3. Stam H, Hartman EE, Deurloo JA, Groothoff J, Grootenhuis MA. Young adult patients with a history of paediatric disease: impact on course of life and transition into adulthood. J Adolesc Health. 2006;39(1):4-13. doi:10.1016/j. jadohealth.2005.03.011

4. Armbrust W, Lelieveld OHTM, Tuinstra J, et al. Fatigue in patients with Juvenile Idiopathic Arthritis: relationship to perceived health, physical health, self-efficacy, and participation. Pediatr Rheumatol. 2016;14(1):65. doi:10.1186/s12969-016-0125-1

5. Huang I-C, Anderson M, Gandhi P, et al. The Relationships Between Fatigue, Quality of Life, and Family Impact Among Children With Special Health Care Needs. J Pediatr Psychol. 2013;38(7):722-731. doi:10.1093/jpepsy/jst016

6. Kim J, Chung H, Amtmann D, Salem R, Park R, Askew RL. Symptoms and quality of life indicators among children with chronic medical conditions. Disabil Health J. 2014;7(1):96-104. doi:10.1016/j.dhjo.2013.08.007

7. Menting J, Tack CJ, Bleijenberg C, et al. Is fatigue a disease-specific or generic symptom in chronic medical conditions? Heal Psychol. 2018;37(6):530-543. doi:10.1037/hea0000598

8. Nap-van der Vlist MM, Burghard M, Hulzebos HJ, et al. Prevalence of severe fatigue among adults with cystic fibrosis: A single center study. J Cyst Fibros. 2018;17(3):368374. doi:10.1016/j.jcf.2018.03.003

9. Nijhof LN, van de Putte EM, Wulffraat NM, Nijhof SL. Prevalence of severe fatigue among adolescents with paediatric rheumatic diseases. Arthritis Care Res (Hoboken). August 2015:n/a-n/a. doi:10.1002/acr.22710

10. Gordijn MS, Suzanne, Cremers EMP, Kaspers GJL, Gemke RJBJ. Fatigue in children: reliability and validity of the Dutch PedsQLTM Multidimensional Fatigue Scale. Qual Life Res. 2011;20(7):1103-1108. doi:10.1007/s11136-010-9836-9

11. Jóhannsdóttir IMR, Hjermstad MJ, Moum T, et al. Increased prevalence of chronic fatigue among survivors of childhood cancers: A population-based study. Pediatr Blood Cancer. 2012;58(3):415-420. doi:10.1002/pbc.23111

12. Timko C, Baumgartner M, Moos RH, Miller JJ. Parental risk and resistance factors among children with juvenile rheumatic disease: a four-year predictive study. J Behav Med. 1993;16(6):571-588. http://www.ncbi.nlm.nih.gov/pubmed/8126713. Accessed July 21, 2016.

13. Lamers F, Hickie I, Merikangas KR. Prevalence and correlates of prolonged fatigue in a U.S. sample of adolescents. Am J Psychiatry. 2013;170(5):502-510. doi:10.1176/appi. ajp.2012.12040454 
14. Engelen V, Haentjens MM, Detmar SB, Koopman HM, Grootenhuis MA. Health related quality of life of Dutch children: psychometric properties of the PedsQL in the Netherlands. BMC Pediatr. 2009;9(1):68. doi:10.1186/1471-2431-9-68

15. Quanjer PH, Stanojevic S, Cole TJ, et al. Multi-ethnic reference values for spirometry for the 3-95-yr age range: the global lung function 2012 equations. Eur Respir J. 2012;40(6):1324-1343. doi:10.1183/09031936.00080312

16. Nijhof SL, Maijer K, Bleijenberg G, Uiterwaal CSPM, Kimpen JLL, van de Putte EM. Adolescent Chronic Fatigue Syndrome: Prevalence, Incidence, and Morbidity. Paediatrics. 2011;127(5):el169-el175. doi:10.1542/peds.2010-1147

17. Upton P, Lawford J, Eiser C. Parent-child agreement across child health-related quality of life instruments: a review of the literature. Qual Life Res. 2008;17(6):895913. doi:10.1007/s11136-008-9350-5

18. Gordijn MS, van Litsenburg RR, Gemke RJ, et al. Sleep, fatigue, depression, and quality of life in survivors of childhood acute lymphoblastic leukaemia. Pediatr Blood Cancer. 2013;60(3):479-485. doi:10.1002/pbc.24261

19. Langeveld NE, Grootenhuis MA, Voûte PA, de Haan RJ, van den Bos C. No excess fatigue in young adult survivors of childhood cancer. Eur J Cancer. 2003;39(2):204214. http://www.ncbi.nlm.nih.gov/pubmed/12509953. Accessed July 24, 2018.

20. Nagai A, Zou N, Kubota M, et al. Fatigue in survivors of childhood acute lymphoblastic and myeloid leukaemia in Japan. Pediatr Int. 2012;54(2):272-276. doi:10.1111/j.1442-200X.2011.03530.x

21. Sawicki GS, Sellers DE, Robinson WM. Self-Reported Physical and Psychological Symptom Burden in Adults with Cystic Fibrosis. J Pain Symptom Manage. 2008;35(4):372-380. doi:10.1016/j.jpainsymman.2007.06.005

22. Eddy L, Cruz M. The Relationship Between Fatigue and Quality of Life in Children With Chronic Health Problems: A Systematic Review. J Spec Pediatr Nurs. 2007;12(2):105-114. doi:10.1111/j.1744-6155.2007.00099.x

23. McCabe M. Fatigue in children with long-term conditions: An evolutionary concept analysis. J Adv Nurs. 2009;65(8):1735-1745. doi:10.1111/j.1365-2648.2009.05046.x

24. Marcus SB, Strople JA, Neighbors K, et al. Fatigue and health-related quality of life in paediatric inflammatory bowel disease. Clin Gastroenterol Hepatol. 2009;7(5):554-561. http://www.ncbi.nlm.nih.gov/pubmed/19418604. Accessed July $24,2018$.

25. Daniel LC, Brumley LD, Schwartz LA. Fatigue in adolescents with cancer compared to healthy adolescents. Pediatr Blood Cancer. 2013;60(11):1902-1907. doi:10.1002/ pbc. 24706

26. Nijhof SL, Bleijenberg G, Uiterwaal CS, Kimpen JL, van de Putte EM. Effectiveness of internet-based cognitive behavioural treatment for adolescents with chronic fatigue syndrome (FITNET): a randomised controlled trial. Lancet. 2012;379(9824):1412-1418. doi:10.1016/S0140-6736(12)60025-7

27. Menting J, Tack CJ, van Bon AC, et al. Web-based cognitive behavioural therapy blended with face-to-face sessions for chronic fatigue in type l diabetes: 
a multicentre randomised controlled trial. Lancet Diabetes Endocrinol. 2017;5(6):448-456. doi:10.1016/\$2213-8587(17)30098-0

28. Abrahams HJG, Gielissen MFM, Donders RRT, et al. The efficacy of Internetbased cognitive behavioural therapy for severely fatigued survivors of breast cancer compared with care as usual: A randomized controlled trial. Cancer. 2017;123(19):3825-3834. doi:10.1002/cncr.30815

29. Kudubes AA, Bektas M, Mutafoğlu K. The Effect of Fatigue-Related Education on Paediatric Oncology Patients' Fatigue and Quality of Life. J Cancer Educ. August 2018. doi:10.1007/s13187-018-1419-4

30. Robinson PD, Oberoi S, Tomlinson D, et al. Management of fatigue in children and adolescents with cancer and in paediatric recipients of haemopoietic stem-cell transplants: a clinical practice guideline. Lancet Child Adolesc Heal. 2018;2(5):371378. doi:10.1016/S2352-4642(18)30059-2

31. Siegel DA, Li J, Henley SJ, et al. Geographic Variation in Paediatric Cancer Incidence - United States, 2003-2014. MMWR Morb Mortal Wkly Rep. 2018;67(25):707-713. doi:10.15585/mmwr.mm6725a2

32. Haverman L, van Rossum MAJ, van Veenendaal M, et al. Effectiveness of a Web-Based Application to Monitor Health-Related Quality of Life. Paediatrics. 2013;131(2):e533-e543. doi:10.1542/peds.2012-0958 
Fatigue in childhood chronic disease 


\section{4}
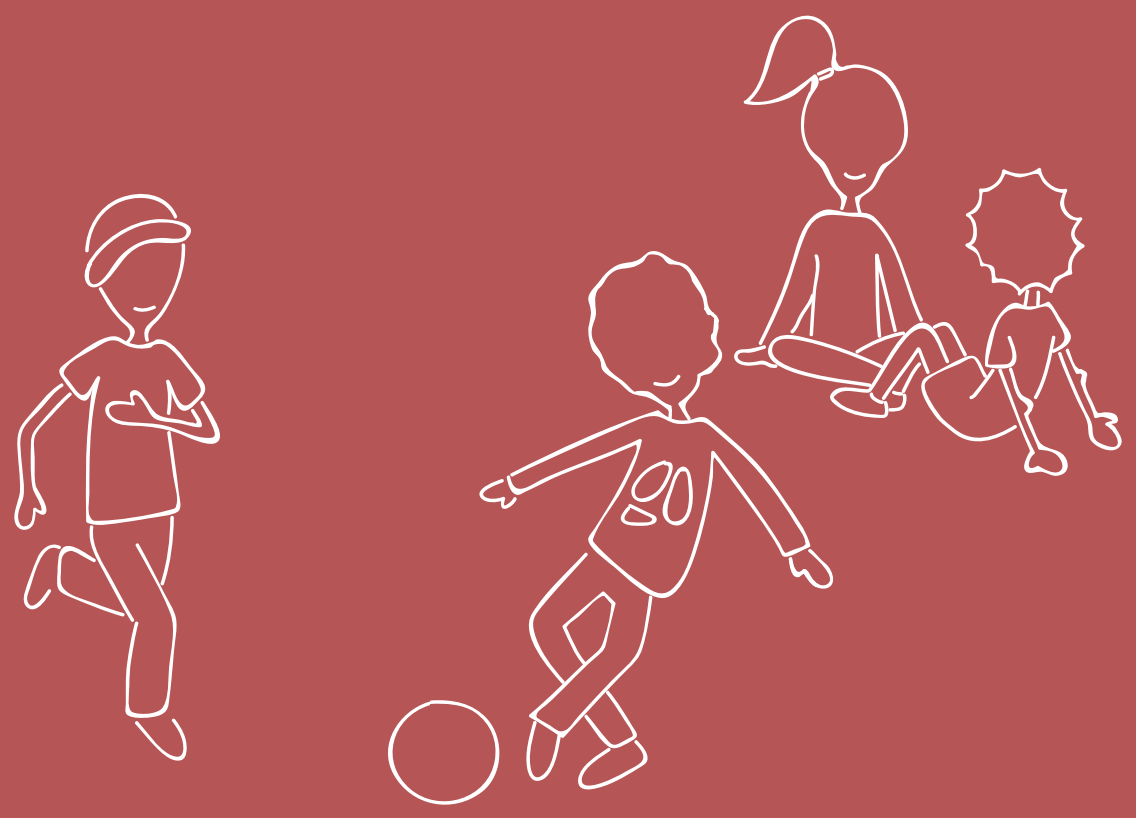


\section{Fatigue among children with a chronic disease: a cross-sectional study}

Merel M. Nap-van der Vlist, MSca; Geertje W. Dalmeijer, PhD ${ }^{\text {; }}$;

Martha A. Grootenhuis, PhD;

Cornelis K. van der Ent, PhD'; Marry M. van den Heuvel-Eibrink, PhDc; Joost F. Swart, PhDe;

Elise M. van de Putte, PhDa; Sanne L. Nijhof, PhDa

a Department of Paediatrics, Wilhelmina Children's Hospital, University Medical Centre Utrecht, Utrecht University, Utrecht, the Netherlands

b Julius Centre for Health Sciences and Primary Care, University Medical Centre Utrecht, Utrecht University, Utrecht, the Netherlands

c Princess Máxima Centre for Paediatric Oncology, Utrecht, the Netherlands

d Department of Paediatric Pulmonology, Wilhelmina Children's Hospital, University Medical Centre Utrecht, Utrecht University, Utrecht, the Netherlands

e Department of Paediatric Rheumatology/Immunology, Wilhelmina Children's Hospital, University Medical Centre Utrecht, Utrecht University, Utrecht, The Netherlands 


\section{ABSTRACT}

\section{Objective:}

To determine: 1) which biological/lifestyle, psychological, and/or social factors are associated with fatigue among children with a chronic disease, and 2) how much each of these factors contributes to explaining variance in fatigue.

\section{Design and setting:}

This was a cross-sectional study across two children's hospitals.

Patients: We included children aged 8-18 years who visited the outpatient clinic with cystic fibrosis, an autoimmune disease, or post-cancer treatment.

\section{Main outcome measures:}

Fatigue was assessed using the PedsQL Multidimensional Fatigue Scale. Generic biological/lifestyle, psychological, and social factors were assessed using clinical assessment tools and questionnaires. Multiple linear regression analyses were used to test the associations between these factors and fatigue. Finally, a multivariable regression model was used to determine which factor(s) have the strongest effect on fatigue.

\section{Results:}

A total of 434 out of 902 children were included (48\% participation rate), with a median age of 14.5 years; $42 \%$ were male. Among these 434 children, $21.8 \%$ were severely fatigued. Together, all biopsychosocial factors explained $74.6 \%$ of the variance in fatigue. More fatigue was uniquely associated with poorer physical functioning, more depressive symptoms, more pressure at school, poorer social functioning, and older age.

\section{Conclusions :}

Fatigue among children with a chronic disease is multidimensional. Multiple generic biological/lifestyle, psychological and social factors were strongly associated with fatigue, explaining 58.4\%; $65.8 \%$ and $50.0 \%$ of the variance in fatigue, respectively. Altogether, almost three quarters of the variance in fatigue was explained by this biopsychosocial model. Thus, when assessing and treating fatigue, a transdiagnostic approach is preferred, taking into account biological, psychological, and social factors. 


\section{INTRODUCTION}

Children who grow up with a chronic disease often face a number of challenges. One of the most prevalent challenges is fatigue, which can cause major disruptions in the child's development and social participation.-4 Fatigue can be triggered by inflammation or the start of a therapeutic regimen, among other factors, ${ }_{1,5,6}^{1,6}$ however, fatigue can persist and cause distress even in children with low - or absent - disease activity. ${ }^{4,7}$ Importantly, factors other than disease-specific biological factors can explain fatigue; indeed, according to the biopsychosocial model, a number of potentially modifiable generic biological/lifestyle, psychological, and/or social factors can be associated with - and can perpetuate - fatigue in these patients. 14-6,8,9 Therefore, understanding fatigue in children with chronic disease, as well as the factors that can cause or perpetuate this fatigue, may require a transdiagnostic approach.10,11

Transdiagnostic can be defined as an approach in which clinicians aim to go beyond the disease-specific biological factors of a disease and look for generic factors. ${ }^{10}$ For example, pain, sleep, and physical activity are potentially modifiable biological or lifestyle factors that are transdiagnostic or generic. $1,3,5,12$ Moreover, modifiable transdiagnostic psychological and social factors such as depressive symptoms, anxiety, and disturbances in the family dynamic have been associated with fatigue., ${ }^{18,13}$ However, whether fatigueperpetuating factors in children with chronic disease are indeed transdiagnostic is an open question, as most studies focused on a single disease. ${ }^{3-5}$ Knowledge regarding the relationship between fatigue and lifestyle, mental, and social factors is particularly relevant, as it can not only help clinicians treat children with a chronic disease, but will also increase our understanding of other fatigue-related syndromes such as fatigue experienced following COVID-19.14

Therefore, we aimed to determine: 1) which modifiable factors (e.g. biological/lifestyle, psychological, and/or social) are associated with fatigue across various paediatric chronic diseases, and 2) how much each of these factors contributes to explaining the variance in fatigue

\section{METHODS}

\section{Study design}

In this cross-sectional study, participating children completed questionnaires prior to their outpatient visit at the Wilhelmina Children's Hospital or the Princess Máxima Centre for Paediatric Oncology in Utrecht, the Netherlands. At the time of the outpatient visit, clinical data were obtained to describe the child's disease activity and duration. Participants were recruited through the PROactive study. ${ }^{2}$ This study was classified by the Institutional Review Board as exempt from the Medical Research Involving Human Subjects Act (16-707/C). Informed consent to use the data from the questionnaires and to extract data from the child's medical records was obtained from both the child and his/her parent(s).

\section{Patient and public involvement}


Patient organisations were involved in setting the agenda and the priorities for this research. Several choices in the design were reviewed by patient representatives. Patients and the public were not involved in the conduct of the study. We added qualitative research methods to our research line in order to stress the patient's and parent's perspective. Patient organisations and societal partners are involved in the dissemination of our research.

\section{Participants}

Children aged 8-18 years with cystic fibrosis (CF), an autoimmune disease, or postcancer treatment were recruited from the PROactive study, in which they were included from December 2016 through February 2020. The lower age limit was chosen because we aimed to investigate self-reported fatigue. The group of children with an autoimmune disease included children with an immunodeficiency disorder, an autoinflammatory condition, or an autoimmune disease in the strictest sense. To best assess which transdiagnostic factors are associated with fatigue, we included children who were at least one year post-diagnosis (the CF and autoimmune disease groups) or who were within one year after completing their cancer treatment. This was done as disease specific factors, such as disease activity (generally highest in the first year after diagnosis), receiving the diagnosis, starting treatment, and the disease itself can cause significant fatigue in the first year post-diagnosis or during cancer treatment.

\section{Study procedures}

Families were approached by e-mail three weeks before a regularly scheduled outpatient visit. All questionnaires were completed by the child via a web-based portal (www.hetklikt.nu), with parental assistance if needed. As needed, the families were reminded once via e-mail and/or once via telephone. A research team was available to answer questions. The questionnaires were linked to each patient's clinical assessment during the outpatient visit. The estimated time participants needed to complete all questionnaires was 30-45 minutes. They were not presented in a random order, but attention was paid that different topics were alternated.

\section{Measurements}

The primary outcome measurement was the child's self-reported fatigue, which was measured using the general fatigue subscale of the validated PedsQL Multidimensional Fatigue Scale (PedsQL MFS), which has good internal consistency.15 In the national population norm, the reported mean values for this general fatigue subscale are 82.66 (95\% Cl: 80.53-84.80) and 76.72 (95\% Cl: 74.44-78.99) for children aged 8-12 years and 13-18 years, respectively. ${ }^{15}$ For descriptive statistics, severe fatigue was defined as a score greater than two standard deviations (SDs) below the norm, taking into account both sex and age categories (i.e. 8-11 and 12-18 years).2

To characterise our sample, we collected the following variables from the child's medical record: age, sex, time elapsed between diagnosis and assessment, and disease activity at assessment. In the CF group, disease activity was measured using forced expiratory volume in one second (FEV), expressed as a percentage of predicted $\mathrm{FEV}_{1}{ }^{16}$ For patients with juvenile idiopathic arthritis (JIA), the validated clinical Juvenile Arthritis Disease Activity Score (cJADAS) and erythrocyte sedimentation rate (ESR) 
were used as a proxy for disease status; only ESR was used for participants with other autoimmune or autoinflammatory diseases..$^{7}$ All children in the post-cancer treatment group were in complete remission.

For all questionnaires and tools used in our study, the number of items, range, interpretation, and Cronbach's alpha are provided in Table 1. In this study, we only used validated concepts and (sub)scales that could be compared to outcomes of other studies with healthy children or children with other diseases.

Table 1. Summary of the factors assessed in this study and features of the corresponding questionnaires/ tools.

\begin{tabular}{|c|c|c|c|c|c|}
\hline Assessed factor & Questionnaire & Construct/Subscale & Items & Range/replies & $\begin{array}{l}\text { Cron- } \\
\text { bach's } \\
\text { alpha }\end{array}$ \\
\hline Fatigue & PedsQL MFS' & General fatigue subscale & 6 & $\begin{array}{l}\text { 0-100: higher score }= \\
\text { less fatigue }\end{array}$ & 0.90 \\
\hline Pain & $\begin{array}{l}\text { Visual Analo- } \\
\text { gue Scale }\end{array}$ & $\mathrm{N} / \mathrm{A}$ & 1 & $\begin{array}{l}0-10 \text { : higher score = } \\
\text { more pain }\end{array}$ & N/A \\
\hline Sleep difficulties & $\mathrm{HBSC}^{3}$ & $\begin{array}{l}\text { In the last six months, } \\
\text { how often have you had } \\
\text { difficulties getting to } \\
\text { sleep? }\end{array}$ & 1 & $\begin{array}{l}\text { Rarely or never; about } \\
\text { every month; about } \\
\text { every week; more } \\
\text { than once a week; } \\
\text { about every day }\end{array}$ & N/A \\
\hline $\begin{array}{l}\text { Number of days } \\
\text { physically active }\end{array}$ & $\mathrm{HBSC}^{3}$ & $\begin{array}{l}\text { Over the past } 7 \text { days, on } \\
\text { how many days were } \\
\text { you physically active } \\
\text { for a total of at least } 60 \\
\text { minutes per day? }\end{array}$ & 1 & 0-7 days per week & $N / A$ \\
\hline $\begin{array}{l}\text { Physical } \\
\text { functioning }\end{array}$ & PedsQL CCS ${ }^{4}$ & $\begin{array}{l}\text { Physical functioning } \\
\text { subscale }\end{array}$ & 8 & $\begin{array}{l}\text { 0-100: higher score = } \\
\text { better functioning }\end{array}$ & 0.89 \\
\hline $\begin{array}{l}\text { Depressive } \\
\text { symptoms }\end{array}$ & RCADS5 & $\begin{array}{l}\text { Major depressive disor- } \\
\text { der subscale }\end{array}$ & 10 & $\begin{array}{l}\text { 0-30: higher score } \\
=\text { more depressive } \\
\text { symptoms }\end{array}$ & 0.85 \\
\hline Anxiety & RCADS5 & Total anxiety subscale & 37 & $\begin{array}{l}\text { 0-111: higher score }= \\
\text { more anxiety }\end{array}$ & 0.94 \\
\hline $\begin{array}{l}\text { Pain } \\
\text { catastrophizing }\end{array}$ & $\mathrm{PCS}-\mathrm{C}^{6}$ & $\mathrm{~N} / \mathrm{A}$ & 13 & $\begin{array}{l}\text { 0-52: } \text { higher score = } \\
\text { more pain } \\
\text { catastrophizing }\end{array}$ & 0.91 \\
\hline $\begin{array}{l}\text { Emotional } \\
\text { functioning }\end{array}$ & PedsQL CCS ${ }^{4}$ & $\begin{array}{l}\text { Emotional functioning } \\
\text { subscale }\end{array}$ & 5 & $\begin{array}{l}0-100 \text { : higher score = } \\
\text { better functioning }\end{array}$ & 0.79 \\
\hline $\begin{array}{l}\text { Pressure at } \\
\text { school }\end{array}$ & $\mathrm{HBSC}^{3}$ & $\begin{array}{l}\text { How pressured do you } \\
\text { feel by the schoolwork } \\
\text { you have to do? }\end{array}$ & 1 & $\begin{array}{l}\text { Not at all; a little; } \\
\text { quite some; a lot }\end{array}$ & N/A \\
\hline Being bullied & $\mathrm{HBSC}^{3}$ & $\begin{array}{l}\text { How often have you } \\
\text { been bullied at school } \\
\text { over the last couple of } \\
\text { months? }\end{array}$ & 1 & $\begin{array}{l}\text { Never; } 1 \text { or } 2 \text { times in } \\
\text { the past month; } 2 \text { or } 3 \\
\text { times a month; about } \\
\text { once a week; a few } \\
\text { times a week }\end{array}$ & N/A \\
\hline $\begin{array}{l}\text { Communication } \\
\text { at home }\end{array}$ & $\mathrm{HBSC}^{3}$ & $\begin{array}{l}\text { Communication at } \\
\text { home subscale }\end{array}$ & 4 & $\begin{array}{l}\text { 1-5: higher score = } \\
\text { better } \\
\text { communication }\end{array}$ & 0.80 \\
\hline
\end{tabular}


Table 1. Summary of the factors assessed in this study and features of the corresponding questionnaires/ tools.

\begin{tabular}{|c|c|c|c|c|c|}
\hline $\begin{array}{l}\text { Support at } \\
\text { home }\end{array}$ & $\mathrm{HBSC}^{3}$ & $\begin{array}{l}\text { Support at home sub- } \\
\text { scale }\end{array}$ & 4 & $\begin{array}{l}\text { 1-7: higher score = } \\
\text { more support at } \\
\text { home }\end{array}$ & 0.92 \\
\hline $\begin{array}{l}\text { Support by } \\
\text { friends }\end{array}$ & $\mathrm{HBSC}^{3}$ & $\begin{array}{l}\text { Support from friends } \\
\text { subscale }\end{array}$ & $\begin{array}{l}3(8-11 \\
\text { years) or } \\
4(12-18 \\
\text { years } \\
\text { old) }\end{array}$ & $\begin{array}{l}\text { 1-7: higher score = } \\
\text { more support from } \\
\text { friends }\end{array}$ & 0.95 \\
\hline $\begin{array}{l}\text { Social } \\
\text { functioning }\end{array}$ & PedsQL CCS & $\begin{array}{l}\text { Social functioning } \\
\text { subscale }\end{array}$ & 5 & $\begin{array}{l}\text { 0-100: higher score = } \\
\text { better functioning }\end{array}$ & 0.75 \\
\hline $\begin{array}{l}\text { Member of a } \\
\text { sports team or } \\
\text { club }\end{array}$ & $\mathrm{HBSC}^{3}$ & $\begin{array}{l}\text { Are you a member of } \\
\text { a sport community or } \\
\text { club? }\end{array}$ & 1 & $\begin{array}{l}\text { Member; not a } \\
\text { member }\end{array}$ & $\mathrm{N} / \mathrm{A}$ \\
\hline Screen time & $\mathrm{HBSC}^{3}$ & $\begin{array}{l}\text { About how many hours } \\
\text { a day do you usually } \\
\text { watch television in your } \\
\text { free time during week- } \\
\text { and weekend days? }\end{array}$ & 4 & $\begin{array}{l}\text { None at all; about } \\
\text { half an hour a day; } \\
\text { about } 1 \text { hour a day; } \\
\text { about } 2 \text { hours a day; } \\
\text { about } 3 \text { hours a day; } \\
\text { about } 4 \text { hours a day; } \\
\text { about } 5 \text { hours a day; } \\
\text { about } 7 \text { or more } \\
\text { hours a day }\end{array}$ & 0.75 \\
\hline
\end{tabular}

References:

1. Gordijn MS, Suzanne, Cremers EMP, Kaspers GJL, Gemke RJBJ. Fatigue in children: reliability and validity of the Dutch PedsQLTM Multidimensional Fatigue Scale. Qual Life Res. 2011;20(7):1103-1108. doi:10.1007/s11136-010-9836-9

2. Rosier EM, ladarola MJ, Coghill RC. Reproducibility of pain measurement and pain perception. Pain. 2002;98(1-2):205-216. Accessed May 31, 2019. http://www.ncbi.nlm.nih.gov/pubmed/12098633

3. Currie C, Zanotti C, Morgan A, et al. Social Determinants of Health and Well-Being Among Young People. Copenhagen: World Health Organization Regional Office for Europe:; 2012. AND de Looze M, van Dorsselaer S, de Roos S, et al. Health Behaviour in School Children 2013 - Health, Wellbeing, and Education of Dutch Children.; 2013.

4. Engelen V, Haentjens MM, Detmar SB, Koopman HM, Grootenhuis MA. Health related quality of life of Dutch children: psychometric properties of the PedsQL in the Netherlands. BMC Pediatr. 2009;9(1):68. doi:10.1186/1471-2431-9-68

5. Kösters MP, Chinapaw MJM, Zwaanswijk M, van der Wal MF, Koot HM. Structure, reliability, and validity of the revised child anxiety and depression scale (RCADS) in a multi-ethnic urban sample of Dutch children. BMC Psychiatry. 2015;15(1):132. doi:10.1186/s12888-015-0509-7

6. Crombez G, Bijttebier P, Eccleston C, et al. The child version of the pain catastrophizing scale (PCS-C): a preliminary validation. Pain. 2003;104(3):639-646. Accessed May 31, 2019. http://www.ncbi. nlm.nih.gov/pubmed/12927636

\section{Generic biological/lifestyle factors}

The following generic biological/lifestyle factors were measured: pain, sleep difficulties, physical functioning, physical activity, and body mass index (BMI). Pain was measured using a visual analogue scale, reflecting the average pain experienced in the previous week. ${ }^{18}$ To measure sleep difficulties and physical activity, we used questions from the Health Behaviour in School Children (HBSC) questionnaire. 19,20 The physical activity score is based on the World Health Organization's recommendation; this measure has an acceptable level of reliability.21,22 Physical functioning was assessed using a subscale of the PedsQL Ceneral Core Scale (PedsQL CCS); this instrument has good validity and reliability. ${ }^{23}$ BMI was extracted from the child's medical record. For the regression analyses, the z-scores of BMI were used. ${ }^{24}$ 


\section{Psychological factors}

Psychological factors included depressive symptoms, anxiety, emotional functioning, and pain catastrophising. Depressive symptoms and anxiety were measured using the respective subscales of the Revised Child Anxiety and Depression Scale (RCADS), which has good internal consistency. ${ }^{25}$ Both scores correspond to the symptoms of childhood anxiety and depressive disorders in the Diagnostic and Statistical Manual of Mental Disorders IV (DSM-IV). Emotional functioning was measured using the PedsQL CCS.23 Pain catastrophising was measured using the Pain Catastrophising Scale for Children (PCS-C), which has good internal consistency. ${ }^{26}$

\section{Social factors}

Social factors included communication and support at home, support by friends, being a member of a sports team or club, social functioning, pressure at school, being bullied, and screen time. Social functioning was measured using the PedsQL CCS:23 all other factors were included in the HBSC questionnaire.19 Screen time was assessed using four questions regarding how much the child watched movies and/or shows and played computer games, calculated as a daily average.

\section{Data analyses}

Descriptive statistics were used to describe the children in the various disease groups. Normally distributed data are presented at the mean \pm SD; otherwise median and interquartile range (IQR) are provided. Differences between participants and nonparticipants, between completers and non-completers, and between disease groups were analysed using the Student's t-test, Kruskal-Wallis test, or chi-square test. First, multiple linear regressions were used to test the putative associations, with fatigue as the dependent variable and each generic biological/lifestyle, psychological, and social factor as the independent variable. All 16 regressions were adjusted for the child's age and sex, as these are known to be important determinants of fatigue. ${ }^{27}$ The assumptions for linear regression analysis were tested, including linearity between the dependent and independent variable, homoscedasticity, and normality of the residuals. Multicollinearity between the separate biopsychosocial factors was ruled out. Second, we investigated whether the associations differed between disease groups by adding a variable of the interaction between disease group and the tested independent variable to the regression model. Third, we built four multivariable linear regression models using: 1) all generic biological/lifestyle factors, 2) all psychological factors, 3) all social factors and 4) all biopsychosocial factors; we then used these four models to describe the variance in fatigue explained by the generic biological/ lifestyle, psychological, and social variables. The associations were described using the unstandardized beta, effect size (standardized beta), and 95\% confidence interval (CI). Effects were assessed in relation to p values, effect sizes, adjusted R2 and the Akaike information criterion. Disease-specific characteristics were not included in the models, as the aim of the study was to describe modifiable, perpetuating factors that go beyond disease-specific variables, given that disease activity was generally low or absent in this sample. To correct for multiple testing, a P-value of $<0.01$ was considered statistically significant in all analyses. Effect sizes $\geq 0.2, \geq 0.5$, and $\geq 0.8$ were considered small, moderate, and large, respectively. 


\section{RESULTS}

\section{Patient characteristics}

Among the 902 children who were approached, 434 (48\%) participated; 409 of these 434 participating families (94\%) also provided informed consent for the use of data from the child's medical record. We found no difference between the 434 participants and the 468 non-participants with respect to age or sex. Although all 434 participants reported their fatigue score, only 357 participants completed all assessments in their entirety, with no significant differences in fatigue scores between completers and noncompleters. The most commonly cited reasons for not participating were personal circumstances and current participation in other research.

Among the 434 participating children, 71 had CF, 262 had an autoimmune disease, and 101 were post-cancer treatment patients (Table 2); we found no significant difference between these three groups with respect to age or sex. The median score (IQR) on the PedsQL MFS general fatigue sub score was 75.0 (54.2-87.5), 75.0 (54.2-88.5), and 75.0 (50.0-91.7) for the CF, autoimmune, and post-cancer treatment groups, respectively, with $21.1 \%, 20.6 \%$, and $26.7 \%$ of children, respectively, scoring as severely fatigued. When only age and sex were entered into a model with fatigue as dependent variable, girls reported more fatigue than boys $(P<0.01)$, and older children reported more fatigue than younger children $(P<0.01)$.

Table 2. Baseline characteristics of the paediatric patients included in the study.

\begin{tabular}{|c|c|c|c|}
\hline & Children with CF & $\begin{array}{l}\text { Children with } \\
\text { autoimmune disease }\end{array}$ & $\begin{array}{l}\text { Post-cancer treatment } \\
\text { patients }\end{array}$ \\
\hline Filled out questionnaires & $N=71$ & $N=262$ & $N=101$ \\
\hline Age, years (median (IQR)) & $15.3(12.8-17.0)$ & $14.4(11.6-16.4)$ & $13.6(10.5-16.6)$ \\
\hline Male sex, N (\%) & $35(49.3 \%)$ & $97(37.0 \%)$ & $50(49.5 \%)$ \\
\hline $\begin{array}{l}\text { PedsQL general fatigue } \\
\text { score, median (IQR) }\end{array}$ & $75.0(54.2-87.5$ & $75.0(54.2-88.5)$ & $75.0(50.0-91.7)$ \\
\hline Severely fatigued, N (\%) & $15(21.1 \%)$ a & $54(20.6 \%)^{a}$ & $26(26.7 \%)^{a}$ \\
\hline $\begin{array}{l}\text { Consented to use } \\
\text { information in the child's } \\
\text { medical record }\end{array}$ & $N=70$ & $N=245$ & $N=93$ \\
\hline \multicolumn{4}{|c|}{$\begin{array}{l}\text { a Based on cut-offs as defined in Nap-van der Vlist et al. (2019).2 } \\
\text { b Disease duration: years since diagnosis until inclusion for children with JIA; years from end of treatment } \\
\text { until inclusion for children post-cancer treatment. } \\
\text { Notes: If the data were normally distributed, the mean } \pm \text { SD is given; if not, the median and interquar- } \\
\text { tile range (IQR) is given. CF = cystic fibrosis; SD = standard deviation; JIA = juvenile idiopathic arthritis; } \\
\text { CJADAS = clinical Juvenile Arthritis Disease Activity Score; ESR = erythrocyte sedimentation rate; FEVI \% = } \\
\text { predicted percentage of forced expiratory volume in one second; NA = not applicable. }\end{array}$} \\
\hline
\end{tabular}


Table 2. Baseline characteristics of the paediatric patients included in the study.

\begin{tabular}{|c|c|c|c|}
\hline & Children with CF & $\begin{array}{l}\text { Children with } \\
\text { autoimmune disease }\end{array}$ & $\begin{array}{l}\text { Post-cancer treatment } \\
\text { patients }\end{array}$ \\
\hline Diagnosis, N (\%) & $\begin{array}{l}43(61 \%) \text { homozygote } \\
\text { dF508; } \\
26(37 \%) \\
\text { heterozygote dF508; } \\
1(1 \%) \text { other }\end{array}$ & $\begin{array}{l}19.2(17.0 \text {-21.9) } \\
37(15 \%) \text { poly-articular JIA; } \\
83(34 \%) \text { oligo-articular } \\
\text { JIA; } \\
12(5 \%) \text { systemic JIA; } \\
31(13 \%) \text { other form of JIA; } \\
35(14 \%) \text { immunodefici- } \\
\text { ency; } \\
16(7 \%) \text { autoinflammatory } \\
\text { condition; } \\
31 \text { (13\%) systemic autoim- } \\
\text { mune disease }\end{array}$ & $\begin{array}{l}32(34 \%) \text { solid tumour; } \\
52(56 \%) \text { leukaemia/ } \\
\text { lymphoma; } \\
9(10 \%) \text { brain tumour }\end{array}$ \\
\hline $\begin{array}{l}\text { Duration of disease status, } \\
\text { years }^{b}\end{array}$ & $15.3(12.8-17.0)$ & $6(3-9)$ & $0.4(0.2-0.7)$ \\
\hline Disease activity ${ }^{b}$ & FEVI \%: $86.1 \pm 17.6$ & $\begin{array}{l}\text { CJADAS: } 0.5(0-4)(\mathrm{N}=144) \\
\text { ESR: } 4 \mathrm{~mm} / \mathrm{lst} \text { hr }(2-7) \\
(\mathrm{N}=222)\end{array}$ & $\begin{array}{l}\text { All less than one year } \\
\text { post-treatment }\end{array}$ \\
\hline \multicolumn{4}{|c|}{$\begin{array}{l}\text { a Based on cut-offs as defined in Nap-van der Vlist et al. (2019).2 } \\
\text { b Disease duration: years since diagnosis until inclusion for children with JIA; years from end of treatment } \\
\text { until inclusion for children post-cancer treatment. } \\
\text { Notes: If the data were normally distributed, the mean } \pm \text { SD is given; if not, the median and interquar- } \\
\text { tile range (IQR) is given. CF = cystic fibrosis; SD = standard deviation; JIA = juvenile idiopathic arthritis; } \\
\text { CJADAS = clinical Juvenile Arthritis Disease Activity Score; ESR = erythrocyte sedimentation rate; FEVI \% = } \\
\text { predicted percentage of forced expiratory volume in one second; NA = not applicable. }\end{array}$} \\
\hline
\end{tabular}

\section{Association between biopsychosocial factors and fatigue}

Among the entire group of participating children with chronic disease, all of the generic biological/lifestyle, psychological, and social factors were significantly associated with fatigue, with three exceptions: BMI, being bullied, and the amount of screen time (Table 3). We found no significant differences between the three disease groups with respect to the association between fatigue and the generic biological/ lifestyle, psychological, or social factors.

\section{Regression models}

The first regression model, entering all of the generic biological/lifestyle factors (i.e. pain, sleep difficulties, physical activity, and physical functioning), explained $58.4 \%$ of the variance in fatigue. Entering all of the psychological factors (i.e. depressive symptoms, anxiety, emotional functioning, and pain catastrophizing) into a second regression model explained $65.8 \%$ of the variance in fatigue. In the depression subscale, two of the ten items are related to feeling fatigued; however, removing these two items did not substantially change the results. The third model, entering all of the social variables (i.e. communication at home, support at home, support by friends, being a member of a sports team or club, social functioning, pressure at school, being bullied, and screen time), explained $50.0 \%$ of the variance in fatigue. Lastly, entering all generic biological/lifestyle, psychological, and social factors into a composite model revealed substantial overlap in the amount of variance explained by these domains, 
with this full model explaining $74.6 \%$ of the variance in fatigue (Figure 1 and Table 4).

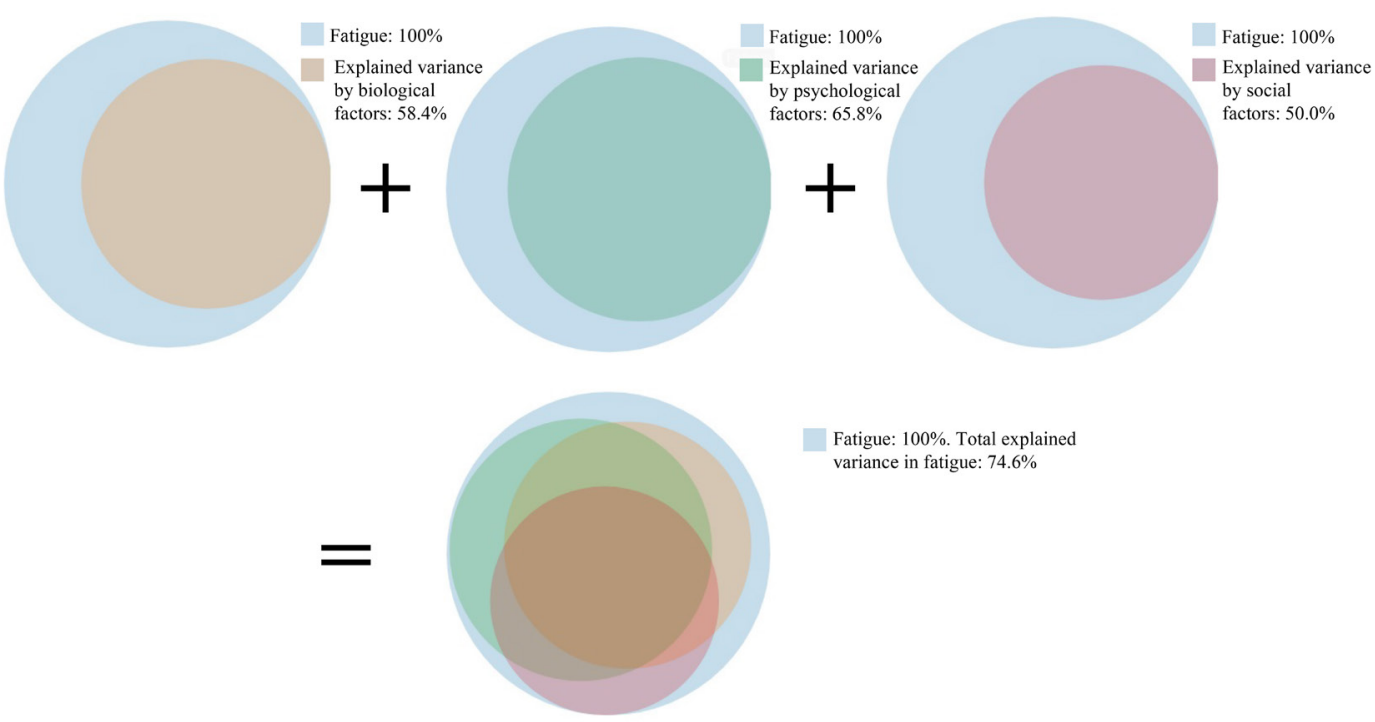

Figure 1. Graphical overview of the explained variance in fatigue by biological, psychological, and social factors

Table 3. Linear regression per factor with dependent variable fatigue (PedsQL MFS general fatigue scale) for the entire group of children with chronic diseases, adjusted for sex and age.

\begin{tabular}{|c|c|c|c|}
\hline Associated modifiable factors & Unstandardised ß & Effect size & $\begin{array}{l}95 \% \text { confidence } \\
\text { interval }\end{array}$ \\
\hline \multicolumn{4}{|l|}{ Biological/lifestyle factors } \\
\hline \multicolumn{4}{|l|}{ Factors associated with more fatigue } \\
\hline Pain (VAS, range 0-10) & -4.0 & -0.5 & $-4.7 ;-3.4^{* *}$ \\
\hline $\begin{array}{l}\text { Difficulties getting to sleep }(0-5 \text {; 'never' to } \\
\text { 'almost every day') }\end{array}$ & -6.1 & -0.4 & $-7.4 ;-4.9^{* *}$ \\
\hline \multicolumn{4}{|l|}{ Factors associated with less fatigue } \\
\hline Number of days physically active/week (0-7) & 1.8 & 0.2 & $0.9 ; 2.8^{* *}$ \\
\hline $\begin{array}{l}\text { Physical functioning (PedsQL CCS subscale, } \\
\text { range 0-100) }\end{array}$ & 0.7 & 0.7 & $0.7 ; 0.8^{* *}$ \\
\hline \multicolumn{4}{|l|}{ Factors not associated with fatigue } \\
\hline BMI z-score & -1.2 & -0.1 & $-3.3 ; 0.8$ \\
\hline Psychological factors & & & \\
\hline
\end{tabular}

* Significant at a $P<0.05$ level, ** significant at a $P<0.01$ level. The PedsQL MFS is scored on a scale from 0-100, with a lower score indicating more severe fatigue. Thus, a negative correlation indicates a lower score, thus indicating more fatigue. PedsQL MFS = PedsQL Multidimensional Fatigue Scale; BMI = body mass index; VAS = visual analogue scale; PedsQL CCS = PedsQL Ceneric Core Scale; RCADS = Revised Child Anxiety and Depression Scale; PCS-C = Pain Catastrophising Scale for Children. 
Table 3. Linear regression per factor with dependent variable fatigue (PedsQL MFS general fatigue scale) for the entire group of children with chronic diseases, adjusted for sex and age.

\begin{tabular}{|c|c|c|c|}
\hline Associated modifiable factors & Unstandardised $ß$ & Effect size & $\begin{array}{l}95 \% \text { confidence } \\
\text { interval }\end{array}$ \\
\hline \multicolumn{4}{|l|}{ Factors associated with more fatigue } \\
\hline Depressive symptoms (RCADS, range 0-30) & -3.9 & -0.8 & $-4.2 ;-3.6 * *$ \\
\hline Anxiety level (RCADS, range 0-111) & -0.9 & -0.5 & $-1.1 ;-0.8^{* *}$ \\
\hline Pain catastrophising (PCS-C, range 0-52) & -1.2 & -0.5 & $-1.4 ;-1.0 * *$ \\
\hline \multicolumn{4}{|l|}{ Factors associated with less fatigue } \\
\hline $\begin{array}{l}\text { Emotional functioning (PedsQL GCS, range } \\
\text { 0-100) }\end{array}$ & 0.7 & 0.6 & $0.6 ; 0.8^{* *}$ \\
\hline \multicolumn{4}{|l|}{ Social factors } \\
\hline \multicolumn{4}{|l|}{ Factors associated with more fatigue } \\
\hline Pressure at school (0-4; 'not at all' to 'a lot') & -8.8 & -0.3 & $-11.2 ;-6.4^{\star *}$ \\
\hline $\begin{array}{l}\text { Being bullied (0-5; 'never' to 'several times per } \\
\text { week') }\end{array}$ & -4.2 & -0.1 & $-7.7 ;-0.8^{*}$ \\
\hline \multicolumn{4}{|l|}{ Factors associated with less fatigue } \\
\hline $\begin{array}{l}\text { Communication at home (1-5, higher score = } \\
\text { better communication) }\end{array}$ & 4.9 & 0.1 & $1.7 ; 8.2^{* *}$ \\
\hline $\begin{array}{l}\text { Support at home (1-7, higher score = more } \\
\text { support) }\end{array}$ & 2.8 & 0.1 & $0.8 ; 4.8^{* *}$ \\
\hline $\begin{array}{l}\text { Support by friends (1-7, higher score = more } \\
\text { support) }\end{array}$ & 3.4 & 0.2 & $1.9 ; 5.0 * *$ \\
\hline $\begin{array}{l}\text { Social functioning (PedsQL CCS subscale, } \\
\text { range 0-100) }\end{array}$ & 0.9 & 0.6 & $0.8 ; 1.0 * *$ \\
\hline $\begin{array}{l}\text { Member of a sports team or club }(0=\text { not a } \\
\text { member, } 1=\text { member })\end{array}$ & 9.2 & 0.2 & $4.8 ; 13.6^{* *}$ \\
\hline \multicolumn{4}{|l|}{ Factors not associated with fatigue in this sample } \\
\hline Screen time per day (hours/day) & -1.2 & -0.1 & $-2.8 ; 0.4$ \\
\hline
\end{tabular}

* Significant at a $P<0.05$ level, ** significant at a $P<0.01$ level. The PedsQL MFS is scored on a scale from 0-100, with a lower score indicating more severe fatigue. Thus, a negative correlation indicates a lower score, thus indicating more fatigue. PedsQL MFS = PedsQL Multidimensional Fatigue Scale; BMI = body mass index; VAS = visual analogue scale; PedsQL CCS = PedsQL Generic Core Scale; RCADS = Revised Child Anxiety and Depression Scale; PCS-C = Pain Catastrophising Scale for Children. 
Table 4. Overview of three models: one model including all generic biological/lifestyle factors, one model containing all psychological factors, and one model containing all social factors. In all models, fatigue is the dependent variable. Models are adjusted for age and sex of the child.

\begin{tabular}{|c|c|c|c|}
\hline Associated factors & Unstandardised ß & Effect size & $\begin{array}{l}95 \% \text { confidence } \\
\text { interval }\end{array}$ \\
\hline \multicolumn{4}{|c|}{ Model 1. Biological/lifestyle factors ( $N=413$, adj. R2 58.4\%) } \\
\hline \multicolumn{4}{|l|}{ Factors associated with more fatigue } \\
\hline Pain (VAS, range 0-10) & -1.1 & -0.1 & $-1.7 ;-0.5^{* *}$ \\
\hline $\begin{array}{l}\text { Difficulties getting to sleep (0-5; 'never' to } \\
\text { 'almost every day') }\end{array}$ & -3.3 & -0.2 & $-4.3 ;-2.4^{* \star}$ \\
\hline \multicolumn{4}{|l|}{ Factors associated with less fatigue } \\
\hline Number of days physically active/week (0-7) & 0.4 & 0.0 & $-0.3 ; 1.1$ \\
\hline $\begin{array}{l}\text { Physical functioning (PedsQL GCS subscale, } \\
\text { range 0-100) }\end{array}$ & 0.6 & 0.5 & $0.5 ; 0.7^{* *}$ \\
\hline \multicolumn{4}{|c|}{ Model 2. Psychological factors ( $N=370$, adj. R2 65.8\%) } \\
\hline \multicolumn{4}{|l|}{ Factors associated with more fatigue } \\
\hline Depressive symptoms (RCADS, range 0-30) & -3.5 & -0.7 & $-4.0 ;-3.0 * *$ \\
\hline Anxiety level (RCADS, range 0-111) & 0.3 & 0.2 & $0.1 ; 0.4^{* *}$ \\
\hline Pain catastrophising (PCS-C, range $0-52$ ) & -0.3 & 0.1 & $-0.5 ;-0.1^{* *}$ \\
\hline \multicolumn{4}{|l|}{ Factors associated with less fatigue } \\
\hline $\begin{array}{l}\text { Emotional functioning (PedsQL CCS, range } \\
0-100 \text { ) }\end{array}$ & 0.2 & 0.2 & $0.1 ; 0.3^{* *}$ \\
\hline
\end{tabular}

\section{Model 3. Social factors ( $N=413$, adj. R2 50.0\%)}

Factors associated with more fatigue

\begin{tabular}{|c|c|c|c|}
\hline Pressure at school (0-4; 'not at all' to 'a lot') & -5.5 & -0.2 & $-7.4 ;-3.5^{* *}$ \\
\hline $\begin{array}{l}\text { Being bullied (0-5; 'never' to 'several times per } \\
\text { week') }\end{array}$ & 4.7 & 0.1 & $1.9 ; 7.5^{* *}$ \\
\hline
\end{tabular}

Factors associated with less fatigue

Communication at home (1-5, higher score = better communication)

\begin{tabular}{l|l|l|l}
$\begin{array}{l}\text { Support at home }(1-7, \text { higher score }=\text { more } \\
\text { support) }\end{array}$ & 1.6 & 0.1 & $-0.5 ; 3.7$ \\
$\begin{array}{l}\text { Support by friends }(1-7, \text { higher score }=\text { more } \\
\text { support) }\end{array}$ & 0.2 & 0.0 & $-1.2 ; 1.6$ \\
\hline $\begin{array}{l}\text { Social functioning (PedSQL GCS subscale, } \\
\text { range } 0-100)\end{array}$ & 0.8 & 0.6 & $0.7 ; 1.0^{* *}$ \\
\hline $\begin{array}{l}\text { Member of a sports team or club }(0=\text { not a } \\
\text { member, } 1=\text { member) }\end{array}$ & 1.8 & 0.0 & $-1.6 ; 5.3$ \\
\hline$*$ S
\end{tabular}

*Significant at a $P<0.05$ level, ** significant at a $P<0.01$ level. The PedsQL MFS is scored on a scale from 0-100, with a lower score indicating more severe fatigue. Thus, a negative correlation indicates a lower score, thus indicating more fatigue. PedsQL MFS = PedsQL Multidimensional Fatigue Scale; BMI = body mass index; VAS = visual analogue scale; PedsQL CCS = PedsQL Generic Core Scale; RCADS = Revised Child Anxiety and Depression Scale; PCS-C = Pain Catastrophising Scale for Children. 
Table 4. Overview of three models: one model including all generic biological/lifestyle factors, one model containing all psychological factors, and one model containing all social factors. In all models, fatigue is the dependent variable. Models are adjusted for age and sex of the child.

Associated factors

Unstandardised $ß$

Effect size

$95 \%$ confidence interval

Factors not associated with fatigue in this sample

\begin{tabular}{|l|l|l|l|}
\hline Screen time per day (hours/day) & -0.9 & -0.1 & $-2.1 ; 0.3$
\end{tabular}

*Significant at a $P<0.05$ level, ** significant at a $P<0.01$ level. The PedsQL MFS is scored on a scale from 0-100, with a lower score indicating more severe fatigue. Thus, a negative correlation indicates a lower score, thus indicating more fatigue. PedsQL MFS = PedsQL Multidimensional Fatigue Scale; BMI = body mass index; VAS = visual analogue scale; PedsQL CCS = PedsQL Generic Core Scale; RCADS = Revised Child Anxiety and Depression Scale; PCS-C = Pain Catastrophising Scale for Children.

Table 5. Complete model including all generic biological/lifestyle, psychological, and social factors and fatigue (PedsQL MFS general fatigue scale) as the dependent variable for the entire group of children with chronic disease $(\mathrm{N}=357)$.

\begin{tabular}{|l|l|l|l|}
\hline Associated modifiable factors & Unstandardised B & Effect size & $\begin{array}{l}\text { 95\% confidence } \\
\text { interval }\end{array}$ \\
\hline Age and sex & -0.9 & -0.1 & $-1.3 ;-0.4^{* *}$ \\
\hline Age & 1.0 & 0.0 & $-1.7 ; 3.7$ \\
\hline Sex & &
\end{tabular}

\section{Biological/lifestyle factors}

Factors associated with more fatigue

\begin{tabular}{|c|c|c|c|}
\hline Pain (VAS, range 0-10) & -0.5 & -0.1 & $-1.1 ; 0.1$ \\
\hline $\begin{array}{l}\text { Difficulties getting to sleep (0-5; 'never' to } \\
\text { 'almost every day') }\end{array}$ & 0.5 & 0.0 & $-0.5 ; 1.6$ \\
\hline \multicolumn{4}{|l|}{ Factors associated with less fatigue } \\
\hline Number of days physically active/week (0-7) & 0.4 & 0.0 & $-0.2 ; 1.0$ \\
\hline $\begin{array}{l}\text { Physical functioning (PedsQL CCS subscale, } \\
\text { range 0-100) }\end{array}$ & 0.3 & 0.3 & $0.2 ; 0.4^{\star *}$ \\
\hline
\end{tabular}

\section{Psychological factors}

Factors associated with more fatigue

Depressive symptoms (RCADS, range 0-30)

Anxiety level (RCADS, range 0-111)

Pain catastrophising (PCS-C, range 0-52)

\begin{tabular}{|l|l|l|}
\hline-2.6 & -0.5 & $-3.1 ;-2.1^{* *}$ \\
\hline-2.6 & 0.1 & $0.0 ; 0.3^{*}$ \\
\hline 0.0 & 0.0 & $-0.2 ; 0.2$ \\
\hline
\end{tabular}

Factors associated with less fatigue

* Significant at a $P<0.05$ level, ** significant at a $P<0.01$ level. The PedsQL MFS is scored on a scale from 0-100, with a lower score indicating more severe fatigue. Thus, a negative correlation indicates a lower score, thus indicating more fatigue. PedsQL MFS = PedsQL Multidimensional Fatigue Scale; BMI = body mass index; VAS = visual analogue scale; PedsQL CCS = PedsQL Generic Core Scale; RCADS = Revised Child Anxiety and Depression Scale; PCS-C = Pain Catastrophising Scale for Children. 
Table 5. Complete model including all generic biological/lifestyle, psychological, and social factors and fatigue (PedsQL MFS general fatigue scale) as the dependent variable for the entire group of children with chronic disease $(\mathrm{N}=357)$.

\begin{tabular}{|c|c|c|c|}
\hline Associated modifiable factors & Unstandardised ß & Effect size & $\begin{array}{l}95 \% \text { confidence } \\
\text { interval }\end{array}$ \\
\hline $\begin{array}{l}\text { Emotional functioning (PedsQL CCS, range } \\
0-100 \text { ) }\end{array}$ & 0.1 & 0.1 & $-0.0 ; 0.2$ \\
\hline \multicolumn{4}{|l|}{ Social factors } \\
\hline \multicolumn{4}{|l|}{ Factors associated with more fatigue } \\
\hline Pressure at school (0-4; 'not at all' to 'a lot') & -2.8 & -0.1 & $-4.4 ;-1.2^{* \star}$ \\
\hline $\begin{array}{l}\text { Being bullied ( } 0-5 \text {; 'never' to 'several times per } \\
\text { week') }\end{array}$ & 1.7 & 0.0 & $-0.5 ; 3.9$ \\
\hline \multicolumn{4}{|l|}{ Factors associated with less fatigue } \\
\hline $\begin{array}{l}\text { Communication at home }(1-5, \text { higher score }= \\
\text { better communication) }\end{array}$ & -0.1 & -0.0 & $-2.5 ; 2.3$ \\
\hline $\begin{array}{l}\text { Support at home (1-7, higher score = more } \\
\text { support) }\end{array}$ & -0.4 & -0.0 & $-2.0 ; 1.3$ \\
\hline $\begin{array}{l}\text { Support by friends (1-7, higher score = more } \\
\text { support) }\end{array}$ & 0.0 & 0.0 & $-1.1 ; 1.2$ \\
\hline $\begin{array}{l}\text { Social functioning (PedsQL GCS subscale, } \\
\text { range 0-100) }\end{array}$ & 0.2 & 0.2 & $0.1 ; 0.3^{* *}$ \\
\hline $\begin{array}{l}\text { Member of a sports team or club }(0=\text { not a } \\
\text { member, } 1=\text { member })\end{array}$ & -1.7 & -0.0 & $-4.4 ; 1.1$ \\
\hline \multicolumn{4}{|l|}{ Factors not associated with fatigue in this sample } \\
\hline Screen time per day (hours/day) & -0.2 & -0.0 & $-1.2 ; 0.8$ \\
\hline
\end{tabular}

* Significant at a $P<0.05$ level, ** significant at a $P<0.01$ level. The PedsQL MFS is scored on a scale from 0-100, with a lower score indicating more severe fatigue. Thus, a negative correlation indicates a lower score, thus indicating more fatigue. PedsQL MFS = PedsQL Multidimensional Fatigue Scale; BMI = body mass index; VAS = visual analogue scale; PedsQL CCS = PedsQL Generic Core Scale; RCADS = Revised Child Anxiety and Depression Scale; PCS-C = Pain Catastrophising Scale for Children.

The complete model revealed that the following factors were significantly associated with more fatigue: poorer physical functioning ( $B=0.3,95 \% \mathrm{Cl}: 0.2 ; 0.4)$, more depressive symptoms ( $B=-2.6,95 \% \mathrm{Cl}:-3.1 ;-2.1)$, more pressure at school $(B=-2.8,95 \%$ $C l:-4.4 ;-1.2)$, poorer social functioning ( $B=0.2,95 \% \mathrm{Cl}$ : $0.1 ; 0.3)$, and older age $(B=-0.9$, 95\% Cl: -1.3; -0.4). The complete model is shown in Table 5.

\section{DISCUSSION}

Our results indicate that fatigue in paediatric chronic disease is strongly associated with several transdiagnostic, potentially modifiable generic biological/lifestyle, psychological, and social factors, factors that can be addressed with interventions. We found substantial overlap in the variance explained by generic biological/lifestyle, psychological, and social factors, suggesting a strong interaction between these domains. Importantly, however, we found no significant difference between disease 
groups with respect to the association between fatigue and generic biological/lifestyle, psychological, or social factors. Taken together, these findings call for a transdiagnostic approach to fatigue in children with chronic disease, taking into account the generic biological/lifestyle, psychological, and social domains.

Fatigue is highly prevalent among children with chronic disease. ${ }^{2}$ The similarity among disease groups with respect to fatigue is in line with the results of Menting et al., who studied fatigue among adults with chronic disease. ${ }^{10}$ Our regression models based on separate domains revealed several moderate effect sizes and one large effect size. However, the final model comprised of all three domains revealed one moderate and two small effect sizes for depressive symptoms, physical functioning, and social functioning, respectively. In the final composite model, all three domains biological/lifestyle, psychological, and social - were still represented, emphasising the importance of all three domains in assessing fatigue.

With respect to generic biological/lifestyle factors, our finding that physical functioning, sleep, and pain play a role in fatigue is consistent with previous studies involving paediatric JIA, CF, and post-cancer treatment patients. ${ }^{3,5-7,28}$ Encouraging the child to, for example, engage in a healthy lifestyle and participate in sports may be beneficial on a biological and social level, thereby reducing fatigue. ${ }^{28-30}$ This is likely true for fatigued children who are in a stable phase of their chronic disease, as well as other patient populations who suffer from fatigue, for example following COVID-19.14 With respect to the psychological domain, modifiable factors such as depression and/ or anxiety - both of which are associated with fatigue - were also identified in other studies regarding chronic disease.12,13 These factors are suitable targets for treatment, for example with cognitive behavioural therapy. ${ }^{31}$

The social context of developing children plays another important role in fatigue. 29,32 We found that social functioning is significantly associated with fatigue, which is consistent with a recent finding that children with a chronic disease generally encounter more difficulties and achieve psychosocial milestones at a later age compared to healthy peers. ${ }^{29}$ Unfortunately, our study cannot distinguish whether poorer social functioning precedes or is a consequence of fatigue or whether the two perpetuate one another. Encouraging these children to engage in social participation and helping them self-manage their disease may empower them to cope with their disease, possibly reducing fatigue. ${ }^{33}$ In assessing social context, proxy reports are highly relevant and may help reveal contributing factors that are not necessarily taken into account in these models. Thus, future studies should include proxy reports and the effect of the child's social network. Interestingly, we found that 'being bullied' was not significantly associated with fatigue, even though chronically ill children are more likely to be bullied compared to healthy peers. ${ }^{34}$ One possible explanation for this finding is that being bullied may have been underreported, as the reported prevalence of bullying varies among reporting methods. ${ }^{35}$ Another possible explanation is that asking only one question regarding bullying may be inadequate for scoring the factor 'being bullied'.

A clear strength of this study is that we structurally assessed potentially modifiable generic biological/lifestyle, psychological, and social factors in a range of paediatric 
chronic diseases, with both congenital and acquired diseases and both life-threatening and non-life-threatening diseases. Thus, our analysis revealed which factors can explain a relatively high degree of the reported variance in fatigue. Moreover, the majority of factors were significantly associated with fatigue, even after we adjusted for multiple testing.

Despite these strengths, our study has several limitations that warrant discussion. First, the participation rate was approximately $50 \%$, and approximately $18 \%$ of the participants did not complete the assessments in their entirety. However, we found no apparent difference between participants and non-participants or between completers and non-completers. Nevertheless, we cannot rule out the possibility that the non-participants were more severely ill or more fatigued, even though this was not the main reason given by the children who chose not to participate. In addition, some patient groups may have been underrepresented, for example children with a brain tumour. Finally, the study was designed to determine which biopsychosocial factors are associated with fatigue, but was not designed to identify causal relationships between the biopsychosocial factors and fatigue.

Because fatigue is both prevalent and distressing, it should be assessed as a multidimensional problem by monitoring the presence of fatigue and potentially modifiable fatigue-related factors in a multidisciplinary setting. Completing simple, validated questionnaires via a web-based portal is both time-efficient and compatible with outpatient care.30,36 Moreover, our finding that older children reported higher levels of fatigue are consistent with previous reports. ${ }^{27}$ It may be beneficial to monitor a child's fatigue from an early age in order to signal possible problems in time, possibly preventing deterioration and impaired functioning.

Although the presence of fatigue did not appear to differ significantly between disease groups, its associated perpetuating biopsychosocial factors can differ between individuals and can change over time. Thus, future studies should use a person-centred approach in order to develop customised interventions designed to help each patient self-manage his/her fatigue, for example using ecological momentary assessments. ${ }^{37}$

\section{CONCLUSION}

Fatigue is a multidimensional concept across various childhood chronic diseases, with strong, overlapping, and potentially modifiable factors in the biological, psychological, and social domains. A transdiagnostic approach that takes into account these factors is therefore preferred for monitoring and treating fatigue in these patients. 


\section{REFERENCES}

1. Armbrust W, Siers NE, Lelieveld OTHM, Mouton LJ, Tuinstra J, Sauer P. Fatigue in patients with juvenile idiopathic arthritis: A systematic review of the literature. Semin Arthritis Rheum. 2016;45(5):587-595. doi:10.1016/j.semarthrit.2015.10.008

2. Nap-van der Vlist MM, Dalmeijer CW, Grootenhuis MA, et al. Fatigue in childhood chronic disease. Arch Dis Child. Published online June 7, 2019:archdischild-2019-316782. doi:10.1136/archdischild-2019-316782

3. Walter LM, Nixon GM, Davey MJ, Downie PA, Horne RSC. Sleep and fatigue in pediatric oncology: A review of the literature. Sleep Med Rev. 2015;24:71-82. doi:10.1016/j.smrv.2015.01.001

4. Nijhof LN, van de Putte EM, Wulffraat NM, Nijhof SL. Prevalence of severe fatigue among adolescents with pediatric rheumatic diseases. Arthritis Care Res (Hoboken). Published online August 28, 2015:n/a-n/a. doi:10.1002/acr.22710

5. Nap-van der Vlist MM, Burghard M, Hulzebos HJ, et al. Prevalence of severe fatigue among adults with cystic fibrosis: A single center study. J Cyst Fibros. 2018;17(3):368374. doi:10.1016/j.jcf.2018.03.003

6. Langeveld NE, Grootenhuis MA, Voûte PA, de Haan RJ, van den Bos C. No excess fatigue in young adult survivors of childhood cancer. Eur J Cancer. 2003;39(2):204214. Accessed July 24, 2018. http://www.ncbi.nlm.nih.gov/pubmed/12509953

7. Van Dijk-Lokkart EM, Steur LMH, Braam KI, et al. Longitudinal development of cancer-related fatigue and physical activity in childhood cancer patients. Pediatr Blood Cancer. 2019;66(12):e27949. doi:10.1002/pbc.27949

8. Vijver E Van de, Gils A Van, Beckers L, Driessche Y Van, Moes ND, Rheenen PF van. Fatigue in children and adolescents with inflammatory bowel disease. World J Gastroenterol. 2019;25(5):632-643. doi:10.3748/wjg.v25.i5.632

9. Engel CL. The need for a new medical model: a challenge for biomedicine. Science. 1977;196(4286):129-136. doi:10.1126/science.847460

10. Menting J, Tack CJ, Bleijenberg C, et al. Is fatigue a disease-specific or generic symptom in chronic medical conditions? Heal Psychol. 2018;37(6):530-543. doi:10.1037/hea0000598

11. Stein REK, Jessop DJ. What diagnosis does not tell: The case for a noncategorical approach to chronic illness in childhood. Soc Sci Med. 1989;29(6):769-778. doi:10.1016/0277-9536(89)90157-3

12. Jarad NA, Sequeiros IM, Patel P, Bristow K, Sund Z. Fatigue in cystic fibrosis: a novel prospective study investigating subjective and objective factors associated with fatigue. Chron Respir Dis. 2012;9(4):241-249. doi:10.1177/1479972312464236

13. Daniel LC, Brumley LD, Schwartz LA. Fatigue in adolescents with cancer compared to healthy adolescents. Pediatr Blood Cancer. 2013;60(11):1902-1907. doi:10.1002/ pbc.24706

14. Garrigues E, Janvier P, Kherabi Y, et al. Post-discharge persistent symptoms and health-related quality of life after hospitalization for COVID-19. J Infect. Published 
online August 25, 2020. doi:10.1016/j.jinf.2020.08.029

15. Gordijn MS, Suzanne, Cremers EMP, Kaspers GJL, Gemke RJBJ. Fatigue in children: reliability and validity of the Dutch PedsQLTM Multidimensional Fatigue Scale. Qual Life Res. 2011;20(7):1103-1108. doi:10.1007/s11136-010-9836-9

16. Quanjer PH, Stanojevic S, Cole TJ, et al. Multi-ethnic reference values for spirometry for the 3-95-yr age range: the global lung function 2012 equations. Eur Respir J. 2012;40(6):1324-1343. doi:10.1183/09031936.00080312

17. McErlane F, Foster HE, Carrasco R, et al. Trends in paediatric rheumatology referral times and disease activity indices over a ten-year period among children and young people with Juvenile Idiopathic Arthritis: results from the childhood arthritis prospective Study. Rheumatology (Oxford). 2016;55(7):1225-1234. doi:10.1093/ rheumatology/kew021

18. Rosier EM, ladarola MJ, Coghill RC. Reproducibility of pain measurement and pain perception. Pain. 2002;98(1-2):205-216. Accessed May 31, 2019. http://www.ncbi.nlm. nih.gov/pubmed/12098633

19. Currie C, Zanotti C, Morgan A, et al. Social Determinants of Health and Well-Being Among Young People. Copenhagen: World Health Organization Regional Office for Europe.; 2012.

20. de Looze M, van Dorsselaer S, de Roos S, et al. Health Behaviour in School Children 2013 - Health, Wellbeing, and Education of Dutch Children.; 2013.

21. Ng K, Hämylä R, Tynjälä J, et al. Test-retest reliability of adolescents' self-reported physical activity item in two consecutive surveys. Arch Public Heal. 2019;77. doi:10.1186/S13690-019-0335-3

22. WHO I Global recommendations on physical activity for health. WHO. Published online 2015.

23. Engelen V, Haentjens MM, Detmar SB, Koopman HM, Grootenhuis MA. Health related quality of life of Dutch children: psychometric properties of the PedsQL in the Netherlands. BMC Pediatr. 2009;9(1):68. doi:10.1186/1471-2431-9-68

24. de Onis M, Onyango AW, Borghi E, Siyam A, Nishida C, Siekmann J. Development of a WHO growth reference for school-aged children and adolescents. Bull World Health Organ. 2007;85(9):660-667. doi:10.2471/blt.07.043497

25. Kösters MP, Chinapaw MJM, Zwaanswijk M, van der Wal MF, Koot HM. Structure, reliability, and validity of the revised child anxiety and depression scale (RCADS) in a multi-ethnic urban sample of Dutch children. BMC Psychiatry. 2015;15(1):132. doi:10.1186/s12888-015-0509-7

26. Crombez G, Bijttebier P, Eccleston C, et al. The child version of the pain catastrophizing scale (PCS-C): a preliminary validation. Pain. 2003;104(3):639-646. Accessed May 31, 2019. http://www.ncbi.nlm.nih.gov/pubmed/12927636

27. ter Wolbeek M, van Doornen LJP, Kavelaars A, Heijnen CJ. Severe Fatigue in Adolescents: A Common Phenomenon? Pediatrics. 2006;117(6):el078-el086. doi:10.1542/peds.2005-2575

28. Armbrust W, Lelieveld OHTM, Tuinstra J, et al. Fatigue in patients with Juvenile 
Idiopathic Arthritis: relationship to perceived health, physical health, self-efficacy, and participation. Pediatr Rheumatol. 2016;14(1):65. doi:10.1186/s12969-016-0125-1

29. Maurice-Stam H, Nijhof SL, Monninkhof AS, Heymans HSA, Grootenhuis MA. Review about the impact of growing up with a chronic disease showed delays achieving psychosocial milestones. Acta Paediatr. Published online August 27, 2019:apa.14918. doi:10.1111/apa.14918

30. Robinson PD, Oberoi S, Tomlinson D, et al. Management of fatigue in children and adolescents with cancer and in paediatric recipients of haemopoietic stem-cell transplants: a clinical practice guideline. Lancet Child Adolesc Heal. 2018;2(5):371378. doi:10.1016/S2352-4642(18)30059-2

31. Thabrew H, Stasiak K, Hetrick SE, et al. Psychological therapies for anxiety and depression in children and adolescents with long-term physical conditions. Cochrane Database Syst Rev. 2018;12:CD012488. doi:10.1002/14651858.CD012488. pub2

32. Pinquart M, Teubert D. Academic, physical, and social functioning of children and adolescents with chronic physical illness: a meta-analysis. J Pediatr Psychol. 2012:37(4):376-389. doi:10.1093/jpepsy/jsr106

33. Schmidt S, Petersen C, Bullinger M. Coping with chronic disease from the perspective of children and adolescents--a conceptual framework and its implications for participation. Child Care Health Dev. 2003;29(1):63-75. Accessed July 10, 2019. http://www.ncbi.nlm.nih.gov/pubmed/12534568

34. Pinquart M. Systematic Review: Bullying Involvement of Children With and Without Chronic Physical Illness and/or Physical/Sensory Disability-a Meta-Analytic Comparison With Healthy/Nondisabled Peers. J Pediatr Psychol. 2017;42(3):245-259. doi:10.1093/jpepsy/jsw081

35. Sawyer AL, Bradshaw CP, O’Brennan LM. Examining ethnic, gender, and developmental differences in the way children report being a victim of ";bullying"; on self-report measures. J Adolesc Health. 2008;43(2):106-114. doi:10.1016/j. jadohealth.2007.12.011

36. Haverman L, van Rossum MAJ, van Veenendaal M, et al. Effectiveness of a Web-Based Application to Monitor Health-Related Quality of Life. Pediatrics. 2013;131(2):e533-e543. doi:10.1542/peds.2012-0958

37. Bolger N, Davis A, Rafaeli E. Diary methods: capturing life as it is lived. Annu Rev Psychol. 2003;54(1):579-616. doi:10.1146/annurev.psych.54.101601.145030 

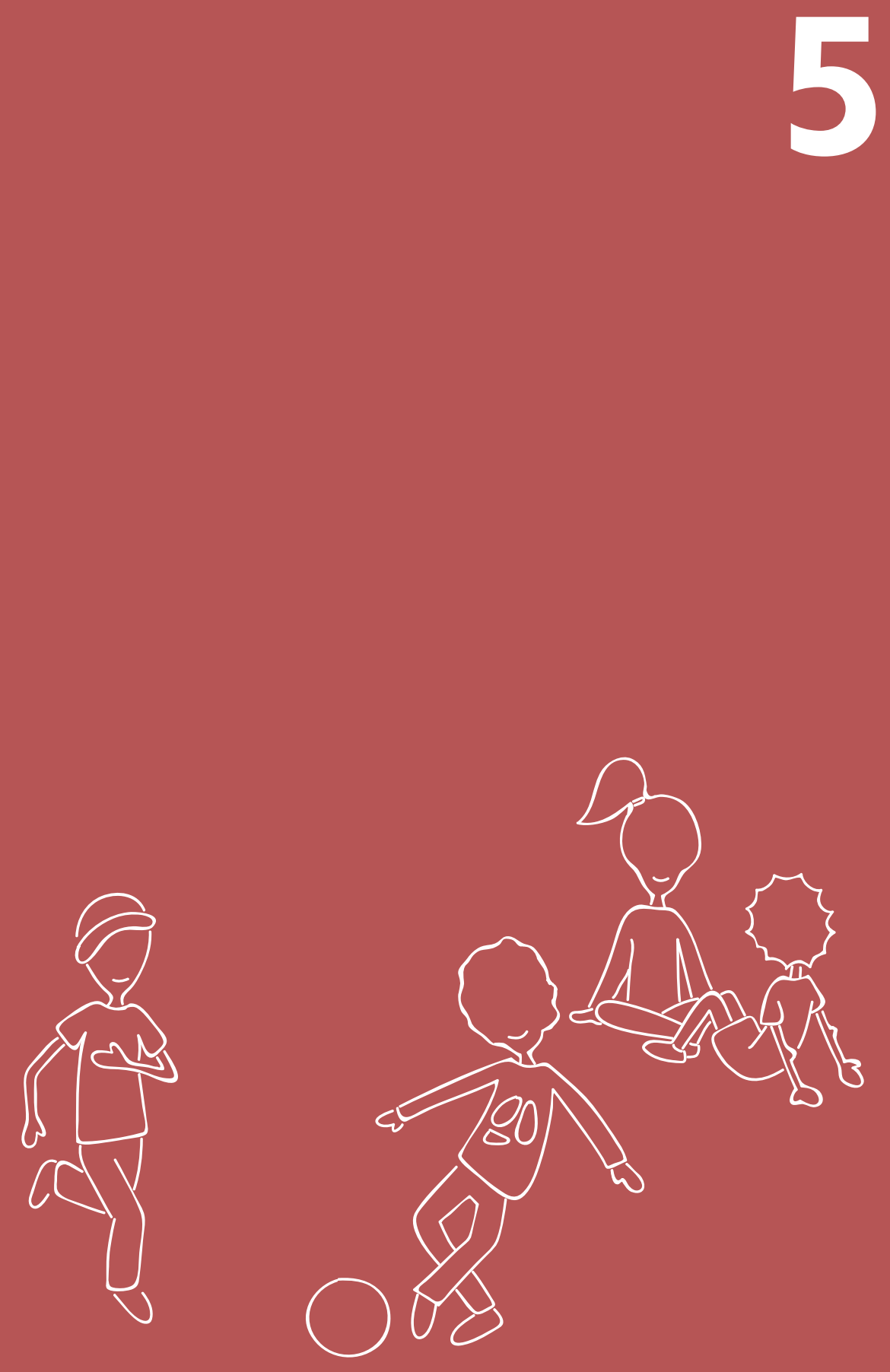


\title{
The role of parents in fatigue of child- ren with a chronic disease: a cross-sec- tional study
}

\author{
Niels Kramer, BSca; \\ Sanne L. Nijhof, PhDa; \\ Elise M. van de Putte, PhDa; \\ Marjolijn Ketelaar, $\mathrm{PhD}^{\text {; }}$; \\ Martha A. Grootenhuis, $\mathrm{PhD}^{\text {c }}$; \\ Cornelis K. van der Ent, PhDd; \\ Joost F. Swart, PhDe; \\ Martine van Grotel, $\mathrm{PhD}^{\mathrm{c}}$; \\ Geertje W. Dalmeijer, PhD; \\ Merel M. Nap-van der Vlist, MSca
}

a Department of Paediatrics, Wilhelmina Children's Hospital, University Medical Centre Utrecht, Utrecht University, Utrecht, The Netherlands

${ }^{b}$ Centre of Excellence for Rehabilitation Medicine, UMC Utrecht Brain Centre, University Medical Centre Utrecht and De Hoogstraat Rehabilitation, Utrecht, The Netherlands c Princess Máxima Centre for Paediatric Oncology, Utrecht, The Netherlands d Department of Paediatric Pulmonology, Wilhelmina Children's Hospital, University Medical Centre Utrecht, Utrecht University, Utrecht, The Netherlands e Department of Paediatric Rheumatology/Immunology, Wilhelmina Children's Hospital, University Medical Centre Utrecht, Utrecht University, Utrecht, The Netherlands f Julius Center for Health Sciences and Primary Care, University Medical Centre Utrecht, Utrecht University, Utrecht, The Netherlands 


\section{ABSTRACT}

\section{Objective:}

As parents majorly impact their child's well-being, and as fatigue is a highly prevalent threat to the well-being of children with a chronic disease, we aimed to explore the association between parental factors and fatigue in children with a chronic disease.

\section{Design:}

Cross-sectional study

\section{Setting:}

Two Dutch children's hospitals.

\section{Population:}

Children 2-18 years of age with either an autoimmune disease, cystic fibrosis, or postcancer treatment, and one of their parents.

\section{Main outcome measures:}

Paediatric fatigue was measured using the PedsQL Multidimensional Fatigue Scale. Parental factors included parental pain, fatigue and physical symptoms, parental distress, catastrophizing thoughts about their child's pain and family empowerment. Multiple linear regressions were used to study associations with paediatric fatigue. A multivariable regression model was used to assess the effect of the different parental factors on paediatric fatigue. All analyses were adjusted for age and sex of the child.

\section{Results:}

204 families participated (mean age 11.0 \pm 4.3 and $43.5 \pm 6.3$ years for children and parents, respectively; 69\% participation rate). More parental pain, fatigue and physical symptoms, and more parental distress and pain catastrophizing were associated with more paediatric fatigue. More parental empowerment was associated with less paediatric fatigue, on both subscales. In the multivariable model, only paediatric age remained significantly associated with fatigue. In a separate multivariable model for children 8-18 years old, more parental distress ( $B=-1.9 ; 95 \% \mathrm{Cl}-3.7 ;-0.1)$ was also significantly associated with more paediatric fatigue.

\section{Conclusions:}

In a population of children with a chronic disease, parental factors, both physical and psychosocial, were associated with paediatric fatigue. Our study provides evidence that more family empowerment is associated with less paediatric fatigue. This exploratory study adds to our knowledge of associated factors with fatigue in paediatric chronic disease, providing starting points for targeted interventions. 


\section{INTRODUCTION}

An increasing number of children with a serious chronic disease reaches adulthood. Unfortunately, this does not go without obstacles. Paediatric chronic disease affects the health and well-being of both children and their families.,3 One of the most common health issues among children with chronic disease is fatigue.4-6 Several child factors, both somatic and psychosocial, have been associated with fatigue., ${ }^{5,-12}$ Although child factors explain a considerable amount of variance in fatigue, part of the variance of fatigue cannot be explained by child factors? Interpersonal factors, family environment and parental functioning are important contributors to how the child functions with his or her disease, especially for younger children.,13

As parents have a major impact on their child's well-being, we hypothesize that parental factors, both physical and psychosocial, influence paediatric fatigue in paediatric chronic disease, in line with the biopsychosocial model.12 Several parental physical factors, such as parental pain, fatigue and a focus on bodily symptoms, have been shown to negatively influence paediatric outcomes in children with chronic pain or chronic fatigue syndrome (CFS).14-18 Regarding parental psychosocial factors, parents of children with a chronic disease experience more psychological distress. 19,20 Several factors, such as parental distress or catastrophizing thoughts, have been shown to negatively influence paediatric health outcomes, such as fatigue or pain, across paediatric chronic diseases.14,15,19-21 However, in line with the concept of positive health, there may also be potentially protective factors, such as family empowerment.22,23 Empowerment can be described as a sense of being able to influence your social environment to mobilize the resources you need and to feel in control over the situation. ${ }^{23,24}$ Family empowerment has been associated with fewer somatic and psychological symptoms in children, although no studies have focused on fatigue yet. ${ }^{25}$

Parental physical and psychosocial factors have been associated with poor paediatric outcomes, but have not yet been investigated in the context of fatigue in children with a chronic disease. Examining the association between parental factors and paediatric fatigue across different paediatric chronic diseases may help us understand more of the perpetuating factors of fatigue across paediatric chronic disease and may open the door for targeted interventions. ${ }^{26}$ Therefore, we aimed to explore the association between parental physical and psychosocial factors and fatigue in children with a chronic disease of 2-18 years old. Second, as higher age is associated with more fatigue and as children of eight years and older can self-report their fatigue, we zoom in on the associations between parental factors and paediatric fatigue in this age group. ${ }^{27}$

\section{METHODS}

\section{Study design}

This is a cross-sectional study, in which parents and children filled out questionnaires prior to an outpatient visit. This study was part of a larger cohort study on fatigue and associated factors across paediatric chronic diseases at the Wilhelmina Children's Hospital and the Princess Máxima Center for Paediatric Oncology in the Netherlands: 
the PROactive cohort. ${ }^{4}$ The data used for this study were collected from January 2018 through February 2020 and were based on an extended follow-up assessment of patients included in the PROactive cohort. Informed consent for the use of questionnaires for scientific purposes was obtained from children twelve years of age and older and from one of the parents. The study was classified by the institutional review board as exempt from the Medical Research Involving Human Subjects Act (16$707 / C)$

\section{Patient and public involvement}

Patient organisations were involved in setting the priorities for this research. Several choices in the design were reviewed by patient representatives. Patients and the public were not involved in the conduct of the study. We added qualitative research methods to our research line in order to stress the patient's and parent's perspective. Patient organisations and societal partners are involved in the dissemination of our research.

\section{Participants}

Families with a child 2-18 years of age with cystic fibrosis (CF), autoimmune disease, or previous treatment for cancer were included. The group of children with an autoimmune disease included children with an immunodeficiency disorder, an auto inflammatory condition, or an autoimmune disease in the strictest sense. We included children who were at least one year post-diagnosis (the CF and autoimmune disease groups), or who were within one year after completing their cancer treatment. This latter inclusion criterion was chosen since disease activity (generally highest in the first year after diagnosis), receiving the diagnosis, starting treatment, and the disease itself can cause significant fatigue in the first year post-diagnosis or during cancer treatment. One parent filled out the questionnaires. The primary outcome measure, paediatric fatigue, was child-reported when the child was between 8 and 18 years of age and parent-reported for younger children (2-7 years of age). All other measures were parent-reported questionnaires.

\section{Study procedures}

Before an outpatient visit, the researchers approached families via email to take part in the study. They then completed the questionnaires via a web-based tool (www.hetklikt. nu). ${ }^{28}$ All participants received one reminder to participate in the study via email and one via telephone. A research team was available to answer questions via mail and telephone.

\section{Measurements}

Paediatric fatigue was the primary outcome measure, which was measured using the general fatigue subscale of the PedsQL Multidimensional Fatigue Scale (PedsQL MFS), which has good internal consistency. ${ }^{29}$ As the primary outcome was the perception of fatigue, we used only the general fatigue subscale, instead of the other subscales of the PedsQL MFS, namely sleep/rest and cognitive fatigue. The subscale general fatigue contains questions about the perception of fatigue and whether the child has enough energy to perform activities.

For all questionnaires and tools used in our study, the number of items, range, interpretation, and Cronbach's alpha are provided in Table 1. 
Table 1. Summary of the factors assessed in this study and features of the corresponding questionnaires/ tools.

\begin{tabular}{|c|c|c|c|c|}
\hline Assessed factor & Questionnaire & Items & Range/replies & $\begin{array}{l}\text { Cronbach's } \\
\text { alpha }\end{array}$ \\
\hline Paediatric fatigue & PedsQL MFS & 6 & $\begin{array}{l}\text { 0-100: } \text { higher score = less } \\
\text { paediatric fatigue }\end{array}$ & 0.92 \\
\hline Parental pain & VAS & 1 & $\begin{array}{l}0-10 \text { : higher score = more } \\
\text { parental pain }\end{array}$ & N/A \\
\hline Parental fatigue & CIS-8 & 8 & $\begin{array}{l}\text { 8-56: higher score = more } \\
\text { parental fatigue }\end{array}$ & 0.93 \\
\hline $\begin{array}{l}\text { Parental physical } \\
\text { symptoms }\end{array}$ & $\begin{array}{l}\text { CDC criteria for CFS- } \\
\text { related symptoms }\end{array}$ & 8 & $\begin{array}{l}\text { 0-8: higher score = } \\
\text { more parental physical } \\
\text { symptoms }\end{array}$ & 0.79 \\
\hline $\begin{array}{l}\text { Parental pain } \\
\text { catastrophizing }\end{array}$ & PCS-P & 13 & $\begin{array}{l}\text { 0-52: higher score = } \\
\text { more parental pain } \\
\text { catastrophizing }\end{array}$ & 0.93 \\
\hline Parental distress & DTP & 1 & $\begin{array}{l}0-10 \text { : higher score = more } \\
\text { parental distress }\end{array}$ & $\mathrm{N} / \mathrm{A}$ \\
\hline $\begin{array}{l}\text { Family empowerment } \\
\text { family subscale }\end{array}$ & FES & 12 & $\begin{array}{l}\text { 1-5: higher score = more } \\
\text { parental empowerment. } \\
\text { The score is calculated as } \\
\text { the mean of the items. }\end{array}$ & 0.89 \\
\hline $\begin{array}{l}\text { Family empowerment } \\
\text { service system subscale }\end{array}$ & FES & 12 & $\begin{array}{l}\text { 1-5: higher score = more } \\
\text { parental empowerment. } \\
\text { The score is calculated as } \\
\text { the mean of the items. }\end{array}$ & 0.91 \\
\hline
\end{tabular}

\section{Physical factors}

The measured parental physical factors included parental pain, fatigue and physical symptoms. A visual analogue scale (VAS) ranging from zero to ten was used to measure last week's average parental pain. ${ }^{30}$ Parental fatigue was assessed using the well-validated Checklist Individual Strength (CIS-8), which has good psychometric properties. ${ }^{31}$ To assess physical symptoms, the eight CFS-related symptoms of the US Center for Disease Control and Prevention (CDC) criteria were used. ${ }^{32}$

\section{Psychosocial factors}

The Pain Catastrophizing Scale for Parents (PCS-P) was used to determine the degree of catastrophizing thoughts parents have regarding their child's pain. This scale has high internal consistency.3. Parental distress was measured using the Distress Thermometer for Parents (DT-P), assessing overall parental distress over the past week. This scale has good internal consistency. ${ }^{20}$ Family empowerment was measured using two subscales of the Family Empowerment Scale (FES) ${ }^{23,34}$ The family subscale assesses 
the parents' management of everyday situations; e.g. . The service system subscale assesses how parents relate to the service system; e.g., "I know what services my child needs".

\section{Data analyses}

Descriptive statistics were used to summarise characteristics of all participants. Normally distributed continuous variables were presented as mean \pm standard deviation; otherwise median and interquartile range were provided. Categorical variables were presented as frequencies. Differences between participants and nonparticipants and between disease groups were analysed using the Student's t-test, Kruskal-Wallis test or chi-square test.

We applied an exploratory aetiological research design. Multiple linear regression analyses were performed for each parental factor to assess its association with the outcome variable paediatric fatigue. As age and sex of the child are important determinants of fatigue, these factors were used as covariates in all analyses. ${ }^{27}$ The associations were described using the unstandardized beta (ß), effect size (standardized beta), and 95\% confidence interval (CI). The unstandardized beta is how much the paediatric fatigue score $(Y)$ changes if the parental factor $(X)$ changes by one point. For example, for every point that parents score higher on parental pain, the paediatric fatigue score goes up with beta points. The assumptions for linear regression analysis were tested, including linearity between the dependent and independent variable, homoscedasticity, and normality of the residuals. Minimal differences were found between standard errors and robust standard errors. Bootstrapping was performed on all regression analyses in table 4 and the results were in line with the initial results from the regression analyses. Multicollinearity between the separate parental factors was investigated. Second, to investigate whether associations differed between disease groups, we added an interaction variable of the interaction between disease group and the tested parental factor to the regression analyses. Third, we build a full model with all parental factors and the covariates entered together, to describe the variance in paediatric fatigue explained by parental factors. This full model was performed for the full age range (2-18 years) and separately for children 8-18 years old. We used these models to describe the explained variance of the parental factors in fatigue. In this explorative study, $P<0.05$ was considered statistically significant. Effect sizes of $<0.5$ were considered small, $\geq 0.5$ moderate and $\geq 0.8$ large..$^{35}$

\section{RESULTS}

\section{emographics of the study population}

Of the 296 families who were approached for this study, 204 participated (69\%). Nonparticipating children were significantly older compared to participating children (13.5 \pm 4.3 vs. $11.0 \pm 4.3$ years). The most commonly cited reasons for not participating were personal circumstances and current participation in other research. Table 2 summarises the general characteristics of the participants and table 3 summarises the parental factors. There were significant differences in age and sex of the child between disease groups, which supports our decision to control for children's sex and age in 
the main analyses. In this sample, sex of the child did not significantly influence fatigue scores ( $P=0.48 ; B=-2.2 ; 95 \% \mathrm{Cl}-8.3 ; 3.9)$. The median paediatric fatigue score was 83.3 (IQR 62.5-95.8) on the general fatigue scale. Paediatric fatigue was self-reported by children 8-18 years old (69.8\%) and parent-reported for children 2-7 years old (30.2\%).

Table 2. Descriptive characteristics of the children and parents included in this study

\begin{tabular}{|c|c|c|c|c|}
\hline & & Disease groups & & \\
\hline & $\begin{array}{l}\text { Entire group } \\
(n=204)\end{array}$ & $\begin{array}{l}\text { Autoimmune } \\
\text { disease }(n=105)\end{array}$ & $\begin{array}{l}\text { Cystic fibrosis } \\
(n=51)\end{array}$ & $\begin{array}{l}\text { Post-cancer } \\
\text { treatment }(n=48)\end{array}$ \\
\hline Child characteristics & & & & \\
\hline Age in years (mean \pm SD) & $11.1 \pm 4.4$ & $12.2 \pm 3.9$ & $11.3 \pm 4.8$ & $8.4 \pm 3.9$ \\
\hline Sex, male $(n, \%)$ & $83(41 \%)$ & $35(33 \%)$ & $24(47 \%)$ & $25(50 \%)$ \\
\hline Fatigue* (median (IQR)) & $83.3(62.5-95.8)$ & $79.2(58.3-93.8)$ & $79.2(58.3-95.8)$ & $91.7(68.8-100)$ \\
\hline Parent characteristics & & & & \\
\hline Age in years (mean \pm SD) & $43.6 \pm 6.4$ & $44.9 \pm 5.8$ & $43.2 \pm 6.9$ & $41.1 \pm 6.3$ \\
\hline Sex, male (n, \%) & $49(24 \%)$ & $22(21 \%)$ & $15(29 \%)$ & $12(25 \%)$ \\
\hline
\end{tabular}

\section{Table 3. Parent-reported outcomes}

Parental factor

Parents $(n=204)$

Physical factors

Pain

Experienced pain in VAS (median \pm IQR)

$0(0-2)$

\section{Fatigue}

Score (CIS-8) fatigue subscale (median \pm IQR)

Percentage severely fatigued (CIS-8 $\geq 35$ )

$24.0(15.0-33.0)$

21.5

\section{Physical symptoms}

Number of CFS-related symptoms (median \pm IQR)

\section{Psychosocial factors}

Pain catastrophizing

PCS Parent total score (median \pm IQR)

$9.0(4.0-14.5)$

\section{Distress}

DT-P stress thermometer (median \pm IQR)

Percentage clinically elevated distress $(\geq 4)$

$2.0(1.0-5.0)$

34.8

\section{Family empowerment}

FES family subscale (median \pm IQR)

FES service system subscale (median \pm IQR)

$4.4(4.1-4.8)$
$4.3(4.0-4.8)$

VAS, visual analogue scale (range: 0-10); SD, standard deviation; CIS, Checklist Individual Strength (range: 8-56); CFS, Chronic Fatigue Syndrome (range: 0-8); PCS, Pain Catastrophizing Scale (range: 0-52); DT-P, Distress Thermometer for Parents (range: 0-10); FES, Family Empowerment Scale (range: 1-5). 


\section{Parental factors and paediatric fatigue}

All parental physical and psychosocial factors were significantly associated with paediatric fatigue, albeit with small effect sizes (Table 4). More parental pain $(B=-1.62$; 95\% Cl-2.90; -0.34), more parental fatigue ( $B=-0.50 ; 95 \% \mathrm{Cl}-0.73 ;-0.27)$, and more parental physical symptoms ( $B=-2.77 ; 95 \% \mathrm{Cl}-4.33 ;-1.21$ ) were significantly associated with more paediatric fatigue. Also, more pain catastrophizing $(B=-0.36 ; 95 \% \mathrm{Cl}-0.67$; -0.05), and more parental distress ( $B=-2.07$; 95\% Cl -3.06; -1.08) were also associated with more paediatric fatigue. More parental empowerment was associated with less paediatric fatigue, both on the family subscale $(B=10.14 ; 95 \% \mathrm{Cl} 3.74 ; 16.53)$ and the service system subscale $(B=7.21$; $95 \% \mathrm{Cl} 1.55 ; 12.86$ ). We found no significant differences between disease groups on any of the physical or psychological parental associations with paediatric fatigue.

Table 4. Linear regression per factor with dependent variable paediatric fatigue (PedsQL MFS general fatigue scale) for the entire group of children with chronic diseases, adjusted for age and sex of the child

\begin{tabular}{|c|c|c|c|}
\hline \multicolumn{4}{|l|}{ Physical factors } \\
\hline \multicolumn{4}{|l|}{ Parental Pain } \\
\hline VAS (range 0-10) & -1.62 & -0.16 & $-2.90 ;-0.34$ \\
\hline \multicolumn{4}{|l|}{ Parental fatigue } \\
\hline CIS-8 (range 0-56) & -0.50 & -0.27 & $-0.73 ;-0.27$ \\
\hline \multicolumn{4}{|c|}{ Reported CDC CFS symptoms } \\
\hline $\begin{array}{l}\text { Number of symptoms } \\
(0-8)\end{array}$ & -2.77 & -0.23 & $-4.33 ;-1.21$ \\
\hline \multicolumn{4}{|l|}{ Psychosocial factors } \\
\hline \multicolumn{4}{|l|}{ Pain catastrophizing } \\
\hline $\begin{array}{l}\text { PCS parent total score } \\
(0-52)\end{array}$ & -0.36 & -0.15 & $-0.67 ;-0.05$ \\
\hline \multicolumn{4}{|l|}{ Parental distress } \\
\hline $\begin{array}{l}\text { DT-P stress thermome- } \\
\text { ter (range 0-10) }\end{array}$ & -2.07 & -0.26 & $-3.06 ;-1.08$ \\
\hline \multicolumn{4}{|l|}{ Family empowerment } \\
\hline FES family subscale (1-5) & 10.14 & 0.20 & $3.74 ; 16.53$ \\
\hline $\begin{array}{l}\text { FES service system } \\
\text { subscale (1-5) }\end{array}$ & 7.21 & 0.17 & $1.55 ; 12.86$ \\
\hline \multicolumn{4}{|c|}{$\begin{array}{l}\text { Note: On the PedsQL MFS Ceneral Fatigue Scale, a higher score indicates less fatigue. VAS, visual analo- } \\
\text { gue scale; CIS, Checklist Individual Strength; CDC CFS, Center for Disease Control and Prevention Chronic } \\
\text { Fatigue Syndrome; PCS, Pain Catastrophizing Scale; DT-P, Distress Thermometer for Parents; FES, Family } \\
\text { Empowerment Scale. Significant results in bold. }\end{array}$} \\
\hline
\end{tabular}

\section{Multivariable regression models}

All parental factors were entered in a regression model, together with the covariates age and sex of the child. This model explained $20.2 \%$ of the variance in fatigue (Table 5). A separate model for children $8-18$ years old $(\mathrm{N}=142)$ explained $20.3 \%$ of the variance in paediatric fatigue. Besides age, more parental distress was significantly associated with more paediatric fatigue in this model (Table 6). 
Table 5. Complete model with all parental factors, covariates age and sex of the child and dependent variable fatigue (PedsQL MFS general fatigue scale) for the entire group of children with chronic disease

\begin{tabular}{|c|c|c|c|}
\hline Associated factors & Unstandardized $ß$ & Effect size & $95 \%$ Conf \\
\hline \multicolumn{4}{|l|}{ Confounders } \\
\hline Age of the child & -1.5 & -0.3 & $-2.2 ;-0.9$ \\
\hline Sex of the child ( $0=$ female) & 2.2 & 0.1 & $-3.4 ; 7.8$ \\
\hline
\end{tabular}

\section{Physical parental factors}

Parental pain (VAS, range 0-10)

Parental fatigue (CIS 8, range 8-56)

Number of CDC CFS symptoms (0-8)

\begin{tabular}{|l|l|l|}
\hline-0.2 & -0.0 & $-1.8 ; 1.4$ \\
\hline-0.1 & -0.0 & $-0.5 ; 0.3$ \\
\hline-0.5 & -0.0 & $-2.6 ; 1.7$ \\
\hline
\end{tabular}

\section{Psychosocial parental factors}

\begin{tabular}{|c|c|c|c|}
\hline $\begin{array}{l}\text { Parental pain catastrophizing } \\
(\text { PCS-P, 0-52) }\end{array}$ & -0.2 & -0.1 & $-0.5 ; 0.1$ \\
\hline $\begin{array}{l}\text { Parental distress (DT-P, range } \\
0-10 \text { ) }\end{array}$ & -1.3 & -0.2 & $-2.7 ; 0.2$ \\
\hline \multicolumn{4}{|l|}{ Family empowerment } \\
\hline FES family subscale (1-5) & 5.9 & 0.1 & $-2.4 ; 14.2$ \\
\hline FES service system subscale (1-5) & 2.4 & 0.1 & $-4.8 ; 9.6$ \\
\hline
\end{tabular}

The PedsQL MFS is scored on a scale from 0-100, with a lower score indicating more severe fatigue. Thus, a negative correlation indicates a lower score, indicating more fatigue. PedsQL MFS = PedsQL multidimensional fatigue scale; VAS = visual analogue scale. Significant results in bold.

Table 6. Complete model with all parental factors and fatigue (PedsQL MFS general fatigue scale) as dependent variable for the group of children 8-18 years of age with chronic disease

\begin{tabular}{|c|c|c|c|}
\hline Associated factors & Unstandardized ß & Effect size & $\begin{array}{l}95 \% \text { Confidence } \\
\text { Interval }\end{array}$ \\
\hline \multicolumn{4}{|l|}{ Confounders } \\
\hline Age of the child & -2.5 & -0.4 & $-3.5 ;-1.4$ \\
\hline Sex of the child ( 0 = female) & 3.5 & 0.1 & $-3.5 ; 10.4$ \\
\hline \multicolumn{4}{|l|}{ Physical parental factors } \\
\hline Parental pain (VAS, range 0-10) & -0.6 & -0.1 & $-2.5 ; 1.4$ \\
\hline Parental fatigue (CIS 8, range 8-56) & 0.2 & 0.1 & $-0.3 ; 0.6$ \\
\hline Number of CDC CFS symptoms (0-8) & 0.5 & 0.0 & $-2.0 ; 3.0$ \\
\hline \multicolumn{4}{|l|}{ Psychosocial parental factors } \\
\hline $\begin{array}{l}\text { Parental pain catastrophizing (PCS-P, } \\
0-52 \text { ) }\end{array}$ & -0.4 & -0.1 & $-0.8 ; 0.1$ \\
\hline Parental distress (DT-P, range $0-10$ ) & -1.9 & -0.2 & $-3.7 ;-0.1$ \\
\hline \multicolumn{4}{|l|}{ Family empowerment } \\
\hline FES family subscale (1-5) & 9.6 & 0.2 & $-0.2 ; 19.5$ \\
\hline FES service system subscale (1-5) & 2.1 & 0.1 & $-6.5 ; 10.6$ \\
\hline
\end{tabular}

The PedsQL MFS is scored on a scale from 0-100, with a lower score indicating more severe fatigue. Thus, a negative correlation indicates a lower score, indicating more fatigue. PedsQL MFS = PedsQL multidimensional fatigue scale; VAS = visual analogue scale. Significant results in bold. 


\section{DISCUSSION}

The aim of this study was to explore the associations between parental factors, both physical and psychosocial, with paediatric fatigue in children with a chronic disease. All parental physical and psychosocial factors were associated with paediatric fatigue. Our study provided evidence that more family empowerment is associated with less paediatric fatigue. Nevertheless, all these parental factors were associated with paediatric fatigue when assessed individually, but when adjusted for each other they did not hold their significance in a full model. Although parental factors did not explain as much of the variance in paediatric fatigue as child factors, this exploratory study adds to our knowledge of associated factors with fatigue in paediatric chronic disease?

Fatigue is highly prevalent in paediatric chronic disease and associated with various factors on the biological, psychological and social domain. ${ }^{7}$ As parents form a major part of the child's social environment, our finding that both physical and psychosocial parental factors are associated with paediatric fatigue, is in line with our hypothesis. First, for physical parental factors, an association between more parental fatigue or bodily symptoms and more paediatric fatigue was also found in children with CFS.6.17 Also in line with our findings, more parental pain and catastrophizing were often associated with worse child outcomes in healthy children or children with chronic conditions. 14,36 Second, for psychosocial parental factors, the significant correlation between parental distress and paediatric fatigue is consistent with the findings reported by Carroll et al., who found a similar correlation in children with multiple sclerosis. ${ }^{21}$

Concerning family empowerment; previous research provided evidence suggesting that parental family empowerment is correlated with fewer somatic and psychological symptoms in children with chronic disease. ${ }^{25}$ In line with these results, our study provides evidence that more family empowerment is correlated with less fatigue in children with chronic disease. Important elements of empowerment include the acquisition of knowledge, skills, attitudes and self-awareness. ${ }^{24}$ Possible ways to support parents may be providing information and education, interventions supporting family function, and interventions supporting parent's own needs. ${ }^{24,37}$ Information needs of families differ between families and vary over time, but in general information needs go beyond information about the diagnosis. ${ }^{38}$ It also concerns issues such as how to make use of available services, how to find information about suitable leisure activities, how to deal with financial issues, how to manage daily care tasks in the family, and how to raise a child with a chronic condition and his/ her siblings. Parent peers can play an important role in information provision and are regarded more and more as an important source of experience-based knowledge and support. ${ }^{38}$ A good example of providing information/education as well as peer support for parents may be an online group course, such as On Track. ${ }^{39}$ A good example of helping parents to gain more control over the service system may be by making the conversations with healthcare providers more family-centred, for example by letting parents fill out parent-reported outcome measures on beforehand or using tools to help parents explore their needs. ${ }^{40,41}$ The effect of such interventions on family 
empowerment is of interest for future studies.

Interestingly, almost all parental factors were not significantly associated with fatigue in the full model when adjusted for each other. Age of the child was significantly associated with paediatric fatigue, but this is not a modifiable factor. In children 8-18 years old, more parental distress was associated with more paediatric fatigue. We already know that fatigue is more prevalent in older children. ${ }^{27}$ Especially for older children, parents of a child with a chronic disease face extra challenges, such as balancing their wish to care for and protect the child and their wish to let the child become autonomous. ${ }^{42,43}$ We also know that these challenges may lead to significant parental distress, which can have substantial negative effects for the child and the family.44 Therefore, in clinical practice, it is important to detect parental distress, for example through a simple validated questionnaire. ${ }^{20}$ Being aware of the well-being of parents may be beneficial for both the parent and the child and could be a starting point for targeted interventions.

A strength of our study is that we examined parental factors across several paediatric chronic diseases, rather than focusing on one specific disease, so our results may be applicable to a wider range of paediatric chronic diseases. We found no significant differences between disease groups on any of the physical or psychological parental associations with paediatric fatigue, which may reflect the general nature of fatigue across all chronic diseases. Another strength is that we included children ranging from 2 to 18 years of age. Most studies focused on adolescents, but fatigue is also prevalent among younger children. ${ }^{4}$ Given that current treatment options for fatigue in younger children are limited, and given the important role that parents play in these early years, identifying parental factors that can be targeted is particularly important in this age group.

A possible limitation is that, although the participation rate was relatively high (69\%), the age of the child was lower for participants than for non-participants. As we already found correlations in our relatively young study population, and as the prevalence of fatigue increases with age, the actual correlations between parental factors and paediatric fatigue may be even stronger. ${ }^{27}$ Second, the group of patients with autoimmune disease contained a relatively high percentage of girls; however, this reflects the epidemiology of those diseases. ${ }^{45}$ Another limitation is that most of the participating parents were mothers; thus, it is possible that certain associations may be more applicable to mothers than fathers. In this study, parents had the choice which parent would participate. It would be of interest to know whether there are differences in representation of symptoms between parents for future studies, as gender differences may influence the outcomes of parental factors and parent-reported child outcomes. ${ }^{46}$ Nevertheless, we compared parental outcomes and found no difference between mothers and fathers, with the exception of a difference in amount of parental physical symptoms. Given the cross-sectional nature of this study, the causal relation between parental factors and paediatric fatigue could not be examined. Within this aetiological, exploratory study design we chose to analyse the data using linear regressions containing a risk factor (parental factor), potential confounders (age and sex of the child) and we added an interaction variable (parental factor $x$ disease group) 
to best answer the research question. Furthermore, we presented a full model to show how these parental factors jointly influence fatigue and how much of the variance in paediatric fatigue is explained by these parental factors. Our goal was not to best predict paediatric fatigue, although that may be of interest for future (preferably longitudinal) studies. This study shows which factors co-occur and possibly perpetuate fatigue, in line with the cognitive behavioural model. ${ }^{26}$

In this exploratory study, we found several physical and psychosocial parental factors that are associated with paediatric fatigue, but all with small effect sizes. For future research, longitudinal studies investigating causal relationships are needed. Also, studies that investigate which parental factors can be used as effective therapeutic targets for treating fatigue in children with chronic disease, are of interest.

\section{CONCLUSION}

In a population of children with a chronic disease, more parental pain, fatigue and physical symptoms, and more parental distress and pain catastrophizing were associated with more paediatric fatigue. Our study also provides evidence that more family empowerment is associated with less paediatric fatigue. This exploratory study adds to our knowledge of associated factors with fatigue in paediatric chronic disease, providing starting points for targeted interventions. 


\section{REFERENCES}

1. Perrin JM, Bloom SR, Gortmaker SL. The Increase of Childhood Chronic Conditions in the United States. JAMA. 2007;297(24):2755. doi:10.1001/jama.297.24.2755

2. Maurice-Stam H, Nijhof SL, Monninkhof AS, Heymans HSA, Grootenhuis MA. Review about the impact of growing up with a chronic disease showed delays achieving psychosocial milestones. Acta Paediatr. Published online August 27, 2019:apa.14918. doi:10.1111/apa.14918

3. Christin A, Akre C, Berchtold A, Suris JC. Parent-adolescent relationship in youths with a chronic condition. Child Care Health Dev. 2016;42(1):36-41. doi:10.1111/ cch. 12266

4. Nap-van der Vlist MM, Dalmeijer CW, Grootenhuis MA, et al. Fatigue in childhood chronic disease. Arch Dis Child. Published online June 7, 2019:archdischild-2019-316782. doi:10.1136/archdischild-2019-316782

5. Nijhof LN, van de Putte EM, Wulffraat NM, Nijhof SL. Prevalence of severe fatigue among adolescents with pediatric rheumatic diseases. Arthritis Care Res (Hoboken). Published online August 28, 2015:n/a-n/a. doi:10.1002/acr.22710

6. van Deuren S, Boonstra A, van Dulmen-den Broeder E, Blijlevens N, Knoop H, Loonen J. Severe fatigue after treatment for childhood cancer. Cochrane Database Syst Rev. Published online March 3, 2020. doi:10.1002/14651858.CD012681.pub2

7. Nap-van der Vlist M, Dalmeijer C, Grootenhuis M, et al. Explaining fatigue in childhood chronic disease within the biopsychosocial model. Submitted.

8. Nap-van der Vlist MM, Burghard M, Hulzebos HJ, et al. Prevalence of severe fatigue among adults with cystic fibrosis: A single center study. J Cyst Fibros. 2018;17(3):368374. doi:10.1016/j.jcf.2018.03.003

9. Vijver E Van de, Gils A Van, Beckers L, Driessche Y Van, Moes ND, Rheenen PF van. Fatigue in children and adolescents with inflammatory bowel disease. World J Gastroenterol. 2019;25(5):632-643. doi:10.3748/wjg.v25.i5.632

10. Armbrust W, Siers NE, Lelieveld OTHM, Mouton LJ, Tuinstra J, Sauer P. Fatigue in patients with juvenile idiopathic arthritis: A systematic review of the literature. Semin Arthritis Rheum. 2016;45(5):587-595. doi:10.1016/j.semarthrit.2015.10.008

11. Langeveld NE, Grootenhuis MA, Voûte PA, de Haan RJ, van den Bos C. No excess fatigue in young adult survivors of childhood cancer. Eur J Cancer. 2003;39(2):204214. Accessed July 24, 2018. http://www.ncbi.nlm.nih.gov/pubmed/12509953

12. Engel GL. The need for a new medical model: a challenge for biomedicine. Science. 1977;196(4286):129-136. doi:10.1126/science.847460

13. Wallander JL, Varni JW. Effects of pediatric chronic physical disorders on child and family adjustment. J Child Psychol Psychiatry. 1998;39(1):29-46. Accessed February 14, 2019. http://www.ncbi.nlm.nih.gov/pubmed/9534085

14. Wilson AC, Moss A, Palermo TM, Fales JL. Parent pain and catastrophizing are associated with pain, somatic symptoms, and pain-related disability among early adolescents. J Pediatr Psychol. 2014;39(4):418-426. doi:10.1093/jpepsy/jst094 
15. Palermo TM, Valrie CR, Karlson CW. Family and parent influences on pediatric chronic pain: a developmental perspective. Am Psychol. 2014;69(2):142-152. doi:10.1037/a0035216

16. Smith MS, Buchwald DS, Bogart A, Goldberg J, Smith WR, Afari N. Adolescent offspring of mothers with chronic fatigue syndrome. J Adolesc Health. 2010;46(3):284-291. doi:10.1016/j.jadohealth.2009.08.001

17. van de Putte EM, van Doornen LJP, Engelbert RHH, Kuis W, Kimpen JLL, Uiterwaal CSPM. Mirrored symptoms in mother and child with chronic fatigue syndrome. Pediatrics. 2006;117(6):2074-2079. doi:10.1542/peds.2005-2307

18. Nijhof SL, Priesterbach LP, Uiterwaal CSPM, Bleijenberg G, Kimpen JLL, van de Putte EM. Internet-based therapy for adolescents with chronic fatigue syndrome: longterm follow-up. Pediatrics. 2013;131(6):el788-95. doi:10.1542/peds.2012-2007

19. Cousino MK, Hazen RA. Parenting stress among caregivers of children with chronic illness: A systematic review. J Pediatr Psychol. 2013;38(8):809-828. doi:10.1093/ jpepsy/jst0 49

20. van Oers HA, Schepers SA, Grootenhuis MA, Haverman L. Dutch normative data and psychometric properties for the Distress Thermometer for Parents. Qual Life Res. 2017;26(1):177-182. doi:10.1007/s11136-016-1405-4

21. Carroll S, Chalder T, Hemingway $C$, et al. Adolescent and parent factors related to fatigue in paediatric multiple sclerosis and chronic fatigue syndrome: A comparative study. Eur J Paediatr Neurol. 2019;23(1):70-80. doi:10.1016/j. ejpn.2018.10.006

22. Huber M, van Vliet M, Giezenberg M, et al. Towards a "patient-centred" operationalisation of the new dynamic concept of health: a mixed methods study. BMJ Open. Published online 2016:5e010091.

23. Koren PE, DeChillo N, Friesen BJ. Measuring empowerment in families whose children have emotional disabilities: A brief questionnaire. Rehabil Psychol. 1992;37(4):305-321. doi:10.1037/h0079106

24. Fumagalli LP, Radaelli G, Lettieri E, Bertele' P, Masella C. Patient Empowerment and its neighbours: Clarifying the boundaries and their mutual relationships. Health Policy (New York). 2015;119(3):384-394. doi:10.1016/j.healthpol.2014.10.017

25. Ashcraft LE, Asato M, Houtrow AJ, Kavalieratos D, Miller E, Ray KN. Parent Empowerment in Pediatric Healthcare Settings: A Systematic Review of Observational Studies. Patient. 2019;12(2):199-212. doi:10.1007/s40271-018-0336-2

26. Deary $V$, Chalder T, Sharpe M. The cognitive behavioural model of medically unexplained symptoms: A theoretical and empirical review. Clin Psychol Rev. 2007;27(7):781-797. doi:10.1016/j.cpr.2007.07.002

27. ter Wolbeek M, van Doornen LJP, Kavelaars A, Heijnen CJ. Severe Fatigue in Adolescents: A Common Phenomenon? Pediatrics. 2006;117(6):el078-el086. doi:10.1542/peds.2005-2575

28. Haverman L, van Rossum MAJ, van Veenendaal M, et al. Effectiveness of a Web-Based Application to Monitor Health-Related Quality of Life. Pediatrics. 
2013;131(2):e533-e543. doi:10.1542/peds.2012-0958

29. Gordijn MS, Suzanne, Cremers EMP, Kaspers GJL, Gemke RJBJ. Fatigue in children: reliability and validity of the Dutch PedsQLTM Multidimensional Fatigue Scale. Qual Life Res. 2011;20(7):1103-1108. doi:10.1007/s11136-010-9836-9

30. Price DD, McGrath PA, Rafii A, Buckingham B. The validation of visual analogue scales as ratio scale measures for chronic and experimental pain. Pain. 1983;17(1):45-56.

31. Worm-Smeitink M, Gielissen M, Bloot L, et al. The assessment of fatigue: Psychometric qualities and norms for the Checklist individual strength. J Psychosom Res. 2017;98:40-46. doi:10.1016/j.jpsychores.2017.05.007

32. Fukuda K, Straus SE, Hickie I, Sharpe MC, Dobbins JG, Komaroff A. The chronic fatigue syndrome: a comprehensive approach to its definition and study. International Chronic Fatigue Syndrome Study Group. Ann Intern Med. 1994;121(12):953-959. Accessed August 30, 2018. http://www.ncbi.nlm.nih.gov/ pubmed/7978722

33. Coubert L, Eccleston C, Vervoort T, Jordan A, Crombez G. Parental catastrophizing about their child's pain. The parent version of the Pain Catastrophizing Scale (PCS-P): A preliminary validation. Pain. 2006;123(3):254-263. doi:10.1016/j. pain.2006.02.035

34. Segers EW, van den Hoogen A, van Eerden IC, Hafsteinsdóttir T, Ketelaar M. Perspectives of parents and nurses on the content validity of the Family Empowerment Scale for parents of children with a chronic condition: A mixedmethods study. Child Care Health Dev. 2019;45(1):111-120. doi:10.1111/cch.12629

35. Cohen J. Statistical Power Analysis for the Behavioural Science (2nd Edition). In: Statistical Power Anaylsis for the Behavioural Science (2nd Edition). Lawrence Erlbaum; 1988:79-80.

36. Lynch-Jordan AM, Kashikar-Zuck S, Szabova A, Goldschneider KR. The Interplay of Parent and Adolescent Catastrophizing and Its Impact on Adolescents' Pain, Functioning, and Pain Behavior. Clin J Pain. 2013;29(8):681-688. doi:10.1097/ AJP.Ob013e3182757720

37. King G, Williams L, Hahn Goldberg S. Family-oriented services in pediatric rehabilitation: a scoping review and framework to promote parent and family wellness. Child Care Health Dev. 2017;43(3):334-347. doi:10.1111/cch.12435

38. Alsem MW, Ausems F, Verhoef M, Jongmans MJ, Meily-Visser JMA, Ketelaar M. Information seeking by parents of children with physical disabilities: An exploratory qualitative study. Res Dev Disabil. 2017;60:125-134. doi:10.1016/j.ridd.2016.11.015

39. Douma M, Maurice-Stam H, Gorter B, et al. Online psychosocial group intervention for parents: Positive effects on anxiety and depression. J Pediatr Psychol. Published online 2020. doi:10.1093/jpepsy/jsaal02

40. Greenhalgh J, Gooding K, Gibbons E, et al. How do patient reported outcome measures (PROMs) support clinician-patient communication and patient care? A realist synthesis. J Patient-Reported Outcomes. 2018;2(1):42. doi:10.1186/s41687-018- 
0061-6

41. Alsem MW, Verhoef M, Braakman J, et al. Parental empowerment in paediatric rehabilitation: Exploring the role of a digital tool to help parents prepare for consultation with a physician. Child Care Health Dev. 2019;45(5):623-636. doi:10.1111/ cch. 12700

42. Peeters MAC, Hilberink SR, van Staa A. The road to independence: lived experiences of youth with chronic conditions and their parents compared. J Pediatr Rehabil Med. 2014;7(1):33-42. doi:10.3233/PRM-140272

43. Schmidt S, Petersen C, Bullinger M. Coping with chronic disease from the perspective of children and adolescents--a conceptual framework and its implications for participation. Child Care Health Dev. 2003;29(1):63-75. Accessed June 8, 2018. http://www.ncbi.nlm.nih.gov/pubmed/12534568

44. Grootenhuis MA, Bronner MB. Paediatric illness! Family matters. Acta Paediatr. 2009;98(6):940-941. doi:10.1111/j.1651-2227.2009.01321.x

45. Armbrust W, Lelieveld OHTM, Tuinstra J, et al. Fatigue in patients with Juvenile Idiopathic Arthritis: relationship to perceived health, physical health, self-efficacy, and participation. Pediatr Rheumatol. 2016;14(1):65. doi:10.1186/s12969-016-0125-1

46. Waters E, Doyle J, Wolfe R, Wright M, Wake M, Salmon L. Influence of Parental Gender and Self-Reported Health and Illness on Parent-Reported Child Health. Pediatrics. 2000;106(6):1422-1428. doi:10.1542/peds.106.6.1422 


\section{6}
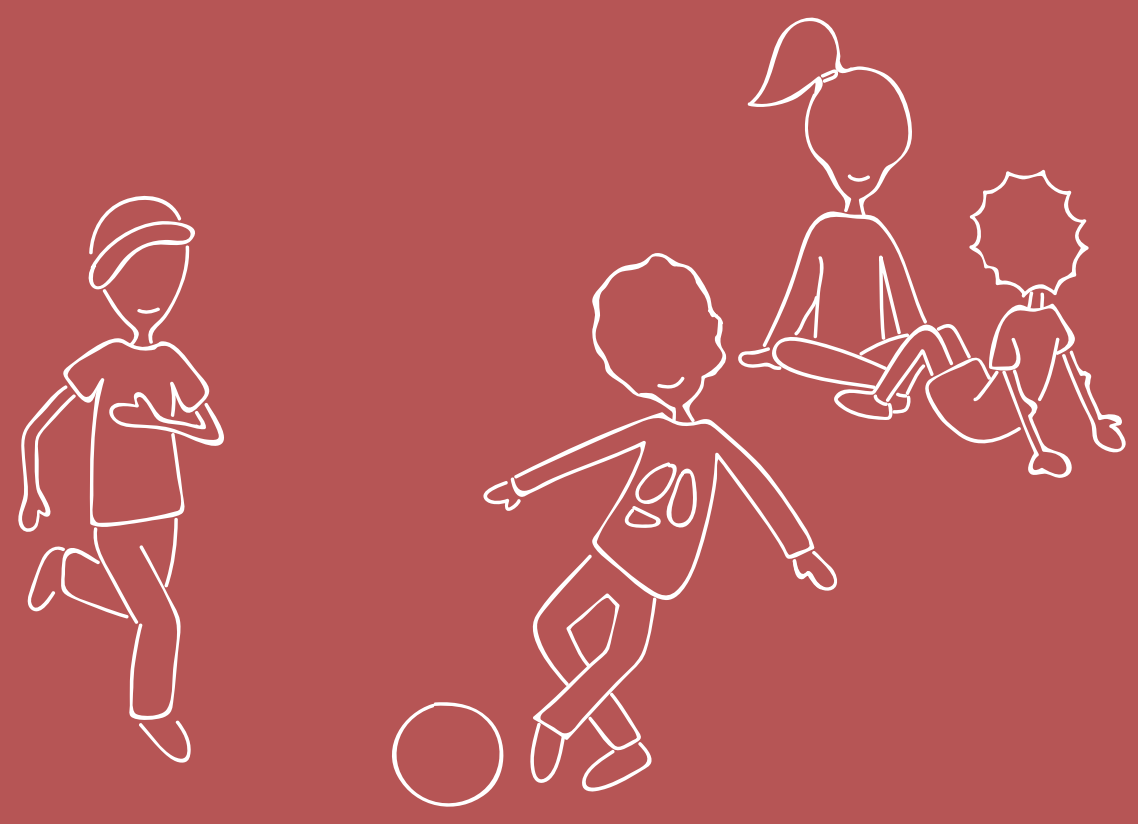


\title{
Parent-child dyadic coping and quality of life in chronically diseased children: an explorative study
}

\author{
Merel M. Nap - van der Vlist*a, \\ Reine C. van der Wal ${ }^{* b}$ \\ Eva Grosfeld ${ }^{b}$ \\ Elise M. van de Puttea, \\ Geertje W. Dalmeijerc, \\ Martha A. Grootenhuis \\ Cornelis K. van der Ente, \\ Marry M. van den Heuvel-Eibrinkd, \\ Joost F. Swart, \\ Guy Bodenmanng, \\ Catrin Finkenauer ${ }^{b}$ \\ \& Sanne L. Nijhof ${ }^{a}$
}

a Department of Paediatrics, Wilhelmina Children's Hospital, University Medical Center Utrecht, Utrecht University, Utrecht, the Netherlands

${ }^{b}$ Faculty of Social Sciences, Utrecht University, The Netherlands c Julius Center for Health Sciences and Primary Care, University Medical Center Utrecht, Utrecht University,

Utrecht, the Netherlands

a Princess Máxima Center for Paediatric Oncology, Utrecht, the Netherlands

e Department of Paediatric Pulmonology, Wilhelmina Children's Hospital, University Medical Center Utrecht, Utrecht University, Utrecht, the Netherlands

f Department of Paediatric Rheumatology/Immunology, Wilhelmina Children's Hospital, University Medical

Center Utrecht, Utrecht University, Utrecht, The Netherlands

s Department of Psychology, University of Zurich, Zurich, Switzerland

* Merel Nap - Van der Vlist and Reine van der Wal contributed equally

Submitted for publication. Frontiers in Psychology. 


\section{ABSTRACT}

Different forms of dyadic coping have repeatedly shown to be associated with positive outcomes in partner relationships, yet little is known about dyadic coping in parent-child relationships. The current research explored the association between parent-child dyadic coping and children's quality of life in children with a chronic disease (i.e., cystic fibrosis, autoimmune diseases and children post-cancer treatment). In a sample of 105 parent-child dyads, self-reported forms of dyadic coping (i.e., stress communication, problem-oriented, emotion-oriented, and negative dyadic coping) and children's quality of life were assessed. Children reported more stress communication and negative dyadic coping than their parents, while parents reported more problem-oriented dyadic coping and emotion-oriented dyadic coping than their children. More stress communication of the child was associated with more emotion-oriented dyadic coping and less negative dyadic coping of the parent. More negative dyadic coping of the child was associated with less stress communication, problem-oriented dyadic coping and emotion-oriented dyadic coping of the parent. Additionally, both children's and parents' negative dyadic coping were associated with lower self-reported paediatric quality of life and parents' emotion-oriented dyadic coping was associated with higher paediatric quality of life. These findings emphasize that children and their parents mutually influence each other and that dyadic coping is associated with children's quality of life. Theoretical and practical implications are discussed. 


\section{INTRODUCTION}

Over the last decades, treatments for childhood diseases have advanced tremendously. Although the high survival rate for these children is indisputable a positive development, it also entails that more and more children grow up with a chronic disease.' When growing up with a chronic disease, children encounter challenges not experienced by their healthy peers, including somatic aspects of the disease and psychosocial distress related to the disease. ${ }^{2-6}$ The quality of the parentchild relationship is crucial in facing these challenges ${ }^{7-10}$, as children often turn to their parents for increased support during stressful times. Yet, parents too are likely to experience extra stress, and this may impair their ability to provide adequate care for their child. In order to guide children and parents towards adaptive ways of coping with children's chronic disease, it is important that parents and children jointly cope with stress, a process that is called dyadic coping.11,12 The present study focusses on parentchild dyadic coping and quality of life in children with a chronic disease.

Dyadic coping involves the process in which two people in a relationship support each other and cope with a common stressor.11,12 It represents a relational, hence dyadic, process because one partner's coping behaviour affects the other's coping behaviour and vice versa. Although several forms of dyadic coping may mitigate the negative effects of stress, such as stress communication, problem-oriented dyadic coping, and emotion-oriented dyadic coping, it may also actually increase stress when it is negative.13 To illustrate, whereas offering emotional support in response to another person's stress (i.e., emotion-oriented dyadic coping) may reduce subsequent stress, withdrawing from it (i.e., negative dyadic coping) may actually increase a person's level of stress. Yet, it is important to note that research on dyadic coping exclusively focused on romantic relationships ${ }^{14}$, in which members have a stable equal standing relationship. The question is whether dyadic coping works differently in parent-child relationships. Most importantly, parents have the responsibility to stimulate their child's autonomy and competence, while providing safety and attachment. It is not expected from children to provide safety for their parents. Moreover, parents' higher standing, in terms of authority, responsibility, life-experience, and knowledge, and the extent to and form in which the parent-child relationship is unequal changes over time. For example, although the parent-child relationship remains unequal, children depend less on their parents when they get older, and their need for autonomy grows. Hence, in order to explore dyadic coping in parent-child relationships, it is crucial to take the child's age into account.

When families are confronted with stressful situations, such as a child's chronic disease, it is crucial to consider children's and parents' mutual influence., ${ }^{9,15}$ Indeed, when the child or one of the family members has a disease, it impacts the quality of life of all family members. ${ }^{8-10,17,18}$ This suggests that the way in which children and parents cope with a child's chronic disease is not only affected by the disease-related stress they experience themselves, but also by the stress they perceive in and from each other.

Various studies among romantic couples have demonstrated that the way and quality of couples' dyadic coping correlate with levels of psychological well-being and 
relationship quality, also for couples in which one of the partners had a disease, such as cystic fibrosis or breast cancer. 13,19,20 Studies in patients with chronic obstructive pulmonary disease or myocardial infarction and their partners have shown that some forms of dyadic coping, such as stress communication or active engagement lead to higher quality of life of the person coping with a medical condition. ${ }^{21,22}$ Also, dyadic coping plays a role in parents' individual and relational outcomes and family adjustment, for example when they face a cancer diagnosis of their child. ${ }^{23,24}$ Even so, to our knowledge, research has not examined dyadic coping in parent-child relationships, especially in light of a chronic disease.

Chronic paediatric disease offers a unique context to study the association between different forms of parent-child dyadic coping and children's quality of life. Although there is a broad range of childhood chronic diseases, the psychosocial impact of growing up with an ever-present disease shows considerable similarities across various diseases. ${ }^{25}$ For example, almost all children experience the burden of a treatment regime, restrictions in daily life activities, and stress surrounding doctor's visits. Parents may experience more parenting stress, more psychological distress, and perhaps more problems with family functioning. ${ }^{8-10,17,18}$ In the current research, we therefore investigated a broad range of childhood chronic diseases; particularly cystic fibrosis, autoimmune diseases and children who face long-term consequences after the treatment of childhood cancer.

The present study explored 1) whether and how children with a chronic disease and their parents engage in dyadic coping, and 2) how different forms of dyadic coping are associated with children's quality of life. We did not have a priori predictions whether parents and children would use different forms of dyadic coping. We did predict however 1) that less negative dyadic coping of the child would be associated with higher self-reported quality of life, and 2) that more stress-communication, problemoriented dyadic coping and emotion-oriented dyadic coping of the parent would be associated with higher quality of life of the child.

\section{METHODS}

\section{Participants}

This study used a sample of patients of the Wilhelmina Children's Hospital and the Princess Máxima Center for Paediatric Oncology in the Netherlands and one of their parents, recruited from January 2018 through November 2020. This cross-sectional data was part of the larger PROactive cohort study with annual measurements with chronically ill patients and their families. ${ }^{26}$ The goal of the larger study was to collect data on fatigue, well-being and associated factors in children with a range of paediatric chronic diseases. ${ }^{26}$ Children are included at least one year after diagnosis (CF/autoimmune disease) or after the completion of treatment for childhood cancer. This study was based on an extended follow-up assessment including children around twelve $(N=32)$, fifteen ( $N=42)$, or eighteen ( $N=31$ ) years of age and one of their parents. The study was classified by the institutional review board as exempt of the Medical Research Involving Human Subjects Act (16-707/C) and adhered to al local 
laws and the declaration of Helsinki.

For this study, 255 families were approached, of which 110 parent-child dyads participated (43.1\% participation rate). We removed five dyads in which parents did not complete the questionnaire within the same month as their child, reducing our total sample to 105 dyads. Children (60 girls; 57\%) had a mean age of 15.43 years $(S D=2.27$; range 12 to 19 years). Parents (84 mothers; $80 \%$ ) had a mean age of 47.49 years $(S D=4.92)$. In total, 19 children were from non-intact families (18\%) (i.e., long or permanent separation of the parents, divorce, or death of a parent). Twenty-seven children suffered from cystic fibrosis (CF), 58 from an autoimmune disease (e.g., Juvenile Idiopathic Arthritis (JIA), and 20 were involved in early post-cancer treatment (median follow-up time 1.9 years since diagnosis). Table 1 presents the descriptive statistics for children and parents. Notably, we did not find any significant differences in participating and non-participating children's sex or disease group, except for children's age. Non-participants were slightly older than participants (Mean $=15.98$ versus Mean $=15.35$ years old respectively, $p=.03$ )

\section{Procedure}

Before an outpatient visit, the researchers approached families via email to take part in the study. If they agreed to participate, formal informed consent was obtained from children and one parent. They then completed the questionnaires via a webbased tool (www.hetklikt.nu) separately from each other. All participants received - if necessary - one reminder to participate in the study via email and one via telephone. A research team was available to answer questions via email and telephone.

\section{Measures - Dyadic coping}

To explore the concept of parent-child dyadic coping, we measured different forms of dyadic coping with five items from the Dyadic Coping Inventory, which originally contains 37 items. ${ }^{27}$ Children and parents were asked how they generally respond to stressful situations. We adapted the items for the parent-child relationship, which covered four sub dimensions of dyadic coping (Supplementary Table S1): 1) stress communication; "I show my father/mother/child when I am not doing well or when I have problems", and "I tell my father/mother/child openly how I feel and that I need his/her support", 2) problem-oriented dyadic coping; "When my father/mother/child is stressed out, I give him/her good advice or practical help", 3) emotion-oriented dyadic coping; "I listen to my father/mother/child so that he/she can tell what really bothers him/her", and 4) negative dyadic coping; "When my father/mother/child is stressed, I tend to withdraw". All items were measured on a scale from 1 (very rarely) to 5 (very often). The two stress communication items correlated strongly with each other ( $r=.70$ for children, and $r=.65$ for parents), we therefore took the mean of these two items as indicator of stress communication.

\section{Measures - Quality of Life}

Children reported on their own quality of life with the validated Paediatric Quality of Life Ceneric Core Scale 4.0 (PedsQL CCS) consisting of 23 items measured on a scale from 0 (never a problem) to 4 (almost always a problem). ${ }^{28}$ The PedsQL CCS covers the domains physical functioning, emotional functioning, social functioning, and school 
functioning. Only the total score was used. Example items were "It is hard for me to do sports activity or exercise" and "It is hard to keep up with my peers". Answers were reverse-coded to a scale from 0-100, such that higher scores indicated a higher quality of life. Cronbach's a of all items for the total-score was 83.

\section{Measures - Clinical characteristics}

In order to characterize our sample, we gathered information regarding the time elapsed between diagnosis and assessment, and disease activity at assessment from the child's medical record. Disease-specific characteristics were not included in the analyses but used to describe that this was a sample in which the disease activity was generally low or absent (Table 3). In CF, disease activity was measured using forced expiratory volume in one second $\left(F E V_{1}\right)$, expressed as percentage of predicted $\mathrm{FEV}_{1}{ }^{29}$ For JIA, the validated clinical Juvenile Arthritis Disease Activity Score (cJADAS) and erythrocyte sedimentation rate (ESR) were used as a proxy for disease status; for participants with other autoimmune diseases, ESR was used. ${ }^{30}$ All children post-cancer treatment finished their treatment protocols and were in complete remission.

\section{Statistical analyses}

We conducted our analyses in RStudio (RStudio Team, 2019). We first explored mean differences between parents and children on their dyadic coping responses by conducting paired t-tests. We additionally explored the effects of the age of the child on parent-child dyadic coping, by conducting a one-way MANOVA analysis with age group as fixed factor and the dyadic coping responses as dependent variables. To address the question whether and how different forms of dyadic coping were associated with children's quality of life we conducted Spearman correlations, since some of the study variables (i.e., children's problem-oriented dyadic coping and quality of life, and parents' stress communication, problem-oriented dyadic coping, and negative dyadic coping) were non-normally distributed. In the supplement (Table S2), we reported the correlation analyses controlling for children's age. Although the small sample sizes of the subgroups did not allow us to draw firm conclusions, we also explored whether family status (non-intact versus intact), family role (father or mother), and disease group revealed different dyadic coping responses. We therefore conducted a one-way full factorial MANOVA analysis with the sub-groups as fixed factors and the dyadic coping responses as dependent variables.

\begin{tabular}{|c|c|c|}
\hline & Children $(n=105)$ & Parents $(n=105)$ \\
\hline Age in years (mean $\pm S D$ ) & $15.43 \pm 2.27$ & $47.49 \pm 4.92$ \\
\hline Sex* (n, percentage) & $60(57 \%)$ & $84(80 \%)$ \\
\hline Non-intact families ( $n$, percentage) & $19(18 \%)$ & $19(18 \%)$ \\
\hline
\end{tabular}

Notes. *Only one of the parents completed the questionnaires 


\begin{tabular}{|c|c|c|c|}
\hline & Cystic fibrosis $(n=27)$ & Autoimmune disease $(n=58)$ & Post-cancer treatment $(n=20)$ \\
\hline Diagnosis & $\begin{array}{l}16(59 \%) \text { homozygote } \\
\text { dF508 } \\
10(37 \%) \text { heterozygote } \\
\text { dF508 } \\
1(4 \%) \text { other }\end{array}$ & $\begin{array}{l}11(19 \%) \text { poly-articular JIA } \\
24(43 \%) \text { oligo-articular JIA } \\
3(7 \%) \text { systemic JIA } \\
6(10 \%) \text { other form of JIA } \\
8(10 \%) \text { immunodeficiency } \\
3(2 \%) \text { auto-inflammatory } \\
\text { condition } \\
3(10 \%) \text { systemic auto- } \\
\text { immune disease }\end{array}$ & $\begin{array}{l}10(43 \%) \text { solid tumours } \\
9(43 \%) \text { leukaemia/lymphoma } \\
1(14 \%) \text { brain tumour }\end{array}$ \\
\hline Disease duration* & $16.0 \pm 2.3$ & $8.5 \pm 3.9$ & $1.9 \pm 0.8$ \\
\hline Disease activity & $\begin{array}{l}\text { FEV, \%: } \\
80.9 \pm 18.1\end{array}$ & $\begin{array}{l}\text { CJADAS: } 0(0-4)(n=43) \\
\text { ESR: } 2 \mathrm{~mm} / \mathrm{lst} \mathrm{hr}(2-5)(n= \\
\text { 50) }\end{array}$ & All post-treatment \\
\hline
\end{tabular}

Notes. JIA = juvenile idiopathic arthritis; cJADAS = clinical Juvenile Arthritis Disease Activity Score; ESR = erythrocyte sedimentation rate; $F E V_{1} \%$ = predicted percentage of forced expiratory volume in one second. *Disease duration: years since diagnosis until inclusion for children with JIA; years from end of treatment until inclusion for children post-cancer treatment. If the data were normally distributed, the mean $\pm S D$ are given; if not, the median and interquartile range (IQR) are given.

\section{RESULTS}

\section{Mean scores of dyadic coping for parents and children}

As shown in Table 3, children reported significantly more stress communication and negative dyadic coping than their parents, while parents reported significantly more problem-oriented dyadic coping and emotion-oriented dyadic coping than their children. Moreover, there was a statistically significant difference in dyadic coping responses by children depending on the age group of the child, $F(16,190)=1.70, p=$ .050; Wilk's $\Lambda=0.766$, partial $\eta^{2}=.13$. Specifically, as can be seen in Table 4, 12-year old children reported significantly higher levels of stress communication than 15-year and 18-year old children.

\section{Correlations between parents' and children's dyadic coping and children's quality of life}

As can be seen in Table 5, within the child sample, stress communication, problemoriented dyadic coping and emotion-oriented dyadic coping were positively associated with each other, and negatively to negative dyadic coping. This suggests that different forms of dyadic coping may reinforce each other and mitigate negative dyadic coping. The same was true for the parent sample, although the effects were less strong.

Moreover, children's dyadic coping was associated with their parents' dyadic coping in several ways. Specifically, more stress communication of the child was associated with more emotion-oriented dyadic coping and less negative dyadic coping of the parent. More negative dyadic coping of the child was associated with less stress communication, less problem-oriented dyadic coping, and less emotion-oriented dyadic coping of the parent. More problem-oriented dyadic coping of the child was associated with more emotion-oriented dyadic coping of the parent. 
The form in which parents and children with a chronic disease dyadically coped was associated with children's quality of life. In particular, both children's and parents' negative dyadic coping were associated with a lower self-reported quality of life of the children. Parents' emotion-oriented dyadic coping was also associated with a higher quality of life of children.

Importantly, controlling for children's age did not essentially change the pattern of results. That is, the different forms of dyadic coping by parents and children were still associated with each other in the same way, albeit a bit weaker. Most importantly, children's and parents' negative dyadic coping were still associated with lower quality of life, whereas parents' emotion-oriented dyadic coping was still associated with higher quality of life for children (see Table S2).

\section{Differences in dyadic coping between subgroups}

The one-way MANOVA did not reveal significant main effects of family situation, family role, or disease group, nor did it reveal any interaction effects, all $F$ 's $<1.55$, and p's $>.15$. See Table 6 for an overview of the means and standard deviations per sub-group.

\section{Table 3. Means and standard deviations of main study variables in the overall sample}

\begin{tabular}{|c|c|c|c|c|c|c|c|}
\hline & \multicolumn{2}{|l|}{ Child } & \multicolumn{2}{|c|}{ Parent } & \multirow[t]{2}{*}{$\mathrm{t}$} & \multirow[t]{2}{*}{ df } & \multirow[t]{2}{*}{$\mathrm{p}$} \\
\hline & M & SD & M & SD & & & \\
\hline 1. Stress communication & 3.94 & 0.81 & 2.98 & 0.71 & -9.279 & 104 & $<.001$ \\
\hline $\begin{array}{l}\text { 2. Problem-oriented dyadic } \\
\text { coping }\end{array}$ & 3.39 & 0.84 & 3.99 & 0.69 & 5.743 & 104 & $<.001$ \\
\hline $\begin{array}{l}\text { 3. Emotion-oriented dyadic } \\
\text { coping }\end{array}$ & 4.03 & 0.77 & 4.24 & 0.56 & 2.427 & 104 & .017 \\
\hline 4. Negative dyadic coping & 2.56 & 1.10 & 1.90 & 0.87 & -4.934 & 104 & $<.001$ \\
\hline 5. Quality of life & 77.87 & 16.14 & & & & & \\
\hline
\end{tabular}

Notes. $n=105$ parent-child dyads. The dyadic coping items are scored on a scale from 1 (very rarely) to 5 (very often). Quality of life was scored with the total score of the PedsQL CCS on a scale from 0-100, with a higher score indicating higher quality of life. $M=$ Mean; SD = standard deviation. 


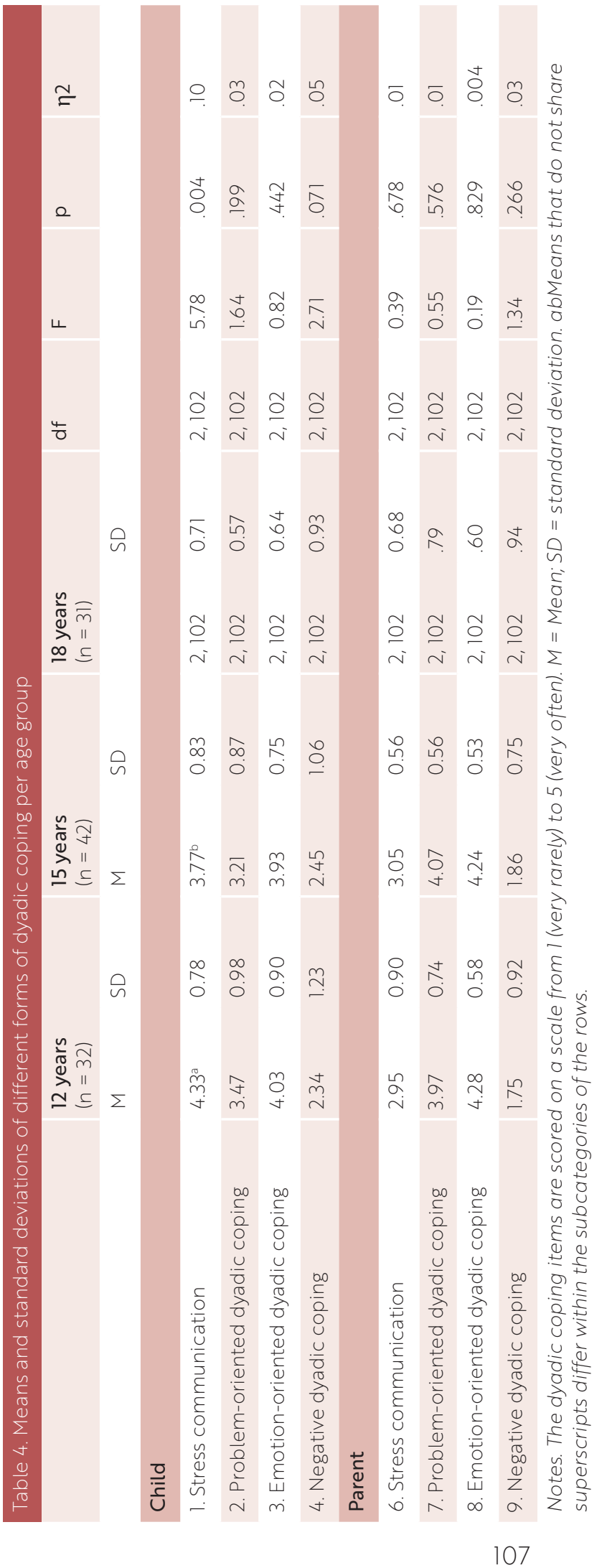




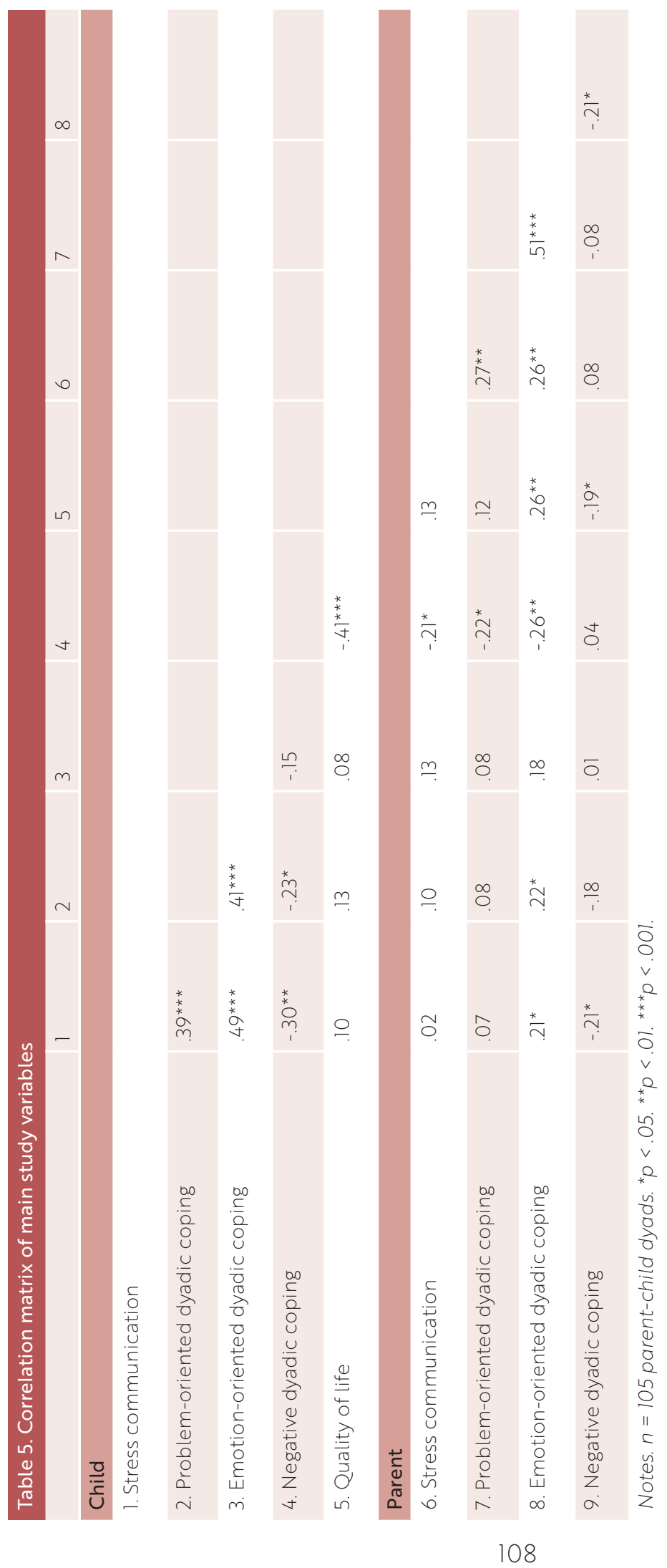




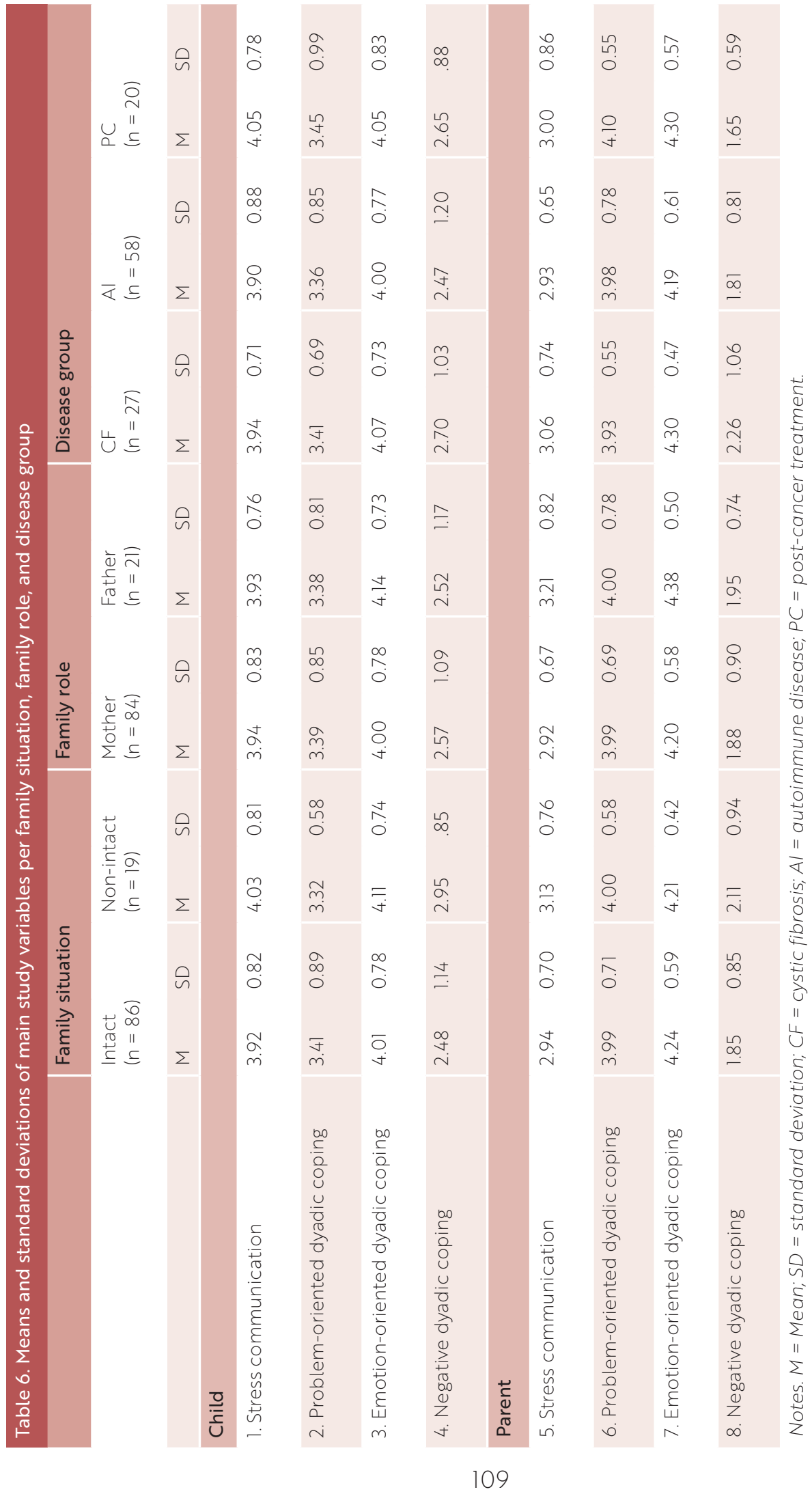



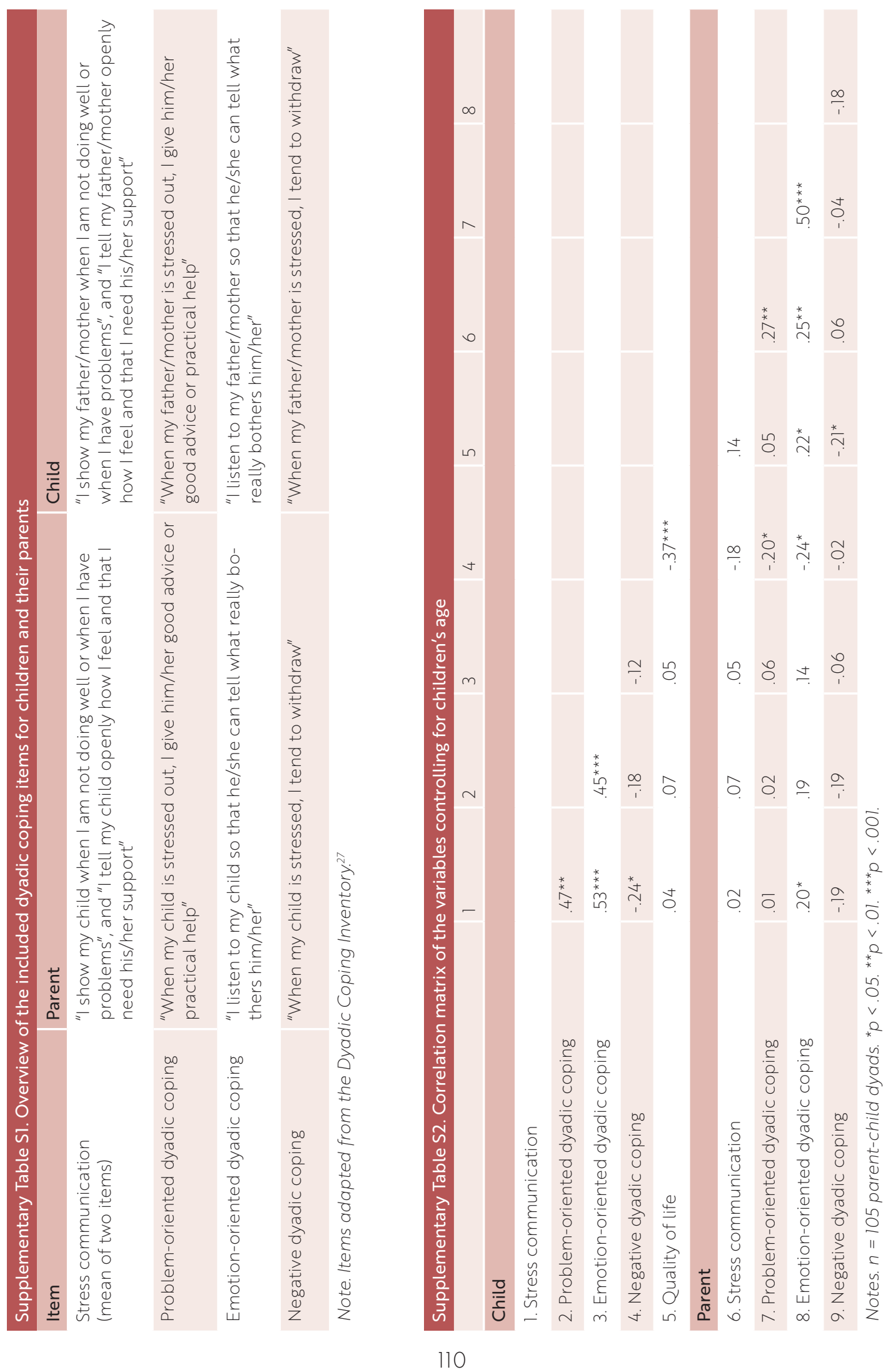


\section{DISCUSSION}

The current research is the first to our knowledge to explore dyadic coping in parentchild relationships and its association with children's quality of life in a population of children with a chronic disease. Children reported more stress communication and negative dyadic coping than their parents, while parents reported more problemoriented dyadic coping and emotion-oriented dyadic coping than their children. More stress communication of the child was associated with more emotion-oriented dyadic coping and less negative dyadic coping of the parent. More negative dyadic coping of the child was associated with less stress communication, problem-oriented dyadic coping and emotion-oriented dyadic coping of the parent. As expected, parents' emotion-oriented dyadic coping (i.e., showing emotional interest and empathy, caring) and parents' negative dyadic coping (i.e., withdrawing and avoiding from the child's stress) were associated with respectively higher and lower paediatric quality of life, while the child's own dyadic coping was not related to their quality of life, except for their own negative dyadic coping that yielded a relatively strong negative association. The more they engage in negative dyadic coping the lower their quality of life, reflecting that either this negativity towards their parents diminishes their own well-being or their negative dyadic coping mirrors a healthy adolescent behaviour to withdraw when parents overburden them with their stress. Latter explanation seems more convincing as the means of stress communication, problem-oriented dyadic coping, and emotion-oriented dyadic coping show a relatively normal level of engagement in dyadic stress management.31 It is also noteworthy that children with a chronic illness reported high scores in own stress communication towards their parents (while those on the other hand scored noticeably lower, probably in order not to burden their child or by respecting generational borders) that speaks for a certain openness towards their parents. This yields an interesting picture. On the one hand they talk about their stress to their parents, feel better (higher quality of life) when they receive emotional supportive dyadic coping and at the same time engage in more negative dyadic coping. Apparently, this pattern is linked to age. The older the children (in the phase of adolescence) the less they express their stress to their parents and the more they engage in negative dyadic coping, possibly standing for a search of autonomy. Possibly, parents may react on this delimitation of the child by suppressing their own stress communication, problem- and emotion-oriented dyadic coping. Overall, these findings may reflect how children and their parents try to find a balance between stress communication and dyadic coping on the one hand and autonomy on the other hand.

A first important contribution of the present study is its focus on dyadic coping specifically in (a) parent-child relationships and (b) dyadic coping processes in the context of a chronic illness and (c) these processes embedded in the phase of adolescence. In previous studies, dyadic coping was generally investigated in romantic adolescent or adult relationships and has not considered parent-child relationships.14,32-34 Albeit, general dyadic processes, but not dyadic coping, have been studied in parent-child relationships. For example, the effect of parental and paediatric behaviour, such as how parents and children talk to one another, on paediatric outcomes has been studied. ${ }^{35,36}$ Extending these findings, our results 
suggest that especially children's and parents' negative dyadic coping (i.e., responding with avoidance or withdrawal to a child's or parent's stress) and parents' emotionoriented dyadic coping (i.e., responding with emotional support to a child's stress) are important indicators for a child's quality of life. These findings correspond with other studies showing the negative outcomes and ineffectiveness of avoidant coping strategies in response to stress, ${ }^{37}$ and the positive effects of an open climate in the family. ${ }^{38-40}$ At the same time, and most importantly, these findings highlight that the way in which children with a chronic disease and their parents cope with stress is not only affected by the stress they experience themselves, but also by the stress of the other, the context (adolescence) and the generational affiliation. Despite this complex framework (chronic illness, parent-child, adolescence), dyadic coping proved to be an important variable for child's quality of life. This is an important, novel and promising finding, which opens up a new field of research for psychologists, medical scientists and nursing staff or general caregivers. It implies that in order to understand factors and processes associated with children's quality of life, we need to consider the social context in which children grow up.

Another theoretically novel and practically useful insight emerging from our study is that parent-child dyadic coping is associated with higher quality of life of children suffering from a chronic disease. Our results suggest that especially children's negative dyadic coping may be an important target of interventions aiming to help children with a chronic disease. For doing so, we need a deeper understanding of the meaning of negative dyadic coping in children. Is it a sign of autonomy and demarcation towards their parents, a lack of appropriate capabilities, or a whim of adolescence?

Many coping interventions promote the parent-child relationship, by helping both parents and children to communicate with one another about stressors related to the disease. 41,42 A specific focus on reducing negative forms of dyadic coping might improve the effectiveness of interventions. Further research may shed more light on how parents and children apply negative dyadic coping in their home situation, for example using an emotional map of the home. ${ }^{43}$ Additionally, studies investigating whether and how to target negative dyadic coping in interventions are of interest. Our results provide empirical support for such a focus in a context of paediatric chronic disease.

\section{Limitations}

The objective of this study was to highlight that parent-child dyadic coping can have an effect on the child's well-being in the context of chronic paediatric disease. An important starting point for future research is to develop and validate a new dyadic coping questionnaire or to adapt the Dyadic Coping Inventory (DCl) assessing coping processes among parents and children. Such a questionnaire is required to examine dyadic associations in which children's and parents' dyadic coping may influence both children's and parents' quality of life or other outcomes relevant to families coping with and adjusting to disease (i.e., dyadic data analysis). A limitation of this study is that we used a limited number of selected items of a pre-existing questionnaire, validated in the context of close relationships. Another limitation concerns the fact that the $\mathrm{DCl}$ is designed to assess dyadic coping in everyday life and not specifically in the 
context of chronic disease. The DCl asks how children and parents deal with common stressors, of which the disease is one, but of course the DCI measures stressors broader than the disease alone. Nevertheless, as parents and children with a chronic disease encounters extra stressors compared to healthy parent-child dyads, supporting them in dyadic coping is still of interest.

Another limitation relates to the statistical analyses that were merely of exploratory nature. Longitudinal data would be necessary to illuminate directionality of the associations between parent-child dyadic coping and children's quality of life. Additional research might also tap into underlying mechanisms that help explain the association between parent-child dyadic coping and children's quality of life. As it was shown that protective buffering in parent-child dyads was associated with reduced authenticity, one possibility is that parents' and children's negative dyadic coping may also be associated with reduced feelings of authenticity, which in turn may hamper children's quality of life. ${ }^{44}$ Last, perceptions of the other person's dyadic coping may affect children's and parents' outcomes to a greater extent than one's own dyadic coping. As the parent-child relationship is by default an unequal relationship, parents and children may differ in their perceptions of each other's behaviour. To illustrate, the way in which children perceive their parent is responding to their stress (for example, by withdrawing) may not correspond to the way in which parents themselves think they are coping with the stress of their child. Therefore, it might be important in a next study to use the complete DCl that allows to compare the different appraisals of dyadic coping by the various protagonists. Indeed, research shows that the support given by one dyad member is not always seen as positive support by the other dyad member ${ }^{45}$ and that equity in the contributions matter particularly. ${ }^{46}$ These are important avenues for future studies.

\section{CONCLUSION}

In conclusion, our findings add to the small body of work on dyadic processes in parent-child relationships, and in particular in the context of a child's chronic disease. The results highlight that children and their parents mutually influence each other and that both parents' and children's negative dyadic coping was associated with lower self-reported paediatric quality of life and parents' emotion-oriented dyadic coping was associated with higher paediatric quality of life, although the correlational nature of the data prohibit causal inferences. It provides further impetus for studies aimed at understanding and promoting adaptive dyadic coping of parents and children facing stress. Helping children and their parents to jointly deal with stressful situations, such as children's chronic disease, may not only benefit the child's quality of life but improved parent-child dyadic coping may also empower children and lead to increased functioning and may also improve the parent's quality of life. The extent to which parent-child dyadic coping affect children's functioning is an intriguing and (yet) unanswered question. We hope that the current findings offer a springboard to further explore the role of parent-child dyadic coping in children with a chronic disease. 


\section{REFERENCES}

1. Verwey-Jonker Instituut. Een Actueel Perspectief Op Kinderen En Jongeren Met Een Chronische Aandoening in Nederland.; 2019.

2. Pinquart $M$, Shen $Y$. Depressive symptoms in children and adolescents with chronic physical illness: An updated meta-analysis. J Pediatr Psychol. 2011;36(4):375-384. doi:10.1093/jpepsy/jsq104

3. Pinquart M, Shen Y. Behavior problems in children and adolescents with chronic physical illness: A meta-analysis. J Pediatr Psychol. 2011;36(9):1003-1016. doi:10.1093/ jpepsy/jsrO42

4. Pinquart M, Shen Y. Depressive symptoms in children and adolescents with chronic physical illness: An updated meta-analysis. J Pediatr Psychol. 2011;36(4):375-384. doi:10.1093/jpepsy/jsq104

5. Maurice-Stam H, Nijhof SL, Monninkhof AS, Heymans HSA, Grootenhuis MA. Review about the impact of growing up with a chronic disease showed delays achieving psychosocial milestones. Acta Paediatr. Published online August 27, 2019:apa.14918. doi:10.1111/apa.14918

6. Perrin JM, Bloom SR, Gortmaker SL. The Increase of Childhood Chronic Conditions in the United States. JAMA. 2007;297(24):2755. doi:10.1001/jama.297.24.2755

7. Cousino MK, Hazen RA. Parenting stress among caregivers of children with chronic illness: A systematic review. J Pediatr Psychol. 2013;38(8):809-828. doi:10.1093/ jpepsy/jst0 49

8. Logan DE, Scharff L. Relationships between family and parent characteristics and functional abilities in children with recurrent pain syndromes: an investigation of moderating effects on the pathway from pain to disability. J Pediatr Psychol. 2005;30(8):698-707. doi:10.1093/jpepsy/jsj060

9. Palermo TM, Valrie CR, Karlson CW. Family and parent influences on pediatric chronic pain: a developmental perspective. Am Psychol. 2014;69(2):142-152. doi:10.1037/a0035216

10. Pinquart M. Do the Parent-Child Relationship and Parenting Behaviors Differ Between Families With a Child With and Without Chronic Illness? A Meta-Analysis. J Pediatr Psychol. 2013;38(7):708-721. doi:10.1093/jpepsy/jst020

11. Bodenmann C. Dyadic coping: A systematic-transactional view of stress and coping among couples: Theory and empirical findings. Eur Rev Appl Psychol. 1997;47:137140.

12. Bodenmann G. Dyadic Coping and Its Significance for Marital Functioning. In: Couples Coping with Stress: Emerging Perspectives on Dyadic Coping. American Psychological Association; 2005:33-49. doi:10.1037/11031-002

13. Falconier MK, Kuhn R. Dyadic coping in couples: A conceptual integration and a review of the empirical literature. Front Psychol. 2019;10(MAR). doi:10.3389/ fpsyg.2019.00571

14. Falconier MK, Jackson JB, Hilpert P, Bodenmann G. Dyadic coping and relationship 
satisfaction: A meta-analysis. Clin Psychol Rev. 2015;42:28-46. doi:10.1016/j. cpr.2015.07.002

15. Berg C, Skinner M, Ko K, et al. The Fit Between Stress Appraisal and Dyadic Coping in Understanding Perceived Coping Effectiveness for Adolescents With Type 1 Diabetes. J Fam Psychol. 2009;23(4). doi:10.1037/A0015556

16. Minuchin P. Families and Individual Development: Provocations from the Field of Family Therapy Author ( $\mathrm{s}$ ): Patricia Minuchin Published by: Wiley on behalf of the Society for Research in Child Development Stable URL : http://www.jstor.org/ stable/1129720 REFERENCES. Child Dev. 1985;56(2):289-302. doi:10.1002/pen.21025

17. Leeman J, Crandell JL, Lee A, Bai J, Sandelowski M, Knafl K. Family Functioning and the Well-Being of Children With Chronic Conditions: A Meta-Analysis. Res Nurs Health. 2016;39(4):229-243. doi:10.1002/nur.21725

18. Cousino MK, Hazen RA. Parenting stress among caregivers of children with chronic illness: A systematic review. J Pediatr Psychol. 2013;38(8):809-828. doi:10.1093/ jpepsy/jst0 49

19. Werner S, Hochman Y, Rosenne H, Kurtz S. Cooperation or Tension? Dyadic Coping in Cystic Fibrosis. Fam Process. Published online April 15, 2020. doi:10.1111/ famp.12538

20. Rottmann N, Hansen DG, Larsen PV, et al. Dyadic coping within couples dealing with breast cancer: A longitudinal, population-based study. Heal Psychol. 2015:34(5):486-495. doi:10.1037/hea0000218

21. Joekes K, Maes S, Warrens M. Predicting quality of life and self-management from dyadic support and overprotection after myocardial infarction. Br J Health Psychol. 2007;12(Pt 4). doi:10.1348/135910706×118585

22. Vaske I, Thöne M, Kühl K, et al. For better or for worse: a longitudinal study on dyadic coping and quality of life among couples with a partner suffering from COPD. J Behav Med. 2015;38(6). doi:10.1007/S10865-015-9657-Y

23. Schoors M Van, Loeys T, Goubert L, et al. Couples dealing with pediatric blood cancer: A study on the role of dyadic coping. Front Psychol. 2019;10(FEB):402. doi:10.3389/fpsyg.2019.00402

24. Van Schoors M, De Paepe AL, Norga K, et al. Family members dealing with childhood cancer: A study on the role of family functioning and cancer appraisal. Front Psychol. 2019;10(JUN). doi:10.3389/fpsyg.2019.01405

25. Stein REK, Jessop DJ. What diagnosis does not tell: The case for a noncategorical approach to chronic illness in childhood. Soc Sci Med. 1989;29(6):769-778. doi:10.1016/0277-9536(89)90157-3

26. Nap-van der Vlist MM, Dalmeijer CW, Grootenhuis MA, et al. Fatigue in childhood chronic disease. Arch Dis Child. Published online June 7, 2019:archdischild-2019-316782. doi:10.1136/archdischild-2019-316782

27. Bodenmann G. Dyadisches Coping Inventar: DCl; Manual.; 2008. Accessed February 25, 2021. https://scholar.google.com/scholar_lookup?title=Dyadisches Coping Inventar\%3A Testmanual\&author=C. Bodenmann\&publication_year=2008 
28. Engelen V, Haentjens MM, Detmar SB, Koopman HM, Grootenhuis MA. Health related quality of life of Dutch children: psychometric properties of the PedsQL in the Netherlands. BMC Pediatr. 2009;9(1):68. doi:10.1186/1471-2431-9-68

29. Quanjer PH, Stanojevic S, Cole TJ, et al. Multi-ethnic reference values for spirometry for the 3-95-yr age range: the global lung function 2012 equations. Eur Respir J. 2012;40(6):1324-1343. doi:10.1183/09031936.00080312

30. McErlane F, Foster HE, Carrasco R, et al. Trends in paediatric rheumatology referral times and disease activity indices over a ten-year period among children and young people with Juvenile Idiopathic Arthritis: results from the childhood arthritis prospective Study. Rheumatology (Oxford). 2016;55(7):1225-1234. doi:10.1093/ rheumatology/kew021

31. Ledermann T, Bodenmann G, Gagliardi S, et al. Psychometrics of the Dyadic Coping Inventory in Three Language Groups. Swiss J Psychol. 2010;69(4):201-212. doi:10.1024/1421-0185/a000024

32. Van Schoors M, De Paepe AL, Lemiere J, et al. Family Adjustment When Facing Paediatric Cancer: The Role of Parental Psychological Flexibility, Dyadic Coping, and Network Support. Front Psychol. 2019;10. doi:10.3389/fpsyg.2019.02740

33. Breitenstein CJ, Milek A, Nussbeck FW, Davila J, Bodenmann C. Stress, dyadic coping, and relationship satisfaction in late adolescent couples. J Soc Pers Relat. 2018;35(5):770-790. doi:10.1177/0265407517698049

34. Bodenmann G, Falconier MK, Randall AK. Editorial: Dyadic Coping. Front Psychol. 2019;10. doi:10.3389/FPSYG.2019.01498

35. Birnie K, Chambers C, Chorney J, Fernandez C, McGrath P. Dyadic Analysis of Child and Parent Trait and State Pain Catastrophizing in the Process of Children's Pain Communication. Pain. 2016;157(4). doi:10.1097/J.PAIN.0000000000000461

36. Neville A, Griep Y, Palermo T, et al. A ";Dyadic Dance"..: Pain Catastrophizing Moderates the Daily Relationships Between Parent Mood and Protective Responses and Child Chronic Pain. Pain. 2020;161(5). doi:10.1097/J.PAIN.0000000000001799

37. Compas BE, Jaser SS, Dunn MJ, Rodriguez EM. Coping with chronic illness in childhood and adolescence. Annu Rev Clin Psychol. 2012;8:455-480. doi:10.1146/ annurev-clinpsy-032511-143108

38. Lutz W, Hock E, Kang M. Children's Communication About Distressing Events: The Role of Emotional Openness and Psychological Attributes of Family Members. Am J Orthopsychiatry. 2007;77(1). doi:10.1037/0002-9432.77.1.86

39. Meriggi F, Andreis F, Liborio N, et al. Parents With Cancer: Searching for the Right Balance Between Telling the Truth and Protecting Children. Palliat Support Care. 2017;15(1). doi:10.1017/S1478951516000444

40. Niemi P. Family Interaction Patterns and the Development of Social Conceptions in the Adolescent. J Youth Adolesc. 1988;17(5). doi:10.1007/BF01537884

41. Douma M, Maurice-Stam H, Gorter B, et al. Online psychosocial group intervention for parents: Positive effects on anxiety and depression. J Pediatr Psychol. Published online 2020. doi:10.1093/jpepsy/jsaal02 
42. Scholten L, Willemen AM, Last BF, et al. Efficacy of psychosocial group intervention for children with chronic illness and their parents. Pediatrics. 2013;131(4):el196-203. doi:10.1542/peds.2012-2222

43. Sallay V, Martos T, Chatfield SL, Dúll A. Strategies of Dyadic Coping and SelfRegulation in the Family Homes of Chronically Ill Persons: A Qualitative Research Study Using the Emotional Map of the Home Interview Method. Front Psychol. 2019;10:403. doi:10.3389/fpsyg.2019.00403

44. van der Wal R, Grosfeld E, Nap-van der Vlist M, Nijhof S, Finkenauer C. The Paradoxical Power of Protecting: How Protective Buffering Harms Post-Divorce Adjustment in Parent-Adolescent Relationships. Submitted.

45. Fales JL, Essner BS, Harris MA, Palermo TM. When Helping Hurts: Miscarried Helping in Families of Youth With Chronic Pain. J Pediatr Psychol. 2014;39(4):427-437. doi:10.1093/jpepsy/jsu003

46. Meier F, Milek A, Rauch-Anderegg V, et al. Fair enough? Decreased equity of dyadic coping across the transition to parenthood associated with depression of first-time parents. PLoS One. 2020;15(2):e0227342. doi:10.1371/journal.pone.0227342 


\section{Part II \\ The consequence of a chronic disease on daily life participation}

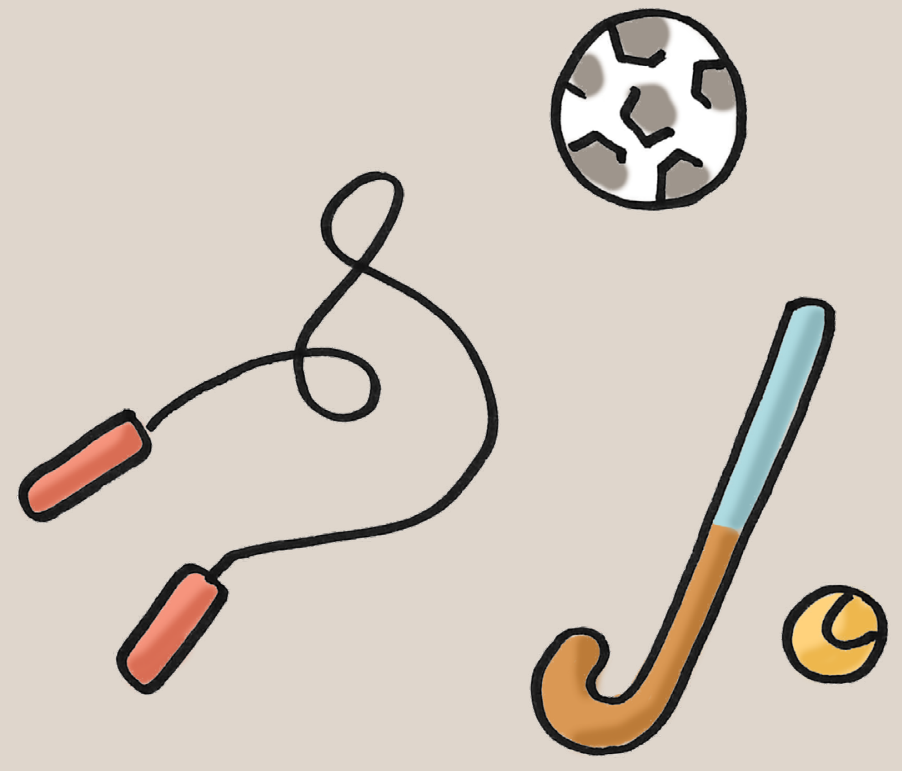



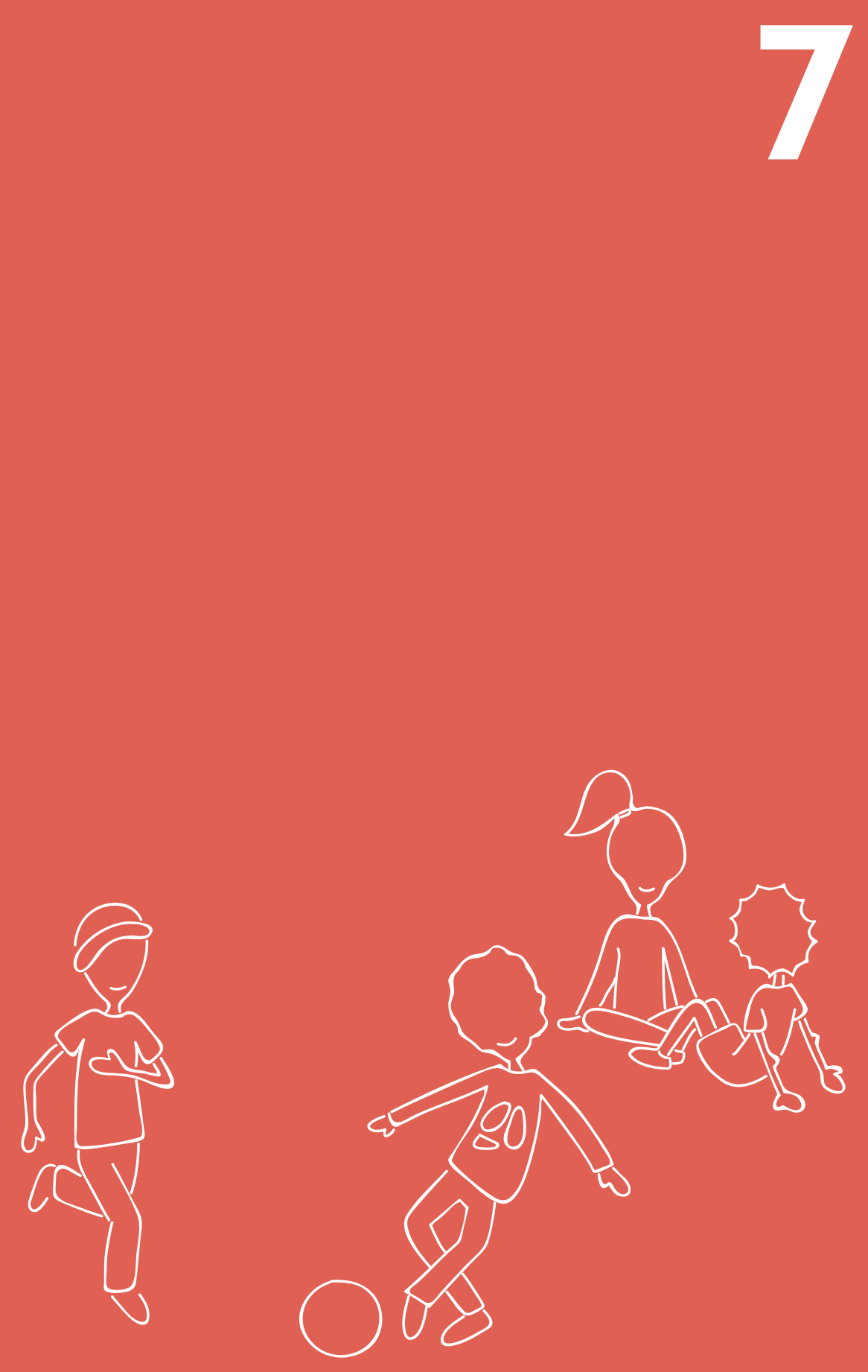


\title{
Daily life participation in childhood chronic disease: a qualitative study
}

\author{
Merel M. Nap-van der Vlist MSca, \\ Marijke C. Kars PhD \\ Emma E. Berkelbach van der Sprenkel MSca, \\ Linde N. Nijhof MSca, \\ Martha A. Grootenhuis $\mathrm{PhD}^{\mathrm{c}}$ \\ Stefan M. van Geelen PhDd, \\ Cornelis K. van der Ent PhDe, \\ Joost F. Swart PhD, \\ Annet van Royen-Kerkhof PhD', \\ Martine van Grotel PhD', \\ Elise M. van de Putte PhDa, \\ Sanne L. Nijhof PhDa.
}

a Department of Paediatrics, Wilhelmina Children's Hospital, University Medical Center Utrecht, Utrecht University, Utrecht, the Netherlands

b Julius Centre for Health Sciences and Primary Care, University Medical Center Utrecht, Utrecht University,

Utrecht, the Netherlands

c Princess Máxima Centre for Paediatric Oncology, Utrecht, the Netherlands d Education Centre, University Medical Centre Utrecht, Utrecht University, Utrecht, the Netherlands e Department of Paediatric Pulmonology, Wilhelmina Children's Hospital, University Medical Centre Utrecht, Utrecht University, Utrecht, the Netherlands

f Department of Paediatric Rheumatology/Immunology, Wilhelmina Children's Hospital, University Medical Centre Utrecht, Utrecht University, Utrecht, The Netherlands 


\section{ABSTRACT}

\section{Objective:}

Opportunities to participate in daily life have improved considerably for children with chronic disease. Nevertheless, they still face challenges associated with their ever-present illness affecting every aspect of their lives. To best help these children, we aimed to assess the child's own perspective on participation and the main considerations that affect participation in a stable phase of disease.

\section{Methods:}

Qualitative design. Semi-structured, in-depth interviews were conducted, and analysed by a general inductive approach using constant comparison, coding and categorization. Children 8-18 years old with a chronic disease were recruited from a cohort study involving cystic fibrosis, autoimmune disease, and post-treatment paediatric cancer.

\section{Results:}

31 of the 56 (54\%) invited patients participated. From the perspective of children with chronic disease, participation is considered more than merely engaging in activities; rather, they view having a sense of belonging, the ability to affect social interactions, and the capacity to keep up with peers as key elements of full participation. Some children typically placed a higher priority on participation, whereas other children typically placed a higher priority on their current and/or future needs, both weighing the costs and benefits of their choices and using disclosure as a strategy.

\section{Conclusions:}

Enabling full participation from the child's perspective will help realize patientcentred care, ultimately helping children self-manage their participation. Caregivers can stimulate this participation by evaluating with children how to achieve a sense of belonging, active involvement, and a role within a peer group. This requires active collaboration between children, healthcare providers, and caregivers. 


\section{INTRODUCTION}

Participation in daily life plays an important role in a child's development and helps facilitate a healthy transition into adulthood.' Participation was defined by the World Health Organization as "involvement in a life situation", such as engaging in social interactions or take on a role in sports or academia. ${ }^{8}$ This participation is vital to a child's well-being; a lack of participation can place a burden on both children and their family, with significant societal costs. Although the opportunities to participate have increased considerably in recent decades for children with chronic diseases, they still face challenges associated with an ever-present illness that affects nearly every aspect of their lives, including their ability and/or readiness to participate..$^{3-7}$

Understanding a child's own perspective on participation is essential in patientcentred care. Patients with disabilities or asthma have reported that participation is more than attending activities. ${ }^{10,11}$ Young adults who grew up with a chronic disease often achieved participation milestones at a later age compared to peers and needed extra social support.,12-14 To stimulate full participation in children with chronic diseases, it is important to understand their perspective, in order to empower and support them in what they perceive as participation.,15

The aim of this study was to characterize participation in daily life in children with chronic disease and to identify the considerations that affect participation from their perspective.

\section{METHODS}

We applied an explorative qualitative interview study design. A general inductive approach and the Qualitative Analysis Guide of Leuven method proposed by Dierckx-de Casterlé et al. were used to describe participation from the children's perspective.16,17

In line with qualitative sampling strategies, patients were purposefully recruited from a larger cohort of children with cystic fibrosis, an autoimmune disease, or posttreatment cancer patients at the Wilhelmina Children's Hospital and the Princess Máxima Centre for Paediatric Oncology in the Netherlands. ${ }^{17}$ Children post-cancer treatment were included within one year after completing treatment. Children 8-18 years old were eligible if their treating physician determined they were in a stable phase of their disease and able to talk about participation. Maximum variation was sought in age, sex, school absence, and fatigue and pain levels. ${ }^{17}$ Fatigue was assessed using the general fatigue scale of the PedsQL Multidimensional Fatigue Scale, which is internationally validated and has good internal consistency (Cronbach's alpha 0.73). ${ }^{18}$ School absence was reported over the previous six months. Average pain over the previous week was reported on a visual analogue scale of 0-10, as this is easily applicable and has higher reproducibility than other pain measurements. ${ }^{19}$

Children were informed via their treating physician. If they were willing to participate, 
an in-depth semi-structured interview lasting 60-90 minutes took place in the hospital or at their home, depending on their preference. ${ }^{20}$ The interviewers were trained in qualitative research methods; actively listening and asking open-ended follow-up questions to identify the children's perspectives. If possible, children were interviewed alone, to reduce socially desirable answers. An interview guide based on literature and the research team's expertise was used (Supplementary table S1). The interview started with an open-ended question: "To what extent does your disease affect your daily life?" To help younger children express their thoughts, a card-based tool was developed by a graphical designer together with the research team with pictures about activities, people in their environment, emotions, and contrasting pairs of statements. The cards were based on the interview guide and the emerging concepts of the first interviews. All interviews were audio recorded and transcribed verbatim.

Data were analysed using two intertwined strategies; coding and thinking theoretically. ${ }^{20}$ Data collection and analysis were alternated. ${ }^{16,21,22}$ Emerging concepts were identified and participants sought that displayed parts of these concepts that were not yet completely clear. When the final concepts surfaced, it became clear that saturation was reached for the main concepts within the recruited sample. Four researchers were involved in the entire process from initial coding towards final results. They were part of a team of eight researchers from various backgrounds (nursing, philosophy, paediatrics, and psychology) who checked findings against transcripts and validated the results. The goal of this researcher triangulation is to repeatedly reassess the data, accurately capturing the content of the qualitative interviews. The first transcripts were read by the complete team and initial concepts identified. Subsequently, two researchers started with open coding and discussed findings with a core team to reach consensus. Constant comparison was established by discussing differences, commonalities and possible explanations for the variation encountered between cases, aimed at a thorough understanding of participation in daily life. 16,21 Coding was supported by MAXQDA. ${ }^{23}$

The Research Ethics Committee classified this study as exempt of the Medical Research Involving Human Subjects Act (16-797/C). Informed consent and/or assent were provided by parents and children right before the interview took place. ${ }^{24}$

\section{RESULTS}

Thirty-one of the 56 (54\%) invited patients agreed to take part. Included were 11 patients with CF, 11 patients with an autoimmune disease, and 9 patients post-cancer treatment (Table 1). One child was interviewed with her parent present. Reasons for not taking part were already being involved in other studies or finding it too burdensome to talk about their disease. In textboxes, the results are illustrated by examples of individuals with different illnesses. 


\begin{tabular}{|c|c|c|c|}
\hline Variable & Category & $\mathrm{N}$ & $\%$ \\
\hline \multirow[t]{2}{*}{ Gender } & Female & 19 & 61.3 \\
\hline & Male & 12 & 38.7 \\
\hline \multirow[t]{3}{*}{ Age } & $8-11$ years & 12 & 38.7 \\
\hline & $12-15$ years & 11 & 35.5 \\
\hline & 16-18 years & 8 & 25.8 \\
\hline \multirow[t]{3}{*}{ Disease/condition } & Cystic fibrosis & 11 & 35.5 \\
\hline & Autoimmune disease & 11 & 35.5 \\
\hline & Post-cancer treatment & 9 & 29.0 \\
\hline School absence & $>10 \%$ school absence over the past 6 months & 9 & 29.0 \\
\hline Fatigue & $\begin{array}{l}\text { Fatigued (score of }>1 \text { SD lower than reference } \\
\text { values on PedsQL MFS) }\end{array}$ & 11 & 35.5 \\
\hline Pain & VAS $\geq 3$ over the past week (range 0-10) & 11 & 35.5 \\
\hline
\end{tabular}

PedsQL MFS = Paediatric Quality of Life Inventory Multidimensional Fatigue Scale, SD = standard deviation, VAS = visual analogue scale.

\section{Daily life participation}

Regarding participation in daily life, children described a large variety of activities within these domains: real-life participation with peers (e.g., school, sports), online participation with peers (e.g., online gaming, social media), participation with family members (e.g., eating together, going on holidays), and participation with a wider social environment (e.g., communities, jobs/internships). Participation was mostly face-toface; online participation played an important role among older children.

\section{Box 1 .}

"Most of the times I play on the playstation while I talk with other people via internet... so you do not have to make an effort to go to other people's house and you can play from your own house." - Boy with CF, 15 years old, describing the importance of online participation.

Although all participants were in a stable phase of their disease, their perception of being able to achieve full participation varied widely. Some children reported they generally felt able to fully participate, regardless of their limitations, while others reported feeling unable to participate fully due to their disease-related limitations. Depending on the situation, children sometimes felt unable to fully participate because they were unable to go out with friends, but were able to fully participate when they were able to overcome this limitation (e.g., by having friends come to their house). These relatively large differences between children and situations indicate that from a child's perspective, the notion of "participation" is more than merely being able to engage in certain activities. 


\section{Box 2.}

"Even though you are able to do less sometimes, there are always things you can do, so you can do something fun with friends. You do not have to go play soccer, you can also ask friends to go do something at somebody's home... Then they adapt: we do not have to do this, we can also do something else." - Boy with JIA, 15 years old, describing feeling unable to participate, but able to fully participate when he is able to adjust the situation to his needs.

From our interviews, we learned that children, who fully participate, experienced this as having a sense of belonging, the ability to affect social interactions, and the capacity to keep up with peers (Table 2).

\section{Full participation}

Having a sense of belonging was identified when a child's presence was undisputed and self-evident, both to themselves and reflected by their social environment. Children reported they felt invited and/or actively involved, and their social environment adapted naturally to their abilities. This sense of belonging meant that children did not need to disclose their "being different" to others, and their patterns in participation were unaffected by the disease-related limitations. In brief, children described this as being different, but not feeling different.

\section{Box 3.}

"When I bike slower than the others, that they do not ask me to hurry up, but that they adjust to my pace." - Girl with JIA, 17 years old, describing being actively involved, with her social environment adapting naturally to her abilities, without the need for explicit disclosure.

The ability of children to influence their social interactions was identified as their ability to guide their participation, as social interactions were perceived an important aspect of participation. Children feel they can influence the social process and experience being viewed as an equal partner within these social interactions (e.g., they are allowed to participate in a project from home rather than being present); children felt they could disclose their limitations and their environment would adapt to their needs (e.g., the child can still design a project, even though they cannot execute it). Children described this as being able to participate in their own way.

\section{Box 4}

"The whole winter we build on the car, every free hour is used and often I am the one who orders everyone around, because I cannot do the heavy tasks. I am really one of the driving forces, everyone comes to me to ask: How do I do this, and what color do you want to have this? I can do that both from the hospital and from home, so than I am involved."

- Boy with CF, 18 years old, explaining being an equal partner within his social interaction and participating in his own way. 
Table 2. Aspects of full participation and example quotes by children with a chronic disease

\begin{tabular}{l|l} 
Aspect & Illustrative quotes*
\end{tabular}

Sense of

"In the end, we were not so much into playing games anymore; the guys still played soccer, belonging but the girls just sat together. I liked that best, because then I could keep up best, just chatting. We walked outside with all the girls and I just walked... Then we went somewhere and sat and chatted, and it went very naturally." - Girl with systemic sclerosis, 11 years old

"I feel the same as everyone, but I am not the same, no." - Boy with CF, 10 years old "In no time felt like I fit into the group." - Girl post-cancer treatment, 11 years old

The ability to affect social interactions

Being able to keep up with others

"Most of the time I am ordering them to do this and that, because I cannot do all those heavy tasks... So everyone comes to me to ask, 'What can I do today?' And I say, 'Well, this needs to be done or that needs to be done.' It feels nice that I can arrange something from home... Then I do feel part of it." - Boy with CF, 18 years old

"I cannot do it the same way they do, but I can do it in my own way." - Girl with systemic sclerosis, 11 years old

"[I made that decision with] my best friend, because I went with her every day and I slept over there... We decided, okay, we cannot go in the afternoon, but we can go in the evening and cut loose." - Girl post-cancer treatment, 15 years old

"You have to strive really hard to attend everything. Being there is an important part of participation. And of course, those girls are at school every day and they talk to everyone. So, they kind of have a head start on you. Yes, that may sound stupid, because they do all kind of things with other children, but it makes you think, 'Oh, I wish they did that with me; they don't do anything with me anymore."'

- Girl post-cancer treatment, 15 years old

"I play a sport now at physiotherapy, so that is different. I used to play hockey, but I stopped because it hurt. Now I am not the only one who has something, so that is different." - Girl with CF, 15 years old

"I think it is good for me to take the stairs [instead of the lift] and that is also more fun, because then I can walk together with my classmates." - Cirl with systemic sclerosis, 11 years old

*Some quotes were edited slightly to increase readability.

CF $=$ cystic fibrosis

The capacity to keep up with peers was expressed primarily by adolescents. When they compared themselves to peers, they felt they had a similar level of knowledge, skills or performance. Some children felt able to participate only when they were kept up-todate regarding social processes (e.g., being kept in the loop about what happened in classes they missed). Other children felt they needed specific abilities (e.g., the need to run fast enough in order to join a field hockey game), or performance levels (e.g., if they were unable to play a computer game for a long time, they no longer had sufficient confidence to play that game with friends). 


\section{Box 5.}

"Online gaming is fun with friends, but if people depend on me I find that hard. In the beginning it was easy, but now other people have become so much better... For a while, I played less, but now I do not play anymore with other persons over the internet, because I am afraid people will get mad at me for not performing well." - Boy post-cancer treatment, 18 years old, describing the need to perform on the same level as peers in order to feel like he can fully participate.

\section{Barriers}

In each child, we identified a desire to achieve full participation, but they experienced intrinsic and extrinsic barriers. Intrinsic barriers were related to the children themselves and disease-related factors (e.g., fatigue, pain, physical changes, the demands of the treatment regimen, feeling "down" or unable to fit in).

\section{Box 6 .}

"When I go out to dinner with friends, I leave early because I cannot keep going, I have so much pain that I do not enjoy myself anymore. Then I feel like: I can better go home than sit here feeling miserable." - Girl with JIA, 17 years old, describing physical barriers to achieve full participation

Extrinsic barriers were related to external factors that make the child feel excluded, such as peers not inviting the child, or when a child has the feeling that he/she would not be able to keep up, e.g. during sports. These barriers are summarized in Table 3 , with illustrative quotes in Table 4.

\section{Box 7 .}

"To be too tired to go to the movies or to go to a concert or to go swimming. And after a while they stop asking you to come. That is stupid."- Boy with CVID, 14 years old, explaining feeling excluded because of his disease-related limitations.

Table 3. Barriers to full participation among children with a chronic disease

\section{trotich}

\section{Intrinsic barriers}

Physical barriers such as fatigue, pain, physical changes, or the demands of the treatment regimen

\section{Mental barriers such as feeling "down" or feeling unable to fit in}

Unpredictability of the manifestations of their disease

\section{Having a sense of be- The ability to affect} longing social interactions

Influences the visibility of the disease and leads to "feeling different"

Makes children feel like they do not belong because they are different and feel different

Reduces the child's ability to commit to participating (e.g., being unable to plan a trip with friends because you might have to cancel)
Increases the necessity for an adapted role in participation, which others may or may not accept

Decreases the initiative to take an adapted role

Influences the choices children make regarding their role (e.g., whether you think it is feasible to obtain a higher education)
Being able to keep up with relevant others

Decreases the possibilities to obtain the same level of knowledge or performance as others

Decreases the initiative to participate, which can lead to being unable to keep up with others

The recurrent need to avoid commitment or the sudden absence in participation can lead to feeling unable to keep up with others 


\section{Table 3. Barriers to full participation among children with a chronic disease}

Extrinsic barriers

Not being invited or actively involved
Others placing an emphasis on the child "being different" leads to the child "feeling different" (e.g., their friends still go to a theme park, even though they know the child cannot join them)

Not being able to keep up with performance
Increases "feeling different" (e.g., the child will not participate in a computer game because they lack confidence and are afraid they will cause the team to lose)
When children are not actively involved, they do not experience an influence within social interactions
Decreases opportunities to participate, thereby decreasing the feeling of being able to "keep up" with others

\author{
Makes children feel as \\ though their individual \\ influence is limited, as \\ they may feel as though \\ the environment cannot \\ meet their needs
}

Decreases the children's feeling that they can reach the same level as their peers

\section{Table 4. Quotes illustrating the barriers to full participation in children with a chronic disease}

\section{Barriers}

Physical barriers

\section{Illustrative quotes*}

"I cannot run so far, because I get short of breath." - Boy with CF, 15 years old

"We switched to injections for my disease, which I have to get once a week. This is usually on a Friday, but it has an impact on the next few days." - Boy with CVID, 14 years old

"You always live in a blur of fatigue." - Girl with JIA, 15 years old

"For example, last weekend I went to a birthday party, but I forgot my medication, so I could not eat any crisps." - Girl with CF, 12 years old

"I was not allowed to jump, because of my bone condition, but then I was invited to a party where we went to a trampoline park. That was a bummer, and I thought, 'Then please do not invite me, or plan something else."' - Cirl post-cancer treatment, 15 years old

"After I received radiotherapy for my bladder and bowels, I noticed that I need to go to the bathroom a lot more often now." - Boy post-cancer treatment, 18 years old

*Some quotes were edited slightly to increase readability.

$C F=$ cystic fibrosis, CVID = common variable immunodeficiency, JIA = juvenile idiopathic arthritis 


\section{Table 4. Quotes illustrating the barriers to full participation in children with a chronic disease}

Mental barriers such as feeling "down" or feeling unable to fit in

Unpredictability of the disease's manifestations
"In the beginning, I was kind of depressed when I first heard that I had a disease that would never go away. But then I went to see a psychologist and she helped me. And I thought, 'I just want to be the same as leveryone elsel; this is not fun, I can barely do a thing.' I always want to be the same as everyone else, and sometimes I still try to adapt, but then I have to remind myself, 'No, you need to be yourself." - Girl with systemic sclerosis, 11 years old

"My mom makes me go to school when I am rested, even though I'm still cranky and sad. Yes, I really do not want to go, but in the end it is better and I know it." - Girl with CF, 16 years old

"I have a stoma... It can make noise and that is difficult, especially in a quiet room. So now I can take my exams alone with just a proctor present; if I had to take the exam in a quiet classroom, $60 \%$ of my attention would be focused on one thought: 'Oh god, what if it makes noise?" - Boy post-cancer treatment, 18 years old

"You can never plan anything, because there is always something that can disrupt your plans. You may say, 'I will finish my education in three years, and then I will do this, and then I will find my own place to live, etc....' But now I have to say, 'I know I am doing this study, but it might take one year, or three years, of maybe two years longer.' You just do not know how it will go with my health, and that makes all the difference." - Boy with CF, 18 years old

"You just know, it can always happen that I can wake up in the morning and my disease will suddenly flare up. It can always happen." - Boy with JIA, 14 years old

"I see it as a flow, and I'll see what happens. I do not plan very much anymore. You cannot plan anyway. So I just try to go with the flow." - Boy post-cancer treatment, 18 years old

Not being invited to participate or not being actively involved

"You cannot do what other people can. And then you feel a bit... I don't know, not really excluded, but a bit of an outsider." - Girl with JIA, 15 years old

"Yes, it's a social setback, with friends and everything, that they went to meet with someone else, and I thought, 'Well, I don't even know who that is."' - Girl post-cancer treatment, 15 years old

"When nothing happens, I don't mind, but most of the time when the weather is nice they go to an outside terrace, and then I have to choose not to go, because I can't." - Boy with CF, 18 years old

Not being able to keep up with respect to performance
"Well, in the beginning it was very easy [to play a computer game], but now people have become so much better at it that it... Yes, if you see certain things that people do in the game, you think, 'How do they do that?' And a lot of my friends are pretty good too, but I played less. And what I notice is that I do not play with random strangers on the internet anymore, because I'm afraid that they will get angry because I am not good enough." - Boy post-cancer treatment, 18 years old

"I would not feel comfortable going back to playing field hockey, because I cannot keep up with the others. My physiotherapist says I can do everything, but I know I cannot." - Girl with CF, 16 years old

"It's really a bummer when I have to tell friends, 'I cannot do that, sorry." - Girl with JIA, 15 years old

*Some quotes were edited slightly to increase readability.

$C F=$ cystic fibrosis, CVID = common variable immunodeficiency, JIA = juvenile idiopathic arthritis. 


\section{Considerations}

Also, considerations regarding participation were described, defined as weighing costs and benefits. First, children described whether they considered participation desirable in terms of relational and/or personal fulfilment, described as personal pleasure, the belief that participation is beneficial, or the knowledge that participation can facilitate accomplishments.

\section{Box 8 .}

"Compared to my classmates I have an average condition, because some of them do not sport and I do sport. But a few bad days can make me start all over again. I work very hard to be at the level where I am, but a small flu can throw all my energy away, all the training, just like that. And then I can start over again." - Boy with CF, 11 years old, describing sports participation as desirable for health benefits and the ability for future participation.

Second, children considered the feasibility of participation, which included the availability of others, the proximity of the activity, the likelihood that others will allow them to participate, and the likelihood that they would not let others down.

\section{Box 9.}

"First I played field hockey. But then you play in a team and I felt unpleasant, because I could not keep up with the rest. The physiotherapist tells me I can do anything, but I know I cannot keep up with the rest." - Girl with CF, 16 years old, describing participation as not feasible, because she feels she will let others down if she participates.

Third, children described the role of barriers. In some situations, children allowed barriers to keep them from participating. A temporary refrain from participation was often justified as a strategy to increase future participation.

\section{Box 10}

"For example with soccer, than I join for 15 minutes, then I wait 10 minutes and join again for 15 minutes and so on. If I notice I cannot do it anymore, than I go home earlier." - Boy post-cancer treatment, 12 years old, explaining that fatigue restricts his current participation

In other situations, children placed a higher priority on participation than on their barriers, investing physical and mental resources. Children used perseverance and tenacity to continue participating despite barriers.

\section{Box 11.}

"At first I did not go dancing or drinking alcohol, but now I told my parents and the doctor that I am still a child. I do not like it that I have pain, but I do want to enjoy and in ten years, I cannot go back and redo this. So then I just grit my teeth and make memories. I prefer that. It is setting priorities." - Girl with JIA, 16 years old, describing prioritizing participation over her physical symptoms.

Finally, some children revealed that the expectation of physical and/or emotional consequences, such as an increase in symptoms, caused them to refrain from participating. Thus, some children typically placed a higher priority on participation, whereas other children typically placed a higher priority on their current and/or future needs, both weighing the costs and benefits of their choices. 


\section{Box 12}

"Sometimes I think about it and I know that if I do this, I will have less energy tonight or tomorrow and then I decide not to do it." - Girl post-cancer treatment, 16 years old, describing that the anticipation of fatigue keeps her from participating.

\section{Disclosure}

Children varied in how much they disclosed in different situations. We define "disclosure" as telling or showing others minor or major aspects of their disease or limitations, making the disease more visible and making it possible for others to adapt accordingly. "Standing out" in a negative way whilst striving to be normal was described as a potentially harmful effect of disclosure for their sense of belonging.

\section{Box 13}

"I do not like being different than others. Therefore I do not tell them when I do not feel well. I do not need to be special." - Girl with JIA, 17 years old, describing that disclosure may affect his sense of belonging.

They described a helpful effect as "leading to a better understanding among peers", which allowed their environment to adapt. Not disclosing can be detrimental to achieving participation if the child is unable to keep up. Because the line between helpful and harmful disclosure was described as thin, disclosure is an ongoing consideration for most children.

\section{Box 14.}

"If you let people now, they can help you think of solutions. Because else you have only one brain and then it is much harder. Others can be way more creative than you, while you think it may be best just to not participate, but when I tell them, they most of the time try to find a solution." - Girl with systemic sclerosis, 11 years old, describing more understanding and better adaptation by peers as a positive effect of disclosure

Children who expressed substantial difficulty in participation with peers tended to engage more in family participation. These children noted that the adaptation needed by peers was a barrier too high to overcome. Within their family, acceptance and adaptation occurred naturally. For example, some children reported usually sharing their free time with their parents, whereas other children spent their free time with peers.

\section{Box 15}

"It also had an impact at home, because there I could really be who I wanted to be. When I came home from a long day, my mom was the one noticing that it did not go well." - Girl with CF, 16 years old, describing that it is easier to be herself, including disease-related limitations, within her family environment 


\section{DISCUSSION}

Children with a chronic disease view full participation as more than engaging in activities; rather, they view having a sense of belonging, the ability to affect social interactions, and the capacity to keep up with peers as key elements. Children weigh participation against their current and future needs, using disclosure as a strategy. Understanding the child's perspective will assist clinicians in empowering children with chronic diseases to fully participate.

Most studies base participation primarily on performance or attendance. ${ }^{25,26}$ Consistent with studies in children with asthma or disabilities, children with chronic disease did not consider full participation to mean participating in the same activities as peers. ${ }^{10,11,27}$ Other qualitative studies in children with chronic diseases describe similar barriers to participation, such as pain, or the unpredictability of the disease. ${ }^{28,29}$ The described "ability to keep up with peers" is in line with the perceived need to be kept in the information loop by healthy individuals. ${ }^{30}$ Also, the ability to influence social interactions and the need for their environment to facilitate participation has been described before, and has similarities with the perceived responsiveness research. 12,31,32 The elements of full participation in our study could be similar in healthy individuals, but achieving autonomy and self-management may be easier for healthy children, since children with chronic diseases are additionally burdened by their disease-related limitations. They generally spend more time alone and at home, and report achieving participation milestones at a later age.,33 Stimulating participation may help them grow into autonomous adults.

One way to stimulate participation for children with chronic disease, may be to help them cope with and adjust to their disease and manage their growing state of independence, for example balancing disclosure and striving for normalcy, using cognitive behavioural techniques and positive thinking. 13,29,34-3839-41 Healthcare providers can support the child's pursuit of full participation by working towards a sense of belonging for the child, active involvement, and the ability to influence their role among peers. This approach requires active collaboration between child, healthcare providers, and caregivers, focusing on the child and their environment.15

A major strength of this study is the focus on the perspective of children with a variety of severe diseases; this is particularly important, as the child's perspective is a key component in patient-centred care and with increasing age, participation becomes the child's own responsibility. Children were encouraged to express their thoughts using a card tool. Finally, this study was conducted using methods that optimized validity and reliability, including analyses from data towards theory by a research team with various professional backgrounds ${ }^{17,22}$

A limitation is that our results may not necessarily reflect children for whom participation is relatively difficult, as one reason for not taking part was finding it too burdensome to talk about their disease. Second, gatekeeping by healthcare professionals may have prevented some children from being invited. ${ }^{2}$ Nevertheless, our study revealed sufficient variation in all disease groups with respect to the 
concepts described. Saturation was reached regarding the features of full participation, although some aspects of the barriers and considerations may not have been fully revealed. Because we interviewed only Caucasian children, our results may not fully reflect children from other ethnic backgrounds.

Some aspects that influence participation may not be described by children themselves, such as the parental influence on participation or the children's mental state or personality traits. 12,14,32 In future studies, the role of parents and/or healthcare providers in facilitating participation is of interest as well as studies that help children overcome their barriers for participation.

\section{CONCLUSION}

From the perspective of children with chronic diseases, full participation is characterized as having a sense of belonging, the ability to affect social interactions, and the capacity to keep up with peers, rather than engaging in activities. Focusing on full participation from the child's perspective will facilitate patient-centred care by helping the child self-manage their participation. 


\section{REFERENCES}

1. King G, McDougall J, Dewit D, Petrenchik T, Hurley P, Law M. Predictors of Change Over Time in the Activity Participation of Children and Youth with Physical Disabilities. Child Health Care. 2009;38(4):321-351. doi:10.1080/02739610903237352

2. Zan H, Scharff RL. The Heterogeneity in Financial and Time Burden of Caregiving to Children with Chronic Conditions. Matern Child Health J. 2015;19(3):615-625. doi:10.1007/s10995-014-1547-3

3. Brinkman TM, Recklitis CJ, Michel G, Grootenhuis MA, Klosky JL. Psychological Symptoms, Social Outcomes, Socioeconomic Attainment, and Health Behaviors Among Survivors of Childhood Cancer: Current State of the Literature. J Clin Oncol. June 2018:JCO2017765552. doi:10.1200/JCO.2017.76.5552

4. Stephenson AL, Tom M, Berthiaume Y, et al. A contemporary survival analysis of individuals with cystic fibrosis: a cohort study. Eur Respir J. 2015;45(3):670-679. doi:10.1183/09031936.00119714

5. Giancane G, Alongi A, Rosina S, Tibaldi J, Consolaro A, Ravelli A. Recent therapeutic advances in juvenile idiopathic arthritis. Best Pract Res Clin Rheumatol. 2017;31(4):476-487. doi:10.1016/j.berh.2018.01.001

6. Berglund MMU. Learning turning points-in life with long-term illness-visualized with the help of the life-world philosophy. Int J Qual Stud Health Well-being. 2014;9(0). doi:10.3402/qhw.v9.22842

7. Stam H, Hartman EE, Deurloo JA, Groothoff J, Grootenhuis MA. Young adult patients with a history of pediatric disease: impact on course of life and transition into adulthood. J Adolesc Health. 2006:39(1):4-13. doi:10.1016/j. jadohealth.2005.03.011

8. World Health Organization. Towards a Common Language for Functioning, Disability and Health - ICF.; 2002.

9. Imms C, Granlund M, Wilson PH, Steenbergen B, Rosenbaum PL, Gordon AM. Participation, both a means and an end: a conceptual analysis of processes and outcomes in childhood disability. Dev Med Child Neurol. 2017;59(1):16-25. doi:10.1111/ dmcn. 13237

10. Martin Ginis KA, Evans MB, Mortenson W Ben, Noreau L. Broadening the Conceptualization of Participation of Persons With Physical Disabilities: A Configurative Review and Recommendations. Arch Phys Med Rehabil. 2017;98(2):395-402. doi:10.1016/j.apmr.2016.04.017

11. Westergren T, Berntsen S, Ludvigsen MS, et al. Relationship between physical activity level and psychosocial and socioeconomic factors and issues in children and adolescents with asthma. JBI Database Syst Rev Implement Reports. 2017;15(8):2182-2222. doi:10.11124/JBISRIR-2016-003308

12. Fereday J, MacDougall C, Spizzo M, Darbyshire P, Schiller W. ";There's nothing I can't do - I just put my mind to anything and I can do it".: a qualitative analysis of how children with chronic disease and their parents account for and manage physical activity. BMC Pediatr. 2009;9(1):1. doi:10.1186/1471-2431-9-1

13. Bailey PK, Hamilton AJ, Clissold RL, et al. Young adults' perspectives on living with 
kidney failure: a systematic review and thematic synthesis of qualitative studies BMJ Open. 2018;8(1):e019926. doi:10.1136/bmjopen-2017-019926

14. Peeters MAC, Hilberink SR, van Staa A. The road to independence: lived experiences of youth with chronic conditions and their parents compared. J Pediatr Rehabil Med. 2014;7(1):33-42. doi:10.3233/PRM-140272

15. Britto PR, Lye SJ, Proulx K, et al. Nurturing care: promoting early childhood development. Lancet. 2017;389(10064):91-102. doi:10.1016/S0140-6736(16)31390-3

16. Dierckx de Casterlé B, Gastmans C, Bryon E, Denier Y. QUACOL: A guide for qualitative data analysis. Int J Nurs Stud. 2012;49(3):360-371. doi:10.1016/j. ijnurstu.2011.09.012

17. Creswell J. Qualitative Inquiry \& Research Design: Choosing among Five Approaches (3rd Ed.). Thousand Oaks, CA: SAGE.; 2013.

18. Cordijn MS, Suzanne, Cremers EMP, Kaspers GJL, Gemke RJBJ. Fatigue in children: reliability and validity of the Dutch PedsQLTM Multidimensional Fatigue Scale. Qual Life Res. 2011;20(7):1103-1108. doi:10.1007/s11136-010-9836-9

19. Rosier EM, Iadarola MJ, Coghill RC. Reproducibility of pain measurement and pain perception. Pain. 2002;98(1-2):205-216. http://www.ncbi.nlm.nih.gov/ pubmed/12098633. Accessed May 31, 2019.

20. Charmaz K. Constructing Grounded Theory. 2nd Edition. Sonoma State University, USA; 2014.

21. Pope C, Ziebland S, Mays N. Qualitative research in health care. Analysing qualitative data. BMJ. 2000;320(7227):114-116. http://www.ncbi.nlm.nih.gov/ pubmed/10625273. Accessed December 21, 2018.

22. Morse J, Barret M, Mayan M, Olson K, Spiers J. Verification strategies for establishing reliability and validity in qualitative research. Int J Qual Meth. 2002;1(2).

23. VERBI Software. MAXQDA 2018. 2017

24. Giesbertz NAA, Bredenoord AL, van Delden JJM. Clarifying assent in pediatric research. Eur J Hum Genet. 2014;22(2):266-269. doi:10.1038/ejhg.2013.119

25. Lambregts SA., Smetsers JE., Verhoeven IMA., et al. Cognitive function and participation in children and youth with mild traumatic brain injury two years after injury. Brain Inj. 2018;32(2):230-241. doi:10.1080/02699052.2017.1406990

26. Di Marino E, Tremblay S, Khetani M, Anaby D. The effect of child, family and environmental factors on the participation of young children with disabilities. Disabil Health J. 2018;11(1):36-42. doi:10.1016/j.dhjo.2017.05.005

27. Willis C, Girdler S, Thompson M, Rosenberg M, Reid S, Elliott C. Elements contributing to meaningful participation for children and youth with disabilities: a scoping review. Disabil Rehabil. 2017;39(17):1771-1784. doi:10.1080/09638288.2016.12 07716

28. Sällfors C, Fasth A, Hallberg LRM. Oscillating between hope and despair--a qualitative study. Child Care Health Dev. 2002;28(6):495-505. http://www.ncbi.nlm. nih.gov/pubmed/12568479. Accessed July 10, 2019.

29. Chew J, Carpenter J, Haase AM. Living with epilepsy in adolescence-A qualitative 
study of young people's experiences in Singapore: Peer socialization, autonomy, and self-esteem. Child Care Health Dev. 2019;45(2):241-250. doi:10.1111/cch.12648

30. Jones EE, Carter-Sowell AR, Kelly JR, Williams KD. 'I'm Out of the Loop': Ostracism Through Information Exclusion. Gr Process Intergr Relations. 2009;12(2):157-174. doi:10.1177/1368430208101054

31. Cook WL, Dezangré M, De Mol J. Sources of perceived responsiveness in family relationships. J Fam Psychol. 2018;32(6):743-752. doi:10.1037/fam0000411

32. Quirk H, Blake H, Dee B, Glazebrook C. "You can't just jump on a bike and go": a qualitative study exploring parents' perceptions of physical activity in children with type 1 diabetes. BMC Pediatr. 2014;14(1):313. doi:10.1186/s12887-014-0313-4

33. Engel-Yeger B, Jarus T, Anaby D, Law M. Differences in patterns of participation between youths with cerebral palsy and typically developing peers. Am J Occup Ther. 63(1):96-104. http://www.ncbi.nlm.nih.gov/pubmed/19192732. Accessed January 10, 2019.

34. van Geelen S. Managing Disease, or Managing the Self?: Philosophical Challenges to Patient Participation in (Mental) Health Care and the Need for Self-Management Training. Am J Bioeth. 2014;14(6):21-22. doi:10.1080/15265161.2014.900147

35. Wallander JL, Varni JW. Effects of pediatric chronic physical disorders on child and family adjustment. J Child Psychol Psychiatry. 1998;39(1):29-46. http://www.ncbi.nlm. nih.gov/pubmed/9534085. Accessed February 14, 2019.

36. Schmidt S, Petersen C, Bullinger M. Coping with chronic disease from the perspective of children and adolescents--a conceptual framework and its implications for participation. Child Care Health Dev. 2003;29(1):63-75. http://www. ncbi.nlm.nih.gov/pubmed/12534568. Accessed June 8, 2018.

37. Tong A, Jones J, Craig JC, Singh-Grewal D. Children's experiences of living with juvenile idiopathic arthritis: a thematic synthesis of qualitative studies. 2012;64(9). doi:10.1002/acr.21695

38. Lambert $V$, Keogh D. Striving to live a normal life: a review of children and young people's experience of feeling different when living with a long term condition. J Pediatr Nurs. 2015;30(1):63-77. doi:10.1016/j.pedn.2014.09.016

39. Hilberink SR, van Ool M, van der Stege HA, et al. Skills for Growing Up-Epilepsy: An exploratory mixed methods study into a communication tool to promote autonomy and empowerment of youth with epilepsy. Epilepsy Behav. 2018;86:116123. doi:10.1016/J.YEBEH.2018.05.040

40. Scholten L, Willemen AM, Last BF, et al. Efficacy of psychosocial group intervention for children with chronic illness and their parents. Pediatrics. 2013;131(4):el196-203. doi:10.1542/peds.2012-2222

41. Huber M, van Vliet M, Giezenberg M, et al. Towards a "patient-centred" operationalisation of the new dynamic concept of health: a mixed methods study. BMJ Open. 2016:5e010091.

42. Kars MC, van Thiel GJ, van der Graaf R, Moors M, de Graeff A, van Delden JJ. A systematic review of reasons for gatekeeping in palliative care research. Palliat Med. 2016;30(6):533-548. doi:10.1177/0269216315616759 


\section{8}
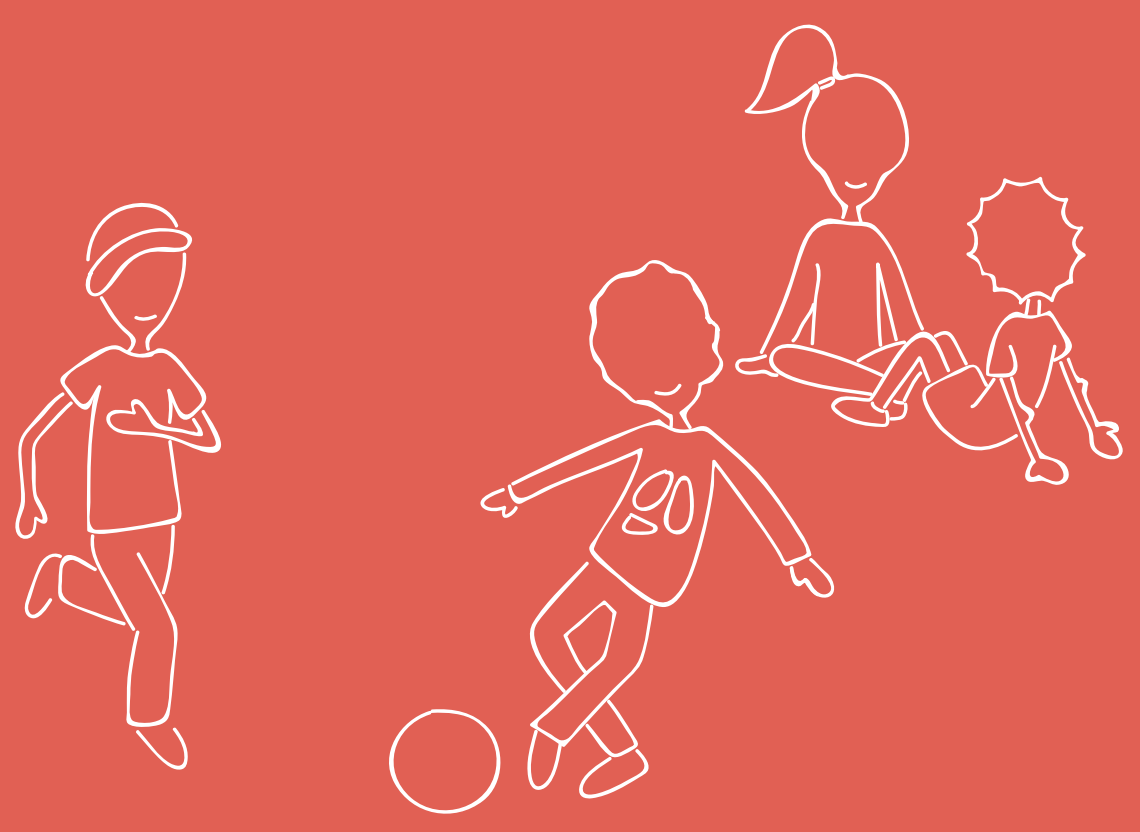


\section{Daily life participation in childhood chronic disease: a qualitative study on the child's and parent's perspective}

Nap-van der Vlist MMa, Berkelbach van der Sprenkel EEa,

Nijhof LNa, Grootenhuis $\mathrm{MA}^{\mathrm{b}}$ van der Ent $\mathrm{CK}^{\mathrm{c}}$,

Swart JFd van Royen-Kerkhof $A^{d}$, van Grotel $\mathrm{M}^{\mathrm{b}}$ van de Putte EMa, Nijhof SLa

Kars $\mathrm{MCe}$

a Department of Paediatrics, Wilhelmina Children's Hospital, University Medical Centre Utrecht, Utrecht University, Utrecht, the Netherlands b Princess Máxima Centre for Paediatric Oncology, Utrecht, the Netherlands c Department of Paediatric Pulmonology, Wilhelmina Children's Hospital, University Medical Centre Utrecht, Utrecht University, Utrecht, the Netherlands d Department of Paediatric Rheumatology/Immunology, Wilhelmina Children's Hospital, University Medical Centre Utrecht, Utrecht University, Utrecht, The Netherlands e Julius Centre for Health Sciences and Primary Care, University Medical Centre Utrecht, Utrecht University, Utrecht, the Netherlands 


\section{ABSTRACT}

\section{Objective:}

To understand how a child with a stable chronic disease and his/her parents shape his/ her daily life participation, we assessed: 1) the parents' goals regarding the child's daily life participation, 2) parental strategies regarding the child's participation, and 3) how children and their parents interrelate when their goals regarding participation are not aligned.

\section{Methods:}

This was a qualitative study design using a general inductive approach. Families of children 8-19 years with a stable chronic disease (cystic fibrosis, autoimmune disease, or post-cancer treatment) were recruited from the PROactive study. Simultaneous in-depth interviews were conducted separately with the child and parent(s). Analyses included constant comparison, coding, and categorization.

\section{Results:}

Thirty-one of the 57 invited families (54\%) participated. We found that parents predominantly focus on safeguarding their child's well-being, using participation as a means to achieve well-being. Moreover, parents used different strategies to either support participation consistent with the child's healthy peers or support participation with a focus on physical well-being. The degree of friction between parents and their child was based on the level of agreement on who takes the lead regarding the child's participation.

\section{Conclusions:}

Interestingly, parents described participation as primarily a means to achieve the child's well-being, whereas children described participation as more of a goal in itself. Understanding the child's and parent's perspective can help children, parents, and healthcare professionals start a dialogue on participation and establish mutual goals. This may help parents and children find ways to interrelate while allowing the child to develop his/her autonomy. 


\section{INTRODUCTION}

Children with a chronic disease are often unable to achieve the same level of participation in daily life as healthy children.' A chronic disease can have a major impact on many aspects of life, including the physical, mental, and social well-being of both the child and his/her family. ${ }^{2-4}$ As an increasing number of children grow up with a chronic disease, the consequences of their disease with respect to their daily life participation become increasingly evident. 1 We previously described the child's perspective on "full participation" among children with a chronic disease.5 We found that these children feel that participation encompasses more than engaging in activities; indeed, the children described having a sense of belonging, the ability to affect social interactions, and the capacity to keep up with healthy peers as key elements. ${ }^{5-9}$ Additionally, an important consideration is that the child's parents also play an essential role in driving the child's participation. ${ }^{10}$

Parents form their child's primary social network and can have a major impact on their child's daily life participation, especially because the presence of a chronic disease can affect the parent-child relationship and increases the child's dependency.11, It is crucial to understand how parents perceive their child's daily life participation, as well as their goals regarding their child's participation.13 In addition to the child's perspective, this can help lay the foundation for establishing mutual goals and a patient-centred approach regarding the child's participation.11,14,15 Paired qualitative analyses in this field are scarce, but provide important insights into the child-parent relationship and the role of their collaboration in shaping the child's daily life. ${ }^{16-18}$ The aim of this study was to determine: 1) the parent's goal regarding the daily life participation of their child with a chronic disease, 2) parental strategies regarding the child's participation, and 3) how the child and his/her parents interrelate when their goals regarding the child's participation are not aligned.

\section{METHODS}

We used an explorative qualitative interview study design to examine parents' view regarding their child's participation, as well as how the child and his/her parents interrelate regarding the child's participation. We used a general inductive approach and the Qualitative Analysis Guide of Leuven method proposed by Dierckx de Casterlé et al. ${ }^{19}$ This study builds upon our recent analysis of the transcripts from interviews with children with a chronic disease. ${ }^{5}$

Patient organisations were involved in setting the agenda and the priorities for this research. Children and their parents were involved in the conduct of this study, as this qualitative method is specifically designed to stress the patient's and parent's perspective. Patient organisations and societal partners are involved in the dissemination of our research.

Families were purposefully recruited in accordance with qualitative sampling strategies ${ }^{20}$ from the PROactive study cohort, which consists of children with cystic 
fibrosis, an autoimmune disease, or children within one year post-cancer treatment at the Wilhelmina Children's Hospital and the Princess Máxima Centre for Paediatric Oncology in the Netherlands. Children who were interviewed were 8-19 years of age, in a stable phase of their disease, and able to verbally communicate in an interview about their participation (both determined by their treating physician). Maximum variation was sought in the children's age, sex, school absences, and fatigue and pain levels. ${ }^{20}$ In the PROactive cohort, fatigue was assessed using the Multidimensional Fatigue Scale of the Paediatric Quality of Life Inventory (PedsQL MFS), ${ }^{21}$ school absences over the previous 2 weeks and 6 months were reported, and average pain experienced over the previous week was reported on a visual analogue scale (VAS). ${ }^{22}$

Families were approached by the child's treating physician. If they indicated that they were willing to participate, the child and his/her parent(s) were interviewed at the same time (in separate interviews) by trained interviewers using an in-depth semi-structured interview lasting 60-90 minutes. ${ }^{23}$ We used separate interview guides covering the same topics for the children and parents, based on the published literature and the research team's expertise. The interview began with the following open-ended question. For parents this was: "What do you notice with respect to the impact that your child's disease has on his/her participation in daily life?" For children this was: "To what extent does your disease affect your daily life?" We then focused on the childrens' and parents' experiences and perspectives.

Data were analysed using two intertwined strategies, namely coding and theoretical thinking, while alternating between data collection and data analysis. 19,24,25 Our previous report focused on our analysis of the children's interviews. ${ }^{5}$ Here, we first analysed all of the transcripts of the parents' interviews and then analysed the children's and parents' paired transcripts in order to determine how children and their parents interrelate when their participation goals are not aligned. Initial coding and theoretical thinking was performed by a core team of four researchers. We used researcher triangulation and constant comparisons in order to achieve a thorough understanding of the qualitative material.19,24 The whole team, consisting of seven researchers from a variety of backgrounds, including paediatric nursing, medicine, and psychology, checked the findings and validated the results. Coding was achieved using the MAXQDA software program. ${ }^{26}$

The Institutional Review Board determined that this study was exempt from the Medical Research Involving Human Subjects Act (16-797/C). Informed consent and/or assent were provided by all participating parents and/or their children.

\section{RESULTS}

Of the 57 invited families, 31 (54\%) participated. Reasons given for declining to participate included currently being involved in another study and the child finding it too burdensome to talk about his/her disease. Characteristics of the children and their parents are summarized in Table 1. We interviewed all 31 children individually, as well as 22 mothers, 1 father, and 8 parental couples. In four cases, the child's sibling(s) were 
present during the parental interview; in two of these cases, the siblings participated in the interview.

\begin{tabular}{|c|c|c|c|c|}
\hline Variable & Category & $\mathrm{N}$ & $\%$ & Median (IQR) \\
\hline \multirow{3}{*}{$\begin{array}{l}\text { Parent(s) present at the } \\
\text { interview }\end{array}$} & Mother & 22 & 71.0 & \\
\hline & Father & 1 & 3.2 & \\
\hline & Both parents & 8 & 25.8 & \\
\hline \multirow[t]{3}{*}{ Parent's age $(\mathrm{N}=28)^{*}$} & $<40$ years & 3 & 10.7 & $48.1(35.4-54.2)$ \\
\hline & 40-49 years & 15 & 53.6 & \\
\hline & $\geq 50$ years & 10 & 35.7 & \\
\hline \multirow[t]{2}{*}{ Child's sex } & Female & 19 & 61.3 & \\
\hline & Male & 12 & 38.7 & \\
\hline \multirow[t]{3}{*}{ Child's age } & $8-11$ years & 12 & 38.7 & $13.1(8.0-19.1)$ \\
\hline & 12-15 years & 11 & 35.5 & \\
\hline & 16-19 years & 8 & 25.8 & \\
\hline \multirow{3}{*}{$\begin{array}{l}\text { Disease/ } \\
\text { Condition }\end{array}$} & Cystic fibrosis & 11 & 35.5 & \\
\hline & Autoimmune disease & 11 & 35.5 & \\
\hline & Post-cancer treatment & 9 & 29.0 & \\
\hline \multirow{3}{*}{$\begin{array}{l}\text { School presence in the } \\
\text { past } 2 \text { weeks }\end{array}$} & Total & 31 & 100 & $100(0-100)$ \\
\hline & $\geq 90 \%$ of the time & 21 & 77.8 & \\
\hline & $<90 \%$ of the time & 10 & 32.2 & \\
\hline \multirow[t]{2}{*}{ Fatigue** } & PedsQL general fatigue score (range 0-100) & 31 & 100 & $79.2(25-100)$ \\
\hline & $\begin{array}{l}\text { Fatigued (score of }>1 \text { SD below the reference } \\
\text { values on PedsQL MFS) }\end{array}$ & 12 & 38.7 & \\
\hline \multirow[t]{2}{*}{ Pain } & VAS (range 0-10) & 31 & 100 & $2.0(0-9)$ \\
\hline & VAS $\geq 3$ over the past week & 11 & 35.5 & \\
\hline
\end{tabular}

PedsQL MFS = Paediatric Quality of Life Inventory Multidimensional Fatigue Scale; SD = standard deviation; IQR, interquartile range; VAS = visual analogue scale. * Only available for 28 parents. **Score 0-100, with lower scores indicating increased fatigue.

\section{Parents reported two main approaches regarding their child's participation}

Parents reported that they predominantly focus on safeguarding their child's current and future well-being. Well-being was defined as their child feeling good/happy or having a sense of fulfilment. Several domains can contribute to the child's well-being; physical, social, spiritual and psychological well-being. Interestingly, we found that how parents react to their child with respect to his/her participation was not necessarily motivated by the disease specific factors; rather, they were motivated primarily by their perception of their child's well-being.

Participation was used as a means to accomplish well-being in these domains, but was not seen as a goal in itself. To increase their child's participation as a means to an end, parents predominantly used two approaches: 1) participation that matches the level of their child's healthy peers, and 2) participation with a focus on physical well-being. Although parents in our study sometimes switched between these two approaches to safeguard well-being, many had a preference for one (Box 1). 
When parents used the approach of promoting their child's participation to be consistent with healthy peers, their goal was for their child to be perceived by his/her peers as not different, even though he/she was unable at times to perform the same activities. These parents attempted to treat their child similarly to his/her siblings and friends (e.g. they encouraged their child to join social activities, even when he/she did not feel well enough). Parents said that they chose this approach either because it aligned with their child's preferences, which supported his/her current psychological, spiritual (sense of fulfilment) and social well-being, or to help their child grow socially from a developmental perspective, which was expected to support his/her future well-being.

On the other hand, when parents used the other approach -participation with a focus on physical well-being- they strive for their child to have as few symptoms as possible, investing in an optimal therapeutic regimen in order to control their child's disease. Consequently, their child's ability to participate at the same level as his/ her healthy peers was replaced by other forms of participation that they considered less threatening to the child's physical well-being (for example, staying at home or participating online). They focused on their child having a good time, thus supporting the child's current and future well-being by focusing on minimizing his/her symptoms

Box 1. Example illustrating a mother using the two participation approaches.

The mother of a ten-year-old boy with cystic fibrosis described: "It is difficult when he goes to a party or a disco that goes on a bit late. I want him to be able to join in, but for two days afterwards he is very bad-tempered and tired, and he complains of having a stomach ache." With the child's well-being in mind, she can choose to let her son go to the party because she considers this beneficial to his current social, spiritual (sense of fulfilment) and psychological well-being, thereby meeting his desire to achieve full participation. This choice would be consistent with the approach of participation consistent with the child's peers. Alternative, she can choose to not let her son go to the party because she believes the party would be dangerous to his physical well-being and that staying home will improve her son's social and emotional well-being in the near future. This choice would be consistent with the approach of participation based on the child's physical well-being, as it means that the child could participate later in a different activity and would experience fewer symptoms.

Figure 1 illustrates how the child's well-being plays a role in how the child's parents shape his/her participation, including the strategies parents can use to support the two approaches discussed above; these strategies are described in more detail in Table 2. It is important to note that these various strategies require different amounts of parental investment, either personal, social or financial.

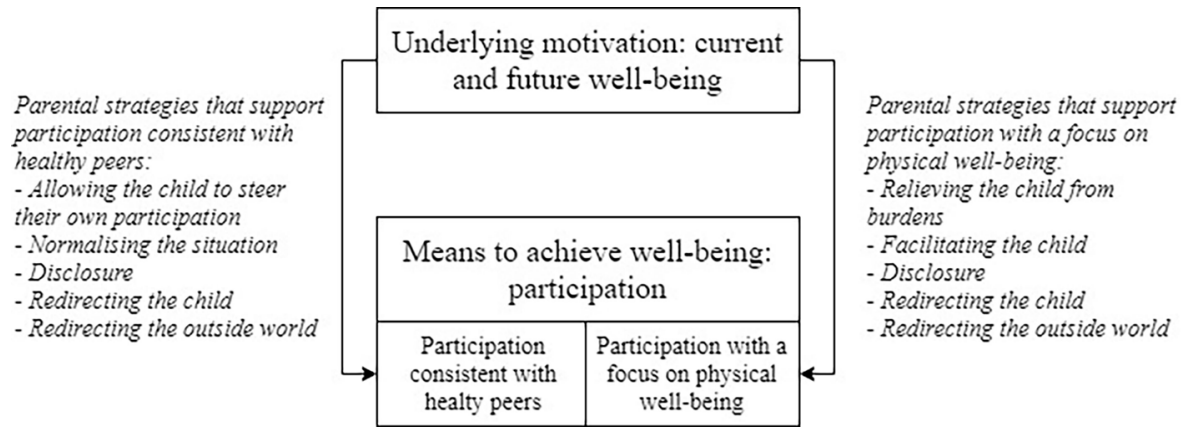

Figure 1. How the child's well-being, participation, and parental strategies interrelate. 
Table 2. Parental strategies regarding their child's participation identified in this study.

\begin{tabular}{|c|c|}
\hline Parental strategy & Description \\
\hline $\begin{array}{l}\text { Allowing the child } \\
\text { to steer their own } \\
\text { participation }\end{array}$ & $\begin{array}{l}\text { Using this strategy, parents } \\
\text { attempted to let their child take } \\
\text { the lead with as little interference } \\
\text { as possible, in order to promote } \\
\text { the child's self-sufficiency and } \\
\text { autonomy. }\end{array}$ \\
\hline
\end{tabular}

\section{Example case}

"I'm not the one who should forbid it. For example, she tried dancing for six months, and it didn't go well at all. I could have forbidden it, but thought it was better that she found out for herself. Now she really likes free running, even though she can't keep up. But the kids there know that, and she does what she can. She's getting exercise, and she enjoys being part of a group. I can see she is benefitting from it and that it's going well. But do I think it's sensible? No, I don't."

"She now thinks her situation is normal; maybe she's always in pain, but she doesn't know any better. She just does everything. She says herself that this is her "normal" and that she doesn't know any better than this. It has been like this since she was 5, and she doesn't really know what normal is."

their child as limited compared to his/her peers

Relieving the child Using this strategy, parents attempted to relieve their child from obligatory activities such as school, appointments, their therapeutic regimen, or the child's responsibility to disclose his/her limitations to others.

$\begin{array}{ll}\text { Facilitating the child } & \text { Using this strategy, parents adjus- } \\ \text { ted their own life and their family } \\ \text { life as much as possible. The } \\ \text { resources for achieving this stra- } \\ \text { tegy can be personal (e.g. time } \\ \text { investment such as a parent who } \\ \text { quits his/her job in order to be } \\ \text { home for the child), social (e.g. } \\ \text { siblings taking over the child's } \\ \text { tasks), or financial (e.g. buying } \\ \text { additional equipment). }\end{array}$

"So, we said it was OK to get a dog, but everyone will have to walk the dog every day, especially J, even in bad weather. But that's not strictly true. I often do it in bad weather, because this time of year (fall), her symptoms are often worse."

"J. is going to high school next year, and we wonder how he's going to get on. Right now, his bag is packed for him, including snacks; his exercise is arranged, and his bike is ready for him outside the door. His brother does all that for him now, but next year he'll have to do it himself. Other 11-year-old boys can be allowed to bike to the gym on their own, but not J; we have to take him there and pick him up." 


\section{Table 2. Parental strategies regarding their child's participation identified in this study.}

Disclosure

Redirecting the child tried to influence the child and what he/she could do either by explicitly telling the child what he/she can and cannot do (e.g. they cannot go on a school trip because it would make them too tired) or by attempting to persuade the child to do or not do certain activities (e.g. to take their medication when away from home or to stop physical exercise when they experience pain).

Redirecting the outside world
Using this strategy, parents tried to influence their child's environment, for example by asking the child's teacher to give him/her a different seat in class so the child would be less cold, or persuading other parents to invite him/her to a party, even though their child may not be able to participate in all of the activities.
Ex. 1) "She went into a new class, and we said that no one was allowed to ask $M$. anything about her condition. If they wanted to know anything, they were to come to us, and we would explain what happened and that she is now better. M. didn't want to talk about it then, but now she's opened up a bit."

Ex. 2) "Because J. had a group of close friends, it wasn't necessary to communicate it to the entire class. When he went to play with a friend, I just said that J. had a problem with his immune system and that there were some minor hygiene rules to follow, especially when he eats (he has to take pills before he eats anything). We keep it vague, so people don't start Googling and labelling him; he can just be J."

"Yes, she didn't need to make that decision But that's me; I make a lot of decisions on her behalf. I don't know if this is a good thing or not, but both of us are very strict at home; we don't believe much in that 'yes, but' culture. I am perfectly willing to explain why I made a certain decision, but we do what I decide we will do."

"When she started at a dance school, we spoke with them beforehand. But within two weeks she was sitting on the side for three-quarters of the hour. So we stopped taking her there. She's now at another dance school; we spoke to the new dance teacher first, and she includes $E$. in everything. Her teacher even choreographs special dances for her, so she can take part in performances and demonstrations."

\section{How the parents and their child interrelate when their goals regarding participation are not aligned}

Most children indicated that their goal was to achieve full participation. In contrast, most parents indicated that their goal was to optimize their child's current and future well-being, using participation as means to achieve that goal, not as goal in itself. Sometimes, achieving both full participation and optimal well-being was possible based on the child's and parent's perception. However, especially among children whose well-being was decreased and among older children, the parents' goals and the child's goals sometimes drifted apart.

When the parents' and child's goals drifted apart, we distinguish four ways in which 
parents and children interrelated to each other, based on who wants to take the lead regarding the child's participation (Table 3). It is important to note that both the child and the parents can change their viewpoint over time and depending on the situation.

Table 3. Four ways parents and their child interrelate when their goals are either aligned or not aligned, based on a combination of the parents' viewpoint and the child's viewpoint.

\begin{tabular}{|c|c|c|c|}
\hline & & \multicolumn{2}{|l|}{ The parents' viewpoint } \\
\hline$\stackrel{+}{\Xi}$ & & $\begin{array}{l}\text { We take the lead regarding the } \\
\text { child's participation }\end{array}$ & $\begin{array}{l}\text { Our child takes the lead } \\
\text { regarding his/her own } \\
\text { participation }\end{array}$ \\
\hline$\frac{\sum_{0}^{\circ}}{2}$ & $\begin{array}{l}\text { My parents take the lead } \\
\text { regarding my participation }\end{array}$ & The parents take the lead & $\begin{array}{l}\text { Neither the parents nor the child } \\
\text { want to take the lead }\end{array}$ \\
\hline 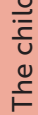 & $\begin{array}{l}\text { I take the lead regarding my own } \\
\text { participation }\end{array}$ & $\begin{array}{l}\text { Both the parents and the child } \\
\text { want to take the lead }\end{array}$ & The child takes the lead \\
\hline
\end{tabular}

We saw scenario one, parents taking the lead regarding the child's participation, primarily in families in which the child is relatively young. This scenario did not lead to considerable friction, as the parent made the final decisions regarding the child's participation, and the child followed their decisions. Scenario two, both the parents and the child want to take the lead, was mostly seen in older children. As children grow older, they search to increase their level of autonomy and are able to guide their own participation. In some cases, however, the parents - particularly parents with a child who is more limited by his/her disease - found it difficult to allow their child to guide his/her own participation. This can lead to conflict between parent and child. Parents noted that they were continuously having to find a balance between their child's growing autonomy and their own goals in safeguarding the child's well-being. In some cases (scenario 3), the parents wish that their child was more autonomous, but the child did not want to take on the challenge of guiding his/her own participation. In the last scenario (scenario 4), the child becomes more autonomous and the parents let him/her determine his/her own participation. The child essentially takes the lead, with the parents serving in a more advisory role. All scenarios are illustrated in text boxes.

\section{Box 2. Example illustrating who takes the lead regarding the child's participation.}

A mother of an eleven-year-old girl with generalized morphea scleroderma discussed how she used to take the lead regarding her daughter's participation by trying to protect her and redirect her participation to keep her from exceeding her physical limitations. As her daughter grew older, she (the daughter) began to take charge of her participation herself and recognized the consequences of these choices on her well-being. Thus, her mother was more comfortable letting her daughter take the lead in determining her own participation. "We've had times when we had to be really confrontational, where we said to E., 'You can't do it, so you aren't allowed to do it...' Back then, she used to get really angry about things and cry. She understands better now. Last year one of her classmates was having a party at a trampoline center, but E. said herself that she wasn't going to go. She said, 'I would really have to pay for it for three days afterwards; I wouldn't be able to walk for three days.' It's still the same now; when we go there, she really goes crazy for a while. Well that's fine, if she thinks she can do it. She knows she won't be able to walk the next day, but she does it anyway. Fine, it's her choice." 
Box 3. Example illustrating the scenario in which the parents take the lead

The mother of an eight-year-old girl with mixed connective tissue disease described: "Yes, she didn't need to make that decision. But that's me; I make a lot of decisions on her behalf. I don't know if this is a good thing or not, but both of us are very strict at home; we don't believe much in that 'yes, but' culture. I am perfectly willing to explain why I made a certain decision, but we do what I decide we will do." The girl herself described it as follows: "I sometimes want to do things, but then mommy says that it's probably better not to, because it will make me too tired."

\section{Box 4. Example illustrating a conflict arising when both the parents and the child want to take the lead.}

The mother of a twelve-year-old girl with juvenile idiopathic arthritis (JIA) described: "She oversteps her boundaries. She is confrontational; she will become confrontational if she doesn't want to do something or doesn't want to admit something."

The girl herself described: "Most of the time my mother asks if I took my medication... Sometimes I just say 'yes' even if I didn't take it; it's annoying."

Box 5. Example illustrating the role of disclosure in the parent-child relationship with respect to the child's participation.

Some children stopped disclosing their limitations or symptoms to their parents (e.g. by not telling the parents that they were in pain, so that their parents would not forbid them from participating), thereby reducing their parents' ability to direct them. The mother of a twelve-year-old girl which JIA describes: "She doesn't want to be any different, and she wants to join in. So even if she's in pain she won't say so or give any indication that she's in pain or can't do something; she never says so." In response, the parents often attempted to "read" how their child felt, believing their mission was to interpret their child's non-verbal signs in order to ascertain their child's true condition. One sixteen-year-old girl with JIA described: "They sometimes ask me if I'm still not feeling well. Every day I just say yes. Well, maybe not every day, you know what I mean; they ask about it sometimes, but I wouldn't tell them myself."

\section{Box 6. Example illustrating the way in which the child's disease can interfere with his/her autonomy.}

One mother of a fourteen-year-old boy with common variable immunodeficiency disorder described: "Because someone is ill, you start trying to fix things, which means you are actually not accepting someone for who they are. He can't accept what he is, even though he wants nothing more than to be accepted for what he is. You very quickly notice that due to the disease the child's 'ownership' of themselves is nipped in the bud, certainly when the child is so young. Ownership of the body, but also of decisions and thoughts; that's what's nipped in the bud, even though our society continually expects everyone to participate and be independent, and to own themselves. So, on one hand you take a lot away from the child, and on the other hand you force independence on them and expect them to undertake things. But when it comes to them wanting to make an autonomous decision about something like getting an injection, that's different; whether they like it or not, they have to get it. It is horrible having to force a child to do awful things, both physically and mentally."

\section{Box 7. Example in which neither the parents nor their child want to take the lead.}

One mother of a 15-year-old boy with cystic fibrosis described her desire for her son to became more autonomous in terms of regulating his own therapeutic regimen and inviting friends over; however, when she saw that her son was not going to step up and take the lead and therefore jeopardized his well-being, she took back the lead: "I could tell him I wasn't going to do it and back off. But then I know that it would all go wrong. I just think to myself, 'Oh well, as long as he is at home and I am still able to do it for him."' 
The mother of a 10-year-old girl with JIA: "I'm not the one who should forbid it. For example, she tried dancing for six months, and it didn't go well at all. I could have forbidden it, but thought it was better that she found out for herself. Now she really likes free running, even though she can't keep up. But the kids there know that, and she does what she can. She's getting exercise, and she enjoys being part of a group I can see she is benefitting from it and that it's going well. But do I think it's sensible? No, I don't." Her daughter: "We often play 'show-jumping', where you put down blocks, lay a hockey stick across them, and then jump over the stick. Even though it isn't very easy, I still join in and play it a lot."

\section{DISCUSSION}

We aimed to describe the parents' and child's perspective on the daily life participation among chronically ill children. We found that parents predominantly focus on safeguarding their child's well-being, using participation as a means to achieve well-being. We identified two approaches that parents take: i) participation consistent with their child's healthy peers, and ii) participation with a focus on their child's physical well-being. We also found that parents use different strategies for supporting these approaches, and we found that friction can arise between parent and child when they felt different on who (i.e. parents or child) should take the lead regarding the child's participation.

A conceptual analysis based on the International Classification of Functioning, Disability and Health criteria describes participation as both a means and an end. ${ }^{27}$ Interestingly, in our interviews parents described participation as primarily a means to achieve well-being, whereas children described participation as more of a goal in itself, as we previously reported. ${ }^{5}$ This apparent discrepancy underscores the importance of establishing a dialogue regarding how participation should take place. Several aspects found in this study are in line with other major themes in qualitative studies among children with various chronic diseases and their parents. These include striving for normalcy or being more like the child's healthy peers, ${ }^{28-33}$ and findings ways to manage the child's disease and symptoms, although the way in which parents and children managed this sometimes differed. 9,16,18,29,30,32,34-36

These differences in viewpoint between parents and children can give rise to friction. The presence of a chronic disease can influence both the parent-child relationship and the child's path to autonomy, as it increases the child's dependency, particularly when additional care is needed and given that parents wish to protect their child."1-13,33 Friction in the parent-child relationship has also been reported in other qualitative studies among young people with chronic diseases, which describe parents who find it difficult to allow their child to make his/her own choices, as well as children who feel unable to fulfil their desire for independence. $9,14,16,32$ Our finding that sometimes neither the parents nor the child want to take the lead is also consistent with several studies that found that young people can be hesitant to take the lead, as they feel safer with their parents.9,16,18 Therefore, opening a dialogue to discuss the parent's and child's perspective on the child's participation may help children and parents better understand each other and may help them find ways to interrelate while giving the child more autonomy. Teaching healthcare professionals to start a dialogue with 
children and parents regarding their goals and preferences may be helpful in clinical practice. $^{37}$

A major strength of this study is our paired analysis of qualitative material in which the child and his/her parent(s) were interviewed separately but simultaneously. This approach provides important insights into the parents' and child's views regarding participation and how these views interrelate among various paediatric chronic diseases. ${ }^{5}$ Finally, our analytical methods were designed to optimize both validity and reliability. ${ }^{20,25}$ Saturation was reached with respect to the goals for participation and how the child and his/her parents interrelate, although some aspects of the parental strategies may not have been fully revealed.

Despite these strengths, our study has limitations that warrant discussion, including the limitations described in our previous report such as the generalizability of our results, as we interviewed Caucasian families only. In addition, the parental interviews focused primarily on how their child viewed his/her participation and not necessarily how the parents defined the participation of the child, as our research design focused on the child.

With respect to the daily life participation of a chronically ill child, healthcare professionals should initiate a conversation regarding the parents' and child's goals, and the child's autonomy as early as possible in order to observe and discuss changes over time. ${ }^{37}$ For future studies, interventions that teach healthcare professionals how to start a dialogue with children and parents regarding their goals and preferences may be beneficial. ${ }^{37}$ Also, whether there are differences in parent-child interactions between children with a genetic disease (early diagnosis, e.g. CF) and those with an acquired disease (later diagnosis, e.g. autoimmune disease or childhood cancer) is of interest.

\section{CONCLUSION}

To optimize the child's daily life participation and well-being, understanding the parents' goals and how parents and children interrelate can allow children, parents, and healthcare professionals to establish and achieve mutual goals. Starting a conversation regarding the child's and parent's goals and decisions may help children and parents find effective ways to interrelate, while allowing the child to increase his/ her autonomy. 


\section{REFERENCES}

1. Perrin JM, Bloom SR, Gortmaker SL. The Increase of Childhood Chronic Conditions in the United States. JAMA. 2007;297(24):2755. doi:10.1001/jama.297.24.2755

2. Zan H, Scharff RL. The Heterogeneity in Financial and Time Burden of Caregiving to Children with Chronic Conditions. Matern Child Health J. 2015;19(3):615-625. doi:10.1007/s10995-014-1547-3

3. Pinquart $M$, Teubert D. Academic, physical, and social functioning of children and adolescents with chronic physical illness: a meta-analysis. J Pediatr Psychol. 2012;37(4):376-389. doi:10.1093/jpepsy/jsr106

4. Leeman J, Crandell JL, Lee A, Bai J, Sandelowski M, Knafl K. Family Functioning and the Well-Being of Children With Chronic Conditions: A Meta-Analysis. Res Nurs Health. 2016:39(4):229-243. doi:10.1002/nur.21725

5. Nap-van der Vlist MM, Kars MC, Berkelbach van der Sprenkel EE, et al. Daily life participation in childhood chronic disease: a qualitative study. Arch Dis Child. 2020;105(5):463-469. doi:10.1136/archdischild-2019-318062

6. Martin Ginis KA, Evans MB, Mortenson W Ben, Noreau L. Broadening the Conceptualization of Participation of Persons With Physical Disabilities: A Configurative Review and Recommendations. Arch Phys Med Rehabil. 2017;98(2):395-402. doi:10.1016/j.apmr.2016.04.017

7. Westergren T, Berntsen S, Ludvigsen MS, et al. Relationship between physical activity level and psychosocial and socioeconomic factors and issues in children and adolescents with asthma. JBI Database Syst Rev Implement Reports. 2017;15(8):2182-2222. doi:10.11124/JBISRIR-2016-003308

8. Willis C, Girdler S, Thompson M, Rosenberg M, Reid S, Elliott C. Elements contributing to meaningful participation for children and youth with disabilities: a scoping review. Disabil Rehabil. 2017;39(17):1771-1784. doi:10.1080/09638288.2016.12 07716

9. Hoefnagels JW, Kars MC, Fischer K, Schutgens R, Schrijvers LH. The Perspectives of Adolescents and Young Adults on Adherence to Prophylaxis in Hemophilia: A Qualitative Study. Patient Prefer Adherence. 2020;14:163-171. doi:10.2147/PPA. S232393

10. Minuchin P. Families and Individual Development: Provocations from the Field of Family Therapy Author ( $\mathrm{s}$ ): Patricia Minuchin Published by: Wiley on behalf of the Society for Research in Child Development Stable URL : http://www.jstor.org/ stable/1129720 REFERENCES. Child Dev. 1985;56(2):289-302. doi:10.1002/pen.21025

11. Schmidt S, Petersen C, Bullinger M. Coping with chronic disease from the perspective of children and adolescents--a conceptual framework and its implications for participation. Child Care Health Dev. 2003;29(1):63-75. Accessed July 10, 2019. http://www.ncbi.nlm.nih.gov/pubmed/12534568

12. Kars MC, Grypdonck MHF, de Bock LC, van Delden JJM. The parents' ability to attend to the "voice of their child" with incurable cancer during the palliative phase. Heal Psychol. 2015;34(4):446-452. doi:10.1037/hea0000166 
13. Wallander JL, Varni JW. Effects of pediatric chronic physical disorders on child and family adjustment. J Child Psychol Psychiatry. 1998;39(1):29-46. Accessed February 14, 2019. http://www.ncbi.nlm.nih.gov/pubmed/9534085

14. Gutman T, Hanson C, Bernays S, et al. Child and Parental Perspectives on Communication and Decision Making in Pediatric CKD: A Focus Group Study. Am J Kidney Dis. 2018;72(4). doi:10.1053/J.AJKD.2018.05.005

15. Coyne I, Amory A, Kiernan G, Gibson F. Children's participation in shared decisionmaking: children, adolescents, parents and healthcare professionals' perspectives and experiences. Eur J Oncol Nurs. 2014;18(3):273-280. doi:10.1016/j.ejon.2014.01.006

16. Peeters MAC, Hilberink SR, van Staa A. The road to independence: lived experiences of youth with chronic conditions and their parents compared. J Pediatr Rehabil Med. 2014;7(1):33-42. doi:10.3233/PRM-140272

17. Fereday J, MacDougall C, Spizzo M, Darbyshire P, Schiller W. "; There's nothing I can't do - I just put my mind to anything and I can do it".: a qualitative analysis of how children with chronic disease and their parents account for and manage physical activity. BMC Pediatr. 2009;9(1):1. doi:10.1186/1471-2431-9-1

18. Hilberink SR, van Ool M, van der Stege HA, et al. Skills for Growing Up-Epilepsy: An exploratory mixed methods study into a communication tool to promote autonomy and empowerment of youth with epilepsy. Epilepsy Behav. 2018;86:116123. doi:10.1016/J.YEBEH.2018.05.040

19. Dierckx de Casterlé B, Gastmans C, Bryon E, Denier Y. QUACOL: A guide for qualitative data analysis. Int J Nurs Stud. 2012;49(3):360-371. doi:10.1016/j. ijnurstu.2011.09.012

20. Creswell J. Qualitative Inquiry \& Research Design: Choosing among Five Approaches (3rd Ed.). Thousand Oaks, CA: SAGE.; 2013.

21. Gordijn MS, Suzanne, Cremers EMP, Kaspers GJL, Gemke RJBJ. Fatigue in children: reliability and validity of the Dutch PedsQLTM Multidimensional Fatigue Scale. Qual Life Res. 2011;20(7):1103-1108. doi:10.1007/s11136-010-9836-9

22. Rosier EM, ladarola MJ, Coghill RC. Reproducibility of pain measurement and pain perception. Pain. 2002;98(1-2):205-216. Accessed May 31, 2019. http://www.ncbi.nlm. nih.gov/pubmed/12098633

23. Charmaz K. Constructing Grounded Theory. 2nd Edition. Sonoma State University, USA; 2014.

24. Pope C, Ziebland S, Mays N. Qualitative research in health care. Analysing qualitative data. BMJ. 2000;320(7227):114-116. Accessed December 21, 2018. http:// www.ncbi.nlm.nih.gov/pubmed/10625273

25. Morse J, Barret M, Mayan M, Olson K, Spiers J. Verification strategies for establishing reliability and validity in qualitative research. Int J Qual Meth. 2002;1(2).

26. VERBI Software. MAXQDA 2018. Published online 2017.

27. Imms C, Granlund M, Wilson PH, Steenbergen B, Rosenbaum PL, Gordon AM. Participation, both a means and an end: a conceptual analysis of processes and outcomes in childhood disability. Dev Med Child Neurol. 2017;59(1):16-25. doi:10.1111/ 
dmen.13237

28. Harden J, Black R, Chin R. Families' experiences of living with pediatric epilepsy: A qualitative systematic review. Epilepsy Behav. 2016;60. doi:10.1016/J. YEBEH.2016.04.034

29. Bailey PK, Hamilton AJ, Clissold RL, et al. Young adults' perspectives on living with kidney failure: a systematic review and thematic synthesis of qualitative studies. BMJ Open. 2018;8(1):e019926. doi:10.1136/bmjopen-2017-019926

30. Tong A, Jones J, Craig JC, Singh-Grewal D. Children's experiences of living with juvenile idiopathic arthritis: a thematic synthesis of qualitative studies. 2012;64(9). doi:10.1002/acr.21695

31. Lambert $V$, Keogh D. Striving to live a normal life: a review of children and young people's experience of feeling different when living with a long term condition. J Pediatr Nurs. 2015;30(1):63-77. doi:10.1016/j.pedn.2014.09.016

32. Jamieson N, Fitzgerald D, Singh-Grewal D, Hanson CS, Craig JC, Tong A. Children's experiences of cystic fibrosis: a systematic review of qualitative studies. Pediatrics. 2014;133(6):el683-97. doi:10.1542/peds.2014-0009

33. Loades ME, James V, Baker L, Jordan A, Sharma A. Parental Experiences of Adolescent Cancer-Related Fatigue: A Qualitative Study. J Pediatr Psychol. 2020;45(10):1093-1102. doi:10.1093/jpepsy/jsaa080

34. Belpame N, Kars MC, Beeckman D, et al. ":The AYA Director",:. A Synthesizing Concept to Understand Psychosocial Experiences of Adolescents and Young Adults With Cancer. Cancer Nurs. 2016;39(4):292-302. doi:10.1097/ NCC. 0000000000000307

35. Quirk H, Blake H, Dee B, Glazebrook C. "You can't just jump on a bike and go": a qualitative study exploring parents' perceptions of physical activity in children with type 1 diabetes. BMC Pediatr. 2014;14(1):313. doi:10.1186/s12887-014-0313-4

36. Smith J, Cheater F, Bekker H. Parents' experiences of living with a child with a long-term condition: a rapid structured review of the literature. Health Expect. 2015;18(4):452-474. doi:10.1111/hex.12040

37. Fahner JC, Beunders AJM, van der Heide A, et al. Interventions Guiding Advance Care Planning Conversations: A Systematic Review. J Am Med Dir Assoc. 2019;20(3):227-248. doi:10.1016/j.jamda.2018.09.014 


\section{Part III \\ PROfeel: personalized assessment and advice}

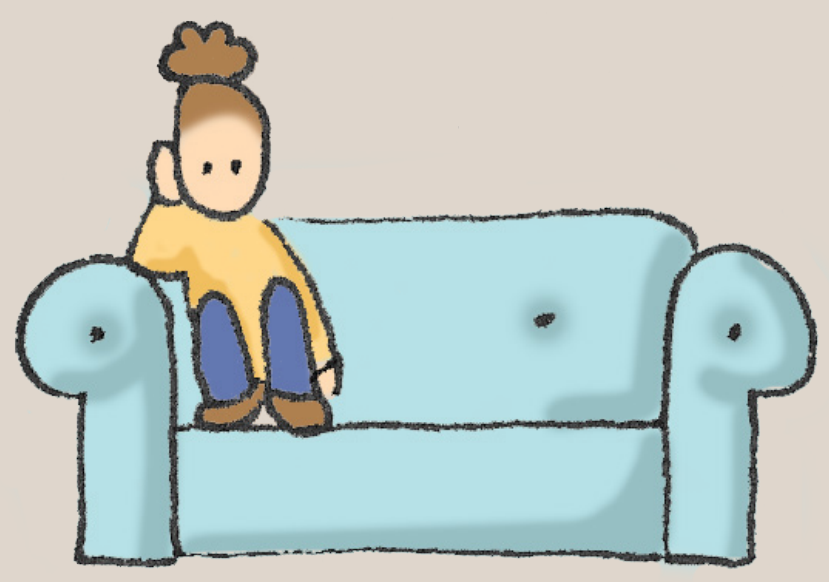



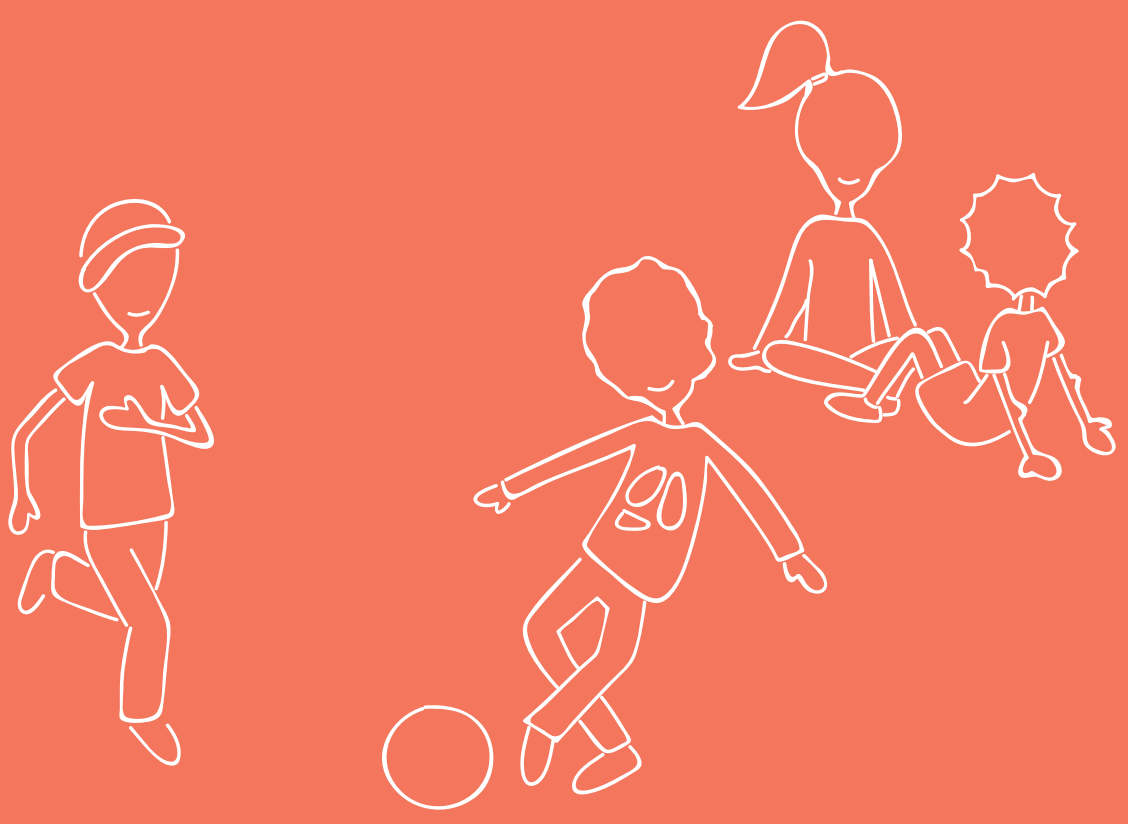


\title{
Internet and smartphone-based eco- logical momentary assessment and personalized advice (PROfeel) in adolescents with chronic conditions: a feasibility study
}

\author{
Merel M. Nap-van der Vlist, MDa; \\ Jan Houtveen, PhDa, \\ Geertje W. Dalmeijer, PhD ${ }^{b}$; \\ Martha A. Grootenhuis, PhD; \\ Cornelis K. van der Ent, MD PhDd; \\ Martine van Grotel, MD PhD \\ Joost F. Swart, MD PhDe; \\ Joris M. van Montfrans, MD PhDe; \\ Elise $M$. van de Putte, MD PhDa. \\ Sanne L. Nijhof, MD PhDa
}

a Department of Paediatrics, Wilhelmina Children's Hospital, University Medical Center

Utrecht, Utrecht University, Utrecht, the Netherlands b Julius Center for Health Sciences and Primary Care, University Medical Center Utrecht, Utrecht University, Utrecht, the Netherlands c Princess Máxima Center for Paediatric Oncology, Utrecht, the Netherlands d Department of Paediatric Pulmonology, Wilhelmina Children's Hospital, University Medical Center Utrecht, Utrecht University, Utrecht, the Netherlands

e Department of Paediatric Rheumatology/Immunology and Infectious Diseases, Wilhelmina Children's Hospital, University Medical Center Utrecht, Utrecht University, Utrecht, The Netherlands 


\section{ABSTRACT}

\section{Objective:}

Growing up with a chronic disease comes with challenges, such as coping with fatigue. Many adolescents are severely fatigued, though its associated factors exhibit

considerable interpersonal and longitudinal variation. We assessed whether PROfeel, a combination of a smartphone-based ecological momentary assessment (EMA) method using the internet, followed by a face-to-face dialogue and personalized advice for improvement of symptoms or tailor treatment based on a dynamic network analysis report, was feasible and useful.

\section{Study design:}

Feasibility study in fatigued outpatient adolescents 12-18 years of age with cystic fibrosis, autoimmune disease, post-cancer treatment, or with medically unexplained fatigue. Participants were assessed at baseline to personalize EMA questions. EMA was conducted via smartphone notifications five times per day for approximately six weeks. Hereby, data was collected via the internet. The EMA results were translated into a personalized report, discussed with the participant, and subsequently translated into a personalized advice. Afterwards, semi-structured interviews on feasibility and usefulness were held.

\section{Results:}

Fifty-seven adolescents were assessed (mean age 16.2y $\pm 1.6,16 \%$ male). Adolescents deemed the smartphone-based EMA feasible, with the app being used for an average of 49 days. Forty-two percent of the notifications were answered and 85\% of the participants would recommend the app to other adolescents. The personalized report was deemed useful and comprehensible and $95 \%$ recognized themselves in the personalized report, with $64 \%$ rating improved insight in their symptoms and subsequent steps towards an approach to reduce one's fatigue as good or very good.

\section{Conclusions :}

PROfeel was found to be highly feasible and useful for fatigued adolescents with a chronic condition. This innovative method has clinical relevance through bringing a patient's daily life into the clinical conversation. 


\section{INTRODUCTION}

\section{Background}

An ever increasing number of children is growing up with a chronic disease.' In the Netherlands, approximately one in four children is affected with a chronic disease. ${ }^{2}$ They face extra challenges associated with their ever-present illness, such as coping with fatigue or pain., ${ }^{4,6}$ Fatigue can be a debilitating symptom, leading to reduced societal participation and quality of life. ${ }^{8-10}$ Although various factors may play a role in fatigue in childhood chronic disease, the exact predisposing, precipitating, and perpetuating roles differ on an individual level (interpersonal) and over time (longitudinal).1-14 To tailor advice to the unique adolescent's needs and mechanisms in a way that fits the adolescent's lifestyle and perception, new personalized (internet and smartphone-based) longitudinal assessment methodologies and data analysis strategies are needed..$^{15}$

\section{Conceptualization of fatigue}

Fatigue could be considered a transdiagnostic symptom.,16 This means that various factors that perpetuate fatigue may be shared by adolescents with a chronic disease, as they may be part of growing up with a chronic disease, independent of their diagnosis. ${ }^{17}$ Examples of such biological, psychological and social factors that influence outcome measures in pediatric chronic diseases $5,6,18$, include sleep patterns, physical activity, and psychological wellbeing. Recent studies show that disease-specific factors may play a role in perpetuating fatigue, but fatigue may persist despite low or absent disease activity. 819 Therefore, potentially modifiable factors other than disease-specific factors may be associated with - and can perpetuate - fatigue in these patients and are potential treatment targets on an individual level.,6,8,20-24

\section{Ecological momentary assessment and single-subject data analyses}

To find out which modifiable factors are associated with fatigue in daily life on an individual level, it is possible to collect highly intensive longitudinal data (ILD) of participants. Real-time fluctuations in one's symptoms and well-being can be investigated through micro-questionnaires multiple times per day. ${ }^{25}$ This Ecological Momentary Assessment method (EMA) can nowadays be implemented using the internet and smartphones to reliably collect more than 50 assessments per person.26,27 With increasing computational power, it has recently become feasible to perform dynamic ILD-analyses. ${ }^{15}$ Using the combination of EMA with novel data analysis techniques such as dynamic structural equation modelling (DSEM ${ }^{28}$ ), it is possible to gain patient-tailored insights into underlying mechanisms of symptoms such as fatigue, when measured with EMA. 26,29-32 The application of this concept into clinically applicable tools, especially in pediatric medicine, is innovative. Examples of feasible applications are yet limited, taking into account the high intensity of the longitudinal measurements and the applicability of personalized feedback. 27,29,32-34

It may be useful for fatigued adolescents with a chronic condition to combine internet-based EMA and ILD analyses to identify, for a particular patient, the core biopsychosocial processes that are related to fatigue in the individual patient. ${ }^{35}$ These dynamic processes and patterns can be used to start a dialogue within the 
adolescent-clinician relationship on how the adolescent can self-manage his/her fatigue, formulating personalized advice for improvement of symptoms (e.g., by lifestyle changes) or to tailor a subsequent treatment. In this study, we will refer to the combination of this measurement method and personalized advice as PROfeel. In the current study, we assessed whether PROfeel is feasible and useful. We defined feasibility as achievability of filling out the EMA measurements and understanding the personalized report. We defined usefulness as effective in helping adolescents gain insight in their symptoms and associated factors.

\section{METHODS}

\section{Study design}

Feasibility study among outpatients of the Wilhelmina Children's Hospital and the Princess Máxima Center for Paediatric Oncology in the Netherlands, from October 2017 through August 2018. Using patient-reported outcomes (PROs), we assessed the feasibility and usefulness of PROfeel, a combination of EMA (using the internet and smartphones) followed by a personalized advice based on a personalized report. We defined feasibility as achievability of filling out the EMA measurements (Feasibility EMA) and understanding the personalized report (Feasibility Report). For the EMA, we looked at compliance (Feasibility EMA 1), user friendliness (Feasibility EMA 2) and the burden of the measurements for adolescents (Feasibility EMA 3). For the personalized report, we looked at whether adolescents found it recognizable (Feasibility Report 1) and comprehensible (Feasibility Report 2). We defined usefulness as effective in helping adolescents gain insight in their symptoms and associated factors. For the EMA, we looked at whether adolescents found it valuable to fill out the EMA and whether they would recommend it to other adolescents (Usefulness EMA). For the personalized report, we asked adolescents to report on new insight based on the report (Usefulness Report 1) and whether they were able to take steps towards an approach to reduce one's fatigue (Usefulness Report 2). This study was classified by the institutional review board as exempt of the Medical Research Involving Human Subjects Act (16-203/C). Informed consent was obtained from adolescents and their parents.

\section{Participants}

Participants were recruited from a larger cohort of children with cystic fibrosis (CF), an autoimmune disease, children post-cancer treatment or children with medically unexplained symptoms, at the Wilhelmina Children's Hospital and the Princess Máxima Center for Paediatric Oncology in the Netherlands: the PROactive cohort. The goal of the PROactive cohort is to collect data on fatigue and associated factors across childhood chronic diseases, in a relatively stable phase of their disease. The methodology of data collection of the PROactive cohort is described elsewhere. ${ }^{5}$ Included in this study were adolescents 12-18 years of age with cystic fibrosis (CF), autoimmune disease, post-cancer treatment, or with medically unexplained fatigue. Participants were eligible if their treating physician determined they were in a stable phase of their disease, if they scored fatigued (see below) on a screening questionnaire of the PROactive data collection and if they indicated that this fatigue restricted 
them in daily life. For the screening on fatigue, the Dutch version of the PedsQL multidimensional fatigue scale was used. ${ }^{36}$ A cut-off of more than one standard deviation below the norm was taken to classify fatigued adolescents, taking into account sex and age. ${ }^{5}$ This norm was chosen in order to be able to offer PROfeel to a broad range of adolescents. The most important inclusion criteria were whether the adolescent him/herself felt restricted by his/her fatigue in daily life, actively desired to gain insight into his/her symptoms and had a wish to actively work on reducing his/her fatigue.

\section{Content of personalized ecological momentary assessments}

For this feasibility study, an existing EMA-platform and application was used that allowed for the delivery of personalized EMA prompts (notifications) and questions on the smartphone, namely the Ethica application. ${ }^{36}$ Part of the questions of the EMA-survey was the same for all participants (fixed) and part was personalized, based on personal preference. The EMA content was built on the theoretical framework of the efficacious elements of cognitive behavioural therapy for fatigue in adolescents. ${ }^{37}$ Central elements in this therapy are, for example, establishing a sleep routine, stimulating an adolescent to find a balance between rest and activity, gradually increasing activity at home, school or with friends, addressing fatigue-related cognitions, and increasing self-management and independency. ${ }^{38}$ Therefore, the fixed content of the EMA questionnaire (i.e., collected for each participant) included questions regarding sleep-wake routines, physical activity and social activity. The personalized part of the EMA questionnaire was focused on targeting a participant's individual cognitions of fatigue (see Supplementary Table SI for an overview of the EMA content). The content was developed in an interdisciplinary team of researchers and clinicians from the fields of psychology, paediatrics, information technology, and graphic design. This was an iterative process in which potential questions were reviewed and tested several times by team members, after which the content and usefulness was tested by a patient.

There were 13 fixed questions. Fatigue and restrictions were measured on a visual analogue scale (VAS) from 0 to 100, and school participation was measured by asking for amount of hours the participant attended school compared to the amount of scheduled hours. In addition, fixed questions were nighttime and daytime sleep, physical activity and mental activity (e.g. working concentrated on a task or paying attention), and social support. These factors were measured as VAS scores (0-100) or categorical outcomes (two to four answer options).

The personalized questions were chosen based on a baseline survey with the participant. Up to three other physical complaints could be chosen that seemed to be associated with fatigue for this particular participant. Furthermore, associated personal factors in thinking or feeling (psychosocial factors) or personal factors that could be associated with the perceived symptoms in the broadest sense of the word could be chosen. Up to five personal factors could be added in total. For example, one participant wanted to add a variable about his food intake, and another requested to add a variable about her boyfriend and the pressure she felt while being with him. Little has been reported in the literature on the ideal length of EMA questionnaires. ${ }^{26}$ 
The choice for the number of EMA questions requires balancing between collecting as much data as possible, while minimizing the burden for adolescents who participated. To achieve minimal burden, we chose to partially personalize the EMA questionnaires, and branching was used to tailor some questions to the specific situation (i.e. other questions were asked in the morning then in the afternoon). Attention was paid to the length of the total EMA survey, so that it did not take more than one minute to fill out per notification. The maximum of questions was therefore set to 26 . The selection of questions was implemented by filling out a baseline survey on the smartphone during intake (see below).

\section{Study procedures}

If an adolescent was willing to participate, the researcher planned an intake to install the app and discuss the personalization of the EMA. Next, the participant downloaded the application on his/her smartphone and filled out the baseline survey, leading to the personalization of both the EMA prompts (adjusted to the waking hours of the participant) and the EMA content. After completion, the personalized EMA started. A signal-contingent method was chosen, in which participants received notifications on their smartphone approximately five times per day, every three hours during waking hours. Data were transferred to a server using the internet, but the EMA could also be filled out when there was no internet connection. Results were then uploaded when the smartphone was reconnected to the internet. A time interval of three hours was chosen, since it was hypothesized that this interval would be suitable to measure changes in fatigue, although empirical evidence in this field is still lacking! 13,39 Participants were followed for approximately six weeks. In order to optimize the ILD analyses, we aimed for at least 50-100 measurements per participant and at least three measurements per day. ${ }^{40}$ This means that more measurements were offered than adolescents needed to fill out, allowing the adolescent to miss measurements occasionally, for example when they were busy or in class. After the measurement period, a personalized report was drafted by a statistician/psychologist and the clinical researcher (see section 2.5 and table 4). This report was discussed by the clinical researcher with the participant and, if possible, with their physician or psychologist. The goal of this appointment was to let the adolescent discover his or her own data, ask questions and help him/her gain insight in one's own symptoms so he/she could, together with the clinical researcher and/or healthcare provider, formulate a personalized advice for improvement of symptoms or to tailor treatment. After the discussion of the personalized report, a semi-structured interview with the participant on feasibility and usefulness was performed by another researcher who was not present at the discussion of the personalized report, to avoid socially desirable answers.

\section{Personalized report Analysing the EMA data}

Several ways were used to gain insight in the intensive longitudinal data. Two report methods were used to gain insight in the intensive longitudinal data: a basic report method and a RDSEM-based report. For the basic report, we used descriptive statistics. For the RDSEM report, we used innovative ILD dynamic time series analyses showing the single-subject dynamics of a process over time, yielding 
Granger causality.13 Granger causality means that a change in one concept repeatedly follows a change in another concept, also referred to as a lagged relationship or cross-correlation. For example, every time an adolescent scored higher on worrying, later that day this adolescent scored higher on fatigue. Granger causality, however, only suggests causality but does not proof it. We presented such a result to the adolescent as the hypothesis that fatigue follows worrying, and although we do not proof causality, it provides a clue. We used RDSEM-frameworks to create individual dynamic networks to identify complaint-perpetuating and influencing factors such as cognitions, affect, physical and mental activity, social support, and sleep quality. A more detailed description of the statistical background of these analyses can be found in Supplementary Table S2. RDSEM analyses were done in MPLUS version 8.2

\section{Presenting the EMA data in a personalized report}

The personalized report always started with a basic report with graphs showing the observed scores of the measured continuous variables (such as fatigue or pain, but also thoughts, feelings, amount of physical or mental activity, etc.). For each variable, the low-frequency trend (i.e., low-pass filtered signal) was also visualized in the same graph. The mean scores per hour of the day and per day of the week were shown in different graphs in the basic report to gain insight in the temporal patterns. Dependency of the continuous variables with the categorical factors observed (e.g., being alone or with others, being at home, at school, somewhere else, etc.) was visualized in the basic report by showing graphs with the mean scores per category. Using this basic method, adolescents could still gain insight in their symptoms, even when a RDSEM analyses was not possible, or yielded little or no clear, significant results. After the basic analyses, all continuous factors were entered into different RDSEM models (max three variables per model) to compute dynamic networks showing the lagged and contemporaneous relationships between these variables, corrected for the low-frequency trends, time of day and weekend effects. RDSEM dynamic networks that were considered of relevance were shown in simplified form to the participant. This was based on: 1) was an estimate significant with $P<0.05,2$ ) had an estimate a standardized $\beta>0.2$, and 3) was an estimate considered clinically relevant. Examples of the visual representation of these networks are found in table 4. This visual representation was developed and refined based on feedback from the interdisciplinary research team and participants.

\section{Measures}

\section{Clinical inclusion measurements}

Patient characteristics such as age, sex, diagnosis, duration of disease and disease activity were extracted from the participant's medical record. For adolescents with CF, forced expiratory volume in one second (FEVI) was used as a proxy for disease status, expressed as the percentage of predicted FEV1. ${ }^{41}$ For adolescents with juvenile idiopathic arthritis (JIA), the clinical Juvenile Arthritis Disease Activity Score (cJADAS) and erythrocyte sedimentation rate (ESR) were used as a proxy for disease status; for adolescents with other autoimmune diseases, only ESR was used.

\section{Compliance assessment}

To assess compliance, the number of notifications sent and answered was recorded. 
Also, the number of days that EMA was used was recorded.

\section{Semi-structured interviews to assess feasibility and usefulness}

The participants were asked to grade eight aspects of the use of the EMA and five aspects of the personalized report (scale of 10 points, questionnaire especially developed for this study). On all these aspects, the researcher encouraged the participant with open questions to express why the specific grade was given and what worked well on this aspect and what could further be improved.

\section{Data analyses feasibility and usefulness}

Descriptive statistics were used to summarize patient characteristics, compliance data and ratings as feedback on the different aspects of the EMA and the personalized report. Differences between participants and non-participants were analysed using the Student's t-test or chi-square test. Normally distributed data are presented as mean \pm standard deviation (SD); otherwise median and interquartile range was provided. A generic explorative qualitative design was used with a two-step approach. All interviews were transcribed and themes were coded and categorized. 42 Main themes were described and illustrated with quotes.

\section{RESULTS}

\section{Patient characteristics}

Of the 97 approached adolescents, 57 (59\%) participated. The mean age was $16.2 \pm 1.6$ years and $16 \%$ was male. There were ten participants with CF, 18 with an autoimmune disease or immune deficiency, three post-cancer treatment, and 26 with medically unexplained fatigue. There were no differences in sex and age between the participants and non-participants, nor were there significant differences in participation rates between groups. Common reasons for not participating were finding it too burdensome to fill out the EMA or not wanting to be confronted with their fatigue. There was no significant difference in fatigue scores between participants and non-participants.

\section{Feasibility EMA measurements Feasibility EMAI: Compliance}

Participants received on average $236 \pm 96$ notifications with an average measurement period of $49 \pm 22$ (range 21-135) days. During this measurement period, participants filled out EMA questionnaires for an average of $36 \pm 11$ (range 10-67) days. Of all the notifications, 42\% was answered. We strived for at least 50-100 measurements per participant. Ten participants (18\%) did not reach this, due to technical difficulties, decreased motivation or a combination of these. Especially at the start of the study, some technical difficulties were encountered. One of the technical difficulties was that for IPhone users, the Ethica app generated duplicate data for expired surveys, which made it harder to reliably calculate the compliance rate. The reported compliance rate $(42 \%)$ is the lowest calculated compliance rate. Compliance was highest at the start of the study and slowly decreased during the measurement period (figure 1). 


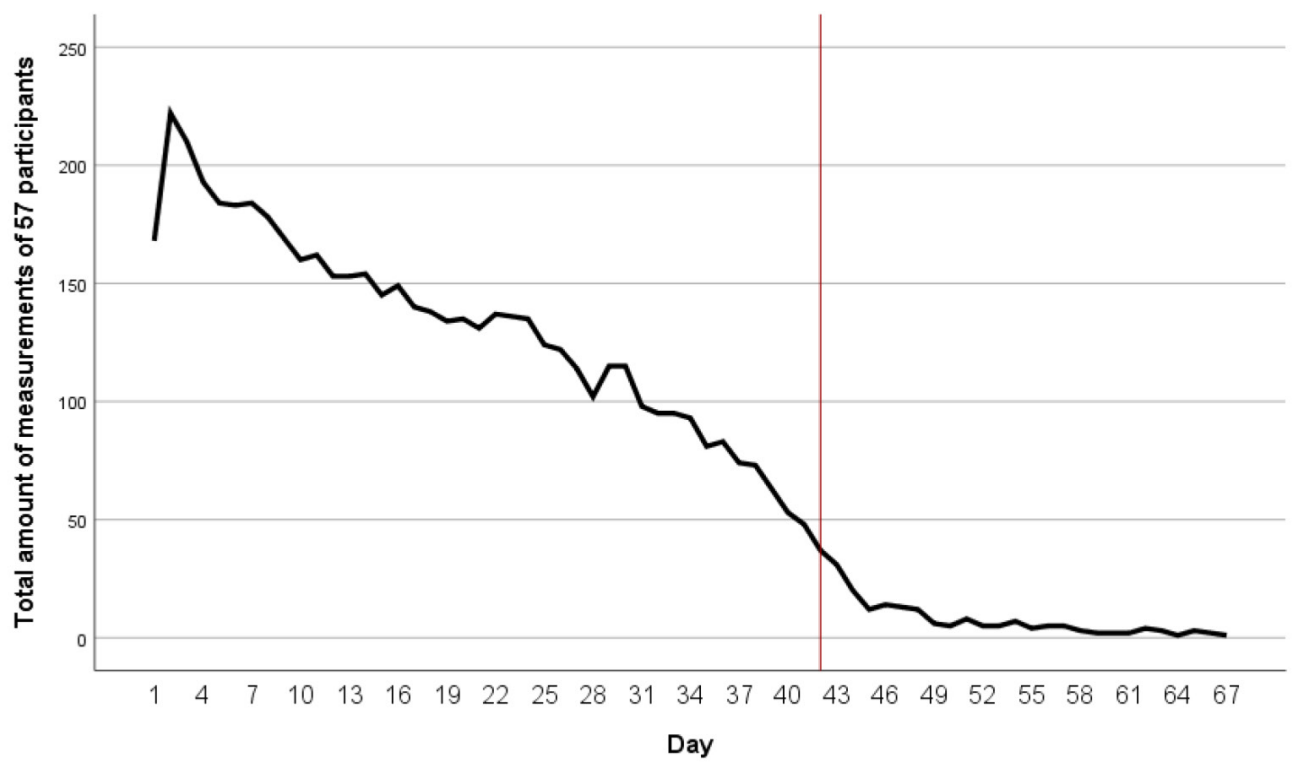

The red line indicates the desired measurement period of six weeks.

Figure 1. Total amount of EMA measurements in all participants per day

\begin{tabular}{|c|c|c|c|c|}
\hline & \multicolumn{3}{|c|}{ Chronic disease groups } & \multirow{2}{*}{$\begin{array}{l}\text { Adolescents with } \\
\text { unexplained fatigue } \\
\text { Adolescents with } \\
\text { medically } \\
\text { unexplained } \\
\text { fatigue }(N=26)\end{array}$} \\
\hline & $\begin{array}{l}\text { Adolescents with } \\
\text { CF }(N=10)\end{array}$ & $\begin{array}{l}\text { Adolescents with } \\
\text { autoimmune } \\
\text { disease }(N=18)\end{array}$ & $\begin{array}{l}\text { Adolescents } \\
\text { post-cancer } \\
\text { treatment }(\mathrm{N}=3)\end{array}$ & \\
\hline Age (mean $\pm S D)$ & $16.9 \pm 1.6$ & $16.2 \pm 1.8$ & $15.1 \pm 1.7$ & $16.0 \pm 1.4$ \\
\hline Sex, female (N, \%) & $9(90 \%)$ & $16(89 \%)$ & $3(100 \%)$ & $20(77 \%)$ \\
\hline Diagnosis & $\begin{array}{l}4(40 \%) \\
\text { homozygous } \\
\text { dF508 mutation } \\
6(60 \%) \\
\text { heterozygous } \\
\text { dF508 mutation }\end{array}$ & $\begin{array}{l}3(17 \%) \text { poly JIA } \\
5(28 \%) \text { oligo JIA } \\
2 \text { (11\%) systemic JIA } \\
2 \text { (11\%) other JIA } \\
\text { subtype } \\
6 \text { (33\%) other } \\
\text { autoimmune } \\
\text { disease }\end{array}$ & $\begin{array}{l}\text { I (33\%) solid } \\
\text { tumours } \\
2(67 \%) \text { leukaemia/ } \\
\text { lymphoma }\end{array}$ & NA \\
\hline $\begin{array}{l}\text { Duration of } \\
\text { disease, years }{ }^{\text {a }} \\
\text { (mean } \pm S D)\end{array}$ & $16.9 \pm 1.6$ & $5.2 \pm 4.0$ & $0.9 \pm 0.8$ & NA \\
\hline
\end{tabular}

a Duration of disease: years since diagnosis until inclusion for adolescents with JIA; years from end of treatment until inclusion for adolescents post-cancer treatment. ${ }^{b}$ If the data were normally distributed, the mean $\pm S D$ is given; if not, the median and interquartile range is given. CF = cystic fibrosis; SD = standard deviation; JIA = juvenile idiopathic arthritis; CJADAS = clinical Juvenile Arthritis Disease Activity Score; ESR = erythrocyte sedimentation rate; FEVI \% = predicted percentage of forced expiratory volume in one second; NA = not applicable. 
Table 1. Baseline characteristics of participants

\begin{tabular}{|c|c|c|c|c|}
\hline Disease activity ${ }^{b}$ & $F E V_{1} \%: 69.5 \pm 15.1$ & $\begin{array}{l}\text { CJADAS: } 2(0-9) \\
\text { ESR: } 7.5 \mathrm{~mm} / 1 \mathrm{st} \mathrm{hr} \\
(2-48)\end{array}$ & $\begin{array}{l}\text { All post-cancer } \\
\text { treatment and in } \\
\text { remission }\end{array}$ & NA \\
\hline \multicolumn{5}{|c|}{$\begin{array}{l}\text { a Duration of disease: years since diagnosis until inclusion for adolescents with JIA; years from end of tre- } \\
\text { atment until inclusion for adolescents post-cancer treatment. "If the data were normally distributed, the } \\
\text { mean } \pm \text { SD is given; if not, the median and interquartile range is given.CF = cystic fibrosis; SD = standard } \\
\text { deviation; JIA = juvenile idiopathic arthritis; CJADAS = clinical Juvenile Arthritis Disease Activity Score; ESR } \\
=\text { erythrocyte sedimentation rate; FEVI \% = predicted percentage of forced expiratory volume in one } \\
\text { second; NA = not applicable. }\end{array}$} \\
\hline
\end{tabular}

\section{Feasibility EMA 2: User friendliness}

All participants rated user friendliness as good or very good (table 2). Of the 46 adolescents who commented on user friendliness, 42 (91\%) found the EMA easy to fill out, short, clear and personal. "The questions were really adapted to my situation and easy to relate to, so I immediately knew what to answer." (Female, 17 years old). Participants told us it took them between 40 seconds and five minutes to fill out and twelve participants mentioned that the time to fill out the EMA shortened during the measurement period.

Other positive points described by participants were the use of notifications on their own smartphone, the possibility to fill out the EMA with and without internet connection, and the use of visual analogue scales. The main barrier in user friendliness was the technical difficulties. Furthermore, almost halve of the adolescents (23 of the 49 that commented on this question, 47\%) found it difficult that the EMA often expired when they were busy or in class. For three adolescents, the continuous confrontation with their symptoms was a negative experience. "The amount of notifications was good, but the timing was bad. I did not always manage to fill out the EMA two or three times per day. When I felt bad, I was really tired, I did not sleep well and then I repeatedly had to fill out that I did not feel well." (Female, 18 years old).

\begin{tabular}{l|l|l|l|l|}
\hline Table 2. Usefulness and feasibility of the EMA & $\begin{array}{l}\text { Clarity of EMA } \\
(\mathbf{n = 5 0 )}\end{array}$ & $\begin{array}{l}\text { User friendliness } \\
(\mathbf{n}=50)\end{array}$ & $\begin{array}{l}\text { Burden of filling } \\
\text { out EMA during } \\
\text { measurement } \\
\text { period }(\mathbf{n}=46)\end{array}$ & $\begin{array}{l}\text { Would recommend } \\
\text { app (n=47) }\end{array}$ \\
\hline Very bad (0-2) & 0 & 0 & $1(2 \%)$ & 2 (Not at all; 4\%) \\
\hline Bad (3-4) & 0 & 0 & $2(4 \%)$ & $0($ No) \\
\hline Medium (5-6) & $2(4 \%)$ & 0 & $10(22 \%)$ & 5 (Maybe; 9\%) \\
\hline Cood (7-8) & $22(44 \%)$ & $20(40 \%)$ & $16(35 \%)$ & 16 (Most likely; 34\%) \\
Very good (9-10) & $26(52 \%)$ & $30(60 \%)$ & $17(37 \%)$ & 24 (Definitely; 51\%) \\
\hline
\end{tabular}

\section{Feasibility EMA 3: Burden of the measurement period}

Thirty-eight of the 43 adolescents that commented on the length of the measurement period (88\%) described the burden of the measurements as doable and part of their daily routine. For 17 of the 50 participants (34\%) who commented on the amount of measurements per day, five notifications per day were too much and some described 
repeatedly filling out the same questions as annoying. Twenty-nine percent of the adolescents described the measurement period as long or too long, but most described that they found this period necessary to provide a clear overview of what their daily life looked like and only two of them found it too burdensome. Nine adolescents described that at the end of the measurement period, they were fed up with filling out the EMA and their motivation to continue to do it decreased during the measurement period. "After four weeks I was tired of filling out the EMA, but I understand that you need six weeks for a good overview. It was not a bad thing, but irritating sometimes." (Female, 18 years old).

\section{Feasibility of the personalized report Feasibility Report 1: Recognisability}

Most adolescents (96\%) recognized their daily life patterns in the personalized report (that includes dynamic networks). Some adolescents did not recognize themselves in all associations and networks. One adolescent did not recognize her patterns at all and found the personalized report illogical. Recognition was needed for adolescents in order to be open to start a dialogue on personalized advice. For example, one adolescent told us: "Here I recognized myself: sleeping while it does not really help. You stay tired." (Female, 16 years old). This insight based on her own data opened the conversation on sleep-wake rhythms and what she could do to improve them to alleviate her fatigue.

\section{Feasibility Report 2: Comprehensibility}

Comprehensibility was rated as good or very good by $86 \%$ of the participants. Twentyfour adolescents told us that the explanation of the personalized report and the conversation on its meaning was helpful. Two adolescents believed the personalized report would be clear enough with textual explanation, but most described the added value of the consultation with the researcher and healthcare provider as crucial. "The graphs gave me insight and made me understand the results. I went to the appointment and said to my mom 'I don't think anything came out of it [the app], because I don't feel it did.' And then you have this conversation and it is really interesting, with all the graphs it becomes clearer." (Female, 17 years old).

\section{Usefulness EMA}

85\% of the participants would recommend the smartphone-based EMA to other adolescents (table 2). They found the EMA easy to fill out and not too time consuming. It helped them to think about their symptoms in another way. Nevertheless, they stated that discipline and time investment were required. "At first I thought: what can this bring me? But I have really seen the result. I think other teenagers can benefit from this, an app that captures daily life and results in an overview: it could be this and this, so that you can take steps to deal with your symptoms." (Female, 18 years old). Two adolescents would not recommend PROfeel at all, because it did not generate new insights and it was seen as too much trouble.

\section{Usefulness of the personalized report Usefulness Report 1: Insight in symptoms}

Of all participants, 64\% reported insight in their symptoms. Results are shown in 
table 3, with illustrative cases in table 4. Adolescents valued the clear overview the personalized report gave them, a confirmation that the patterns they experienced were not just in their head, but could be made visible. Seventeen adolescents (35\%) mentioned little or no new insights. The most common reason for this, given by nine adolescents, was because they were already aware of the patterns found in the personalized reports.

\begin{tabular}{|c|c|c|c|c|}
\hline Ranking & $\begin{array}{l}\text { Recognition of } \\
\text { personalized } \\
\text { report }(n=44)\end{array}$ & $\begin{array}{l}\text { Comprehensibility } \\
\text { of report }(n=42)\end{array}$ & $\begin{array}{l}\text { Insight in } \\
\text { symptoms }(n=48)\end{array}$ & $\begin{array}{l}\text { Report enabled } \\
\text { steps towards } \\
\text { treatment }(n=40)\end{array}$ \\
\hline $\begin{array}{l}\text { Very bad } \\
(0-2)\end{array}$ & $1(2 \%)$ & $1(2 \%)$ & 9 (19\%) & $8(20 \%)$ \\
\hline $\operatorname{Bad}(3-4)$ & 0 & 0 & $1(2 \%)$ & $2(5 \%)$ \\
\hline $\begin{array}{l}\text { Medium } \\
(5-6)\end{array}$ & $1(2 \%)$ & $5(12 \%)$ & $7(15 \%)$ & $5(13 \%)$ \\
\hline Good (7-8) & $14(32 \%)$ & $11(26 \%)$ & $17(35 \%)$ & $15(38 \%)$ \\
\hline Very good (9-10) & $28(64 \%)$ & $25(60 \%)$ & $14(29 \%)$ & $10(25 \%)$ \\
\hline
\end{tabular}

\section{Usefulness Report II: Steps towards an approach to reduce one's fatigue}

Based on the personalized report, 63\% reported they were able to take steps towards an approach to reduce one's fatigue (Table 3). Adolescents described the discussion of the report with the researcher and/or healthcare provider as valuable in taking steps toward an approach to reduce their fatigue. We will illustrate this with four example cases in table 4, to show different outcomes of the EMA measurements and the discussion of the personalized report. In case 1, a contemporaneous association between mental inactivity and fatigue was found, leading to the collective conclusion that distraction (i.e., by being mentally active) may help this participant to take her mind of her symptoms. In contrast, in case 2, more mental activity was contemporaneously related with fatigue and prevention of overstimulation was defined as a possible treatment target. Case 3 shows us an example of how physical activity was followed (i.e., three hours later) by less symptoms (less headache in this case) and less restrictions. In case 4, however, physical activity in the weekends was associated with more symptoms. Also, in this latter case, worrying was followed by more fatigue. Regarding the tailored advice, in case 3, increasing physical activity may be the next step towards a tailored approach to reduce fatigue, while in case 4, psychological support to cope with worrying may be more effective in addition to more balanced physical activity during the weekend. 

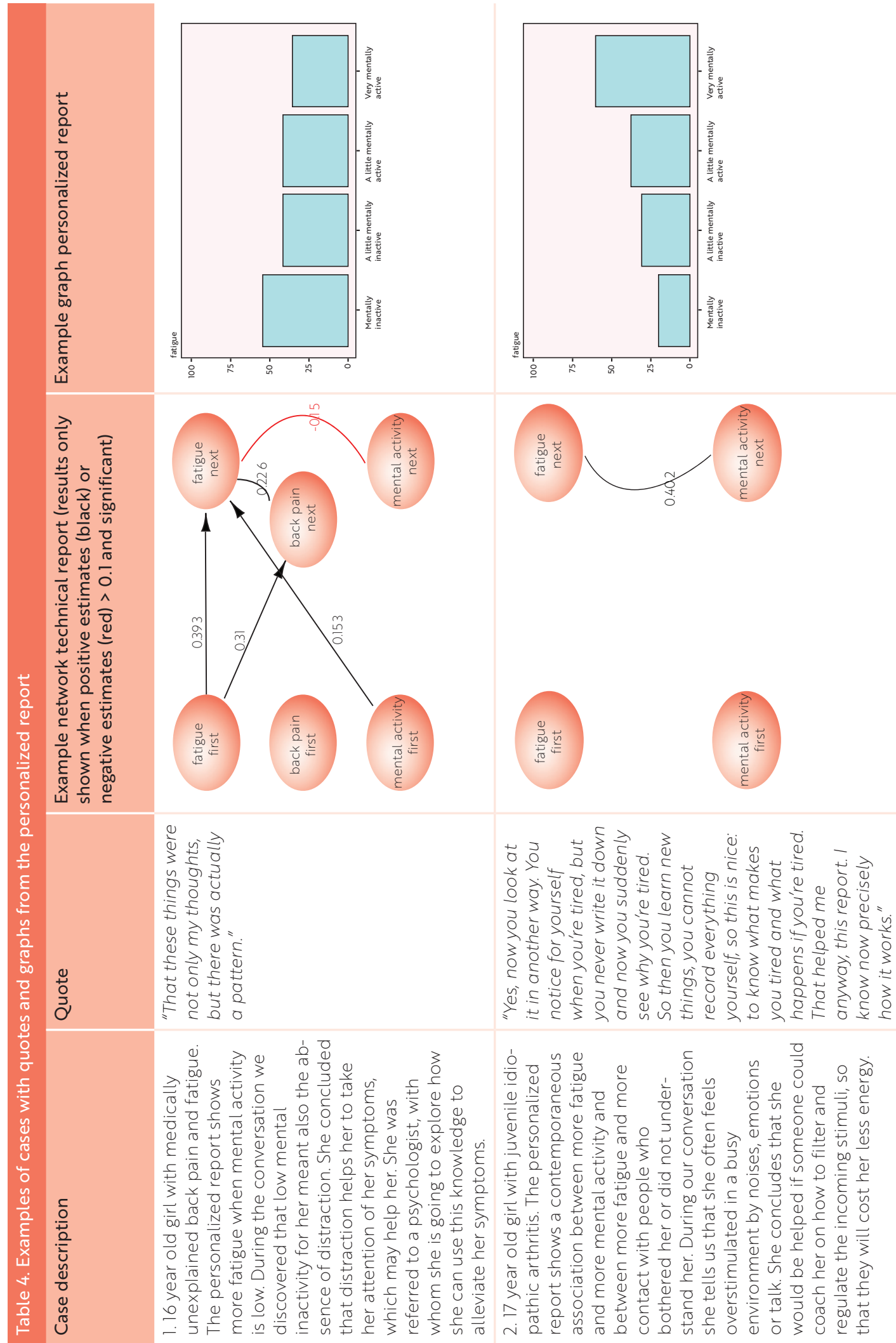


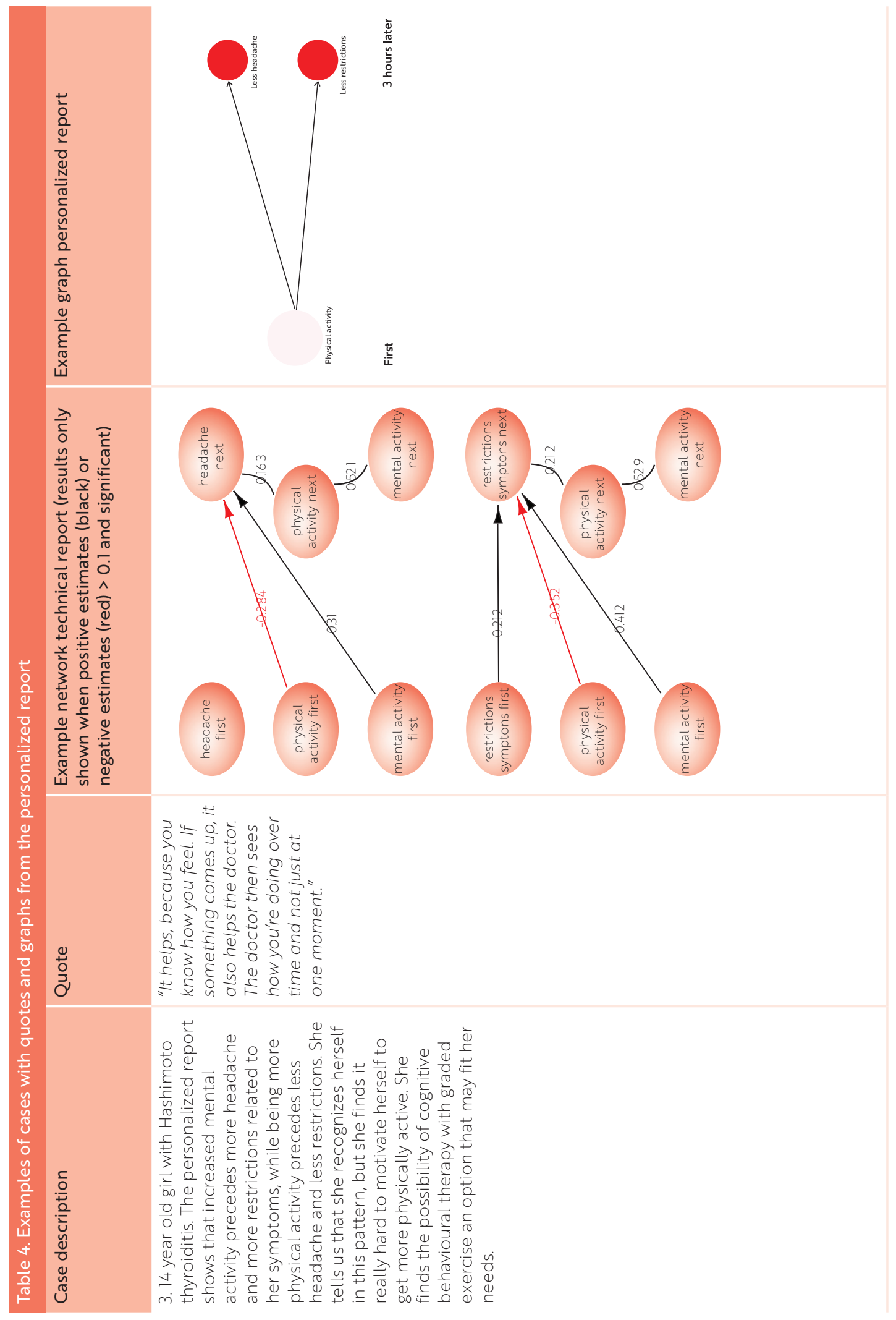




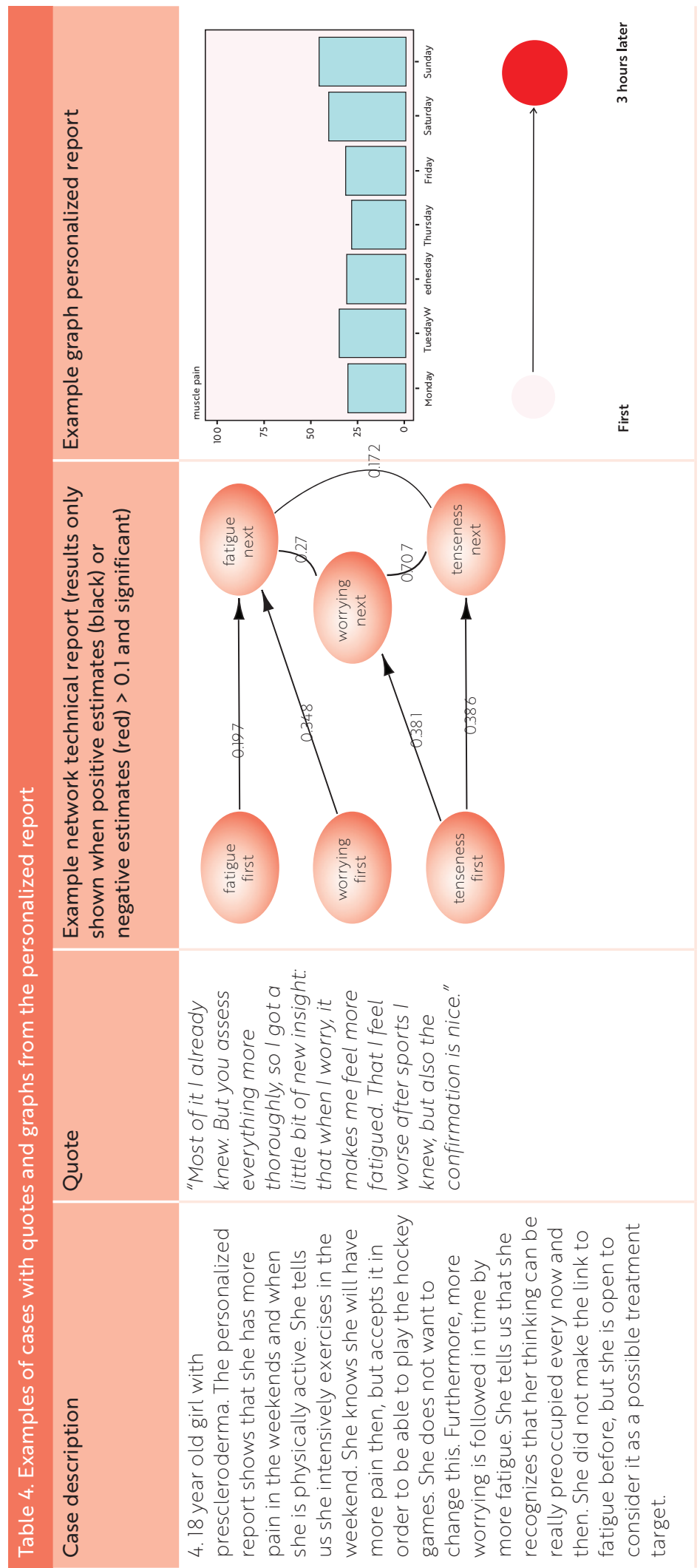


Supplementary Table SI. Content of the EMA questionnaire

[always asked] 1 Is this the first time you fill out the survey after the night? [No, Yes]

If I yes: 2 I slept last night for: [0-2 hours; 2-4 hours; 4-6 hours; 6-8 hours; 8-10 hours; $10-12$

hours; longer than 12 hours]

If 1 yes: 3 I felt rested when I woke up [visual analogue scale (VAS) 0-100 Not at all, a little, quite, good, very good]*

If 1 no: 4 For the last three hours I slept or lied resting during daytime (in bed or on the couch): [No Yes] If 1 no and 4 yes: 5 I slept or lied resting during daytime for: [0-1 hour; 1-2 hours; 2-3 hours; 3-4 hours; 4-5 hours; 5-6 hours; longer than 6 hours]

If 1 no and 4 yes: 6 I felt rested afterwards [VAS 0-100 Not at all, a little, quite, good, very good]*

[always asked] 7 For the last three hours, the majority of the time I was: [At home; Somewhere else]

[always asked] 8 For the last three hours, the majority of time I was doing things: [Alone, With others]

[always asked] 9 For the last three hours, I was in touch with people who helped me, supported me or understood me [No, Yes]

[always asked] 10 For the last three hours, I was in touch with people who bothered me, who I was in conflict with or who did not understand me [No, Yes]

[always asked] 11 For the last three hours, I was physically:

1. Inactive - Lying down, sleeping

2. A little bit inactive - sitting, reading, using the computer, tablet or smartphone

3. A little bit active - walking, shopping, doing chores

4. Very active - running, sporting

If 4 very active:

12 Amount of time that I was physically very active [up to 15 minutes; 15 min - 30 min; 30 min - 1 hour; 1 hour - 2 hours; longer than 2 hours]

[always asked] 13 For the last three hours, I was mentally:* *

1. Inactive

2. A little bit inactive

3. A little bit active

4. Very active

If 4 very active:

14 Amount of time that I was mentally very active lup to 15 minutes; 15 min - 30 min; 30 min - 1 hour; 1 hour - 2 hours; longer than 2 hours]

[always asked] 15 The last three hours I was fatigued [VAS 0-100 from not at all to very much]* [personalized depending on the baseline survey] 16-18 For the last three hours I was bothered by (personalized symptoms) [VAS 0-100 from not at all to very much]*

- 1, 2 or 3 personalized symptoms based on the baseline survey

[always asked] 19 For the last three hours, my symptoms restricted me in what I wanted to do (i.e. go to school, play sports, meet with friends) [VAS 0-100 from Not at all to very much]

[personalized depending on the baseline survey] 20-22 In the last three hours, I was/had (personalized question(s), e.g. worried, anxious, proud) [VAS 0-100 from not at all to very]

- 1, 2 or 3 psychosocial factors based on the baseline survey

[always asked] 23 Is today a school day? [No, Yes]

If 23 yes : 24 Has your school day just finished? [No, Yes]

If 23 and 24 yes: 25 I went to school to day for: [I did not go; 1 hour; 2 hours; 3 hours; 4 hours; 5 hours; 6 hours; 7 hours; 8 hours or more]

If 23 and 24 yes: 26 My classmates went to school today for: [There were no classes; 1 hour; 2 hours; 3 hours; 4 hours; 5 hours; 6 hours; 7 hours; 8 hours or more $]^{* * *}$

27 Thank you for filling out this survey. If you want to (you do not have to) you can fill out an extra symptom or event here, if this was relevant for you the last three hours. Press submit to save your answers. [non mandatory open text box] 


\section{Supplementary Table SI. Content of the EMA questionnaire}

*On the VAS, a participant could slide to any number between 0-100, but there was an additional text visible when sliding back and forth that changed depending on the score.

** Mental activity was discussed with adolescents during the baseline survey and they often described it as working concentrated on a task or being alert during social interactions.

*** We explained to the participants that we wanted to compare their participation to their total amount of hours. If participants had no classmates with the same schedule, they filled this out as the amount of hours they planned to go to school.

\section{Supplementary Table S2. Additional statistical background on the PROfeel analyses}

\section{Analysing intensive longitudinal data with Residual Dynamic Structural Equation Modelling (RDSEM)}

Dynamic analysis was needed to gain insight in the lagged and contemporaneous associations between fluctuations over the time in fatigue and associated factors. Individual dynamic networks were computed using a general modelling framework, referred to as Dynamic Structural Equation Modelling (DSEM) (Asparouhov, Hamaker, and Muthen 2018). DSEM can deal with several statistical challenges such as imputation of missing values, standardization of the estimates, and observations with unequal spaced time-intervals. A corresponding modelling framework for residuals correlated across time (Residual DSEM) was used to control for effects of the circadian cycle (e.g., participants normally report more fatigue in the evening), day-of-week cycles (of which weekend-effects are the most important), and non-stationary low-frequency trends.

We have applied a single-subject RDSEM, using MPLUS version 8.2. First, residuals were created corrected for low-frequency trends, weekend and time of day affects. Then a VAR(1) model is fitted on these residuals yielding standardized estimates for the contemporaneous and auto and cross-lagged temporal associations. The effects of the trends, and the time of day and weekend effects are visualized (as standardized estimates) in the RDSEM output.

In this RDSEM approach, latent variables are created, but they are not based on multiple indicators, Rather, these latent variables are residuals that are corrected for trends derived from the corresponding observed variables, weekend effects and time of day. You can consider our residuals as a filtered signal, for example, a residual without its own low-frequency trend. Then a VAR(1) is fitted on these residuals, which is a dynamic network interpretation comparable to the work of Bringmann et al., but more sophisticated ${ }^{54}$ Therefore, the RDSEM results are referred to as individual dynamic (symptom) networks.

\section{DISCUSSION}

\section{Principal findings}

This study describes the feasibility and usefulness of PROfeel, a combination of a smartphone-based EMA-method using the internet, followed by face-to-face dialogue and personalized advice for improvement of symptoms or to tailor treatment based on a dynamic network analysis report. Participants described the EMA as feasible and the personalized report and tailored advice as useful in gaining understanding in symptoms and taking steps towards an approach to reduce one's fatigue. Most participants would recommend this method (PROfeel) to other adolescents. There were large interindividual differences in the outcomes of the personalized reports and in the advices. 


\section{Feasibility and usefulness of EMA in adolescents with chronic conditions}

In this feasibility study, we combined the feasibility and usefulness of EMA and a tailored advice based on a personalized report. EMA was already found feasible as a measurement instrument in participants with psychopathology and in several adolescent populations. ${ }^{26,32}$ In line with van Roekel et al., we found that a smartphonebased EMA-tool aligned with the adolescents' lifestyle was not an intrusive means of investigation, especially since adolescents became quicker in filling out the EMA during the measurement period and since EMA prompts were adjusted to their daily rhythm. ${ }^{26}$ Also, other electronic diary methods for children and adolescents with chronic diseases have been described before and were deemed feasible, but collection and storage of data keeps improving and opening new ways of collecting and analysing increasing amounts of longitudinal data. ${ }^{43-45}$ Some participants in our study described the continual confrontation while filling out EMA as a burden. Although burdensome, research suggests that when EMA is applied for a short period of time, this does not necessarily increase symptoms. ${ }^{28,46,47}$

\section{Feasibility and usefulness of the personalized report}

Although a lot of applications to improve wellbeing for children and adolescents are available, evidence-based apps of good quality are scarce. ${ }^{48}$ The application of personalized (i.e., patient-tailored) feedback based on single-subject EMA results is relatively new, but positive experiences in line with our study have already been described for young adults with anhedonia and depressed adults. ${ }^{28,31,33}$ Adolescents within our study described the use of PROfeel within the adolescent-clinician relationship in our study as valuable, in line with other studies describing an added value of personalized feedback and blended care in eHealth interventions. ${ }^{28,31,33}$ Several biopsychosocial factors may play a role in fatigue in chronic diseases, but interindividual differences are most likely large. The large interindividual differences in the outcomes of the personalized reports and advices found in the current study are in line with other studies describing large heterogeneity in networks between individuals, underscoring the importance of personalized medicine.11,49,50 Nevertheless, no studies have yet been performed testing whether insights into a patient's network dynamics can significantly alter treatment decisions and patient outcomes. ${ }^{51}$

\section{Strengths and limitations}

A clear strength of our study is its relatively large sample size for a feasibility study, including adolescents with various chronic conditions. It shows the advantages of internet and smartphone-delivered EMA, combined with the potential of innovative ILD analyses ${ }^{13}$ to gain insight in fatigue. The possibilities the internet provides with controlled intensive and longitudinal data collection have high potential and lead to more complete and reliable datasets and better equidistant time series than EMA collected on paper. Together with the possibility to provide notifications on smartphones, which is suitable to the adolescent's lifestyle, this methodology is very promising for clinical practice, according to the involved adolescents. Another strength of this study is that we personalized the EMA prompts and questions, tailoring EMA to the daily life of the adolescent, which may lead to higher adherence. ${ }^{26}$

Our study also had its limitations. First, we encountered several technical difficulties, 
especially at the start of the study, and consequently the compliance and motivation of some of the participants went down with a total compliance of $42 \%$. Also, as a result of technical difficulties, compliance calculation was difficult, since duplicate data was generated for expired surveys for IPhone users at the start of the study. Considering this, we assume that when these difficulties will be resolved, the compliance may be even higher than found in this study. Second, there may have been a selection bias, since common reasons for not participating included an anticipated burden of filling out the EMA or unwillingness to be confronted with their fatigue. Nevertheless, there was no significant difference in fatigue questionnaire scores of the PROactive study between participants and non-participants. Third, female participants were overrepresented, so the results may be less generalizable to boys with chronic diseases. The mean age was relatively high for the included age range, but this was in line with our expectations, as fatigue is more prevalent among older adolescents. ${ }^{52}$ Last, we did not calculate patterns in missing data on a group level. We therefore cannot exclude the possibility that missings were non-random, possibly leading to biased results. This is an important issue for future studies.

\section{Suggestions for future research and clinical practice}

For future research, assessment of the (long-term) effectiveness of internet and smartphone-based EMA and personalized advices based on single-subject dynamic network analyses reports in adolescents with chronic conditions is needed. Since EMA proved feasible in this population, other applications of EMA could be: assessing and comparing networks based on two EMA episodes assessed pre and post treatment, assessing whether a network changes during an intervention, or combining EMA with continuous feedback as an intervention in itself (Ecological Momentary Interventions; EMI). ${ }^{53,54}$ The novelty of the ILD dynamic network analyses (RDSEM) make the interpretation of the data and the construction of the personalized report time consuming. Automation of these analyses and processes and automatic generation of a report will make EMA combined with ILD analyses and personalized reports more scalable for use in clinical practice. This also requires training of healthcare professionals how to interpret and explain a personalized report, as now this was mostly done by a clinical researcher.

\section{CONCLUSION}

Based on the compliance and quantitative results and the qualitative feedback presented in the current study, EMA combined with personalized advice based on a dynamic network analysis report (PROfeel), was demonstrated to be a feasible and useful method to improve health care for adolescents with chronic conditions suffering from fatigue. The way PROfeel renders personalized advices offers promising options for clinical practice, acknowledging that each person is unique, and enabling and motivating users to gain insight in and take steps towards treatment of fatigue, tailored to individual needs. 


\section{REFERENCES}

1. Perrin JM, Bloom SR, Gortmaker SL. The Increase of Childhood Chronic Conditions in the United States. JAMA. 2007;297(24):2755. doi:10.1001/jama.297.24.2755

2. Verwey-Jonker Instituut. Een Actueel Perspectief Op Kinderen En Jongeren Met Een Chronische Aandoening in Nederland:; 2019.

3. Jóhannsdóttir IMR, Hjermstad MJ, Moum T, et al. Increased prevalence of chronic fatigue among survivors of childhood cancers: A population-based study. Pediatr Blood Cancer. 2012;58(3):415-420. doi:10.1002/pbc.23111

4. Armbrust W, Siers NE, Lelieveld OTHM, Mouton LJ, Tuinstra J, Sauer P. Fatigue in patients with juvenile idiopathic arthritis: A systematic review of the literature. Semin Arthritis Rheum. 2016;45(5):587-595. doi:10.1016/j.semarthrit.2015.10.008

5. MM N der V, M B, HJ H, et al. Prevalence of severe fatigue in Cystic Fibrosis. J Cyst Fibros.

6. Nijhof LN, van de Putte EM, Wulffraat NM, Nijhof SL. Prevalence of severe fatigue among adolescents with pediatric rheumatic diseases. Arthritis Care Res (Hoboken). Published online August 28, 2015:n/a-n/a. doi:10.1002/acr.22710

7. Huang I-C, Anderson M, Gandhi P, et al. The Relationships Between Fatigue, Quality of Life, and Family Impact Among Children With Special Health Care Needs. J Pediatr Psychol. 2013;38(7):722-731. doi:10.1093/jpepsy/jst016

8. Kim J, Chung H, Amtmann D, Salem R, Park R, Askew RL. Symptoms and quality of life indicators among children with chronic medical conditions. Disabil Health J. 2014;7(1):96-104. doi:10.1016/j.dhjo.2013.08.007

9. Kratz AL, Murphy SL, Braley TJ. Ecological Momentary Assessment of Pain, Fatigue, Depressive, and Cognitive Symptoms Reveals Significant Daily Variability in Multiple Sclerosis. Arch Phys Med Rehabil. 2017;98(11):2142-2150. doi:10.1016/j. apmr.2017.07.002

10. Ebner-Priemer UW, Trull TJ. Ecological momentary assessment of mood disorders and mood dysregulation. Psychol Assess. 2009;21(4):463-475. doi:10.1037/a0017075

11. Molenaar PCM. A Manifesto on Psychology as Idiographic Science: Bringing the Person Back Into Scientific Psychology, This Time Forever. Meas Interdiscip Res Perspect. 2004;2(4):201-218. doi:10.1207/s15366359mea0204_1

12. Frijns $T$, Keijsers L, Finkenauer $C$. Keeping secrets from parents: on galloping horses, prancing ponies and pink unicorns. Curr Opin Psychol. 2020;31:49-54. doi:10.1016/j. copsyc.2019.07.041

13. Hamaker EL, Wichers M. No Time Like the Present. Curr Dir Psychol Sci. 2017;26(1):10-15. doi:10.1177/0963721416666518

14. Nap-van der Vlist MM, Dalmeijer CW, Grootenhuis MA, et al. Fatigue in childhood chronic disease. Arch Dis Child. Published online June 7, 2019:archdischild-2019-316782. doi:10.1136/archdischild-2019-316782

15. Menting J, Tack CJ, Bleijenberg G, et al. Is fatigue a disease-specific or generic symptom in chronic medical conditions? Heal Psychol. 2018;37(6):530-543. 
doi:10.1037/hea0000598

16. Stein REK, Jessop DJ. What diagnosis does not tell: The case for a noncategorical approach to chronic illness in childhood. Soc Sci Med. 1989;29(6):769-778. doi:10.1016/0277-9536(89)90157-3

17. Maurice-Stam H, Nijhof SL, Monninkhof AS, Heymans HSA, Grootenhuis MA. Review about the impact of growing up with a chronic disease showed delays achieving psychosocial milestones. Acta Paediatr. Published online August 27, 2019:apa.14918. doi:10.1111/apa.14918

18. Van Dijk-Lokkart EM, Steur LMH, Braam KI, et al. Longitudinal development of cancer-related fatigue and physical activity in childhood cancer patients. Pediatr Blood Cancer. 2019;66(12):e27949. doi:10.1002/pbc.27949

19. Nap-van der Vlist MM, Burghard M, Hulzebos HJ, et al. Prevalence of severe fatigue among adults with cystic fibrosis: A single center study. J Cyst Fibros. 2018;17(3):368374. doi:10.1016/j.jcf.2018.03.003

20. Vijver E Van de, Gils A Van, Beckers L, Driessche Y Van, Moes ND, Rheenen PF van. Fatigue in children and adolescents with inflammatory bowel disease. World J Gastroenterol. 2019;25(5):632-643. doi:10.3748/wjg.v25.i5.632

21. Langeveld NE, Grootenhuis MA, Voûte PA, de Haan RJ, van den Bos C. No excess fatigue in young adult survivors of childhood cancer. Eur J Cancer. 2003;39(2):204214. Accessed July 24, 2018. http://www.ncbi.nlm.nih.gov/pubmed/12509953

22. Engel GL. The need for a new medical model: a challenge for biomedicine. Science. 1977;196(4286):129-136. doi:10.1126/science.847460

23. Deary $\vee$, Chalder $T$, Sharpe M. The cognitive behavioural model of medically unexplained symptoms: A theoretical and empirical review. Clin Psychol Rev. 2007;27(7):781-797. doi:10.1016/j.cpr.2007.07.002

24. Stone AA, Shiffman S. Ecological Momentary Assessment (Ema) in Behavioral Medicine. Ann Behav Med. 1994;16(3):199-202. doi:10.1093/abm/16.3.199

25. Myin-Cermeys I, Oorschot M, Collip D, Lataster J, Delespaul P, van Os J. Experience sampling research in psychopathology: opening the black box of daily life. Psychol Med. 2009;39(9):1533-1547. doi:10.1017/S0033291708004947

26. van Roekel E, Keijsers L, Chung JM. A Review of Current Ambulatory Assessment Studies in Adolescent Samples and Practical Recommendations. J Res Adolesc. 2019;29(3):560-577. doi:10.1111/jora.12471

27. Asparouhov T, Hamaker E, Muthen B. Dynamic structural equation models. Struct Equ Model a Multidiscip J. 2018;25(3):359-388.

28. Van Roekel E, Vrijen C, Heininga VE, Masselink M, Bos EH, Oldehinkel AJ. An Exploratory Randomized Controlled Trial of Personalized Lifestyle Advice and Tandem Skydives as a Means to Reduce Anhedonia. Behav Ther. 2017;48(1):76-96. doi:10.1016/j.beth.2016.09.009

29. Houtveen JH, Sorbi MJ. Prodromal functioning of migraine patients relative to their interictal state--an ecological momentary assessment study. Sommer C, ed. PLoS One. 2013;8(8):e72827. doi:10.1371/journal.pone.0072827 
30. Houtveen JH, Lipovsky MM, Kool M, Sorbi M, Bühring MEF, van BroeckhuysenKloth S. The day-to-day concurrence of bodily complaints and affect in patients with severe somatoform disorder. Scand J Psychol. 2015;56(5):553-559. doi:10.1111/ sjop. 12228

31. Kroeze R, van der Veen DC, Servaas MN, et al. Personalized feedback on symptom dynamics of psychopathology: A proof-of-principle study. J Pers Res. 2017;3(1):1-11. doi:10.17505/jpor.2017.01

32. Bell IH, Lim MH, Rossell SL, Thomas N. Ecological Momentary Assessment and Intervention in the Treatment of Psychotic Disorders: A Systematic Review. Psychiatr Serv. 2017;68(11):1172-1181. doi:10.1176/appi.ps.201600523

33. Kramer I, Simons CJP, Hartmann JA, et al. A therapeutic application of the experience sampling method in the treatment of depression: a randomized controlled trial. World Psychiatry. 2014;13(1):68-77. doi:10.1002/wps.20090

34. Hofmann SG, Hayes SC. The Future of Intervention Science: Process-Based Therapy. Clin Psychol Sci. 2019;7(1):37-50. doi:10.1177/2167702618772296

35. Gordijn MS, Suzanne, Cremers EMP, Kaspers GJL, Gemke RJBJ. Fatigue in children: reliability and validity of the Dutch PedsQLTM Multidimensional Fatigue Scale. Qual Life Res. 2011;20(7):1103-1108. doi:10.1007/s11136-010-9836-9

36. Ethica Data. Ethica. Published online 2019.

37. Nijhof SL, Bleijenberg G, Uiterwaal CS, Kimpen JL, van de Putte EM. Effectiveness of internet-based cognitive behavioural treatment for adolescents with chronic fatigue syndrome (FITNET): a randomised controlled trial. Lancet. 2012;379(9824):1412-1418. doi:10.1016/S0140-6736(12)60025-7

38. Nijhof S, Bleijenberg G, Uiterwaal CS, Kimpen J, van de Putte E. Fatigue In Teenagers on the interNET--the FITNET Trial. A randomized clinical trial of web-based cognitive behavioural therapy for adolescents with chronic fatigue syndrome: study protocol. [ISRCTN59878666]. BMC Neurol. 2011;11. doi:10.1186/1471-2377-11-23

39. Dormann C, Griffin MA. Optimal time lags in panel studies. Psychol Methods. 2015;20(4):489-505. doi:10.1037/met0000041

40. Voelkle MC, Oud JHL, von Oertzen T, Lindenberger U. Maximum Likelihood Dynamic Factor Modeling for Arbitrary N and T Using SEM. Struct Equ Model A Multidiscip J. 2012;19(3):329-350. doi:10.1080/10705511.2012.687656

41. Quanjer PH, Stanojevic S, Cole TJ, et al. Multi-ethnic reference values for spirometry for the 3-95-yr age range: the global lung function 2012 equations. Eur Respir J. 2012;40(6):1324-1343. doi:10.1183/09031936.00080312

42. Holloway I, Wheeler S, Holloway I. Qualitative Research in Nursing and Healthcare. Wiley-Blackwell; 2010. Accessed March 26, 2020. https://books.google.nl/books/ about/Qualitative_Research_in_Nursing_and_Heal.html?id=8AP3sCglkdYC\&redir_ esc $=y$

43. Bromberg MH, Connelly M, Anthony KK, Gil KM, Schanberg LE. Self-Reported Pain and Disease Symptoms Persist in Juvenile Idiopathic Arthritis Despite Treatment Advances: An Electronic Diary Study. Arthritis Rheumatol. 2014;66(2):462-469. 
doi:10.1002/art.38223

44. Connelly M, Bromberg MH, Anthony KK, Gil KM, Franks L, Schanberg LE. Emotion regulation predicts pain and functioning in children with juvenile idiopathic arthritis: an electronic diary study. J Pediatr Psychol. 37(1):43-52. doi:10.1093/jpepsy/ jsr088

45. Elsbernd A, Hjerming M, Visler C, et al. Cocreated Smartphone App to Improve the Quality of Life of Adolescents and Young Adults with Cancer (Kræftværket): Protocol for a Quantitative and Qualitative Evaluation. JMIR Res Protoc. 2018;7(5):el0098. doi:10.2196/10098

46. Broderick JE, Vikingstad G. Frequent Assessment of Negative Symptoms Does Not Induce Depressed Mood. J Clin Psychol Med Settings. 2008;15(4):296-300. doi:10.1007/s10880-008-9127-6

47. Cruise CE, Broderick J, Porter L, Kaell A, Stone AA. Reactive effects of diary selfassessment in chronic pain patients. Pain. 1996;67(2):253-258. doi:10.1016/03043959(96)03125-9

48. Schoeppe S, Alley S, Rebar AL, et al. Apps to improve diet, physical activity and sedentary behaviour in children and adolescents: a review of quality, features and behaviour change techniques. Int J Behav Nutr Phys Act. 2017;14(1):83. doi:10.1186/ sl2966-017-0538-3

49. Bos FM, Blaauw FJ, Snippe E, van der Krieke L, de Jonge P, Wichers M. Exploring the emotional dynamics of subclinically depressed individuals with and without anhedonia: An experience sampling study. J Affect Disord. 2018;228:186-193. doi:10.1016/j.jad.2017.12.017

50. Bosley HC, Fisher AJ, Taylor CB. Differential responses of positive affect, negative affect, and worry in CBT for generalized anxiety disorder: A person-specific analysis of symptom course during therapy. Psychother Res. 2018;28(4):630-642. doi:10.1080 /10503307.2016.1233366

51. Wichers M, Wigman JTW, Bringmann LF, de Jonge P. Mental disorders as networks: some cautionary reflections on a promising approach. Soc Psychiatry Psychiatr Epidemiol. 2017;52(2):143-145. doi:10.1007/s00127-016-1335-z

52. ter Wolbeek M, van Doornen LJP, Kavelaars A, Heijnen CJ. Severe Fatigue in Adolescents: A Common Phenomenon? Pediatrics. 2006;117(6):el078-el086. doi:10.1542/peds.2005-2575

53. Snippe E, Viechtbauer W, Geschwind N, Klippel A, de Jonge P, Wichers M. The Impact of Treatments for Depression on the Dynamic Network Structure of Mental States: Two Randomized Controlled Trials. Sci Rep. 2017;7:46523. doi:10.1038/ srep46523

54. Fisher AJ, Reeves JW, Lawyer G, Medaglia JD, Rubel JA. Exploring the idiographic dynamics of mood and anxiety via network analysis. J Abnorm Psychol. 2017;126(8):1044-1056. doi:10.1037/abn0000311

55. Bringmann LF, Pe ML, Vissers N, et al. Assessing Temporal Emotion Dynamics Using Networks. Assessment. 2016;23(4):425-435. doi:10.1177/1073191116645909 


\section{0}
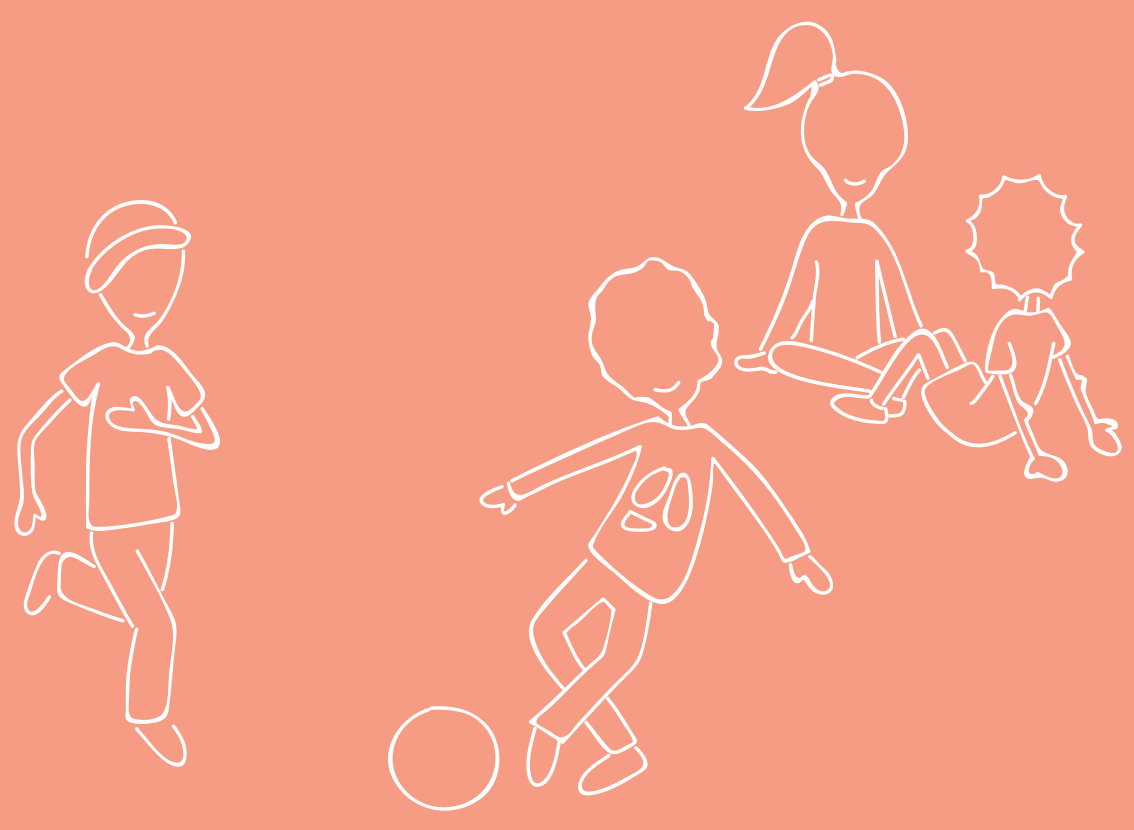
General Discussion 


\section{GENERAL DISCUSSION}

"I feel the same as everyone, but I am not the same, no." - Boy with CF, 10 years old

This thesis focusses on three important outcomes for children with a chronic disease: fatigue, participation, and health-related quality of life. Children with a chronic disease often face more obstacles than their healthy peers, which may impact their physical, social-emotional and cognitive development. ${ }^{-3}$ In the long run, children with a chronic disease reach developmental milestones later than their healthy peers and many children will remain dependent on medication and/ or will be limited in their daily life activities. ${ }^{4}$ Therefore, it is of utmost importance to assess fatigue, participation, and health-related quality of life in children with a chronic disease, as these factors have the potential to majorly influence their current well-being and how they grow into autonomous adults that take part in our society.

This thesis mostly uses data from the PROactive cohort and describes two embedded design studies within this cohort. The PROactive cohort lays a foundation for life cycle paediatrics: following children, adolescents and adults with a chronic disease over time in order to monitor them and offer tailored assistance when needed to help them grow up as healthy as possible. Within this line of thought, this thesis also looks into one adult patient population and assesses fatigue and its associated disease-specific and generic biopsychosocial associated factors for (young) adults with CF.
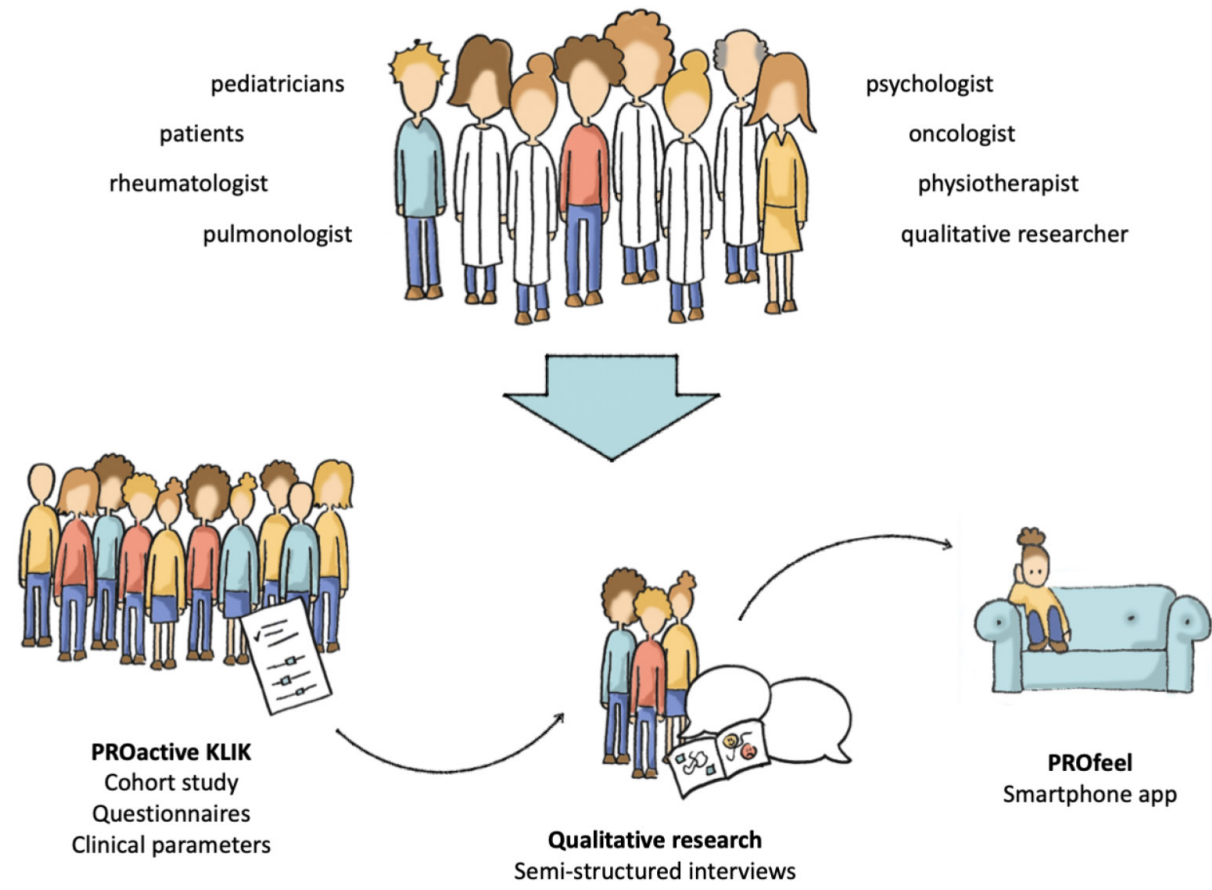

Figure 1. Overview of the PROactive cohort study 


\section{Main findings}

The aim of this thesis was to 1) gain insight into the frequency, extent and aetiology of fatigue in children and young people with a chronic disease and its association with health-related quality of life (HRQOL), 2) assess the consequence of growing up with a chronic disease on daily life participation and 3) investigate how we can help children and adolescents to regain control over their fatigue and daily life participation in a personalized way.

The message of this thesis can be summarized in two key messages. First, fatigue is a prevalent problem among children and young people growing up with a chronic disease. The disease affects their daily life participation. Second, fatigue, daily life participation, and HRQOL are complex outcomes. Biological, psychological and social factors - as well as interactions between these factors-all play a role. The key to empowering children with a chronic disease may lie in identifying the multidimensional cause on an individual level and tailor treatment accordingly. The main findings are summarized in Appendix 1.

\section{Part I: Fatigue in paediatric chronic disease}

"You always live in a blur of fatigue." - Girl with JIA, 15 years old

The first part of this thesis focuses on gaining insight into the frequency, extent and aetiology of fatigue in paediatric chronic disease. This is important, as patients indicate that they experience fatigue as a prevalent and distressing symptom. ${ }^{5-8}$ Concordantly, every individual recognizes the feeling of being tired or fatigued every now and then. Quantifying this fatigue helps to acknowledge the downstream effects on children and young adults with a chronic disease, and prompt a conversation during the doctor's visit.

\section{Fatigue as a transdiagnostic symptom}

Chapter 2 reports that one out of four (young) adults with cystic fibrosis reports severe fatigue. In addition, a significant association was found between their lung function (forced expiratory volume in one second) and fatigue, but not as strong as the association between their psychosocial determinants and fatigue. This is in line with recent literature, showing that disease-specific factors, such as a clinical score for children with juvenile idiopathic arthritis (JIA) or lung function in people with cystic fibrosis, are often not the most strongly associated factors with fatigue. $., 9,10$ It may be the case that fatigue is associated with the challenge of growing up and living with a chronic disease, more than it is a side effect of the disease and the therapeutic regimen. Chapter 3 describes that children with a chronic disease are severely fatigued over four times more often than children from the general Dutch population. This fatigue affects their HRQOL and severe fatigue is prevalent in all age groups. Interestingly, in chapter 3 the average fatigue scores for children with different chronic diseases were comparable. In other words, independent of their somatic diagnosis, children with different chronic diseases did not report significantly different on fatigue. In line with research in adults, fatigue in children with a chronic disease can be seen as a transdiagnostic symptom." Transdiagnostic is defined as an approach in which clinicians aim to go beyond the disease-specific biological factors of a disease and look for generic factors. The term transdiagnostic is synonymous with the terms 
generic or non-categorical, though in this thesis transdiagnostic is preferred. As fatigue can be seen as a transdiagnostic problem and as it is highly prevalent among children with a chronic disease, it is of importance to screen for fatigue in clinical care, preferably from an earlier age onwards to signal possible problems in time, possibly preventing deterioration and impaired functioning.

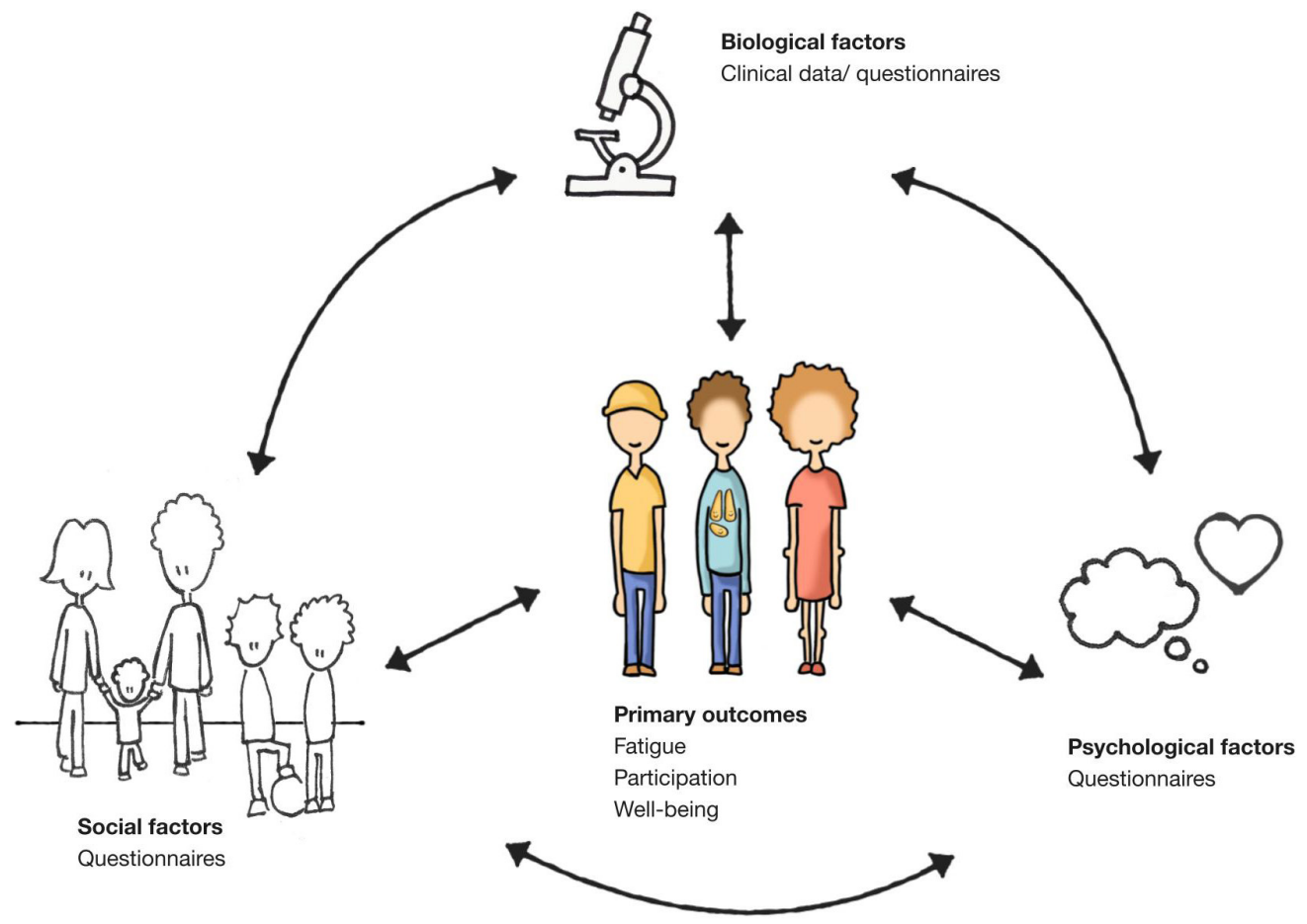

Figure 2. Biological, psychological, and social factors play a role in fatigue, participation, and health-related quality of life in children with a chronic disease

\section{Biological, psychological and social factors associated with fatigue and HRQoL}

In chapter 4, multiple generic biological/lifestyle, psychological and social factors were associated with fatigue, together explaining almost three quarters of the variance in fatigue across disease groups. This confirms our hypothesis that a biopsychosocial approach to fatigue is justified in paediatric chronic disease. ${ }^{2}$ More specifically, poorer physical functioning, more depressive symptoms, more pressure at school, poorer social functioning, and older age were uniquely associated with more fatigue. Here again, we found no significant differences in associations with fatigue between disease groups, which is in line with fatigue as a transdiagnostic symptom. This knowledge regarding the relationship between fatigue and generic biological or lifestyle, psychological, and social factors may not only help clinicians who treat children with a chronic disease, but may also increase our understanding of other fatigue-related syndromes such as fatigue experienced following COVID-19.13 If fatigue is not so closely related to disease-specific factors and it presents itself in a similar way across diseases, fatigue in children with a chronic disease may not be so different from other fatigue-related syndromes that have other triggers, such as fatigue after Q-fever or COVID-19 infection. ${ }^{13,14}$ In any case, it is important to search for modifiable factors on 
the generic biological or lifestyle, psychological, and social domain

These findings also align with the disability-stress-coping model by Wallander \& Varni, which identifies that the stressors children with a chronic disease face are multifaceted and that several personal and family risk- and protective are of influence. ${ }^{15}$ For a more detailed description of the theoretical models that form the foundation of this thesis, I refer the reader to chapter 1. In figure 3 a summary of this theory behind the PROactive cohort study can be found, based on the biopsychosocial model, the disability-stresscoping model, and the cognitive behavioural model. $12,15,16$

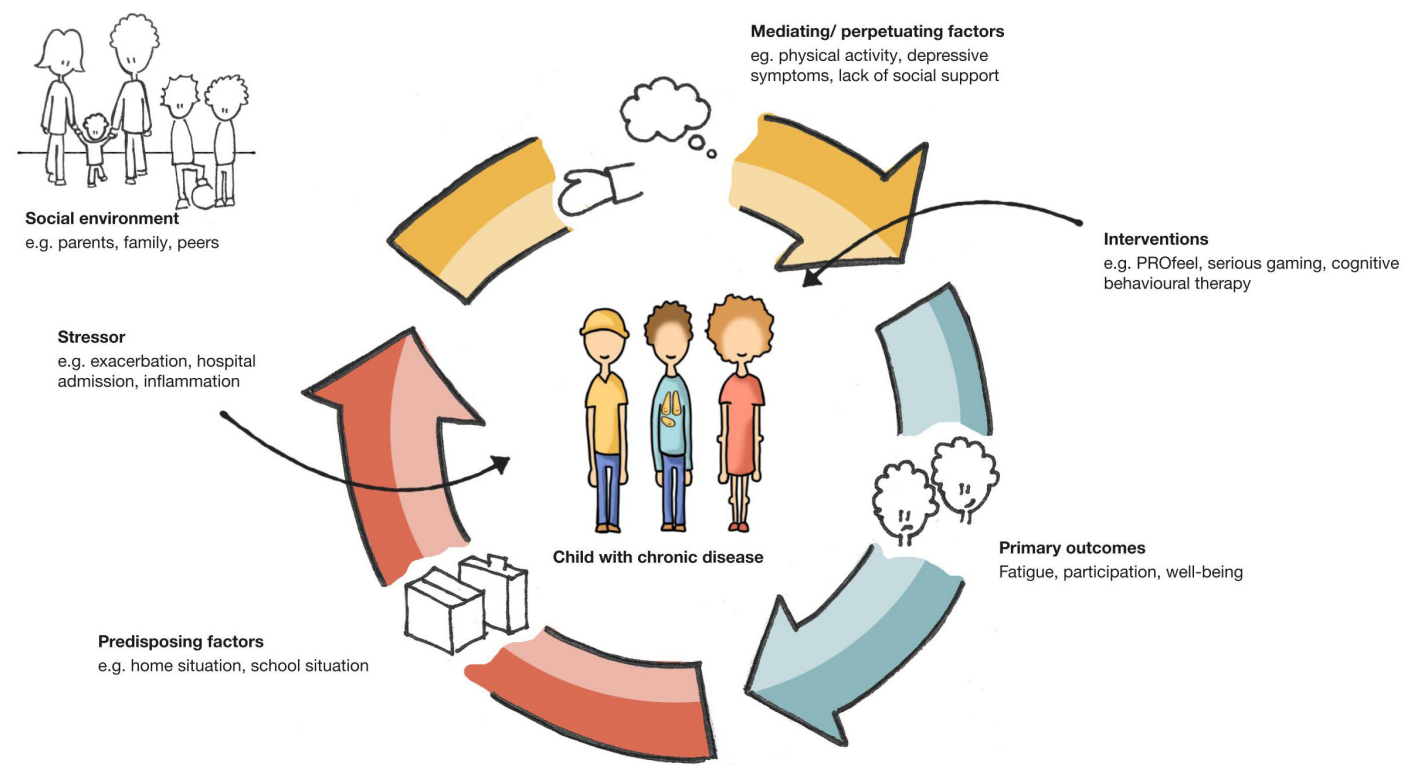

Figure 3. Theoretical model of the PROactive cohort study

\section{Family factors}

As mentioned above, family factors are of influence on fatigue and health-related quality of life of the child. Chapter 5 describes that parental factors, regarding both their physical and psychosocial functioning, are associated with the child's fatigue. Parents form the child's primary social network and as such influence the child's outcome. The quality of the parent-child relationship is crucial in facing the extra challenges associated of growing up with a chronic disease, as children often turn to their parents for increased support during stressful times. ${ }^{17-20}$ Yet, parents too are likely to experience extra stress, and this may impair their ability to provide adequate care for their child. In order to guide children and parents towards adaptive ways of coping with children's chronic disease, it is important that parents and children jointly cope with stress, a process that is called dyadic coping. ${ }^{21,22}$ Chapter 6 reports on this mutual influence parents and children have on each other. The process of dyadic coping in parent-child dyads is associated with the child's HRQOL. The latter was not a direct association with fatigue, but as fatigue and HRQOL are strongly associated, dyadic coping is worth further investigation. Altogether, there are various factors in the biological or lifestyle, psychological and social domain that are associated with fatigue 


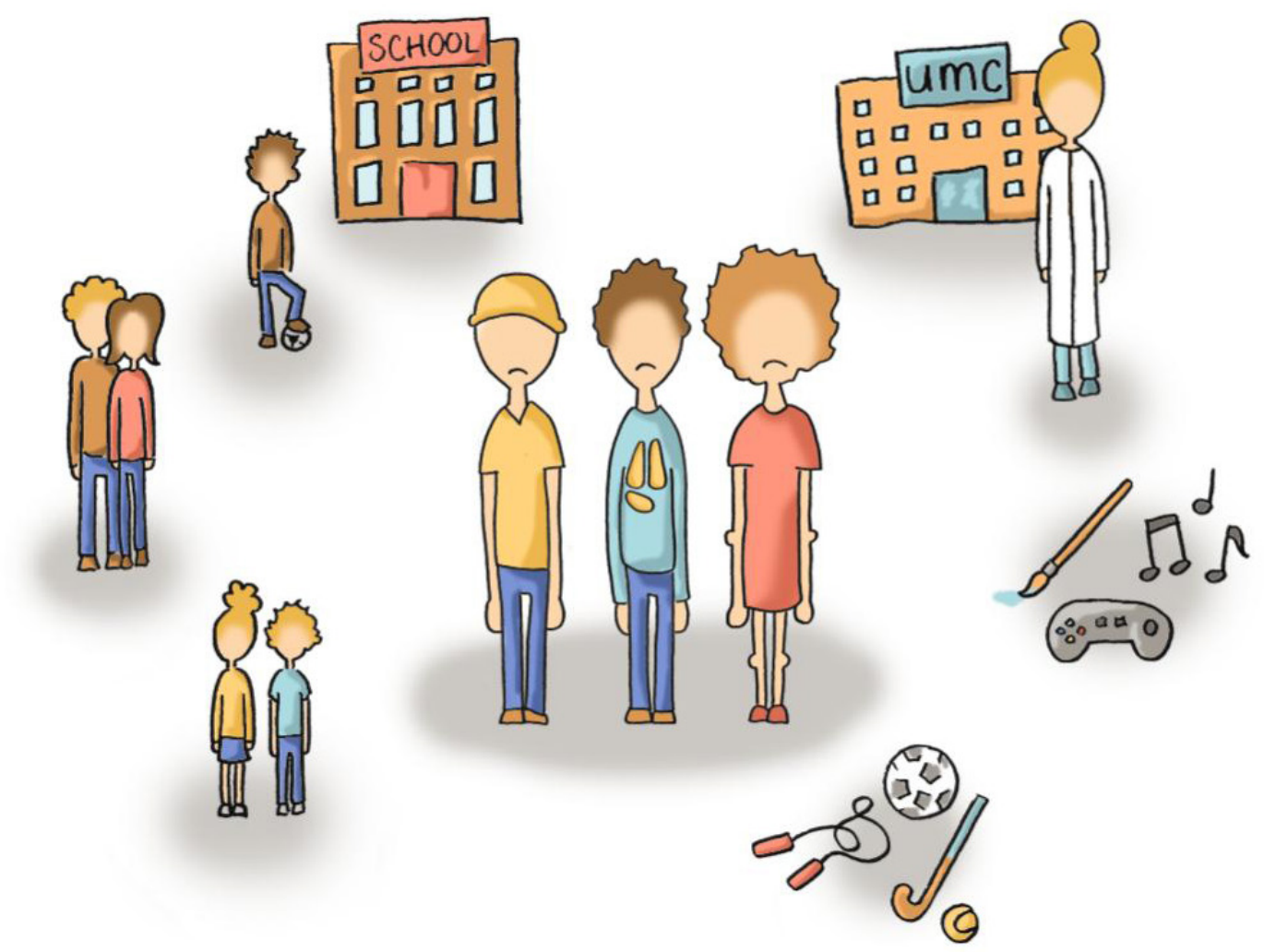

Figure 4. The social environment of the child with a chronic disease plays a crucial role

\section{Causality}

These cross-sectional studies cannot be used to infer causality, but they can be used to generate hypotheses. Also, the cognitive behavioural model to explain fatigue uses the term perpetuating factors to describe biopsychosocial factors that co-occur with fatigue and perpetuate the fatigue, but do not necessarily precede the fatigue. ${ }^{16}$ This model of perpetuation is thought to be self-maintaining; symptoms and perpetuating factors sustain one another in a vicious circle.

If you apply this model to fatigue, one may say that the modifiable biopsychosocial factors in our study, such as depressive symptoms, physical functioning or (lack of) social support, may be perpetuating factors. If that is the case, intervening on these perpetuating co-occurring factors may directly influence the fatigue and improve HRQOL.

\section{Fatigue in a stable phase of a chronic disease}

Another point worth discussing is that this thesis describes children in a stable phase of a chronic disease. In the PROactive study we include children who are at least one year post-diagnosis (the CF and autoimmune disease groups) or who are within one year after completing their cancer treatment. This choice was made as for two reasons. First, the diagnostic phase and initial treatment phase are often hectic for parents and children and participation in research, with reflection on psychosocial 
factors, may be perceived as too burdensome in this phase. Second, it may be easier to assess which transdiagnostic factors are associated with fatigue after the diagnostic and initial therapeutic phase when children are in a relatively stable phase of their disease. In the first year post-diagnosis or during cancer treatment, disease specific factors, such as disease activity (generally highest in the first year after diagnosis), receiving the diagnosis, starting treatment, and the disease itself can cause significant fatigue and disruptions. Of course, even after this phase, some children are still not in a 'stable' phase of their chronic disease. This also brings up the argument that in most chronic diseases there are no clear descriptions of what 'in a stable phase' means. On top of that, it is interesting to philosophize what this means for their assessment of fatigue, daily life participation and health-related quality of life. After a year of trying to optimize all biomedical parameters, such as disease activity and medication use, is it not worthwhile to expand our focus on other modifiable biopsychosocial factors that influence their fatigue and health-related quality of life, regardless of how stable their disease is? Or is it not even better to start measuring children from the moment they receive the diagnosis? Although this may be a burden to children and parents in this hectic time, does the benefit of early screening and intervention possibilities not outweigh this burden? As screening fatigue, daily life participation, and health-related quality of life via a digital portal is seen by children and their parents as a relatively low burden, it may be worthwhile to implement these already at diagnosis. ${ }^{23,24}$ That this is possible, is shown by the successful implementation of assessing health-related quality of life from diagnosis in paediatric oncology care. ${ }^{24,25}$ Regarding interventions for fatigue, the questions regarding the right timing remain. If an intervention is proposed, it is important to know whether the child improves due to the intervention or due to other factors, such as a recent medication change. Still, in clinical practice such an intervention would still be valuable, as long as the patient improves, while in a scientific context you would like to know exactly what happened to whom and why.

\section{Challenges and opportunities of combining research and clinical care}

As the example in the previous paragraph already illustrates, combining research and clinical care may be challenging. Another example of such a challenge is that for research, it would be ideal to measure patients annually exactly at the same time, while for clinical practice, it may be better to postpone or move up appointments and discuss the patient-reported outcomes (PROs) during a regular visit to the hospital. On the other hand, measuring PROs in a digital way may also provide opportunities. It makes it possible to systematically screen on PROs and may assist in providing econsults or digital care by evaluating outcomes such as fatigue, participation and psychosocial well-being without children and parents having to come to the hospital. Of course, such a change will require adjusting our care pathways and implementation of this combination of care and research. For such an implementation to be sustainable, commitment from both researchers, patients, parents and healthcare professionals is required. Implementing innovations is quite challenging, even when they are proven effective. Successful implementation and uptake is a major challenge for many innovations emerging from scientific research as it requires active engagement of multiple stakeholders and the investment of capital, skills, and resources. ${ }^{24,26,27}$ Nevertheless, investing in implementing research may be very promising to improve care in a sustainable manner. 


\section{Life cycle paediatrics}

The PROactive cohort study is a combination of research and clinical care and an example of life cycle paediatrics. The PROactive cohort comprises chronically ill children in the outpatient clinic who are measured annually. Besides the primary outcomes fatigue, participation and health-related quality of life, various predisposing, precipitating (stressors) and mediating or perpetuating factors are assessed. How the child scores on fatigue, pain, and health-related quality of life, may subsequently influence their predisposing and mediating/perpetuating factors, which may then again influence his/her outcomes. For example, imagine a child that is very fatigued and is therefore underperforming at school. Subsequently, the fatigue may lead to missing school hours and staying more at home (different environment, predisposing factor). This may then lead to more depressive symptoms and possibly less social support (mediating/perpetuating factors), which may lead to more fatigue the next year. This is an example of how predisposing factors, mediating factors and outcomes may follow each other over time.

The annual assessment of children with a chronic disease may help children on two levels. First, in research, these longitudinal data will help us build prediction models. These prediction models may teach us which children are at risk for severe fatigue, decreased daily life participation or decreased health-related quality of life. That knowledge may be translated into timely screening and intervention in order to improve the child's functioning.

Second, in clinical care, it is important that the PROs in PROactive are discussed immediately with the patient as part of clinical care. Assessing and discussing PROs is directly relevant for clinical care and may improve clinical outcomes. ${ }^{28-31}$ Especially in a vulnerable population of developing children, systematic assessment and early intervention may be crucial in helping them develop into healthy, autonomous adults. ${ }^{23}$ In the above-mentioned example, if the fatigue would have been noticed and an appropriate intervention would have been offered, this may have prevented the fatigue from becoming worse and debilitating. This way, the individual child and his/her parents immediately benefit from participating in research, as problems are immediately discussed. If children are followed over time, it gives clinicians the opportunity to timely intervene if problems are detected. This is the reason that the PROactive cohort was set up as a combination of research and clinical care from the beginning.

\section{Directions for future research}

Evidently, this thesis opens up several avenues for future research. First, it is of interest to investigate whether interventions targeted at the modifiable biopsychosocial factors described in chapter 4 are suitable to treat fatigue in children with chronic disease in a stable phase of their disease. A promising example is cognitive behavioural therapy (CBT), which was already proven to reduce fatigue in adolescents with chronic fatigue syndrome. ${ }^{32}$ CBT focuses on generic biological or lifestyle factors, such as improving one's sleep-wake rhythm and gradually increasing physical activity, psychological factors, such as helpful and non-helpful thoughts, and social factors, such as involving family and peers in building healthy patterns. ${ }^{32}$

Second, the identified biopsychosocial factors may show high inter-individual variation. 
Therefore, it is of interest to invest in personalized medicine. I will elaborate this in part III of this discussion. Third, we investigated several possible modifiable biopsychosocial factors. Other protective factors that may serve as possible treatment targets to improve a child's outcomes are also worth investigating. In line with the concept of positive health, factors such as resilience, family empowerment or social support are of interest. ${ }^{33-35}$ Fourth, even though it may be that the modifiable biopsychosocial factors co-occur with fatigue as perpetuating factors, longitudinal studies are still of interest. If we know whether there are factors that precede fatigue, this could be used to prevent symptoms from occurring or becoming debilitating. These longitudinal analyses can very well be performed with data from the PROactive cohort.

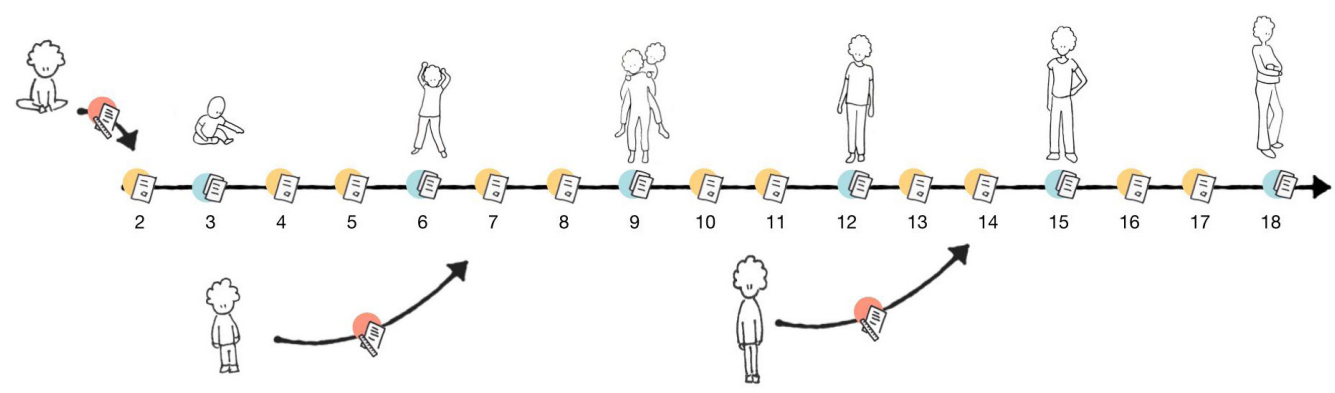

Baseline meting op moment van inclusie

园 Jaarlijkse vragenlijst

每 Vitgebreide vragenlijst

Figure 5. Longitudinal data collection in the PROactive cohort study

\section{Clinical implications}

This thesis underlines the importance of a structural assessment of the child with a chronic disease on fatigue, daily life participation, and health-related quality of life. Ideally, important modifiable factors, such as physical functioning, depressive symptoms, social functioning, and family functioning should also be taken into account. This will give us the opportunity to assess how the child is functioning and developing with his/her chronic disease. It will give healthcare professionals the opportunity to get a good impression of the child's health in the broadest sense of the word: "the ability to adapt and to self-manage, in the face of social, physical and emotional challenges". ${ }^{3}$ A good way of achieving such a structural assessment is by using PROs. Completing simple, validated questionnaires via a web-based portal is both time-efficient and compatible with outpatient care. ${ }^{23,36}$ Even so, as mentioned before, real-world implementation requires considerable investment in terms of commitment of healthcare professionals, financial resources, and willingness to change existing work flows. ${ }^{27}$ The benefits of this investment are the possibility to open dialogues between children, parents, and healthcare professionals on how to tailor care to the individual child's needs. It provides the opportunity to monitor a child's outcomes from an early age, in order to signal possible problems in time.

Tailored assessments or interventions on modifiable biopsychosocial factors that are associated with fatigue (such as PROfeel, see part III) are desirable, but not widely 
available. If systematic screening is in place for children with a chronic disease, this not only benefits them now. It also creates the opportunity to offer preventive or early interventions to children who may show early signs of developing problems later on. For now, there are promising interventions available that target the biological, psychological or social domain. Examples of such interventions are promoting a healthy lifestyle and sports participation, cognitive behavioural therapy for anxiety or depressive symptoms, or helping both parents and children to communicate with one another about stressors related to the disease. ${ }^{36-40}$ Ideally, tailored interventions on modifiable biopsychosocial factors will become available in the near future to further optimize treatment for these patients.

\section{Part II: Daily life participation in paediatric chronic disease \\ "I cannot do it the same way they do, but I can do it in my own way." - Girl with systemic sclerosis, 11 years old}

\section{Overview, directions for future research, and clinical implications}

Qualitative studies give us important insights into the perspective of children with a chronic disease and their parents. In that respect, it is important to assess all children with a chronic disease and not only the ones with poor outcomes in terms of daily life participation or fatigue. It is important to know that children view full participation as more than engaging in activities, but they view having a sense of belonging, the ability to affect social interactions, and the capacity to keep up with peers as key elements (chapter 7). This is crucial, as it opens up new possibilities to involve children with a chronic disease and make them feel that they are participating, even if they are not able to physically attend activities. In that light, it may not only be a disadvantage that we are living in a time were, due to the COVID-19 pandemic, social and academic interactions are becoming more and more digital. This may make it easier to participate for children with a chronic disease. In a recent analysis of PROactive data (not published), it was found that children with a chronic disease reported less often that the pandemic had negatively impacted their life compared to children from the Dutch population. In addition, children with a chronic disease scored better on physical and social functioning compared to the average scores of children with a chronic disease before the pandemic. One possible explanation is that these children are more resilient, because they have experienced more adversities already. ${ }^{4}$ On top of that, perhaps this shift towards digital participation also has its benefits for children with a chronic disease. Digital participation can be used for communication or learning, but it may also be useful to offer tailored assistance or interventions to vulnerable children with a chronic disease. Here, we may even find a role for serious games, both in person or digital.42

Chapter 8 reports that parents describe daily life participation primarily as a means to achieve the child's well-being, whereas children describe participation as more of a goal in itself. The degree of friction between parents and their child is based on the level of agreement on who takes the lead regarding the child's participation. Children and parents both have their perspective on the child's daily life participation and in order to empower children and their parents to jointly manage the child's daily life participation, the clinician can help them explore these perspectives. As the human mind always sees the world through its own frame of reference, it may not necessarily 
be easy for healthcare professionals to bring the child's and parent's perspective on participation above board in the consultation room. It may be worthwhile to actively train clinicians to help parent and child explore the other person's perspective. An interesting communication training in this perspective is advanced care planning. ${ }^{43}$ Although this method is often applied with respect to end of life conversations, the techniques behind it can very well be applied to talking about daily life participation. In this thesis I often speak of multidisciplinary collaboration, which ideally involves an active collaboration between children, parents, and healthcare professionals, both doctors as well as psychologists, social workers, and physical therapists.

Part III: PROfeel, a personalized assessment followed by a face-to-face dialogue and personalized advice

"That these things were not only my thoughts, but there was actually a pattern." - Girl with pain and fatigue, 16 years old

\section{Overview and directions for future research, and clinical implications}

Interestingly, the first part of this thesis showed that fatigue and its associated factors present itself in a similar manner across disease groups. As every child is unique and as results on a group level cannot be translated in a one-on-one manner to the individual child, it may be even more important to know, as Hippocrates said, "what sort of person has a disease, than to know what sort of disease a person has." In others words, it is of importance to invest in personalized medicine. Personalized assessment and feedback on possible modifiable factors that influence fatigue may empower children to self-manage their symptoms. In this thesis, PROfeel, a personalized assessment followed by a face-to-face dialogue and personalized advice, was feasible and useful (chapter 9).

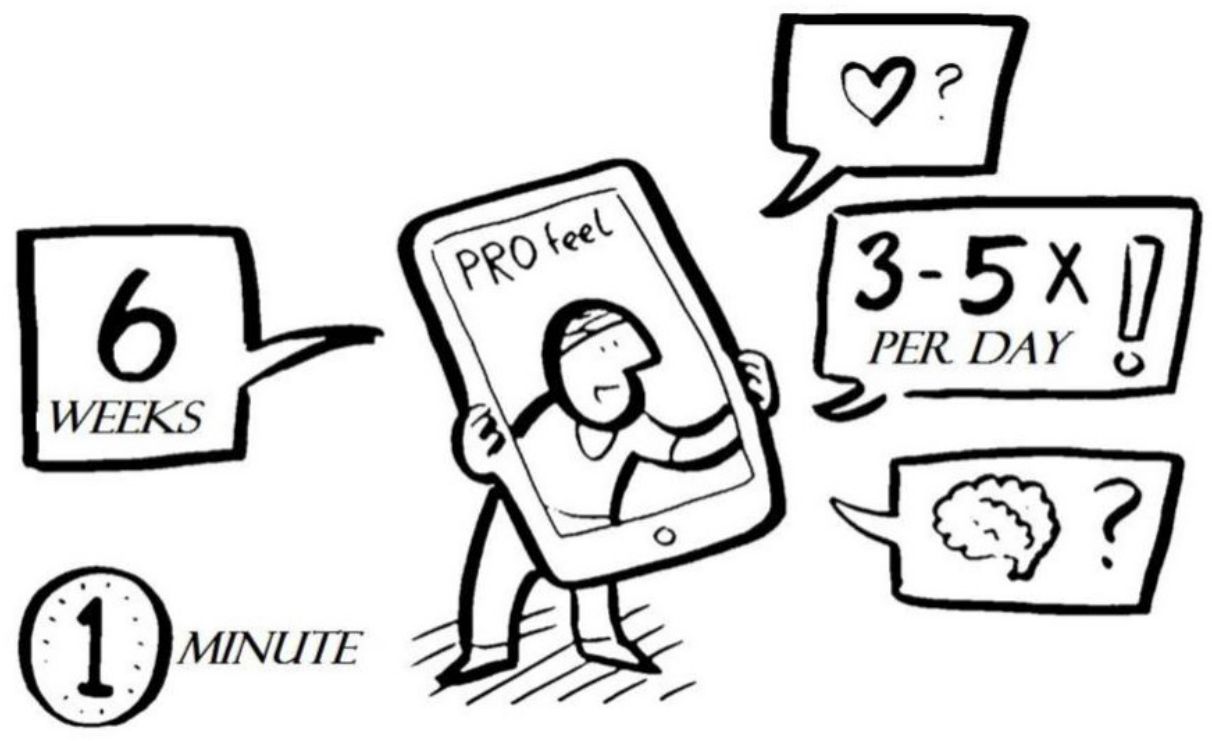

Figure 6. Personalized assessment via the PROfeel app 


\section{Future studies}

This first feasibility study of PROfeel should ideally be followed by a study investigating the effectiveness of PROfeel on self-management and fatigue. So far, PROfeel is used to deliver personalized assessment and advice, but not as an intervention in itself. It is of interest to know whether personalized assessment and advice can be seen as an intervention in itself, which directly improves symptoms, or whether it should be seen as a stepping-stone towards a tailored treatment by improving insight in symptoms and motivation for treatment. What is also of interest is that the studied method of assessment and analysis generates networks that show how the measured factors and symptoms relate to each other. The theory of the cognitive behavioural model is that perpetuating factors, through their interaction with each other and with fatigue, generate recursively the same network of processes which produced them. ${ }^{16}$ Mapping these networks and aiming interventions at modifying these perpetuating factors, may not only change the outcome (i.e. fatigue), but may indeed change children's behavioural patterns or networks, leading to sustainable change. ${ }^{44,45}$ Of course, this theory and these assumptions require further investigation, for example by creating networks based on EMA measurements before and after interventions.

\section{Clinical implications}

Although this specific application is not yet freely available, a personalized approach to fatigue and participation may already be achieved in the consultation room. As figure 7 shows, a structured assessment of fatigue and associated factors may help identify modifiable factors on an individual level. This may open the dialogue between healthcare professional and child on how the child's symptoms can best be managed and which intervention would be most suitable to the child's situation. ${ }^{23}$

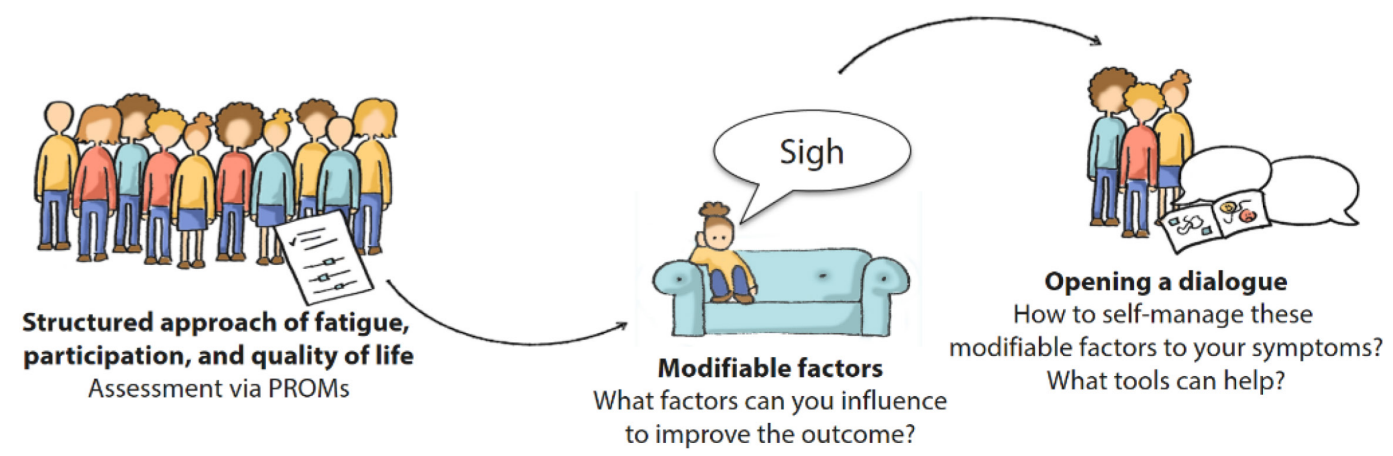

Figure 7. Visual representation of topics in this thesis

\section{CONCLUSION}

This thesis explored fatigue, daily life participation, and health-related quality of life in children with a chronic disease. First, fatigue is a highly prevalent problem among children and young people growing up with a chronic disease and associated with poorer health-related quality of life. Several modifiable factors are associated with this fatigue and may provide possible treatment targets. A structured assessment as 
described above (figure 7) may help clinicians to broaden their view on the child's functioning and make this a topic of conversation in the consultation room. Actively training healthcare professionals on these subjects and how to discuss them in the consultation room may be of added value. This discussion or dialogue may empower children, parents, and healthcare professionals to search for tailored solutions to optimally support the child in his/her functioning and development.

Second, the perception of daily life participation of children and their parents gives us an unique insight in what they value in the child's daily life participation. These insights may help lay the foundation for establishing mutual goals and a patient-centred approach regarding the child's participation.

Third, this thesis explored one particular promising personalized solution to empower children in self-managing their fatigue and daily life participation (PROfeel). As fatigue was confirmed as a transdiagnostic symptom, this opens new possibilities to study and implement interventions for a larger target audience of children with a chronic disease. Even so, there lies a challenge ahead to develop care pathways and tailored interventions for children of different ages and with different challenges. PROfeel, and the way it was used in this study, is only one way to offer a personalized intervention that targets fatigue, daily life participation and health-related quality of life in children with a chronic disease. Investing in other transdiagnostic and personalized interventions may be worthwhile. This thesis opens up new possibilities in research and clinical care to assess and treat fatigue in children with a chronic disease. The ultimate goal of this approach is to improve the daily life participation and healthrelated quality of life of chronically ill children.
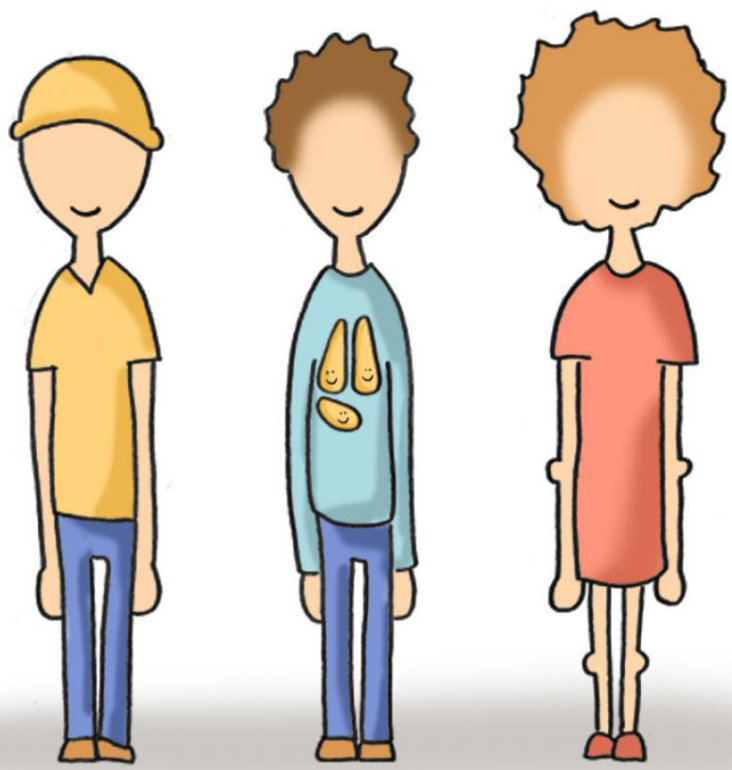


\section{REFERENCES}

1. Zan H, Scharff RL. The Heterogeneity in Financial and Time Burden of Caregiving to Children with Chronic Conditions. Matern Child Health J. 2015;19(3):615-625. doi:10.1007/s10995-014-1547-3

2. Pinquart $M$, Teubert D. Academic, physical, and social functioning of children and adolescents with chronic physical illness: a meta-analysis. J Pediatr Psychol. 2012;37(4):376-389. doi:10.1093/jpepsy/jsr106

3. Leeman J, Crandell JL, Lee A, Bai J, Sandelowski M, Knafl K. Family Functioning and the Well-Being of Children With Chronic Conditions: A Meta-Analysis. Res Nurs Health. 2016:39(4):229-243. doi:10.1002/nur.21725

4. Maurice-Stam H, Nijhof SL, Monninkhof AS, Heymans HSA, Grootenhuis MA. Review about the impact of growing up with a chronic disease showed delays achieving psychosocial milestones. Acta Paediatr. Published online August 27, 2019:apa.14918. doi:10.1111/apa.14918

5. Walter LM, Nixon GM, Davey MJ, Downie PA, Horne RSC. Sleep and fatigue in pediatric oncology: A review of the literature. Sleep Med Rev. 2015;24:71-82. doi:10.1016/j.smrv.2015.01.001

6. Nijhof LN, van de Putte EM, Wulffraat NM, Nijhof SL. Prevalence of severe fatigue among adolescents with pediatric rheumatic diseases. Arthritis Care Res (Hoboken). Published online August 28, 2015:n/a-n/a. doi:10.1002/acr.22710

7. Sawicki CS, Sellers DE, Robinson WM. Self-Reported Physical and Psychological Symptom Burden in Adults with Cystic Fibrosis. J Pain Symptom Manage. 2008;35(4):372-380. doi:10.1016/j.jpainsymman.2007.06.005

8. Armbrust W, Siers NE, Lelieveld OTHM, Mouton LJ, Tuinstra J, Sauer P. Fatigue in patients with juvenile idiopathic arthritis: A systematic review of the literature. Semin Arthritis Rheum. 2016;45(5):587-595. doi:10.1016/j.semarthrit.2015.10.008

9. Jarad NA, Sequeiros IM, Patel P, Bristow K, Sund Z. Fatigue in cystic fibrosis: a novel prospective study investigating subjective and objective factors associated with fatigue. Chron Respir Dis. 2012;9(4):241-249. doi:10.1177/1479972312464236

10. Van Dijk-Lokkart EM, Steur LMH, Braam KI, et al. Longitudinal development of cancer-related fatigue and physical activity in childhood cancer patients. Pediatr Blood Cancer. 2019;66(12):e27949. doi:10.1002/pbc.27949

11. Menting J, Tack CJ, Bleijenberg C, et al. Is fatigue a disease-specific or generic symptom in chronic medical conditions? Heal Psychol. 2018;37(6):530-543. doi:10.1037/hea0000598

12. Engel CL. The need for a new medical model: a challenge for biomedicine. Science. 1977;196(4286):129-136. doi:10.1126/science.847460

13. Garrigues E, Janvier P, Kherabi Y, et al. Post-discharge persistent symptoms and health-related quality of life after hospitalization for COVID-19. J Infect. Published online August 25, 2020. doi:10.1016/j.jinf.2020.08.029

14. Morroy G, Keijmel SP, Delsing CE, et al. Fatigue following Acute Q-Fever: A 
Systematic Literature Review. PLoS One. 2016;11(5):e0155884. doi:10.1371/journal. pone. 0155884

15. Wallander JL, Varni JW. Effects of pediatric chronic physical disorders on child and family adjustment. J Child Psychol Psychiatry. 1998;39(1):29-46. Accessed February 14, 2019. http://www.ncbi.nlm.nih.gov/pubmed/9534085

16. Deary $\vee$, Chalder T, Sharpe M. The cognitive behavioural model of medically unexplained symptoms: A theoretical and empirical review. Clin Psychol Rev. 2007;27(7):781-797. doi:10.1016/j.cpr.2007.07.002

17. Cousino MK, Hazen RA. Parenting stress among caregivers of children with chronic illness: A systematic review. J Pediatr Psychol. 2013;38(8):809-828. doi:10.1093/ jpepsy/jst049

18. Logan DE, Scharff L. Relationships between family and parent characteristics and functional abilities in children with recurrent pain syndromes: an investigation of moderating effects on the pathway from pain to disability. J Pediatr Psychol. 2005;30(8):698-707. doi:10.1093/jpepsy/jsj060

19. Palermo TM, Valrie CR, Karlson CW. Family and parent influences on pediatric chronic pain: a developmental perspective. Am Psychol. 2014;69(2):142-152. doi:10.1037/a0035216

20. Pinquart M. Do the Parent-Child Relationship and Parenting Behaviors Differ Between Families With a Child With and Without Chronic Illness? A Meta-Analysis. J Pediatr Psychol. 2013;38(7):708-721. doi:10.1093/jpepsy/jst020

21. Bodenmann G. Dyadic coping: A systematic-transactional view of stress and coping among couples: Theory and empirical findings. Eur Rev Appl Psychol. 1997;47:137140.

22. Bodenmann G, Falconier MK, Randall AK. Editorial: Dyadic Coping. Front Psychol. 2019;10. doi:10.3389/FPSYG.2019.01498

23. Haverman L, van Rossum MAJ, van Veenendaal M, et al. Effectiveness of a Web-Based Application to Monitor Health-Related Quality of Life. Pediatrics. 2013;131(2):e533-e543. doi:10.1542/peds.2012-0958

24. Schepers SA, Sint Nicolaas SM, Haverman L, et al. Real-world implementation of electronic patient-reported outcomes in outpatient pediatric cancer care. Psychooncology. 2017;26(7):951-959. doi:10.1002/pon.4242

25. Bult MK, van Bindsbergen KLA, Schepers SA, et al. Health-Related Quality of Life of Adolescents with Cancer During the First Year of Treatment. J Adolesc Young Adult Oncol. 2019;8(5):616-622. doi:10.1089/jayao.2019.0017

26. Greenhalgh T, Wherton J, Papoutsi C, et al. Beyond Adoption: A New Framework for Theorizing and Evaluating Nonadoption, Abandonment, and Challenges to the Scale-Up, Spread, and Sustainability of Health and Care Technologies. J Med Internet Res. 2017;19(11):e367. doi:10.2196/jmir.8775

27. van Oers HA, Teela L, Schepers SA, Grootenhuis MA, Haverman L, ISOQOL PROMS and PREMs in Clinical Practice Implementation Science Group. A retrospective assessment of the KLIK PROM portal implementation using the Consolidated 
Framework for Implementation Research (CFIR). Qual Life Res. Published online August 15, 2020. doi:10.1007/s11136-020-02586-3

28. Greenhalgh J, Gooding K, Gibbons E, et al. How do patient reported outcome measures (PROMs) support clinician-patient communication and patient care? A realist synthesis. J Patient-Reported Outcomes. 2018;2(1):42. doi:10.1186/s41687-0180061-6

29. Valderas JM, Kotzeva A, Espallargues M, et al. The impact of measuring patientreported outcomes in clinical practice: a systematic review of the literature. Qual Life Res. 2008;17(2):179-193. doi:10.1007/s11136-007-9295-0

30. Kotronoulas G, Kearney N, Maguire R, et al. What is the value of the routine use of patient-reported outcome measures toward improvement of patient outcomes, processes of care, and health service outcomes in cancer care? A systematic review of controlled trials. J Clin Oncol. 2014;32(14):1480-1501. doi:10.1200/JC0.2013.53.5948

31. Bele S, Chugh A, Mohamed B, Teela L, Haverman L, Santana MJ. Patient-Reported Outcome Measures in Routine Pediatric Clinical Care: A Systematic Review. Front Pediatr. 2020;8:364. doi:10.3389/fped.2020.00364

32. Nijhof SL, Bleijenberg G, Uiterwaal CS, Kimpen JL, van de Putte EM. Effectiveness of internet-based cognitive behavioural treatment for adolescents with chronic fatigue syndrome (FITNET): a randomised controlled trial. Lancet. 2012;379(9824):1412-1418. doi:10.1016/S0140-6736(12)60025-7

33. Huber M, van Vliet M, Giezenberg M, et al. Towards a "patient-centred" operationalisation of the new dynamic concept of health: a mixed methods study. BMJ Open. Published online 2016:5e010091.

34. Ashcraft LE, Asato M, Houtrow AJ, Kavalieratos D, Miller E, Ray KN. Parent Empowerment in Pediatric Healthcare Settings: A Systematic Review of Observational Studies. Patient. 2019;12(2):199-212. doi:10.1007/s40271-018-0336-2

35. Compas BE, Jaser SS, Dunn MJ, Rodriguez EM. Coping with chronic illness in childhood and adolescence. Annu Rev Clin Psychol. 2012;8:455-480. doi:10.1146/ annurev-clinpsy-032511-143108

36. Robinson PD, Oberoi S, Tomlinson D, et al. Management of fatigue in children and adolescents with cancer and in paediatric recipients of haemopoietic stem-cell transplants: a clinical practice guideline. Lancet Child Adolesc Heal. 2018;2(5):371378. doi:10.1016/S2352-4642(18)30059-2

37. Douma M, Maurice-Stam H, Gorter B, et al. Online psychosocial group intervention for parents: Positive effects on anxiety and depression. J Pediatr Psychol. Published online 2020. doi:10.1093/jpepsy/jsaal02

38. Scholten L, Willemen AM, Last BF, et al. Efficacy of psychosocial group intervention for children with chronic illness and their parents. Pediatrics. 2013;131(4):el196-203. doi:10.1542/peds.2012-2222

39. Thabrew H, Stasiak K, Hetrick SE, et al. Psychological therapies for anxiety and depression in children and adolescents with long-term physical conditions. Cochrane Database Syst Rev. 2018;12:CD012488. doi:10.1002/14651858.CD012488. 
pub2

40. Lelieveld OTHM, van Brussel M, Takken T, van Weert E, van Leeuwen MA, Armbrust W. Aerobic and anaerobic exercise capacity in adolescents with juvenile idiopathic arthritis. Arthritis Rheum. 2007;57(6):898-904. doi:10.1002/art.22897

41. van Gorp M, Maurice-Stam H, Teunissen LC, et al. No increase in psychosocial stress of Dutch children with cancer and their caregivers during the first months of the COVID-19 pandemic. Pediatr Blood Cancer. 2021;68(2):e28827. doi:10.1002/ pbc.28827

42. Nijhof SL, Vinkers CH, van Geelen SM, et al. Healthy play, better coping: The importance of play for the development of children in health and disease. Neurosci Biobehav Rev. 2018;95:421-429. doi:10.1016/j.neubiorev.2018.09.024

43. Fahner JC, Beunders AJM, van der Heide A, et al. Interventions Guiding Advance Care Planning Conversations: A Systematic Review. J Am Med Dir Assoc. 2019;20(3):227-248. doi:10.1016/j.jamda.2018.09.014

44. Snippe E, Viechtbauer W, Geschwind N, Klippel A, de Jonge P, Wichers M. The Impact of Treatments for Depression on the Dynamic Network Structure of Mental States: Two Randomized Controlled Trials. Sci Rep. 2017;7:46523. doi:10.1038/ srep46523

45. Fisher AJ, Reeves JW, Lawyer G, Medaglia JD, Rubel JA. Exploring the idiographic dynamics of mood and anxiety via network analysis. J Abnorm Psychol. 2017;126(8):1044-1056. doi:10.1037/abn0000311 

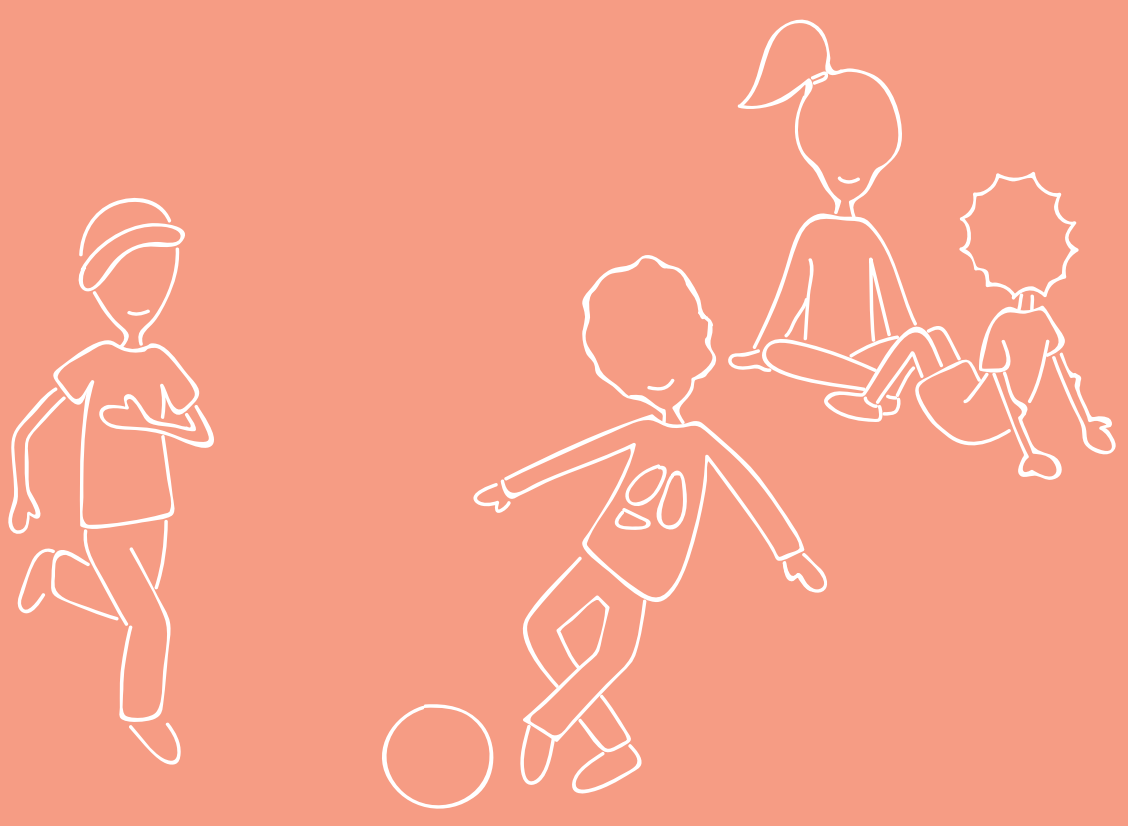


\section{ADDENDA}

Summary of findings

Nederlandse samenvatting I Summary in Dutch

Dankwoord I Acknowledgements

Curriculum vitae

List of publications

List of abbreviations 


\section{SUMMARY OF FINDINGS}
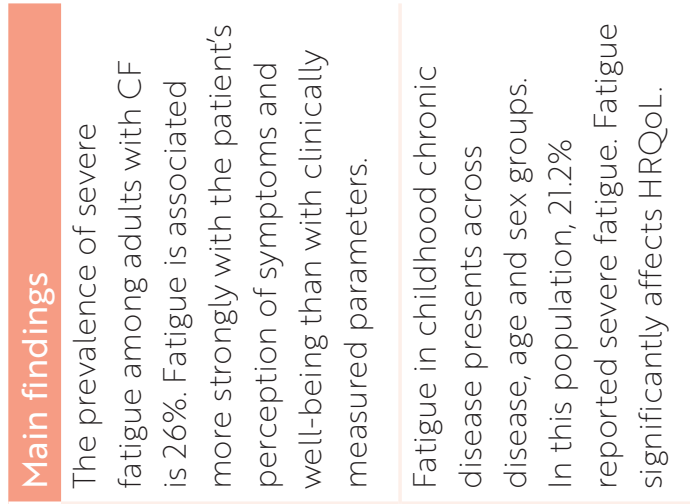

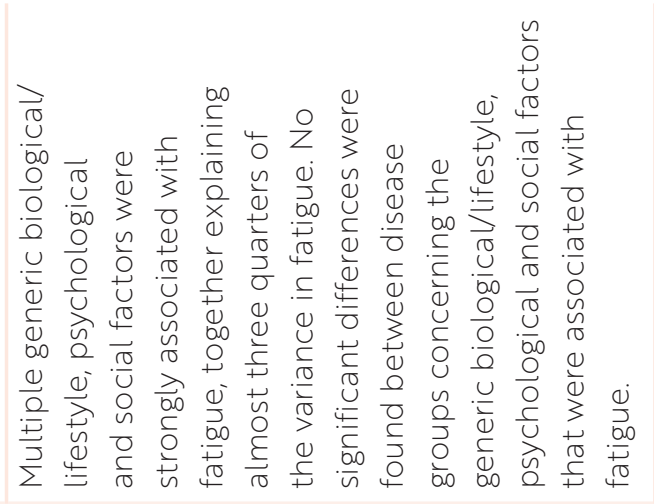
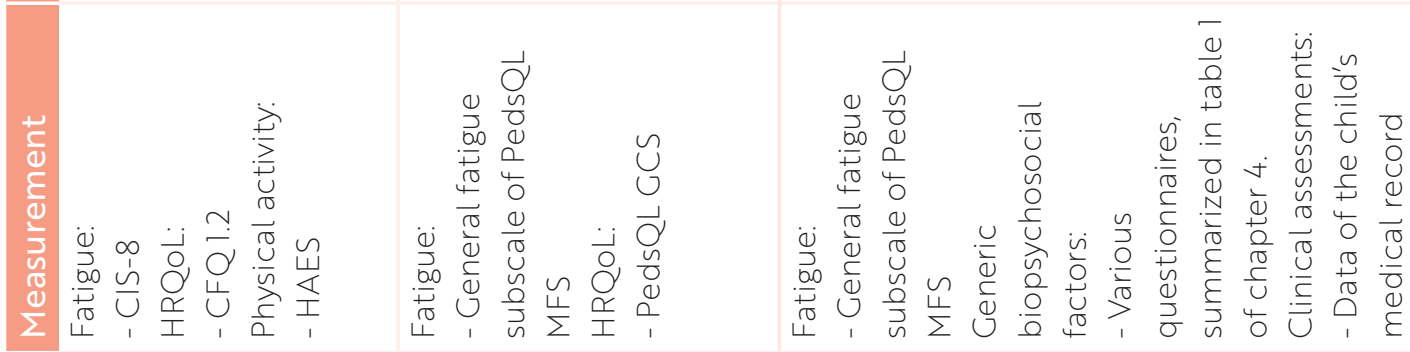

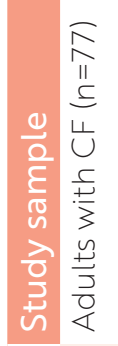
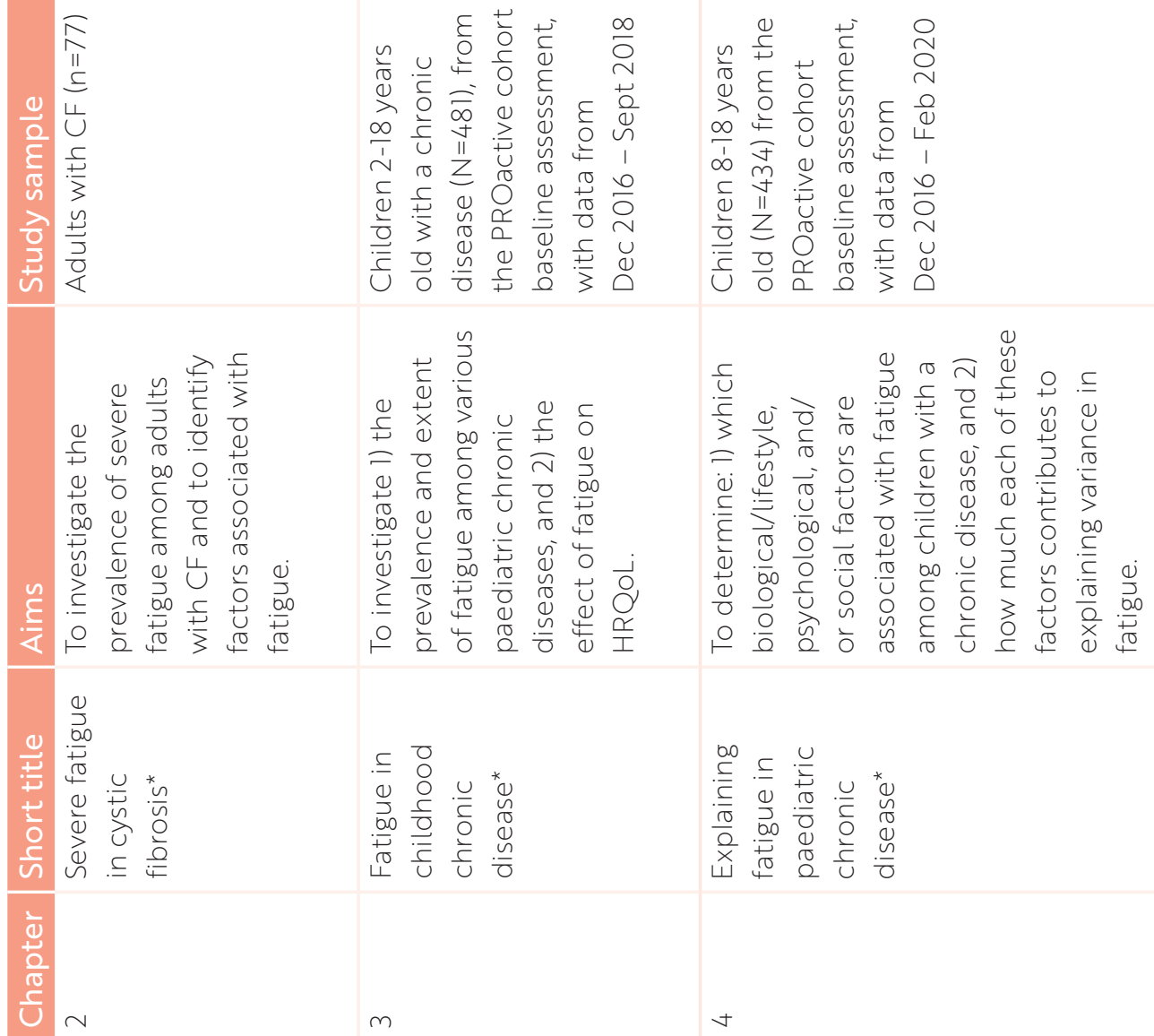

$m$ 

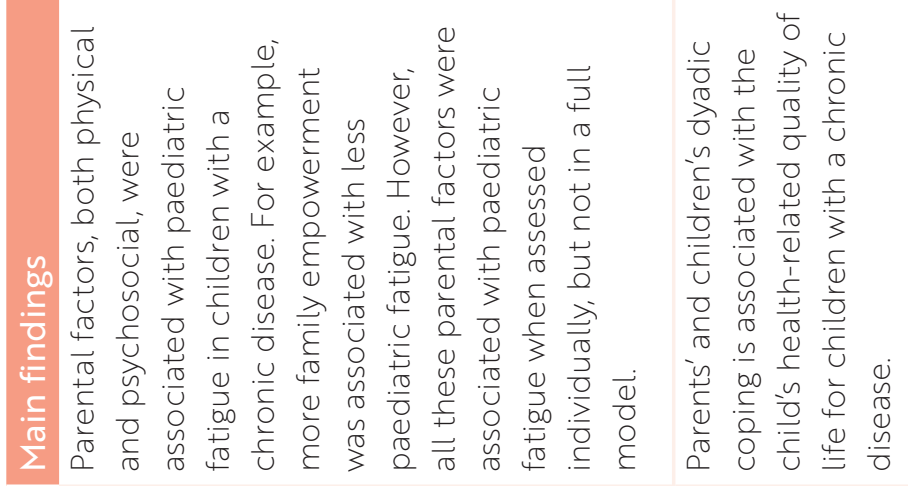

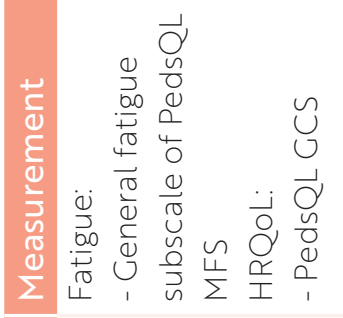

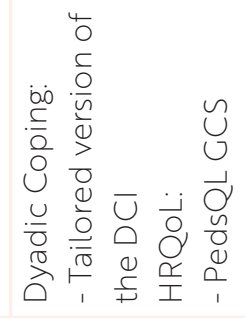

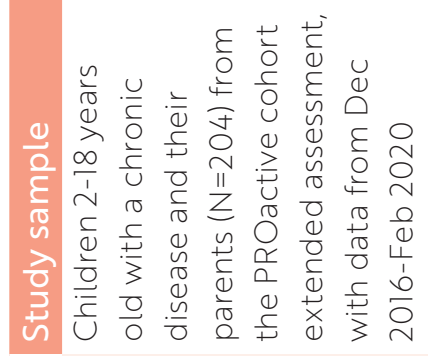

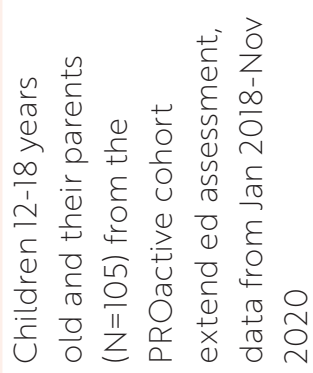
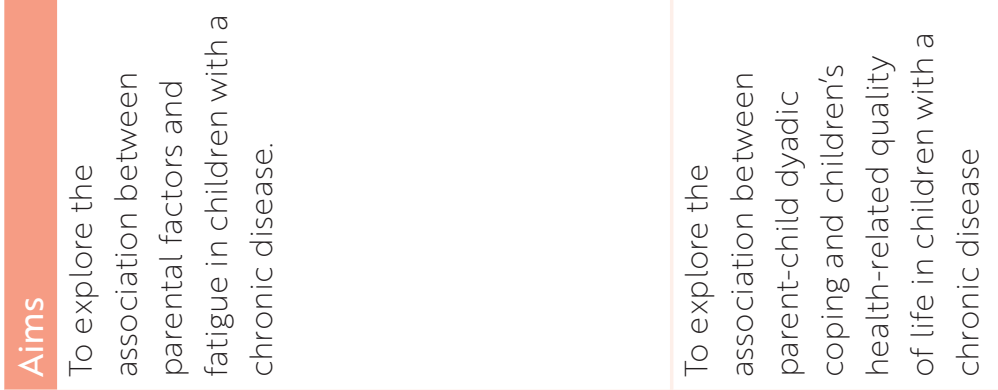

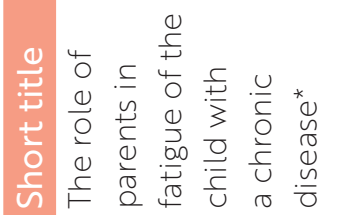

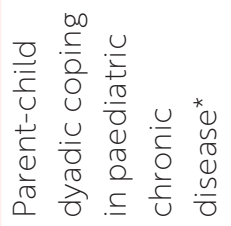




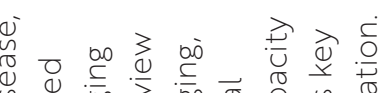

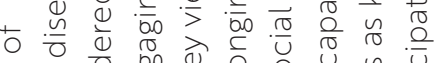

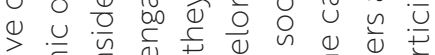

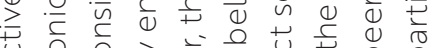
U $ᄋ$ ல

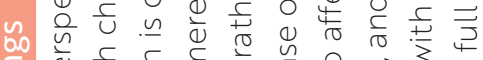

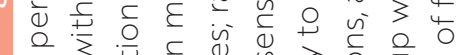
0

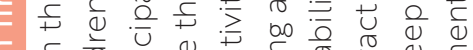

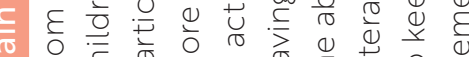

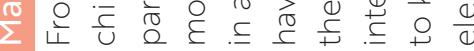

ᄃ

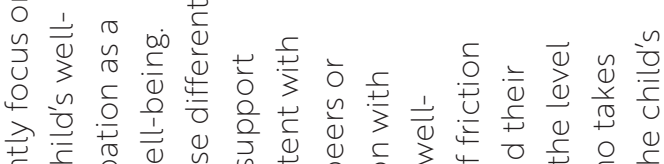

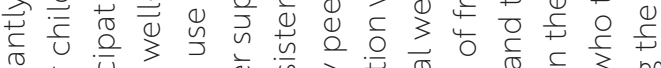
西:

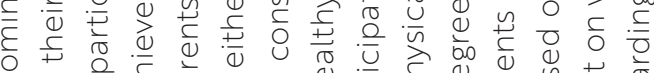

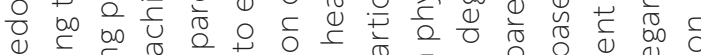

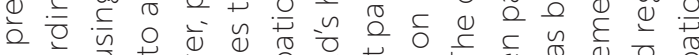

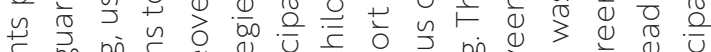

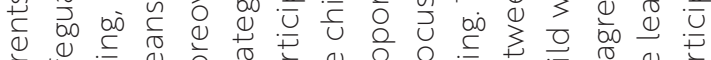

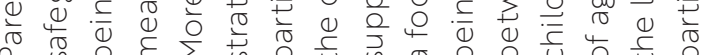

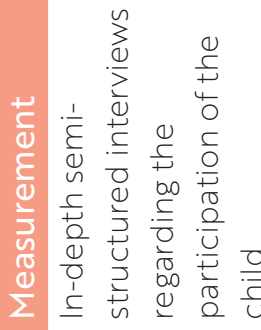

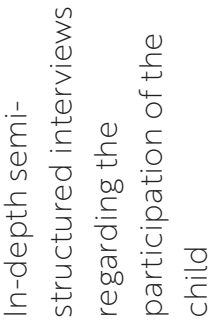

흥 $\stackrel{\bar{m}}{\underline{I I}}$

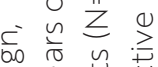

ñ 0

$0 \infty \frac{0}{0} \infty$

o 0

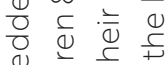

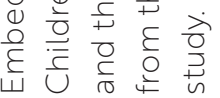

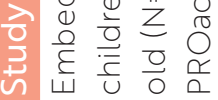

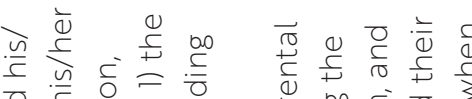

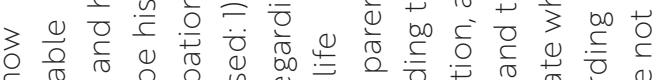

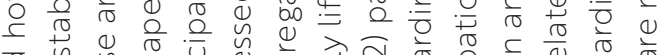
ర一

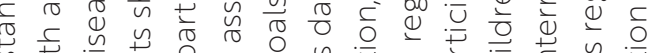

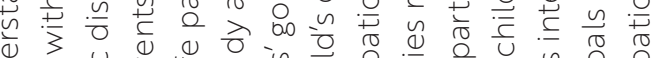

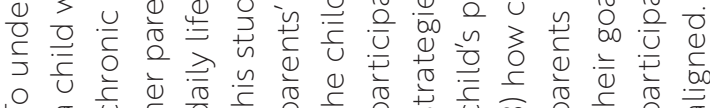

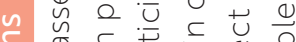

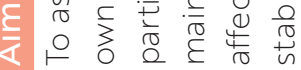

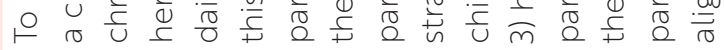

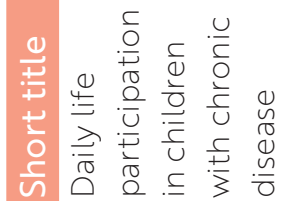

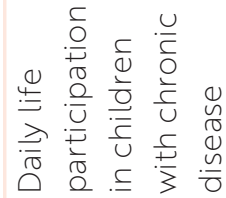




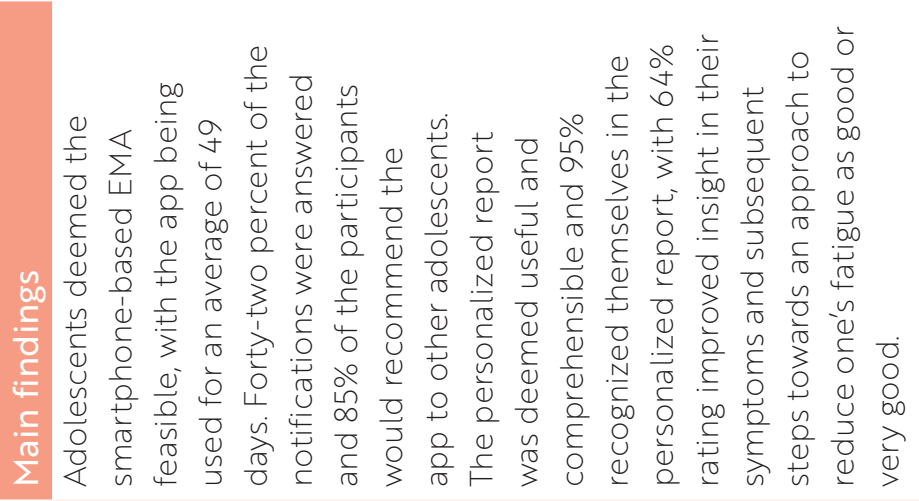

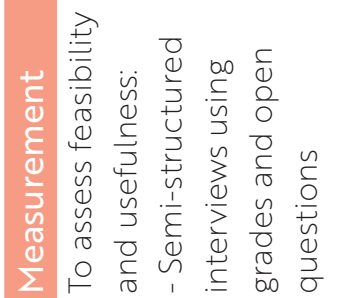

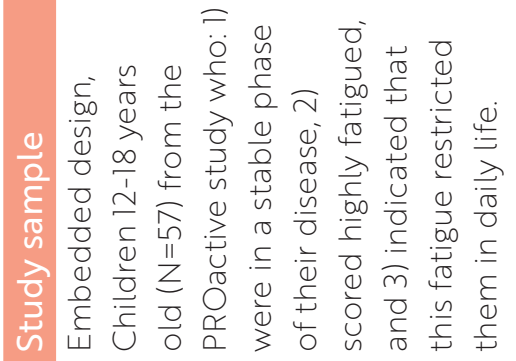

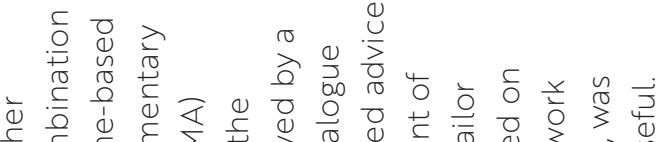

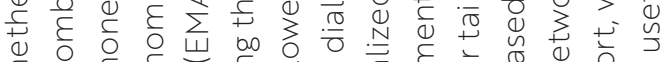

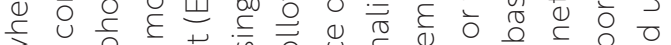

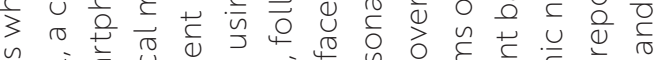

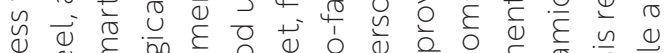

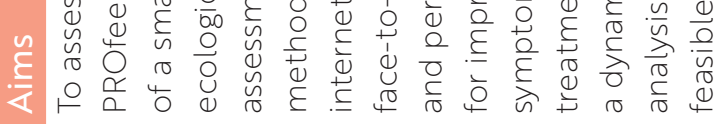

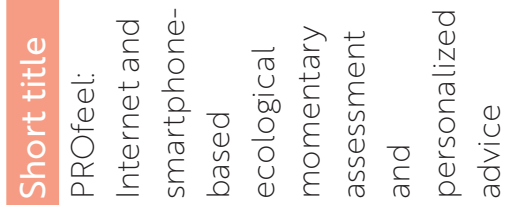

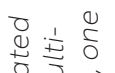

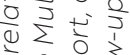

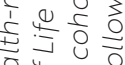

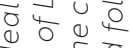

1
1

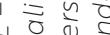

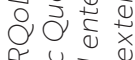

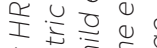

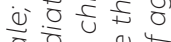

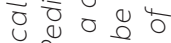

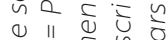

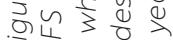

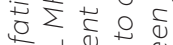

व वे है है

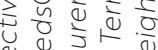

बa 0

जे $\frac{\dot{s}}{0}$ है

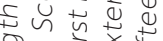

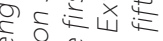

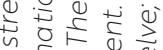

वे

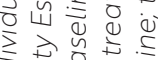

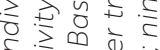

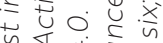

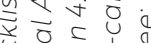

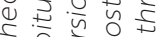

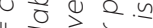

更

ज出话志政

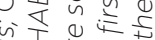

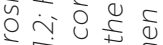

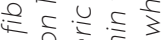

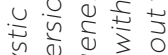

人) 이

"I

$U=0$ o d

जั. व $\frac{u}{0}$

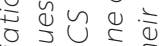

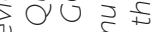

ज ज वे 의 के 这过䒓

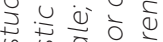

б

हा

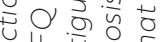

ये प्र क्ष

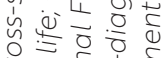

पे 0 के

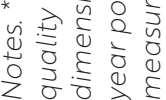




\section{NEDERLANDSE WETENSCHAPPELIJKE SAMENVATTING}

Steeds meer ziekten op de kinderleeftijd kunnen worden behandeld of gestabiliseerd. Dat is een positieve ontwikkeling, maar het zorgt er ook voor dat steeds meer kinderen opgroeien met de gevolgen van een chronische en/of levensbedreigende ziekte, zoals taaislijmziekte, een auto-immuunziekte of leven na de behandeling van kanker. Vanaf hier worden in deze samenvatting al deze aandoeningen samen 'een chronische ziekte' genoemd. Uitdagingen die kinderen met een chronische ziekte tegen kunnen komen, zijn symptomen zoals vermoeidheid en pijn, stress van doktersbezoeken of het minder mee kunnen doen dan leeftijdsgenoten. Dit kan van invloed zijn op hoe chronische zieke kinderen zich ontwikkelen op zowel lichamelijk als psychosociaal gebied. Deze kinderen behalen psychosociale ontwikkelingsmijlpalen vaak later dan hun gezonde leeftijdsgenoten.

Omdat kinderen nog zo in ontwikkeling zijn, is er juist ook veel winst te behalen in deze leeftijdsfase. Als problemen tijdig gesignaleerd worden, kan er onderzocht worden wat er nodig is aan ondersteuning om het kind zich optimaal te laten ontwikkelen. In dit proefschrift proberen we daarom meer grip te krijgen op drie uitkomstmaten die belangrijk zijn voor het functioneren van het kind met een chronische ziekte: vermoeidheid, participatie in het dagelijks leven en kwaliteit van leven. We doen dat op drie verschillende manieren: allereerst door op groepsniveau te onderzoeken hoeveel vermoeidheid voorkomt en welke biologische, psychologische en sociale factoren van invloed kunnen zijn op die vermoeidheid. Ook onderzoeken we de samenhang tussen vermoeidheid en kwaliteit van leven. Als tweede gaan we met ouders en kinderen in gesprek over hun kijk op participatie in het dagelijks leven met een chronische ziekte. Als derde onderzoeken we of een gepersonaliseerde smartphone tool ingezet kan worden om jongeren zelf meer regie te geven over hun vermoeidheid en participatie.

\section{Deel 1: Vermoeidheid en kwaliteit van leven in het opgroeien met een chronische ziekte}

In het onderzoek naar welke factoren bij een chronische ziekte bepalend zijn voor vermoeidheid, vragen we ons af of vermoeidheid gerelateerd is aan ziekte specifieke factoren (verschilt het per ziekte welke factoren het meest samenhangen met vermoeidheid) en/of aan generieke factoren (zien we dezelfde factoren samenhangen met vermoeidheid, onafhankelijk van de ziekte die het kind heeft). Met ziekte specifieke factoren bedoelen we bijvoorbeeld de diagnose, hoe actief de ziekte is of welke medicijnen iemand gebruikt. Met generieke factoren bedoelen we factoren die niet per se gerelateerd zijn aan welke ziekte iemand heeft, zoals fysieke fitheid, depressieve symptomen of sociale steun.

We onderzoeken in hoofdstuk 2 vermoeidheid bij 77 volwassenen met taaislijmziekte en de relatie met zowel ziekte specifieke als generieke factoren. Daaruit blijkt dat 26\% van deze volwassenen ernstige moeheid rapporteert. De vermoeidheid hangt wel samen met ziekte specifieke factoren, zoals een lagere longfunctie, maar deze relatie is niet zo sterk als de relatie met generieke factoren, zoals verminderd sociaal of emotioneel functioneren. 
De andere hoofdstukken in dit deel van het proefschrift komen voort uit data verkregen uit het PROactive cohort. PROactive is een cohort dat we hebben opgezet om uitkomsten zoals vermoeidheid, participatie en kwaliteit van leven beter in kaart te brengen bij kinderen met verschillende diagnosen. In dit cohort includeren we kinderen van 2-18 jaar oud met taaislijmziekte, een auto-immuunziekte en kinderen na de behandeling van kanker én hun ouders. Kinderen en hun ouders vullen voorafgaand aan een polikliniek bezoek vragenlijsten in (ouders vullen vragenlijsten in over hun kind en deels over zichzelf, en kinderen vanaf 8 jaar vullen ook zelf vragenlijsten in). De uitkomsten van deze vragenlijsten worden gekoppeld aan de klinische metingen die plaatsvinden tijdens het polikliniek bezoek. De vragenlijsten richten zich op vermoeidheid, participatie en kwaliteit van leven. Daarnaast vragen we naar determinanten die mogelijk gerelateerd zijn aan de genoemde uitkomstmaten, zoals fysieke activiteit, depressieve symptomen of sociale steun. Uit het elektronisch patiëntendossier van het kind worden gegevens geëxtraheerd over ziekteactiviteit, ziekteduur en andere medische gegevens verzameld gedurende dit polikliniek bezoek. Op deze manier kunnen vragenlijstdata en klinische data aan elkaar worden gekoppeld. De volgende hoofdstukken bevatten resultaten van cross-sectionele analyses van de dataverzameling uit het PROactive cohort.

Als eerste onderzoeken we in hoofdstuk 3 hoe vaak vermoeidheid voorkomt bij 481 kinderen van 2 tot 18 jaar met verschillende chronische ziektes. Hieruit blijkt dat $21,2 \%$ van de kinderen met een chronische ziekte ernstig moe scoort. Dit is ruim vier keer zoveel als kinderen in de Nederlandse bevolking. Ook blijkt dat meer moeheid samenhangt met een verminderde kwaliteit van leven. Wat opvallend is, is dat de gemiddelde vermoeidheidsscores niet significant verschillen tussen de ziektegroepen. Dit doet vermoeden dat vermoeidheid wellicht meer samenhangt met het opgroeien met een chronische ziekte, dan welke ziekte dat precies is. We beschrijven vermoeidheid daarom als een 'ziekte-overstijgend' symptoom bij kinderen met een chronische ziekte. De volgende vraag is dan welke mogelijk beïnvloedbare factoren samenhangen met vermoeidheid.

Dat beschrijven we in hoofdstuk 4 waarin we onderzoeken welke ziekte overstijgende, mogelijk beïnvloedbare, factoren samenhangen met zelf-gerapporteerde vermoeidheid bij 434 kinderen met een chronische ziekte van 8-18 jaar. Daarbij denken we aan generieke biologische/leefstijlfactoren (zoals fysiek functioneren of slaap), psychologische factoren (zoals depressieve symptomen of catastroferende gedachten) of sociale factoren (zoals sociale steun of ervaren schooldruk). Uit dit onderzoek blijkt dat zowel biologische/leefstijl, psychologische en sociale factoren allemaal sterk samenhangen met vermoeidheid en dat als je vermoeidheid in kaart brengt, je met alle deze factoren rekening moet houden. Al deze factoren samen verklaren bijna driekwart van de variantie in vermoeidheid. Het meest sterk geassocieerd met meer vermoeidheid zijn minder goed lichamelijk functioneren, meer depressieve symptomen, meer ervaren schooldruk en minder goed sociaal functioneren.

Daarnaast zien we opnieuw geen grote verschillen tussen de verschillende ziektegroepen, wat wederom pleit voor vermoeidheid als ziekte-overstijgend 
symptoom. Dat betekent ook dat het wellicht zinvol is om bij behandelingen in te zetten op die ziekte-overstijgende factoren die mogelijk beïnvloedbaar zijn.

In hoofdstuk 5 beschrijven we de invloed van ouderfactoren op de vermoeidheid van het kind met een chronische ziekte, zoals gerapporteerd door 204 ouders en kinderen. Verschillende factoren in het lichamelijk en sociaal-emotioneel functioneren van de ouder hangen samen met de vermoeidheid van het kind. Ouder en kind beïnvloeden elkaar en de ouder-kindrelatie is cruciaal voor het welbevinden van het kind. Voor onderzoek naar tijdig signaleren en behandelen van vermoeidheid bij het kind, zijn ouderfactoren dus ook belangrijk.

Ook in hoofdstuk 6 onderzoeken we de relatie tussen ouder en kind in 105 ouderkindparen. Dat een kind een chronische ziekte heeft, kan extra stress met zich meebrengen voor het kind, de ouder en het gezin er omheen. In partnerrelaties wordt dit proces van gezamenlijk omgaan met stress dyadic coping genoemd. In deze verkennende studie laten we zien dat kinderen en ouders op elkaars stress reageren en dat de wijze waarop ze dat doen (manier van coping) samenhangt met de kwaliteit van leven van het kind. Als de ouder of het kind zich terugtrekt als reactie op de stress van de ander, hangt dat samen met een lagere kwaliteit van leven van het kind. Als ouders de tijd nemen om echt naar hun kind te luisteren, hangt dat samen met een hogere kwaliteit van leven van het kind. Hoewel dit een exploratieve studie is, zou het (vroegtijdig) ondersteunen van ouders en kinderen bij het samen omgaan met stressoren of inzicht hierin geven als onderdeel van de behandeling van het chronische zieke kunnen helpen in het verbeteren van de kwaliteit van leven van het kind.

\section{Deel 2: Participatie in het dagelijks leven van het kind met een chronische ziekte}

In het tweede deel van dit proefschrift beschrijven we het kwalitatieve onderzoek dat we hebben uitgevoerd om het perspectief van kind en ouders weer te geven op de participatie van het kind met een chronische ziekte in het dagelijks leven. Daarbij werd een representatief deel van het PROactive cohort uitgenodigd om mee te doen aan deze studie. De diepte-interviews werden gelijktijdig voor kind en ouder gepland, met ieder een eigen interviewer.

In hoofdstuk 7 beschrijven we hoe het kind (8-18 jaar) zelf aankijkt tegen volledig mee kunnen doen, oftewel participatie. Kinderen ( $N=31)$ beschrijven drie aspecten die zij daarin het meest van belang vinden: 1) het gevoel hebben erbij te horen, 2) het gevoel hebben zelf invloed uit te kunnen oefenen op sociale interacties en 3) het gevoel mee te kunnen komen met leeftijdsgenoten of vrienden. Wat hieraan interessant is, is dat deze aspecten los blijken te staan van het daadwerkelijk fysiek mee kunnen doen. Sommige kinderen hebben het gevoel heel goed mee te kunnen doen, ondanks dat ze vaak niet aanwezig kunnen zijn bij activiteiten. Andere kinderen hebben het gevoel helemaal niet mee te doen, ondanks dat ze lichamelijk veel dingen kunnen. Het perspectief of de invulling aan het begrip participatie van de hulpverlener kan anders zijn dan dat van het kind. Als we het perspectief van het kind willen weten, zouden hulpverleners daar actief naar moeten vragen. Het gesprek vanuit het kindperspectief helpt in het gezamenlijk doelen stellen rondom de participatie van het kind met een 
chronische ziekte.

In hoofdstuk 8 omschrijven we naast het perspectief van het kind ook het perspectief van de ouder op de participatie van hun kind. Hiervoor interviewden we naast 31 kinderen ook hun ouders. Wat opvalt is dat veel ouders omschrijven primair te streven naar welbevinden voor hun kind, nu en in de toekomst. Zij gebruiken daarbij participatie als een middel, maar niet als doel op zichzelf. Soms ligt het streven van kinderen naar participatie en het streven van ouders naar welbevinden niet op één lijn. Er kan wrijving ontstaan tussen ouder en kind, als ouder en kind het niet eens zijn over wie de leiding heeft in de beslissingen rondom de participatie van het kind. Het gesprek over wie er welke stem heeft in de beslissingen rondom de participatie van het kind, is daarin essentieel, met name als het kind toegroeit naar meer autonomie. We raden aan om hulpverleners te trainen in het voeren van deze gesprekken, omdat dat uiteindelijk leidt tot beslissingen die breder gedragen worden door het kind en de ouders.

\section{Deel 3: PROfeel: gepersonaliseerd meten en een advies op maat}

In het derde deel van dit proefschrift onderzoeken we hoe we het welbevinden van kinderen met een chronische ziekte in kaart kunnen brengen op een geïndividualiseerde manier. Deze meetmethode, met de bijbehorende terugkoppeling, noemen we PROfeel. Kinderen $(\mathrm{N}=57)$ die veel vermoeidheid rapporteren binnen het PROactive cohort, worden gevraagd om mee te doen. Met PROfeel meten we vermoeidheid gedurende een periode van zes weken dagelijks en, samen met een aantal andere factoren, zoals slaap, lichamelijke activiteit en sociale activiteit. Elk kind brengt zelf ook factoren in waarvan hij of zij denkt dat die samenhangen met de vermoeidheid. Dat kunnen lichamelijke en/of sociaalemotionele factoren zijn, zoals bijvoorbeeld hoofdpijn of piekeren. Zowel helpende als niet-helpende factoren worden in kaart gebracht. Hiervoor gebruiken we ecological momentary assessments (EMA), oftewel heel korte, gepersonaliseerde vragenlijstjes die worden afgenomen via notificaties via een app op de smartphone. Kinderen vullen gedurende zes weken drie tot vijf keer per dag deze notificaties in waardoor fluctuaties over tijd zichtbaar worden. Na zes weken ontstaat er een persoonlijk rapport wat inzicht geeft in wat samenhangt met vermoeidheid. Dat rapport kan in het gesprek met de zorgverlener gebruikt worden om samen te komen tot een advies op maat om inzicht te krijgen in welke (beïnvloedbare) factoren samenhangen met moeheid bij dit individuele kind en hoe deze factoren mogelijk beïnvloedt zouden kunnen worden.

In hoofdstuk 9 beschrijven we de haalbaarheid en bruikbaarheid van PROfeel. Zevenenvijftig vermoeide adolescenten van 12-18 jaar met verschillende chronische ziekten doen mee aan deze studie. Uit deze studie blijkt dat PROfeel haalbaar en bruikbaar is. Adolescenten gebruiken de app gemiddeld 49 dagen en vullen $42 \%$ van de notifications in, wat ruim voldoende is om tot een betrouwbaar persoonlijk rapport te kunnen komen. Vijfentachtig procent van de deelnemers raadt de app aan, aan andere adolescenten die last hebben van moeheid. Adolescenten vinden het gepersonaliseerde rapport bruikbaar en inzichtelijk. Vijfennegentig procent herkent zichzelf in het rapport. Vierenzestig procent rapporteert dat ze meer inzicht hebben gekregen in hun symptomen en dat ze stappen kunnen zetten richting een oplossing. 


\section{Algemene discussie}

In hoofdstuk 10 zijn de resultaten van dit proefschrift samengevat en wordt gereflecteerd op vervolgstappen voor de toekomst en wat nu al (blijvend) kan worden toegepast.

\section{Mogelijke toepassingen}

Dit proefschrift laat zien dat vermoeidheid veel voorkomt bij kinderen met een chronische ziekte en/of levensbedreigende ziekte en dat vermoeidheid invloed heeft op hun kwaliteit van leven. Ook laat het zien dat kinderen met een chronische ziekte aanpassingen moeten maken in hun participatie in het dagelijks leven. Hoewel ook veel kinderen met een chronische ziekte goed functioneren, hebben kinderen met een chronische ziekte wel een verhoogd risico op uitdagingen zoals vermoeidheid en verminderde kwaliteit van leven. Het is daarom belangrijk om structureel te monitoren op de mate van vermoeidheid, participatie en kwaliteit van leven van het kind en hierover met elkaar het gesprek aan te gaan. In een ideale situatie worden daarbij ook factoren meegenomen die samenhangen met deze uitkomstmaten en die mogelijk te beïnvloeden zijn, zoals fysiek functioneren, depressieve symptomen, sociaal functioneren en hoe de ouders/het gezin functioneert.

Digitale vragenlijsten afgenomen voorafgaand aan het bezoek van de zorgverlener zijn een goede manier zijn om dit in kaart te brengen en bespreekbaar te maken in de spreekkamer. Met deze manier van werken is het mogelijk om zorg en onderzoek met elkaar te combineren: 1) Kind en ouders hebben direct profijt van het invullen van de vragenlijsten, doordat ze in de zorg besproken worden en 2) de uitkomsten leren ons meer over het functioneren van chronisch zieke kinderen, waardoor op den duur vroegsignalering en preventie van (de gevolgen van) vermoeidheid steeds meer mogelijk wordt.

\section{Mogelijke vervolgstappen}

Er zijn verschillende vervolgvragen die uit dit proefschrift naar voren komen. Allereerst zou het waardevol zijn om interventies te onderzoeken voor vermoeidheid die zich richten op de generieke mogelijk te beïnvloeden factoren die we hebben gevonden in hoofdstuk 4. Daarin lieten we zien dat meer vermoeidheid geassocieerd was met minder goed lichamelijk functioneren, meer depressieve symptomen, meer ervaren schooldruk en minder goed sociaal functioneren.

Ondanks dat de onderliggende mechanismen die samenhangen met de moeheid over ziekten heen gelijk zijn op groepsniveau, kunnen er grote interindividuele verschillen zijn. Een benadering afgestemd op het unieke profiel van een kind is daarom van groot belang en veelbelovend. PROfeel is een mooi voorbeeld van zulke gepersonaliseerde geneeskunde. PROfeel vraagt nog wel verder onderzoek naar de effectiviteit van deze manier van gepersonaliseerd meten en terugkoppelen. Heeft het meten op zichzelf al effect op de klachten of moet het gezien worden als een opstapje naar de juiste behandeling (toepassing van het verkregen inzicht)? Wat zijn andere manieren om kinderen met een chronische ziekte op maat ondersteuning te bieden bij waar zij tegenaan lopen? 
Ten derde is het waardevol om onderzoek te doen naar die kinderen met een chronische ziekte die het juist 'heel goed doen', ondanks dat zij aan dezelfde stressoren blootstaan als andere kinderen met een chronisch ziekte (dus de groep kinderen die erg weerbaar of resilient genoemd zouden kunnen worden). Zijn in deze groep samenhangende factoren die vinden die kunnen worden gezien als beschermende of steunende factoren, en kunnen we interventies gericht op deze factoren inzetten om de meer kwetsbare groep kinderen met een chronische ziekte verder te helpen? Hierbij kan men bijvoorbeeld denken aan interventies gericht op bevorderen van veerkracht/ resilience, bekrachtiging van positieve familie dynamieken of stimuleren van verschillende vormen van sociale steun.

Als vierde is het belangrijk om longitudinale analyses uit te voeren met als uitkomstmaat vermoeidheid, participatie en kwaliteit van leven. Op die manier kunnen we niet alleen de huidige problemen signaleren, maar ook voorspellen welke kinderen een verhoogd risico lopen op minder functioneren. Op die manier kunnen we hopelijk tijdig signaleren en interventies bieden.

Het PROactive cohort is een 'levend cohort, d.w.z. includeert en groeit op dit moment nog steeds. Er worden inmiddels jaarlijks vragenlijsten afgenomen bij ruim 2300 chronisch zieke kinderen en hun ouders. Ook wordt er (toenemend) ingezet op een vergelijking tussen zieke en gezonde kinderen door steeds intensievere samenwerking met Utrechtse populatiecohorten en strategisch speerpunt 'Dynamics of Youth' van de Universiteit Utrecht. Hierdoor kunnen steeds beter vragen worden beantwoord over in hoeverre de bevindingen passen bij het opgroeien met een chronische ziekte en in hoeverre zij (ook) kunnen passen bij de uitdagingen van het opgroeien in onze huidige maatschappij waar ook 'gezonde' leeftijdsgenoten aan blootgesteld worden. In dit PROactive cohort hebben we in het kader van dit proefschrift al twee studies met een 'embedded design' uitgevoerd: een kwalitatieve studie en PROfeel. PROactive biedt de mogelijkheid om in de toekomst meer embedded design (interventie) studies te faciliteren, waardoor vroege interventie en preventie steeds beter mogelijk wordt voor het chronisch zieke kind. Het systematisch in kaart brengen van kinderen met een chronische ziekte geeft op die manier ook weer nieuwe mogelijkheden aan kinderen met een chronische ziekte om te profiteren van nieuwe interventies in zorg en onderzoek.

Dit proefschrift geeft meer inzicht in vermoeidheid, participatie in het dagelijks leven en kwaliteit van leven van kinderen met een chronische ziekte. Het creëert nieuwe mogelijkheden om zorg voor kinderen met een chronische ziekte nog meer op maat te maken. 


\section{DANKWOORD}

Ik raad iedereen aan om af en toe een dankwoord te schrijven, je wordt er namelijk een heel dankbaar mens van. Ik had nog lang door kunnen typen en veel meer mooie eigenschappen kunnen benoemen van alle mensen waar ik het voorrecht heb gehad om mee samen te werken, maar ik zal proberen om het leesbaar te houden. Dankjulliewel allemaal voor de rol die jullie in dit proefschrift hebben gespeeld en het voorrecht met jullie samen op te lopen, koffie te drinken, te videobellen en jullie verhalen te horen.

Allereerst wil ik alle kinderen en ouders bedanken die mee hebben gewerkt aan dit onderzoek. De tijd die jullie namen om vragenlijsten in te vullen, de kwetsbaarheid waarmee jullie je verhalen deelden en de energie die jullie hebben gestoken in het heel vaak - invullen van een app maakten dit onderzoek tot wat het nu is.

Prof. dr. E.M. van de Putte, beste Elise, jouw visie en enthousiasme namen me vanaf het begin mee op reis en het was en is een enorm mooie reis. Dankjewel voor je oprechte interesse, dat je moeilijke dingen niet uit de weg gaat en dat we als team kunnen samenwerken en elkaar versterken.

Prof. dr. M.A. Grootenhuis, beste Martha, dankjewel voor je persoonlijke manier van begeleiden, je zorgvuldigheid en hoe je altijd de tijd nam om door te vragen en de stukken weer naar een hoger niveau te brengen. Dankjewel voor al je werk als bruggenbouwer en dat je overal linkjes zag en dat ik niet alleen van jou mocht leren, maar ook van je mooie groep POPPI's.

Dr. S.L. Nijhof, lieve Sanne, wat zijn wij een goed team. Ik heb vanaf het begin genoten om samen met jou PROactive op te zetten. Ik heb onwijs veel bewondering voor de manier waarop jij mensen met elkaar verbindt, schijnbaar onmogelijke zaken in beweging krijgt en hoe we samen zoveel voor elkaar hebben gekregen. Van een hoop logistiek, inhoud en brandjes blussen tot persoonlijke gesprekken bij de koffie of aan de keukentafel.

Dr. G.W. Dalmeijer, lieve Cerdien, wat heerlijk om regelmatig met jou te mogen sparren. Jouw helikopterview, nuchterheid en humor maken het onderzoek en leven veel leuker. Jouw manier van analyseren en leidinggeven met twee voeten op de grond, inspireren me elke keer weer. We hebben het gehad over een aantal bladzijden dankwoord, maar ik hoop dat deze kortere samenvatting daarvan niet minder uitdrukt hoe blij ik met je ben.

Prof. dr. C.K. van der Ent, beste Kors, dankjewel dat je voor een jaar mijn promotor wilde zijn. Ik ben dankbaar voor jouw scherpe blik en analyse van waar het in de kern om gaat en de mogelijkheden die je creërt om samen van A naar B te komen.

De leden van de leescommissie: prof.dr. M.J. Jongmans, prof.dr. C. Kemner, prof.dr. A.B.J. Prakken, prof.dr. J.A. Knoop en prof.dr. H.J. Escher wil ik bedanken voor jullie tijd en energie in het beoordelen van het manuscript. 
Een promotieonderzoek gaat gepaard met een hoop eerste stapjes. Ineke de Kruiff, dankjewel dat jij me voor het eerst enthousiast gemaakt hebt voor sociale pediatrie en me naar het WKZ hebt gestuurd. Linde, dankjewel dat je me zo warm hebt opgevangen en samen met me vol hebt gehouden totdat ons artikel werd gepubliceerd. Marcella, naast jou voor het eerst op een congres presenteren maakte het al een stuk minder spannend, dankjewel. Myriam, Jolien en Femke, alle verdwaalde mensen die jullie helpen om een beetje te landen, maken het WKZ een mooiere plek, dankjulliewel! En nu na al het onderzoeken: dankjulliewel collega's van het Meander, voor de veilige en fijne plek om mijn eerste stapjes terug in de kliniek te zetten.

Prof. dr. C. Finkenauer, beste Catrin, prof.dr. G. Bodenmann, beste Guy, dr. R.C. van der Wal, beste Reine en E. Grosfeld, MSc, beste Eva, dankjulliewel voor de waardevolle samenwerking rondom dyadic coping. Ik vond het onwijs inspirerend om een uitstapje te maken buiten mijn eigen denkkaders en ik heb heel veel van jullie geleerd. Het was een feestje om met jullie samen op te trekken.

Alle coauteurs wil ik bedanken voor hun tijd en expertise, zonder jullie was dit boekje nooit tot zo'n goed einde gekomen. Marijke, dankjewel voor al je kennis en dat je me hebt mee willen nemen in de wereld van het kwalitatieve onderzoek. Jan, dankjewel voor je onuitputtelijke enthousiasme en je geduld in het uitleggen van alle complexe kennis over EMA en intensieve longitudinale data analyse.

De vertegenwoordigers van de verschillende groepen van PROactive wil ik bedanken voor hun tijd, geduld, enthousiasme en het mee blijven denken hoe we PROactive zo goed mogelijk in kunnen zetten in zorg en onderzoek: dankjewel Joost, Kors, Annet, Joost, Joris, Alinde, Marc, Marry, Martine, Victorien en Hans! Ook dank aan het KLIK team van het AMC voor de samenwerking in het inzetten van KLIK voor PROactive voor al ruim 2300 families. Anne, dankjewel voor het overnemen van mijn rol binnen PROactive. Je hebt het niet alleen overgenomen, maar op een hoger niveau getild, ik vond het heerlijk om met je te kunnen sparren, van FAIR data tot kleine mensjes en promotieperikelen.

Bert en Joost, dankjulliewel voor de fijne begeleiding als mijn aiobegeleidingscommissie.

Annelies en Annelotte, dankjulliewel voor jullie creativiteit in het samen vormgeven van dit proefschrift, het is onwijs fijn met jullie samen te werken.

Alle studenten die de afgelopen jaren met me mee op hebben gelopen als MST-er of wetenschappelijke stage student wil ik onwijs bedanken: Pleun, Lotte, Eline, Floris, Inez, Clara, Fieke, Sophie, Dionne, Sophie, Tijs, Annelieke en Niels. Dankjulliewel voor jullie frisse blik, kritische vragen, harde werk en gezelligheid. Niels, dankjewel voor je volhardendheid, zo hebben we uiteindelijk samen ook een mooi artikel kunnen publiceren!

Laura, dankjewel voor je vriendschap en dat ik naast je mocht staan als paranimf. Zoveel over onderzoeken heb ik van jou geleerd. Lieve collega's en mede-PhDers: 
het leven is zoveel leuker met jullie erbij! Dankjewel voor de vele koffietjes, het samen kunnen relativeren (met taart) en de gekkigheid: van zwembadjes op de onderzoekskamer tot overkoelde biertjes, het was een feestje.

Wat een twee fantastische paranimfen heb ik:

Lieve Emma, ik denk elke keer met een glimlach terug aan de vele kilometers die we samen in de auto hebben doorgebracht: files, ongemakkelijke interviews, reuzehonden, op camera broodjes Subway halen, niks was ons te gek. Ik waardeer het enorm om in jou een maatje te hebben gehad in onderzoek, samen te sparren, modellen te tekenen, veel koffie te drinken en natuurlijk heel veel kleurtjes aan het leven toe te voegen.

Lieve Amber, ook wij hebben vele kilometers samen gemaakt, van Friesland tot Madagaskar. Dankjewel voor je nuchtere blik, je trouw, creativiteit en omdenkblik op het leven. Ik vind het superfijn dat we het zo open over alles kunnen hebben en ik had me geen enthousiastere paranimf kunnen voorstellen.

Amber, Wobs en May, vanaf moment 1 in de geneeskundebanken waren we met elkaar verbonden. Wobs, wat lijken we veel op elkaar en zijn we verschillend, ik hoop dat we nog lang samen jong mogen blijven. May, dankjewel voor samen onszelf mogen zijn, diepgang en verbinding.

Lieve Mirjam, Debbie, Wouda, Marije, Jorijn, Zuzanne, Marieke, Hannah, Johan\& Josianne, vrienden van de Vineyard, buurtjes van Timon, nieuwe en oude vrienden: dankjulliewel voor jullie vriendschap, koffie/theetjes, wijntjes, goede gesprekken en jullie veelkleurigheid! Jullie verbreden mijn blik en doen me telkens opnieuw verwonderen en genieten.

Dik en Ans, dankjulliewel dat jullie altijd voor ons klaar staan en jullie zulke lieve verbindende schoonpapa en mama zijn. Lieve Napjes: Wim, Maya, Dilano, Noa, Jokelyn, Juriaan, miniJJ, Neline en Jip: een leukere schoonfamilie had ik me niet kunnen wensen.

Lieve Peter en Hennie, Melle en Thijs, dankjulliewel voor met jullie samen optrekken de afgelopen jaren en met jullie meekijken hoe jullie gezin zijn.

Papa en mama, dankjulliewel voor jullie onvoorwaardelijke steun en jullie geloof in mij. Zonder jullie aanmoediging, zorg, liefde en oppasuurtjes was ik hier nooit gekomen. Lieve Rik, Mirte, Sanne en Ilse: dankjulliewel voor het samen optrekken, het altijd welkom zijn bij elkaar, de goeie vragen die gesteld mogen worden en de knuffels, het is heerlijk zo'n belangrijk onderdeel van elkaars leven te kunnen zijn. Lieve oma, u bent een voorbeeld voor mij in oprechte interesse, geloof en vastberadenheid, dankuwel!

Lieve Elias, ik ben zo blij met jou en trots op jou. Je bent een heerlijk ventje, een uniek, sterk, eigen persoontje. Ik zie ernaar uit om samen met jou de wereld te blijven ontdekken. 
Lieve Jaap, wat heerlijk om samen met jou een eenheid te zijn. Je maakt me blij, je bent mijn beste maatje, we maken elkaar sterker en bij jou mag ik helemaal zijn wie ik ben. Dankjewel!

Dit boek heb ik opgedragen aan Diegene die de mens zo wonderbaarlijk mooi en complex gemaakt heeft. Jezus, volgens mij geniet $U$ ervan om ons alles uit te zien vogelen wat $U$ zo mooi in elkaar gezet heeft. Ik zie uit naar nog meer verwonderen, want er zit veel waarheid in wat Albert Einstein al zei:

"There are two ways to live: you can live as if nothing is a miracle; you can live as if everything is a miracle." 


\section{CURRICULUM VITAE}

Merel Nap-van der Vlist was born on the $18^{\text {th }}$ of August 1992 in Woerden. She grew up with her parents and three younger siblings in Bodegraven. After secondary education at the Passie in Utrecht, she stayed in Utrecht for her medical study, which started in 2010.

During secondary school she spent three summers volunteering in an orphanage in Bolivia. It therefore did not come as a surprise that she chose an internship in

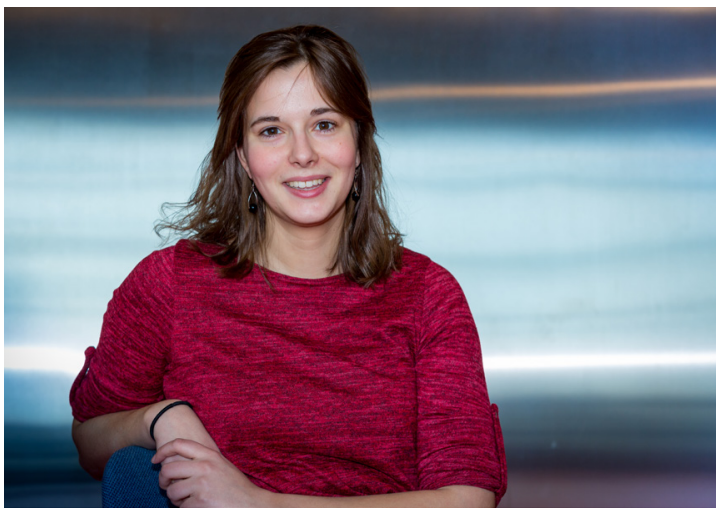
tropical medicine in Madagasker during her study. In her medical study she developed a growing interest to look beyond a person's disease, which led her to social paediatrics. There, she started to write a systematic review on non-pharmacological options for pain management in her fourth year of study under the supervision of dr. Sanne Nijhof and prof. dr. Elise van de Putte. In continuation of this collaboration, together they set up the PROactive study in the final stage of Merel's medical study. This study is described in this thesis and assess fatigue, daily life participation, and quality of life across paediatric chronic diseases. She graduated in April 2017 and continued working on the PROactive study as a PhD candidate under the supervision of prof. dr. Elise van de Putte, prof. dr. Martha Grootenhuis, dr. Sanne Nijhof en dr. Gerdien Daalmeijer. During this time period, she was co-applicant on the Vertex Circle of Care grant for the PROfeel project in 2017 and the Dynamics of Youth Invigoration grant for a collaborative project with the Social Sciences department on dyadic coping in 2019. During this time the PROactive study grew out to a longitudinal cohort on fatigue, daily life participation, and psycho-social well-being in pediatric chronic disease, now assessing over 2.300 families of children with a chronic disease annually.

As of April 2021, she has started working as a resident in paediatric medicine in the Meander Medical Centre, Amersfoort. Merel lives together with her husband Jaap and her son Elias (2019) as a volunteer in a youth care facility in Bunnik. 


\section{LIST OF PUBLICATIONS}

Nap-van der Vlist MM, Burghard M, Hulzebos HJ, Doeleman WR, Heijerman HGM, van der Ent CK, Nijhof SL. Prevalence of severe fatigue among adults with cystic fibrosis: A single center study. J Cyst Fibros. 2018 May;17(3):368-374

Nap-van der Vlist MM, Dalmeijer CW, Grootenhuis MA, van der Ent CK, van den HeuvelEibrink MM, Wulffraat NM, Swart JF, van Litsenburg RRL, van de Putte EM, Nijhof SL. Fatigue in Childhood Chronic Disease. Arch Dis Child. 2019 Nov; 104 (11):1090-1095

Nap-van der Vlist MM, Dalmeijer CW, Grootenhuis MA, van der Ent CK, van den HeuvelEibrink MM, Swart JF, van de Putte EM, Nijhof SL. Fatigue among children with a chronic disease: a cross-sectional study. BMJ Paediatr Open. 2021 Feb 17;5(1)

Kramer N, Nijhof SL, van de Putte EM, Ketelaar M, van der Ent CK, Grootenhuis MA, Swart JF, van Grotel M, Dalmeijer CW, Nap-van der Vlist MM. What is the role of parents in the fatigue of a chronically diseased child? BMJ Paediatrics Open 2021 May 18;5(1):e001057.

Nap-van der Vlist MM, Kars MC, Berkelbach van der Sprenkel EE, Nijhof LN, Grootenhuis MA, van Geelen SM, van der Ent CK, Swart JF, van Royen-Kerkhof A, van Grotel M, van de Putte EM, Nijhof SL. Daily life participation in childhood chronic disease: a qualitative study. Arch Dis Child. 2020 May;105(5):463-469.

Nap-van der Vlist MM, Berkelbach van der Sprenkel EE, Nijhof LN, Grootenhuis MA, van der Ent CK, Swart JF, van Royen-Kerkhof A, van Grotel M, van de Putte EM, Nijhof SL, Kars MC. Daily life participation in childhood chronic disease: a qualitative study on the child's and parent's perspective. BMJ Paediatrics Open 2021 May 21;5(1):e001055.

Nap-van der Vlist MM, Houtveen J, Dalmeijer CW, Grootenhuis MA, van der Ent CK, van Grotel M, Swart JF, van Montfrans JM, van de Putte EM, Nijhof SL. Internet and smartphone-based ecological momentary assessment and personalized advice (PROfeel) in adolescents with chronic conditions: a feasibility study. Internet Interventions. 2021 May; 25:100395.

Nijhof LN*, Nap-van der Vlist MM*, van de Putte EM, van Royen-Kerkhof A, Nijhof SL. Non-pharmacological options for managing chronic musculoskeletal pain in children with pediatric rheumatic disease: a systematic review. *Shared first authorship. Rheumatol Int. 2018 Nov;38(11):2015-2025

Nap-van der Vlist MM, Burghard M, Hulzebos HJ, Doeleman WR, Heijerman HCM, van der Ent CK, Nijhof SL. Authors' response: Letter to the Editor 'Anaemia and iron deficiency in relation to fatigue in cystic fibrosis'. J Cyst Fibros. 2019 Jan;18(1)

\section{SUBMITTED}

Nap-van der Vlist MM*, van der Wal RC*, Grosfeld E, van de Putte EM, Dalmeijer CW, Grootenhuis MA, van der Ent CK, van den Heuvel-Eibrink MM, Swart JF, Bodenmann G, Finkenauer C, Nijhof SL. Parent-child dyadic coping and quality of life in chronically diseased children. *Shared first authorship. Submitted. 
ter Haar AM, Nap-van der Vlist MM, Van den Hof M, Nijhof SL, van Litsenburg RRL, Oostrom KJ, Pajkrta D. Children and adolescents perinatally infected with HIV experience few symptoms of fatigue. PLOS ONE. Submitted.

Burghard M, Takken T, Nap-van der Vlist MM, Nijhof SL, van der Ent CK, Heijerman HGM, Hulzebos HJ. Cardiorespiratory fitness levels and predictors in children with Cystic Fibrosis without ventilatory limitation. Manuscript in preparation.

\section{( NTER) NATIONAL PRESENTATIONS}

- SIOP 2020 - Pediatric oncology conference: Poster discussion session on biological, psychological, and social factors that influence fatigue in pediatric chronic disease.

- PRES 2020 - Pediatric rheumatology conference: Lightening talk on PROfeel: a smartphone application to help adolescents gain insight in their symptoms and associated factors.

- SIOP 2019 - Pediatric oncology conference: 1) Poster discussion session on the prevalence of severe fatigue across pediatric chronic diseases. 2) Poster on the outcomes of a qualitative study on participation in children with a chronic disease.

- Workshop Intimate Relationships 2019 - Social sciences conference: oral presentation on dyadic coping in children with a chronic disease and their parents, in collaboration with the department of Social Sciences of the Utrecht University.

- $\quad$ NVK symposium 2019 - General pediatrics conferences: Pitch on PROfeel.

. 198

- NVK symposium 2018 - General pediatrics conference: Pitch on the prevalence of severe fatigue in pediatric chronic disease.

- NCFS symposium 2018 - conference on cystic fibrosis: Presentation on PROfeel.

- NCFS/ECFS symposium 2017 - National and international conference on cystic fibrosis: Poster presentation on the prevalence of severe fatigue in adults with cystic fibrosis.

\section{AWARDS}

- PRES 2020 - Third prize best clinical presentation

- SIOP 2019 - Poster award

- NVK 2018 - Pitch (SLAM) award

- $\quad$ ECFS 2017 - Travel grant 


\section{LIST OF ABBREVIATIONS}

\begin{tabular}{|c|c|}
\hline ANCOVA & Analysis of Covariance \\
\hline BMI & Body Mass Index \\
\hline CBT & Cognitive Behavioral Therapy \\
\hline CDC & US Center for Disease Control and Prevention \\
\hline CF & Cystic Fibrosis \\
\hline CFQ & Cystic Fibrosis Questionnaire \\
\hline FS & Chronic Fatigue Syndrome \\
\hline $\mathrm{Cl}$ & Confidence Interval \\
\hline CIS $(-8)$ & Checklist Individual Strength (with eight items) \\
\hline CJADAS & clinical Juvenile Arthritis Disease Activity Score \\
\hline CVID & Common variable immunodeficiency \\
\hline $\mathrm{Cl}$ & Dyadic Coping Inventory \\
\hline DT-P & Distress Thermometer for Parents \\
\hline EMA & Ecological momentary assessments \\
\hline ESR & Erythrocyte Sedimentation Rate \\
\hline FES & Family Empowerment Scale \\
\hline FEVl & Predicted percentage of Forced Expiratory Volume in 1 second \\
\hline HAES & Habitual Activity Estimation Scale \\
\hline HBSC & Health Behaviour in School Children \\
\hline HRQOL & Health-related quality of life \\
\hline ILD & Intensive longitudinal data \\
\hline$J \mid A$ & Juvenile Idiopathic Arthritis \\
\hline MST & Modified Shuttle Test \\
\hline PC & Post-cancer treatment \\
\hline PedsQL GCS & PedsQL Generic Core Scale 4.0 \\
\hline PedsQL MFS & PedsQL multidimensional fatigue scale \\
\hline PROs & Patient-reported outcomes \\
\hline PSC-P & Pain Catastrophizing Scale for Parents \\
\hline & Standard Deviation \\
\hline AS & Visual Analogue Scale \\
\hline
\end{tabular}


